\title{
OECD Science, Technology and Industry Scoreboard 2009
}
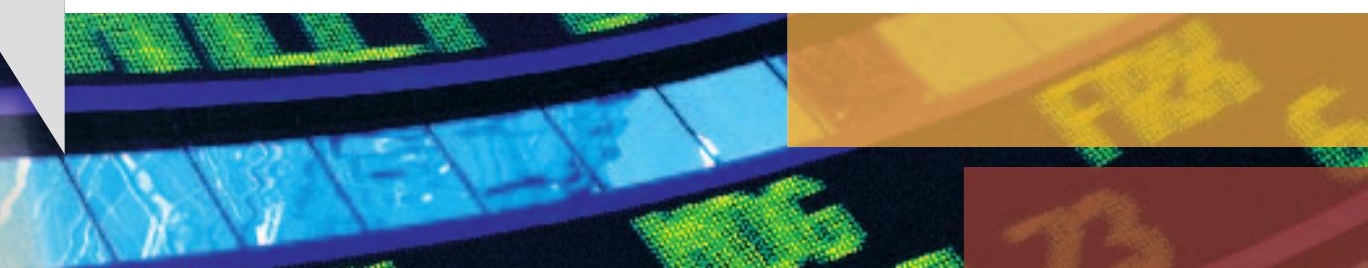

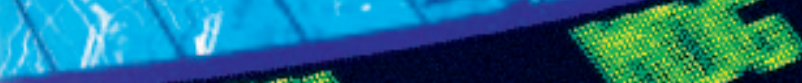

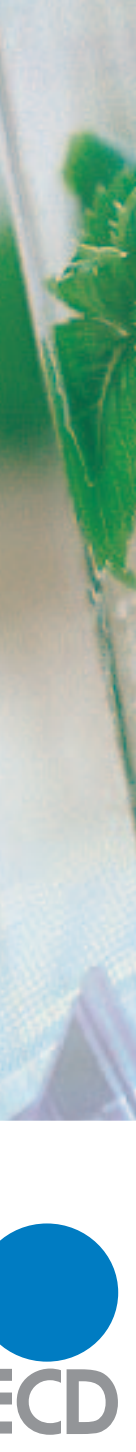




\section{OECD Science, \\ Technology and Industry Scoreboard}

\section{9}

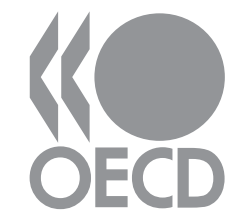




\section{Organisation for Economic Co-operation and Development}

The OECD is a unique forum where the governments of 30 democracies work together to address the economic, social and environmental challenges of globalisation. The OECD is also at the forefront of efforts to understand and to help governments respond to new developments and concerns, such as corporate governance, the information economy and the challenges of an ageing population. The Organisation provides a setting where governments can compare policy experiences, seek answers to common problems, identify good practice and work to co-ordinate domestic and international policies.

The OECD member countries are: Australia, Austria, Belgium, Canada, the Czech Republic, Denmark, Finland, France, Germany, Greece, Hungary, Iceland, Ireland, Italy, Japan, Korea, Luxembourg, Mexico, the Netherlands, New Zealand, Norway, Poland, Portugal, the Slovak Republic, Spain, Sweden, Switzerland, Turkey, the United Kingdom and the United States. The Commission of the European Communities takes part in the work of the OECD.

OECD Publishing disseminates widely the results of the Organisation's statistics gathering and research on economic, social and environmental issues, as well as the conventions, guidelines and standards agreed by its members.

This work is published on the responsibility of the Secretary-General of the OECD. The opinions expressed and arguments employed herein do not necessarily reflect the official views of the Organisation or of the governments of its member countries.

ISBN 978-92-64-06371-6 (print)

ISBN 978-92-64-07543-6 (PDF)

ISBN 978-92-64-07644-0 (HTML)

Also available in French: Science, technologie et industrie : Tableau de bord de l'OCDE 2009

Photo credits:

Cover illustration: @ Comstock/Comstock Image/Getty Images

Chapters 1, 2, 3: ๑ Aspireimages/Inmagine

Chapters 4, 5: @ Stockbyte/Getty Images

Corrigenda to OECD publications may be found on line at: www.oecd.org/publishing/corrigenda.

(C) OECD 2009

You can copy, download or print OECD content for your own use, and you can include excerpts from OECD publications, databases and multimedia products in your own documents, presentations, blogs, websites and teaching materials, provided that suitable acknowledgment of OECD as source and copyright owner is given. All requests for public or commercial use and translation rights should be submitted to rights@oecd.org. Requests for permission to photocopy portions of this material for public or commercial use shall be addressed directly to the Copyright Clearance Center (CCC) at info@copyright.com or the Centre français d'exploitation du droit de copie (CFC) at contact@cfcopies.com. 


\section{Foreword}

$\prod$ he OECD Science, Technology and Industry Scoreboard 2009 brings together the latest internationally comparable data to explore the global challenges faced by OECD and other leading economies in the aftermath of the economic crisis. It draws mainly on OECD databases, indicators and methodology developed by the Directorate for Science, Technology and Industry and focuses on five key areas of policy interest.

- Responding to the economic crisis: venture capital, research and development (R\&D) expenditure, researchers, patents, trademarks, productivity and foreign direct investment (FDI) statistics up to the second quarter of 2009.

- Targeting new growth areas: R\&D, patents and scientific publications in key research fields: health, biotechnology, nanotechnology and environmental sciences, access to telecommunication networks, government $R \& D$ budgets, $R \& D$ tax subsidies, and co-operation with innovative firms.

- Competing in the world economy: international trade by technological intensity, trade in Information and communication technology (ICT) goods and services, e-commerce and e-business penetration, activities of multinational firms, non-technological innovation and entrepreneurship.

- Connecting to global research: international co-operation in R\&D, patents and scientific publications among countries and sub-national regions; technological balance of payments; international flows in inventions and doctoral students.

- Investing in the knowledge economy: new university graduates and doctorate holders by discipline and gender, human resources in science and technology, employment of graduates and doctorate holders, relative earnings by level of education and gender.

This volume was prepared by the Economic Analysis and Statistics Division (EAS) of the OECD Directorate for Science, Technology and Industry (DSTI). Vincenzo Spiezia co-ordinated and contributed to the publication, Brigitte van Beuzekom supervised the preparation of statistics and figures, and Chrystyna Harpluk, Beatrice Jeffries and Paula Venditti provided secretarial support. Laudeline Auriol, Frédéric Bourassa, Agnes Cimper, Koen De Backer, Hélène Dernis, Isabelle Desnoyers-James, Sandrine Kergroach, Elif Koksal-Oudot, Guillaume Kpodar, Vladimir Lopez-Bassols, Valentine Millot, Laurent Moussiegt, Wonkyung Rhee, Cristina Serra Vallejo, Sharon Standish, Hiroyuki Tomizawa, Colin Webb and Alison Young all contributed to the publication. Alessandra Colecchia, Dominique Guellec and Yoshiaki Tojo offered guidance and commented on the draft. 



\section{Table of Contents}

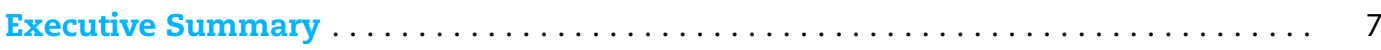

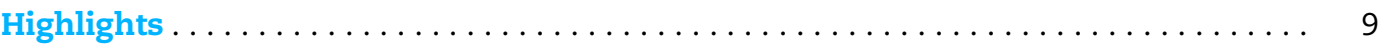

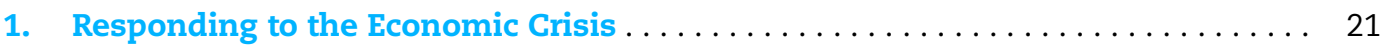

1.1. Venture capital in the economic crisis . . . . . . . . . . . . 22

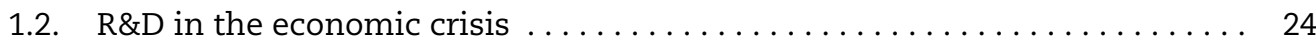

1.3. R\&D growth over the business cycle..................... 26

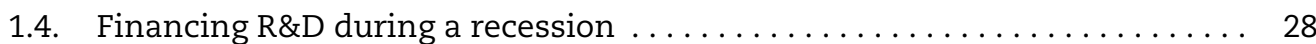

1.5. Trends in business R\&D . . . . . . . . . . . . . . . . . . . . 30

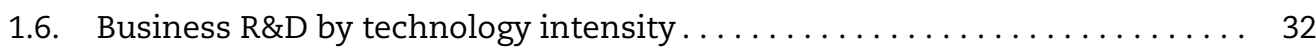

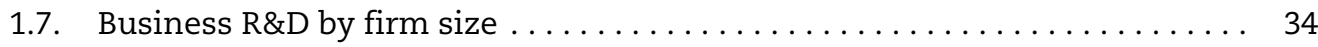

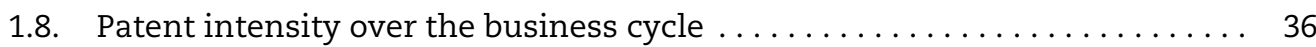

1.9. Trademarks over the business cycle ................... 38

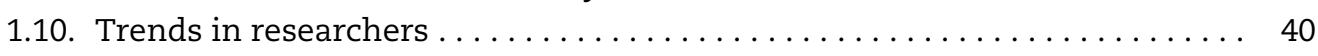

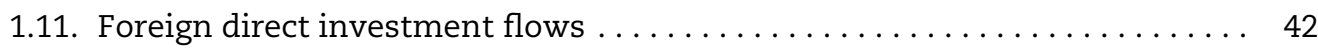

1.12. Trends in the employment of foreign affiliates $\ldots \ldots \ldots \ldots \ldots \ldots \ldots . \ldots 4$

1.13. Labour productivity growth over the business cycle $\ldots \ldots \ldots \ldots \ldots \ldots 46$

1.14. ICT investment over the business cycle . . . . . . . . . . . . . . 48

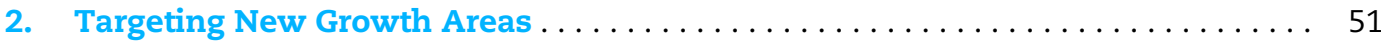

2.1. Patents in environment-related technologies . . . . . . . . . . . 52

2.2. Environmental sciences . . . . . . . . . . . . . . . . . . . . . 54

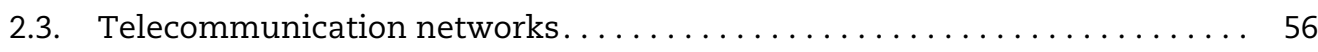

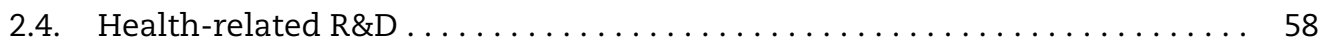

2.5. Health-related patents . . . . . . . . . . . . . . . . . . . . . . 60

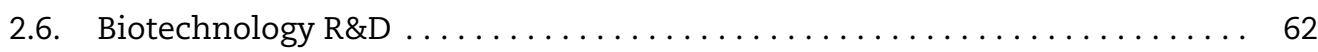

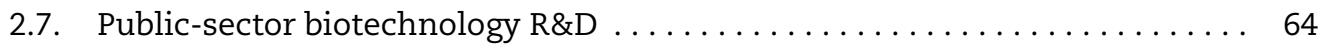

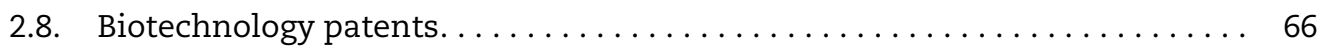

2.9. Biosciences ........................................... 68

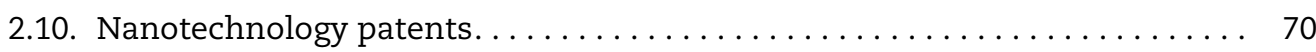

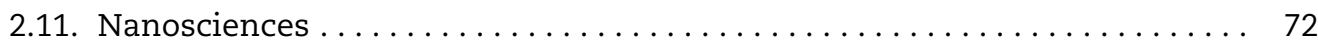

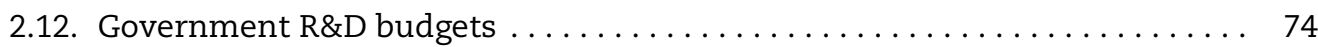

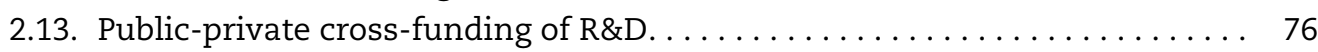

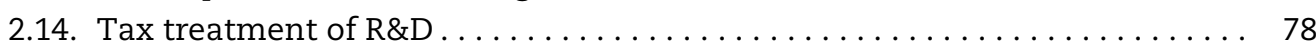

2.15. Collaboration by innovating firms $\ldots \ldots \ldots \ldots \ldots \ldots \ldots \ldots \ldots \ldots \ldots \ldots \ldots \ldots$

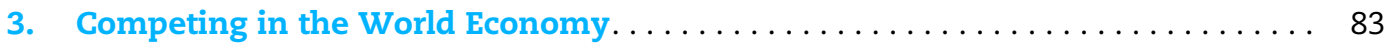

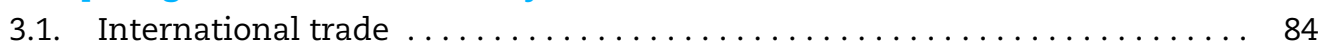

3.2. International trade by technology intensity $\ldots \ldots \ldots \ldots \ldots \ldots \ldots \ldots .66$

3.3. Manufacturing trade balance by technology intensity $\ldots \ldots \ldots \ldots \ldots . \quad 88$ 
3.4. International trade in ICT goods and services................. 90

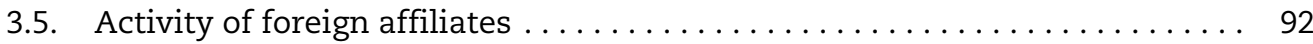

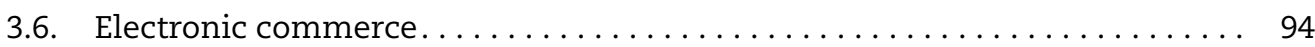

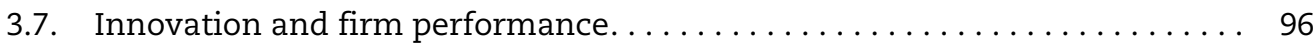

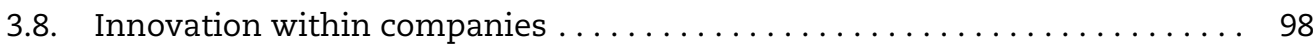

3.9. Non-technological innovation . . . . . . . . . . . . . . . . . . . . . 100

3.10. Product and marketing innovation using trademarks . . . . . . . . . . . 102

3.11. Internet access and use by businesses . . . . . . . . . . . . . . . . 104

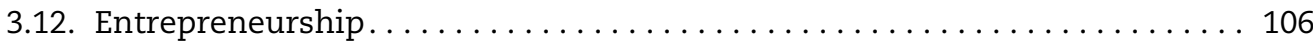

4. Connecting to Global Research . . . . . . . . . . . . . . . . . . . . . . . . 109

4.1. International co-operation in research $\ldots \ldots \ldots \ldots \ldots \ldots \ldots \ldots \ldots \ldots \ldots$

4.2. International research co-operation among regions $\ldots \ldots \ldots \ldots \ldots \ldots \ldots$

4.3. International co-operation in science. ...................... 114

4.4. Cross-border inventions . . . . . . . . . . . . . . . . . . . . . . . . . . 116

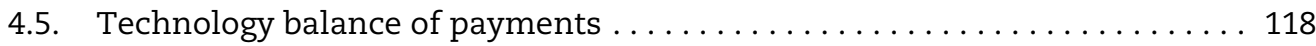

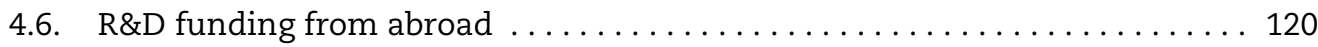

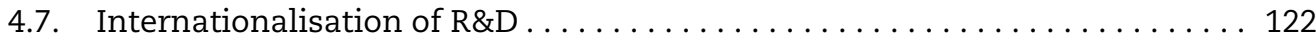

4.8. International collaboration on innovation. . . . . . . . . . . . . . . . . 124

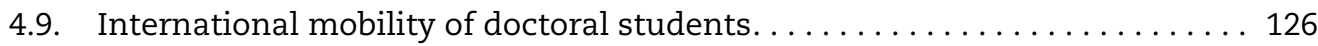

4.10. Foreign scholars in the United States . . . . . . . . . . . . . . . . 128

5. Investing in the Knowledge Economy ....................... 131

5.1. New university graduates. . . . . . . . . . . . . . . . . . . . . . . 132

5.2. New doctoral graduates . . . . . . . . . . . . . . . . . . . . . . 134

5.3. Human resources in science and technology . . . . . . . . . . . . . 136

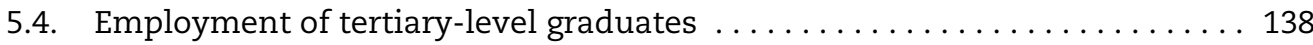

5.5. Employment of doctorate holders. . . . . . . . . . . . . . . . . . . . . 140

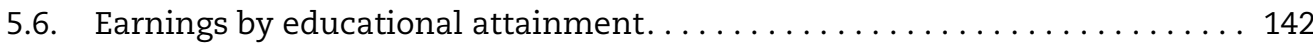

\section{This book has...}

\section{《lstan \\ StatLinks 部官L \\ A service that delivers Excel $^{\circledR}$ files from the printed page!}

Look for the StatLinks at the bottom right-hand corner of the tables or graphs in this book. To download the matching Exce $^{\circledR}$ spreadsheet, just type the link into your Internet browser, starting with the $h t t p: / / d x_{.}$doi.org prefix.

If you're reading the PDF e-book edition, and your PC is connected to the Internet, simply click on the link. You'll find StatLinks appearing in more OECD books. 


\section{Executive Summary}

$I_{\text {nnovation is a major source of economic performance and social welfare. It directly affects }}$ productivity, job creation and citizens' well-being and helps to address global challenges such as the economic crisis, health and the environment. As the role of innovation has taken on greater prominence and its characteristics have evolved, statistical information is necessary to measure these global challenges and to identify directions for responding to them.

The ninth edition of the OECD Science, Technology and Industry Scoreboard explores recent developments in matters relating to innovation, science, technology and globalisation. In this regard, it compares characteristics of OECD member and major non-member economies and provides information on the economic crisis and other global challenges. Major findings include:

- Historical data show that research and development (R\&D) and venture capital are among the first expenditures to be cut during recessions in OECD countries. Preliminary data confirm this finding for the first half of 2009.

- Foreign direct investment (FDI) inflows to G7 countries decreased by $25 \%$ in 2008 . In the first quarter of 2009, FDI flows to Canada, Germany, Italy, Japan and the United States dropped by a further $63 \%$. On the contrary, FDI inflows to the United Kingdom more than doubled in the first quarter of 2009, back to the same level as the previous year. As foreign affiliates provide access to new technologies and generate knowledge spillovers for domestic firms, lower inflows of FDI will reduce innovation capabilities in the host country.

- Patents in renewable energy and air pollution control are the most dynamic groups of environmental technologies. Over 1996-2006, they increased more rapidly than total patents filed under the Patent Co-operation Treaty (PCT).

- The United States accounted for over $42 \%$ of pharmaceutical patents in the mid-2000s; China and India together for nearly $5 \%$. A decline in productivity of the pharmaceutical sector has been evident since the mid-1990s.

- A decrease in biotechnology patents has been observed in some countries in recent years in relation to the more stringent criteria on the patenting of genetic inventions.

- Inventive activities in nanotechnology have risen substantially since the end of the 1990s but the share of nanotechnology in total patenting remains just above $1 \%$ on average. Singapore is the country most specialised in nanotechnology.

- Business is an important source of funding for R\&D performed in the higher education and government sectors, with an OECD-area average of 5.3\% in 2006.

- High-technology goods have been among the most dynamic components of international trade over the last decade. In 2007 high- and medium-high-technology manufactures accounted for $23 \%$ and $39 \%$, respectively, of total manufacturing trade.

- Information and communication technology (ICT) goods and services have been among the most dynamic components of international trade over the last decade. But the share of OECD 
countries in total world ICT trade decreased from $75 \%$ in 1997 to $52 \%$ in 2007 with the rapid rise in trade from non-OECD Asian economies.

- Patent data show a significant degree of internationalisation of research activities. On average, over 15\% of the patents filed by an OECD country in 2004-06 under the Patent Co-operation Treaty concerned inventions made abroad.

- International co-authorship has also been growing fast. In $2007,21.9 \%$ of scientific articles involved international co-authorship, a figure three times higher than in 1985.

- The number of foreign students within the OECD area has tripled since 1980, and doubled between 2000 and 2006. The United States hosted the largest foreign doctoral population, with more than 92000 students from abroad, followed by the United Kingdom (38 000) and France (28 000).

- Emerging countries are expanding their first-stage university system. Graduation rates in Russia (45\%) are significantly above the EU average. In China the number of graduates has almost tripled since 2000 , although the graduation rate $(12 \%)$ is still low compared to the OECD average.

- Between 1998 and 2007, employment of tertiary-level graduates rose on average almost three times faster than total employment. Overall, 35\% of persons employed in the OECD area had a tertiary-level degree in 2007. 


\section{Highlights}

$\mathrm{T}_{\mathrm{l}}$

he world is at a crossroads. Economies are slowly recovering from the most severe economic downturn since the Great Depression. International competition from new players is eroding the lead of more established economies. Environmental pressures call into question the sustainability of current development models. Longer life expectancy is putting a greater strain on the capability of health systems to meet the needs of an ageing population. All these challenges are global, in the sense that they affect all countries regardless of income or geography. But they are also global because the scale of problems exceeds the capability of any one country and requires co-operation by all countries.

Increasingly, innovation is seen as a critical part of an effective response to these challenges. It will be one of the keys to emerging from the downturn and putting countries back on a path to sustainable - and smarter - growth.

How is the economic crisis affecting innovation efforts? How can innovation help to solve environmental and social threats? How are countries tackling these challenges? The OECD Science, Technology and Industry Scoreboard 2009 provides the statistical information necessary to see the contours of these global challenges more clearly and to identify directions for responding to them. It considers these challenges in five chapters:

- Responding to the Economic Crisis

- Targeting New Growth Areas

- Competing in the World Economy

- Connecting to Global Research

- Investing in the Knowledge Economy

\section{Responding to the economic crisis}

$R \& D$ expenditures and venture capital are among

the first to be cut during recessions

Research and development (R\&D) expenditures are among the first to be cut during recessions. Preliminary data suggest that companies have reduced their R\&D investment in the aftermath of the crisis. Companies quoted on the New York Stock Exchange report a reduction of about $7 \%$ in their R\&D expenditures in the first quarter of 2009, with a slight increase in the subsequent quarter. The semiconductor industry, which is at the core of the information and communication technology (ICT) industries, appears particularly affected by the recession, with a drop in R\&D over the first semester of 2009 exceeding 13\%. These findings are consistent with historical trends showing that R\&D expenditure exhibits larger variations than gross domestic product (GDP) over the business cycle. Hence, any drop in GDP would result in an even larger decrease in R\&D expenditure. 
The business enterprise sector remains the main source of R\&D funding in the majority of OECD countries, accounting for around two-thirds of the total in 2007. R\&D financed by the business enterprise sector is also the component most affected by the business cycle: over 1982-2006, the observed variations in the OECD area were significantly larger than the variations in total $R \& D$. A similar pattern is likely to occur in the current crisis, with the largest decrease in business-financed R\&D.

Venture capital, a key source of funding for innovative firms and technological start-ups, becomes rarer as venture capitalists wait out the crisis. In the United States, for example, venture investments started declining in early 2008. In the first quarter of 2009 , they plunged $60 \%$ compared with the same period a year earlier. The drop was even more dramatic in communication industries, where venture investments decreased by over $80 \%$. The small increase in the second quarter of 2009 remains too timid to indicate an inversion of this trend.

New trademarks, an indicator of product

and marketing innovation, plunged $19 \%$ in 2008

Not only technological, but also non-technological innovation is cyclical. Product or marketing innovations, as measured by trademarks, have been significantly affected by the crisis. Over 2008 the number of new trademarks went down by $20 \%$ and continued to plummet over the first half of 2009.

Innovation will be also negatively affected by the drop in foreign direct investment (FDI) due to the crisis. FDI inflows to G7 countries dropped by 25\% in 2008. In the first quarter of 2009 the decrease accelerated in Canada (-97\%), Germany $(-67 \%)$, Italy $(-41 \%)$, Japan $(-59 \%)$ and the United States $(-63 \%)$. On the contrary, FDI inflows to the United Kingdom more than doubled in the first quarter of 2009, back to the same level as the previous year. As foreign affiliates provide access to new technologies and generate knowledge spillovers for domestic firms, lower inflows of FDI will reduce innovation capabilities in the host country.

Growth in labour productivity will slow significantly as a result of the economic crisis, both in the short run, owing to labour hoarding, and in the medium run, owing to a decrease in innovation efforts. This decrease will contribute to the negative trend in labour productivity growth, which slowed significantly well before the crisis and indeed from 2002.

\section{Targeting new areas of growth}

In addition to being the primary driver of economic performance, innovation also plays an important role in improving social welfare. This role takes on increased importance as policy makers face challenges that are global in scale and for which technological innovation is envisioned as a crucial aspect of the solution.

Patented inventions in renewable energy and air pollution control grew fast over 1996-2006

For the environment, investment in "clean" technologies can help achieve a wide range of objectives, from mitigating climate change to enhancing resource efficiency in general. Patents in renewable energy and air pollution control are the most dynamic groups of environmental technologies. Over 1996-2006, patented inventions in renewable energy $(+20 \%)$ and air pollution 
control $(+12 \%)$ increased more rapidly than total patents $(+11 \%)$ filed under the Patent Co-operation Treaty (PCT).

More than $30 \%$ of environment-related patents had European inventors in the mid-2000s. The United States and Japan contributed shares of between $18 \%$ and $26 \%$ in the four technological areas. The BRIICS (Brazil, the Russian Federation, India, Indonesia, China and South Africa) are also substantially involved in waste management, water pollution control and renewable energy. In 2006, no less than 7\% of world patents in these three technologies were invented by the BRIICS.

Ageing is another of the major challenges that most societies - OECD countries but also China - will face in the next decades. Innovation is an important way to meet this challenge by improving the performance of the health system and reducing its costs.

In 2006, R\&D expenditure by the pharmaceutical industry represented around $0.3 \%$ of GDP in Belgium, Sweden, the United Kingdom and the United States and reached almost $0.5 \%$ in Denmark. Direct government support for health-related R\&D in OECD countries was about $0.11 \%$ of their combined GDP in 2008.

\section{Nearly $5 \%$ of all pharmaceutical patents in 2004-06 were invented in India and China}

In 2004-06, the United States confirmed its world leadership in medical technologies, accounting for almost half of patented inventions worldwide, twice as many as the European Union. Israel accounted for $2.7 \%$, twice its share in total patents (1.3\%). Additionally, the United States had more than $42 \%$ of pharmaceutical patents in the mid-2000s. China and India together accounted for nearly $5 \%$ of patents in pharmaceuticals over the period.

A decline in productivity of the pharmaceutical sector has been evident since the mid-1990s, when increased R\&D investment coincided with a decline in the number of new drugs approved for marketing.

Biotechnology research has received extensive investment from both the public and private sectors, with a growing impact on health care. New treatments and drugs, genetically modified foods, biologically controlled production processes, new materials, biologically based computing and many other applications are improving health, the environment, and industrial, agricultural and energy production.

\section{Biotechnology R\&D is over $10 \%$ of total business \\ $R \& D$ in Ireland, Belgium, Canada and \\ the United States}

Biotechnology R\&D accounts for about 22\% of all business sector R\&D in Ireland, and for above $10 \%$ in Belgium, Canada and the United States. Denmark, Japan and the United Kingdom also have substantial business sector capabilities in biotechnology, but data on biotechnology R\&D expenditure are not available for these countries.

The surge in biotechnology patents in the late 1990s was partly due to patent applications pertaining to the human genome. The recent decrease observed in some countries raises concerns that more stringent criteria on the patenting of genetic inventions may discourage further research and reduce access to the benefits of the technology.

Nanotechnology - the science of the very small - is also likely to have a major economic and social impact in the years ahead. It may help further miniaturise information technology devices, 
resolve fundamental questions related to the immune system, accelerate advances in genomics and contribute to the generation of renewable energy.

\section{Singapore is the country most specialised}

in nanotechnology

Inventive activities in nanotechnology have risen substantially since the end of the 1990s although the share of nanotechnology in total patenting remains relatively limited $1.1 \%$ of total patents on average). Singapore is the country most specialised in nanotechnology: its proportion of nanotechnology patents is nearly three times the average share of nanotechnology patents in all patents over 2004-06. During the same period, more than two-thirds of nanotechnology patents originated from the United States (43\%), Japan (17\%) and Germany $(10 \%)$. Korea has also broadly invested in nanotechnology and ranks as the fourth producer of nanotechnology patents (3.7\%).

Public policies are called to play an important role in orienting innovation efforts towards the solution of global challenges. Government R\&D budget data provide an indication of the relative importance in public R\&D spending of various socioeconomic objectives, such as defence, health and the environment.

Government R\&D budgets as a share of GDP are the largest in Portugal, Spain and the United States. In 2008 defence accounted for $57 \%$ of the total government R\&D budget in the United States, 30\% in France and 24\% in the United Kingdom. Together with Portugal and Spain, Denmark, Finland and Iceland had the largest government R\&D budgets for civil programmes as a share of GDP in 2008.

Over 1998-2008, government R\&D increased in all countries except Israel and France. The increase was above 10\% a year in Estonia, Ireland, Korea and Spain and exceeded $20 \%$ a year in Luxembourg.

\footnotetext{
In the EU27, business financed over $7 \%$ of all R\&D

performed in public institutions and universities

in 2006
}

Business funds an important share of the R\&D performed in the higher education and government sectors, with an OECD-area average of 5.3\% in 2006. In the EU27, companies financed $7.4 \%$ of all R\&D performed in public institutions and universities, compared to only $3.2 \%$ in the United States and $2.2 \%$ in Japan.

\section{Competing in the world economy}

Progress in reducing tariff barriers, dismantling non-tariff barriers and liberalising capital markets has opened up opportunities for trade and international investment. ICTs have helped make it possible to slice up the value chain and to fragment the production of goods and services across countries. They have also enlarged the number of goods and services that can be traded internationally. These trends have increased competition in international markets and resulted in the emergence of new global players, such as China and India. 


\section{In 2007 high- and medium-high-technology manufactures accounted for over $60 \%$ of total manufacturing trade}

High-technology goods have been among the most dynamic components of international trade over the last decade. Trade in manufacturing was in fact mostly driven by high-technology industries over the second half of the 1990s and until the beginning of 2005. From 2005, the value of trade in high-technology manufactures started to slow and trade in medium-low-technology manufactures surged owing to significant increases in commodity prices for oil, petroleum products and basic metals. Still, in 2007 high- and medium-high-technology manufactures accounted for $23 \%$ and $39 \%$, respectively, of total manufacturing trade.

The manufacturing trade balance is an indicator of a country's comparative advantage. In 2007, 11 OECD countries and 2 non-members (Israel and Slovenia) had a strong comparative advantage in trade in high-technology manufactures. Switzerland had a trade surplus of over $7 \%$, followed by Ireland with 5\%. Trade in high-technology industries represented around 3\% of total manufacturing trade in Korea, Mexico and the United States. Between 1997 and 2007, the comparative advantage in high-technology industries remained unchanged for most countries, although it dropped by 5 percentage points in Japan and by 3 percentage points in China and in India.

In the same period, more countries increased their comparative advantage in medium-hightechnology manufactures. Japan led with a trade surplus of $15 \%$, followed by Germany and Ireland with 7\% and 5\%, respectively. Between 1997 and 2007, the contribution of trade in medium-hightechnology industries increased by 13 percentage points in Indonesia, 11 percentage points in Turkey and 6 percentage points in China, despite these industries' continuous negative contribution to their overall manufacturing trade balance. In 2007, much of the manufacturing trade balance of these countries relied on low-technology industries.

\section{The share of OECD countries in total world ICT trade decreased from $75 \%$ in 1997 to $52 \%$ in 2007}

ICT goods and services have been among the most dynamic components of international trade over the last decade. Global trade in ICT goods (the sum of exports and imports) expanded strongly to USD 3.7 trillion in 2007. But the share of OECD ICT trade in total world ICT trade decreased steadily from $75 \%$ in 1997 to $52 \%$ in 2007 with the rapid rise in trade from non-OECD Asian countries. In 2007 , ICT goods trade accounted for $11 \%$ of total trade within the OECD area. China has been the world's largest exporter of ICT goods since 2004 with exports growing by $30 \%$ a year from 1996 to almost USD 360 billion in 2007.

Business use of the Internet has become the standard in most OECD countries. Increasingly, access to broadband Internet is important to compete in the global economy. On average, $83 \%$ of all OECD firms with 10 or more employees use broadband but this share ranges from $46 \%$ in Mexico to $99 \%$ in Iceland. In a majority of OECD countries, over half of businesses have their own website.

Use of the Internet to sell goods or services varies across industries and countries. In OECD countries, on average, over 33\% of all businesses (with 10 or more employees) use the Internet for purchasing and about $17 \%$ for selling goods or services. 


\section{In 2007, the share of foreign affiliates in total turnover in manufacturing varied from about $80 \%$ in Ireland to $3 \%$ in Japan}

Foreign affiliates provide access to new markets and new technologies for domestic firms. In 2006, the share of firms under foreign control in total turnover in manufacturing varied from about $80 \%$ in Ireland to 3\% in Japan. It exceeded 50\% in Belgium, Canada, the Czech Republic, Hungary and the Slovak Republic. In services, the share of turnover under foreign control is over $30 \%$ in Belgium, the Czech Republic, Hungary, Ireland, Poland, the Slovak Republic and Sweden.

\section{Connecting to global research}

Today, scientific and technological innovation requires more complex and interactive processes. This added complexity has led innovators to partner to share costs, find complementary expertise, gain access to different technologies and knowledge quickly, and collaborate as part of an innovative network. This entails a need for individuals and institutions to adopt a more "open" perspective on innovation.

Over $15 \%$ of the patents filed by an OECD country

in 2004-06 concerned inventions made abroad

In Belgium, Chinese Taipei and Switzerland, over $40 \%$ of the patents filed in the mid-2000s resulted from collaboration with at least one inventor from abroad. For France, Germany, Sweden, the United Kingdom and the United States between 11\% and 24\% of patents in 2004-06 involved international co-operation. In Sweden and the United Kingdom, the share of co-invented patents increased by more than 5 percentage points from 1996-98 to 2004-06. Japan and Korea have the lowest shares of international co-invention, and these have declined from the mid-1990s.

Patent data show a significant degree of internationalisation of research activities. On average, over $15 \%$ of the patents filed by an OECD country in 2004-06 under the Patent Co-operation Treaty (PCT) concerned inventions made abroad. Similarly, the share of inventions owned by another country accounted for just below $15 \%$ of all OECD filings.

In 2007, about $22 \%$ of scientific articles involved international co-authorship, a figure three times higher than in 1985.

These figures show that the mode of production of scientific knowledge has shifted from individuals to group, from single to multiple institutions, and from the national to the international level. Researchers are increasingly networked across national and organisation borders. Moreover, international co-authorship has been growing as fast as domestic co-authorship. In $2007,21.9 \%$ of scientific articles involved international co-authorship, a figure three times higher than in 1985.

While scientific publications are concentrated in a few countries - over $80 \%$ of the articles in science and engineering published worldwide are from the OECD area - growth has recently been faster in emerging economies. Scientific articles from Latin America have more than tripled since 1993 and those from south-east Asian economies (Indonesia, Malaysia, the Philippines, Thailand and Vietnam) expanded almost three times over the period. 
The technology balance of payments provides a measure of international technology transfers: licence fees, patents, purchases and royalties paid, know-how, research, and technical assistance. Unlike R\&D expenditure, these are payments for production-ready technologies.

Between 1996 and 2006, the European Union

transformed its technology balance of payments

deficit into a surplus

In most OECD countries, technological receipts and payments increased sharply during the 1990s and up to mid-2000. Between 1996 and 2006, the European Union transformed its technology balance of payments deficit into a surplus, although this includes intra-EU flows. The US surplus increased slightly while the most spectacular improvement occurred in Japan. Overall, the OECD area maintained its position as net technology exporter vis-à-vis the rest of the world.

Technological development can be achieved either through domestic R\&D expenditure or the acquisition of foreign technology. In Greece, Hungary, Ireland, Poland and the Slovak Republic, among others, technology imports exceed technology exports.

R\&D funding from abroad also plays quite an important role in the funding of business R\&D. Most R\&D investments still go to OECD countries; however, China and India, among other emerging countries, are increasingly considered as attractive locations for R\&D. In the EU27, funding from abroad represented around 10\% of total business enterprise R\&D in 2006.

The share of foreign affiliates in industrial $R \& D$ varies widely across countries, ranging from $5 \%$ in Japan to over $60 \%$ in Ireland and the Slovak Republic. In Belgium, the Czech Republic, Portugal and Sweden the share of R\&D expenditure by foreign affiliates is over $40 \%$.

Collaboration with foreign partners can play an important role in the innovation process by allowing firms to gain access to a broader pool of resources and knowledge at lower cost and also offers a way to share the risks with partners. The share of European firms collaborating on innovation with partners across Europe ranges from less than 2\% in Spain and Turkey to over 13\% in Finland, Luxembourg and Slovenia. Collaboration with partners outside Europe is much less frequent and concerns between $1 \%$ and $5 \%$ of firms in most European countries. Overall, innovating firms from the Nordic countries and some small European economies (Belgium, Luxembourg and Slovenia) tend to collaborate more frequently with partners abroad.

The number of foreign students within the OECD

has doubled between 2000 and 2006

International migration is another essential means of fostering global innovation. The importance of migrants in the innovation process has increased in recent years and there is growing global competition for talent. Moreover, mobility contributes to the creation and diffusion of knowledge.

As part of this trend, the number of foreign students within the OECD area has tripled since 1980 and doubled between 2000 and 2006. This trend is likely to continue, fuelled by the ease and decreasing costs of international travel and communication, by education and migration policy initiatives, and possibly by a labour market premium for those who have studied abroad.

International mobility of doctoral students has increased significantly since the early 2000s. The rise has been particularly strong in Canada and New Zealand, but also in Norway and in Spain. Non-citizens represent more than $40 \%$ of the doctoral population in New Zealand, Switzerland and 
the United Kingdom, but less than $5 \%$ in Italy and Korea. The United States hosted the largest foreign doctoral population, with more than 92000 students from abroad in 2006, followed by the United Kingdom (38 000) and France (28 000).

\section{Investing in the knowledge economy}

In times of recession, education and the formation of human capital undergo opposing forces: on the one hand, budget constraints - in government, households and businesses - tend to reduce expenditure; on the other hand, rising unemployment leads to greater demand for training. Public policies, therefore, have an important role in ensuring continuous investments in education and training.

\section{1 million degrees were awarded in the OECD area in 2007}

New university graduates indicate a country's capacity to absorb, develop and diffuse knowledge and to supply the labour market with highly skilled workers. In 2006, more than one young person in three graduated at the first-stage university level in the OECD area. This represents 7.1 million degrees awarded.

Australia, Iceland and New Zealand had the highest graduation rates (over 50\%). Japan (39\%) ranks slightly above the OECD average (37\%). The United States (36\%) and the EU $(35 \%)$, the two main university systems with 2.9 and 2.2 million degrees awarded, respectively, rank just below.

\section{In China the number of graduates has almost \\ tripled since 2000 but the graduation rate is \\ only $12 \%$}

Emerging countries are also expanding their first-stage university system. Graduation rates in the Russian Federation (45\%) are significantly above the EU average. In China the number of graduates has almost tripled since 2000 , although the graduation rate $(12 \%)$ is still low compared to the OECD average.

Most university degree recipients graduate in the social sciences. Scientific studies are more popular in Korea and the Nordic countries, where science and engineering (S\&E) degrees account for $37 \%$ and $29 \%$, respectively, of total awards. In most OECD countries, universities deliver more engineering than science degrees.

OECD governments are concerned about the low level of female participation in scientific studies. The presence of women is overwhelming in humanities and the arts (67\%), health (74\%) and education $(75 \%)$ but low in engineering (23\%) or computing (23\%).

$40 \%$ of OECD doctoral students graduate in

science and engineering

Doctoral graduates are key players in research and innovation. They have been specifically trained to conduct research and contribute to the diffusion of knowledge in society. Despite the declining share of S\&E doctorates, $40 \%$ of OECD doctoral students graduate in scientific fields; the S\&E orientation of doctoral programmes is even more pronounced in emerging countries. 
In 2006, EU universities awarded half of the total OECD doctoral degrees; they are particularly strong in S\&E disciplines. The United States and Germany awarded $28 \%$ and 13\%, respectively.

Women are under-represented in advanced research programmes. They account for just $32 \%$ of the S\&E programmes in OECD. However, the gender imbalance at the doctoral level is less pronounced than at lower levels of education.

In 2006, Brazil, China, India and the Russian

Federation combined trained half as many

doctoral graduates as OECD countries together

In many OECD countries doctoral degrees have multiplied faster than other university degrees. Since 2000 the number of OECD-area doctorates has increased by $5 \%$ a year and the number of first-stage university degrees has grown by $4.6 \%$. In 2006, Brazil, China, India and the Russian Federation combined trained half as many doctoral graduates as OECD countries taken together. Although graduation rates are lower outside the OECD area, Brazil and the Russian Federation award more doctorates per inhabitant than the OECD average.

\section{Human resources in science and technology \\ represent over a quarter of total employment in most OECD countries}

Human resources in science and technology (HRST) are major actors in innovation. In most OECD countries, they represented more than a quarter of total employment in 2008. Over the past decade, HRST occupations increased more rapidly than total employment in most OECD countries. In services, the average annual growth rate has always been positive, ranging from $1.1 \%$ in the United States to $6.3 \%$ in Spain. However, in manufacturing, the share of professionals and technicians decreased in Luxembourg $(-2.1 \%)$, the United States $(-1.3 \%)$, Japan $(-1.2 \%)$ and Sweden $(-0.5 \%)$.

A particular characteristic of HRST employment is the increasing share of women. Indeed, women are traditionally more numerous than men among HRST employees in OECD countries. In Hungary, Poland and the Slovak Republic, 60\% of HRST in 2008 were women.

On average, $35 \%$ of persons employed in the OECD

area had a tertiary-level degree in 2007

Employment of tertiary-level graduates is an indicator of the innovative potential of an economy and of the capacity of its labour market to allocate human capital to the production process. On average, 35\% of persons employed in the OECD area had a tertiary-level degree in 2007. Canada (over 50\%), Finland, Japan, New Zealand and the United States (over 40\%) ranked far ahead of the European Union, where just over one worker in four holds a tertiary-level degree. In the Czech Republic, Italy, Portugal and the Slovak Republic tertiary-level graduates account for $20 \%$ of employment or less.

Between 1998 and 2007, employment of tertiary-level graduates rose on average almost three times faster than total employment. This growth is due in part to the increased presence of women in the labour market. Despite their greater propensity to graduate at tertiary level, women represent on average $46 \%$ of tertiary-level employment. 
University graduates are also generally less likely than non-graduates to remain unemployed. However, the unemployment rate among university graduates is higher in Turkey (6.9\%), Poland (6.2\%), Greece (5.4\%) and France (5.3\%). Women with a university degree are less likely to be unemployed than women without one, yet their unemployment rate is higher than that of men with the same level of education.

Doctorate holders have a research qualification and are a pillar of the research system. Their presence is an indicator of a country's attractiveness for new and foreign talents. Employment of doctorate holders ranges from $97 \%$ to $99 \%$ and exceeds that of university graduates ( $83 \%$ to $89 \%$ ). Many doctorate holders face temporary employment in the early stage of their careers. After five years of activity, $60 \%$ of doctorate holders in the Slovak Republic and over $45 \%$ in Belgium, Germany and Spain remain under temporary contracts. Yet permanent engagements account for over $80 \%$ of all jobs in almost all countries.

\section{In some OECD countries, the average earnings premium for a tertiary-level diploma holder is above $75 \%$}

The earnings premium from education is an important incentive for individuals to enrol in tertiary education. In all OECD countries, annual earnings increase with educational attainment levels. In the Czech Republic, Hungary, Portugal and the United States, the average earnings premium for a tertiary-level diploma holder was no less than $75 \%$ in 2006 . Such differentials are traditionally smaller in Nordic countries and lower than $30 \%$.

Over the past decade, the earnings premium of highly skilled workers decreased the most in Italy $(-6.4 \%)$, Ireland $(-4.3 \%)$, Hungary $(-4 \%)$, Germany $(-3.4 \%)$ and Poland $(-2.9 \%)$. The opposite trend is observed in Australia, New Zealand, Spain and Sweden it increased at an average annual rate of between $1 \%$ and $3 \%$.

Earnings differentials between males and females still remain significant in all OECD countries. In Austria, Germany, Italy and the United States, women earn at least $40 \%$ less than men in HRST occupations. This gap seems smaller in Belgium, Spain and Turkey (22\% less in each) and in Luxembourg, although the data do not control for part-time work. 



\section{RESPONDING TO THE ECONOMIC CRISIS}

1.1. Venture capital in the economic crisis ............. 22

1.2. R\&D in the economic crisis..................... 24

1.3. R\&D growth over the business cycle............... 26

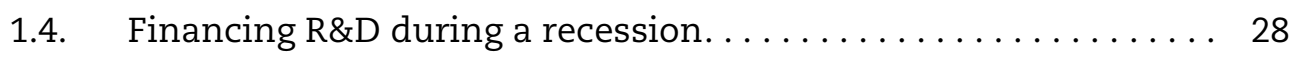

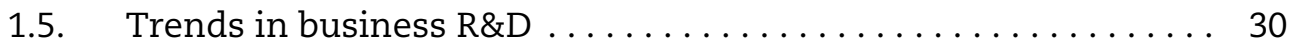

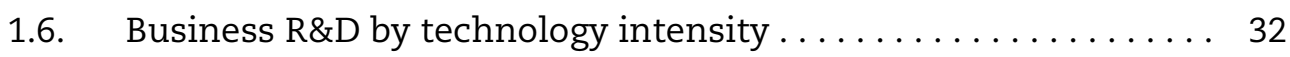

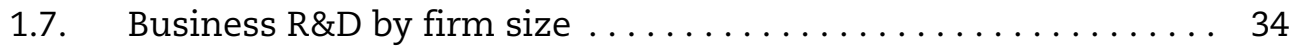

1.8. Patent intensity over the business cycle $\ldots \ldots \ldots \ldots \ldots \ldots \ldots$

1.9. Trademarks over the business cycle . . . . . . . . . . . 38

1.10. Trends in researchers . . . . . . . . . . . . . . . . 40

1.11. Foreign direct investment flows . . . . . . . . . . . . 42

1.12. Trends in the employment of foreign affiliates. . . . . . . . . . 44

1.13. Labour productivity growth over the business cycle . . . . . . . 46

1.14. ICT investment over the business cycle ............. 48 


\section{RESPONDING TO THE ECONOMIC CRISIS}

\subsection{Venture capital in the economic crisis}

Venture capital is a major source of funding for new technology-based firms. It plays a crucial role in promoting radical innovations and is one of the key determinants of entrepreneurship.

In 2008, the United States accounted for $49 \%$ of total venture capital investments in OECD countries. The United Kingdom was the only other country where this share exceeded $10 \%$ of the OECD total.

Denmark and Luxembourg have the highest intensity of venture capital investment, with just below $0.3 \%$ of their GDP. The intensity is also high in Finland (0.23\%) and the United Kingdom (0.21\%).

The Internet bubble in the early 2000s clearly showed that venture capital is very sensitive to economic downturns. The total amount of US venture capital investment dropped by about $42 \%$ in just one quarter at the beginning of 2001. By the end of first quarter of 2003, venture investment had decreased by a striking $85 \%$ since the first quarter of 2000 .

At a time when access to bank credit and stock market financing is very tight, venture capital becomes rare as venture capitalists wait out the crisis. In the United States, for example, total venture investments started declining in early 2008. In the first quarter of 2009, they plunged $60 \%$ from a year earlier. The small increase in the second quarter of 2009 remains too timid to indicate an inversion of this trend.

Early stage and start-up and seed investments followed the same pattern, with decreases of $56 \%$ and $60 \%$, respectively, over the same period.

The drop was particularly dramatic in the communication industries, where the decrease in venture investments started in the third quarter of 2007 and exceeded $80 \%$ by the end of the first quarter of 2009 .

In information technologies and the health and biotechnology industries, the reduction of venture investment was in line with the overall decrease and equal to $59 \%$ and $55 \%$, respectively.

\section{Venture capital}

Venture capital is provided by specialised financial firms acting as intermediaries between primary sources of finance (such as pension funds or banks) and firms (formal venture capital). It is also provided by so-called "business angels" (usually wealthy individuals experienced in business and finance who invest directly in firms).

The PricewaterhouseCoopers/National Venture Capital Association MoneyTree ${ }^{\mathrm{TM}}$ Report is a quarterly study of venture capital investment activity in the United States. It records cash for equity investments in US companies as the cash is actually received by the company (also called a tranch).

The development of a venture-backed company has three basic financing stages:

- Seed capital is provided to research, assess and develop an initial concept.

- Start-up financing is provided for product development and initial marketing.

- Expansion financing is provided for the growth and expansion of a company that is breaking even or trading profitably.

\section{Source}

OECD calculations, based on Pricewaterhouse Coopers/National Venture Capital Association MoneyTree ${ }^{\mathrm{TM}}$ Report.

\section{Going further}

PricewaterhouseCoopers/National Venture Capital Association (2009), Second Quarter 2009 MoneyTreeTM Report, www.pwcmoneytree.com/MTPublic/ns/index.jsp. 


\section{RESPONDING TO THE ECONOMIC CRISIS}

\subsection{Venture capital in the economic crisis}

\section{Venture capital investment, 2008}

USD millions and as a percentage of GDP

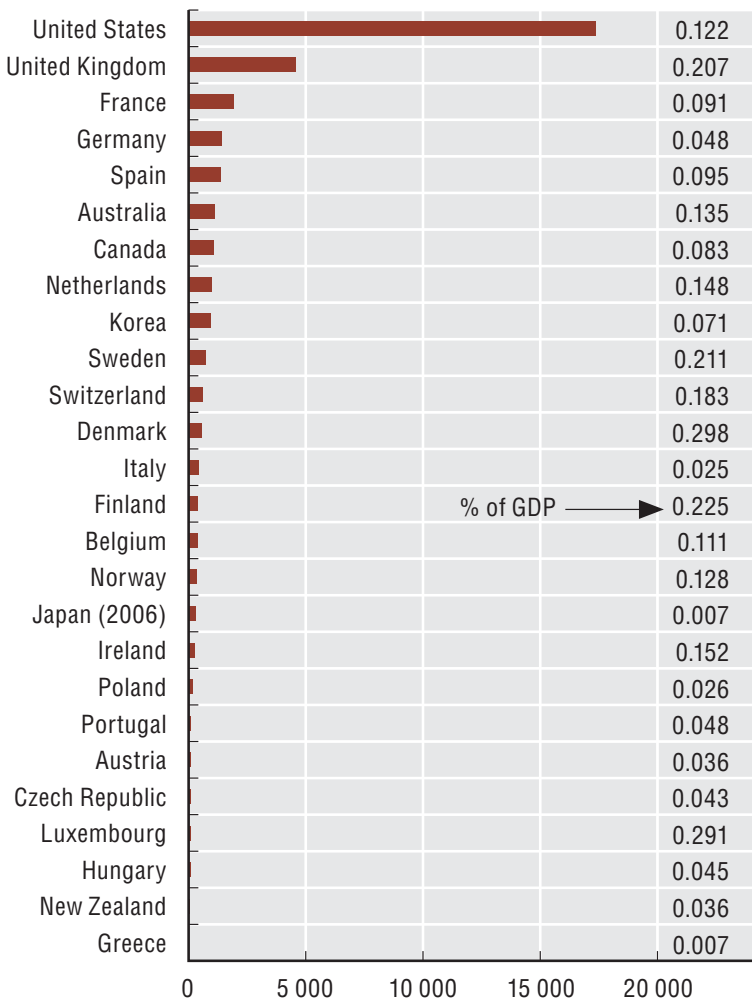

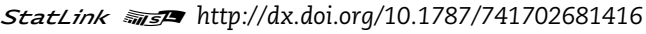

\section{US venture capital investment, by stage - latest quarters}

USD millions

$\longrightarrow$ Total $\longrightarrow$ Early stage - - - Startup/seed

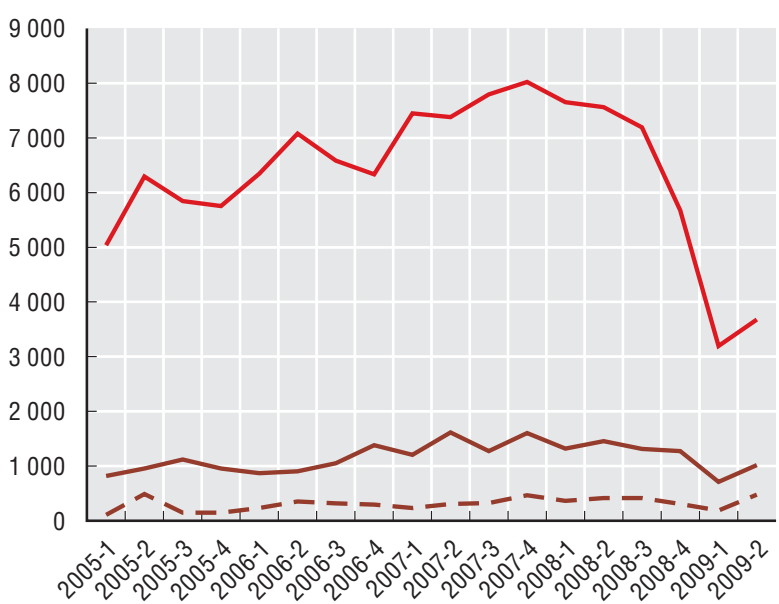

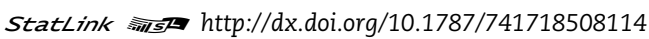

US venture capital investment, by industry - historical trends USD millions
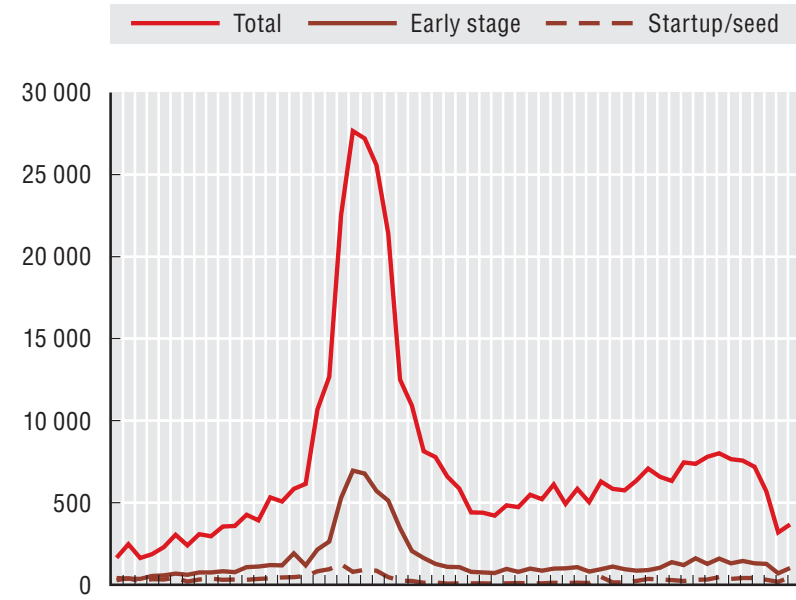

.

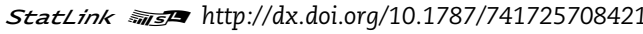

US venture capital investment, by industry - latest quarters USD millions

$\begin{array}{lll} & \text { Communication } & \\ \text {...... } & \text { Health/biotechnology }\end{array}$

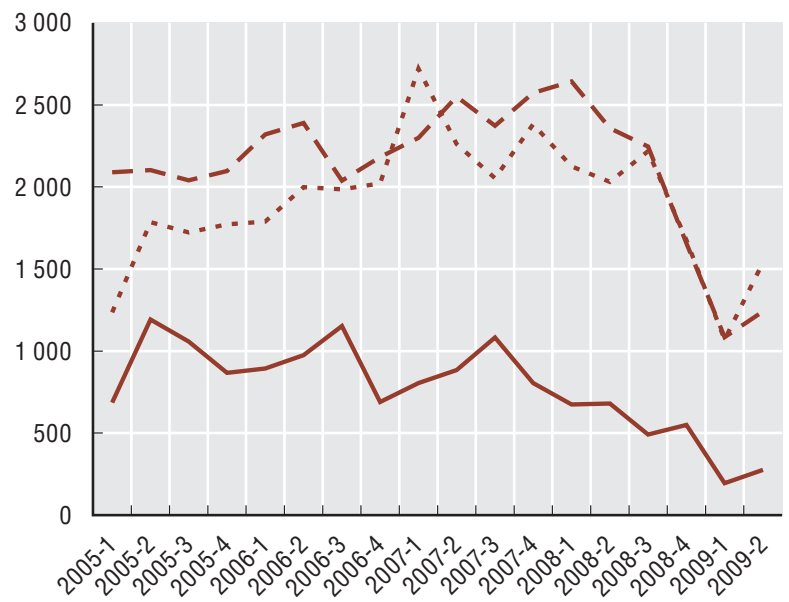

StatLink गाडs http://dx.doi.org/10.1787/741735517440 


\section{RESPONDING TO THE ECONOMIC CRISIS}

\section{2. $R \& D$ in the economic crisis}

Economies are slowly recovering from the most severe economic downturn since the Great Depression. To emerge from the downturn and put countries back on a path to sustainable growth, continuous innovation will be required. However, financing innovation becomes harder in economic downturns when both cash flows and investment funds are shrinking.

Official statistics on R\&D are available only until 2007, but preliminary US stock markets data suggest that companies have significantly reduced their $R \& D$ investments in the aftermath of the crisis.

Domestic and foreign companies quoted in US stock markets report a reduction of $6.6 \%$ in their $R \& D$ expenditures in the first quarter of 2009, with a small increase in the subsequent quarter.

$R \& D$ in some information and communication technologies (ICTs) seems to be particularly affected. In the second quarter of 2009, the semiconductors industry and communications equipment and services registered a decrease in R\&D of $12.9 \%$ and $11.3 \%$, respectively, from the same period a year earlier. However, the decrease in $R \& D$ spending in computer manufacturing and computer services was less pronounced, at $-5.9 \%$ in the first quarter of 2009 with a slight increase in the second quarter.

\section{R\&D in financial statements}

All companies quoted in US stock markets must file quarterly and annual reports about their financial situation with the US Securities and Exchange Commission (SEC). Among other information, the quarterly income statement provides the company's latest expenditures on R\&D.

The R\&D statistics reported here refer to 2079 companies from around the world, although most are based in the United States, which have reported $R \& D$ expenditures from the second quarter of 2007 to the second quarter of 2009. Although this set of companies is not representative of all companies, it provides timely insight into the effect of the economic crisis on R\&D spending.

\section{Source}

OECD calculations, based on quarterly income statements to the SEC.

\section{Going further}

Securities and Exchange Commission (2008), 2008 Annual Report, www.sec.gov/2008annual/index.htm. 


\section{Quarterly R\&D expenses, all industries 2007-09}

SEC-registered companies, June $1997=100$

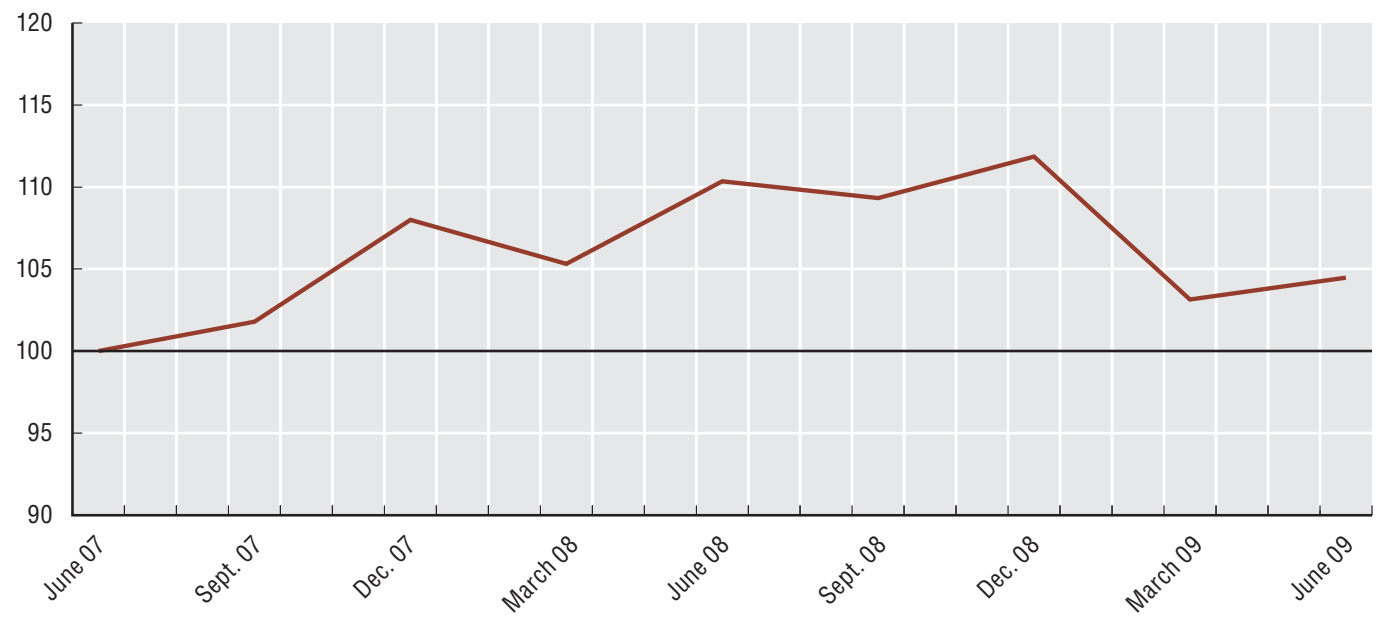

StatLink तilst http://dx.doi.org/10.1787/741758558300

Quarterly R\&D expenses, ICT industries, 2007-09

SEC-registered companies, June $1997=100$

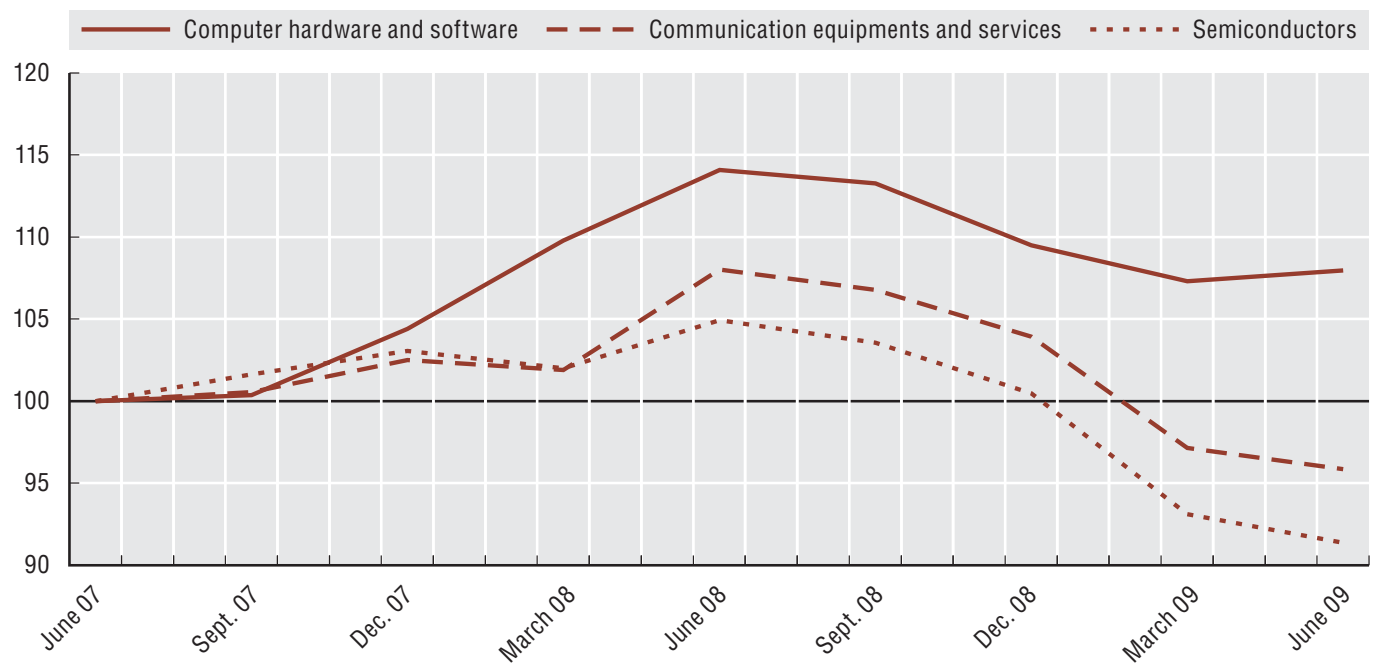

StatLink काज्s http://dx.doi.org/10.1787/741801610222 


\section{RESPONDING TO THE ECONOMIC CRISIS}

\subsection{R\&D growth over the business cycle}

Research and development (R\&D) expenditure is one of the most widely used measures of the innovative efforts of firms and countries. It is directly linked to innovation via new products and new processes, and indirectly as investment in knowledge.

For the OECD area as a whole, R\&D tends to show larger variations than gross domestic product (GDP) over the business cycle. This suggests that the expected drop in GDP due to the current crisis would result in an even larger decrease in R\&D expenditure.

This decrease is likely to affect some countries more than others. Responsiveness of R\&D to the business cycle (see box right) appears strongest in Hungary, the Slovak Republic, Poland and Spain where on average, over 1981-2007, any variation in GDP has been associated with a variation two to three times greater in R\&D. This suggests that in these countries the current crisis will have a significant impact on R\&D. In Denmark, Japan and the United States, R\&D expenditure has been moving nearly proportionally with GDP. Belgium, Germany, Austria, Norway and the United Kingdom have been better able to preserve their $R \& D$ levels over the business cycle. If this pattern is maintained, the impact of the current crisis on R\&D in these countries is likely to be relatively contained.

In 2007, R\&D expenditure in the OECD area reached USD 886.3 billion (in current purchasing power parity, PPP), or about $2.29 \%$ of overall GDP. Gross domestic expenditure on R\&D (GERD) has been growing steadily since the 1980s despite a slowdown in the early 1990s and 2000s.

R\&D intensity (GERD/GDP) is a relatively stable measure: in 2007 in only four OECD countries (Finland, Japan, Korea and Sweden) was it greater than 3\%; the OECD average was $2.3 \%$ and that of the EU $1.8 \%$. In the last two years, significant positive growth in terms of $R \& D$ intensity was reported for Portugal (0.4 percentage points) and Australia (0.2); R\&D intensity declined slightly in Canada from $2.1 \%$ in 2004 to $1.8 \%$ in 2008.

Non-OECD economies are also important R\&D spenders: China's GERD is equivalent to around $11.5 \%$ of that of the OECD area and Israel's R\&D intensity (4.7\%) is higher than that of any OECD country.

\section{R\&D expenditure and responsiveness to GDP}

Resources allocated to a country's R\&D efforts are measured using two indicators, R\&D expenditure and personnel. For R\&D expenditure, the main aggregate used for international comparisons is gross domestic expenditure on $R \& D$ (GERD), which represents a country's domestic R\&D-related expenditure for a given year. The R\&D data are compiled on the basis of the Frascati Manual which defines R\&D as "creative work undertaken on a systematic basis in order to increase the stock of knowledge, including knowledge of man, culture and society, and the use of this stock of knowledge to devise new applications".

The magnitude of estimated resources allocated to R\&D is affected by several national characteristics, principally:

- Coverage of national surveys on R\&D in terms of industries, firm size, sampling methods.

- Frequency of national surveys.

- Methodology used, e.g. for the United States, capital expenditure is not covered.

Responsiveness is measured as the estimated elasticity of GERD to GDP. The estimation is based on an OLS regression on the first-order differences of natural logs. Only coefficients significant at the $10 \%$ level and below are reported.

\section{Source}

OECD, Main Science and Technology Indicators Database, June 2009.

\section{Going further}

OECD (2002), Frascati Manual: Proposed Standard Practice for Surveys on Research and Experimental Development, OECD, Paris, www.oecd.org/sti/frascatimanual. 


\section{RESPONDING TO THE ECONOMIC CRISIS}

1.3. R\&D growth over the business cycle

R\&D growth over the business cycle, OECD, 1982-2007

Average annual real growth rate, percentage

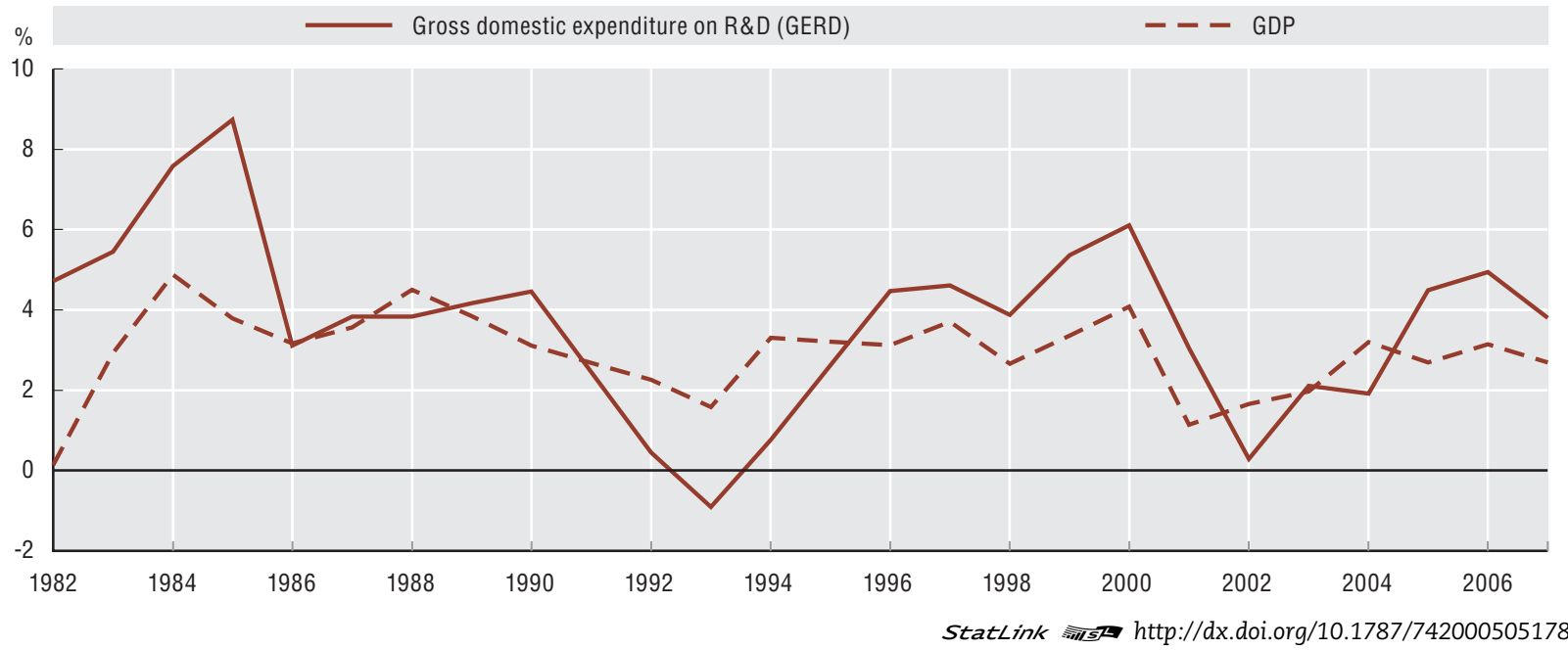

\section{Responsiveness of R\&D to the business cycle, 1981-2007}

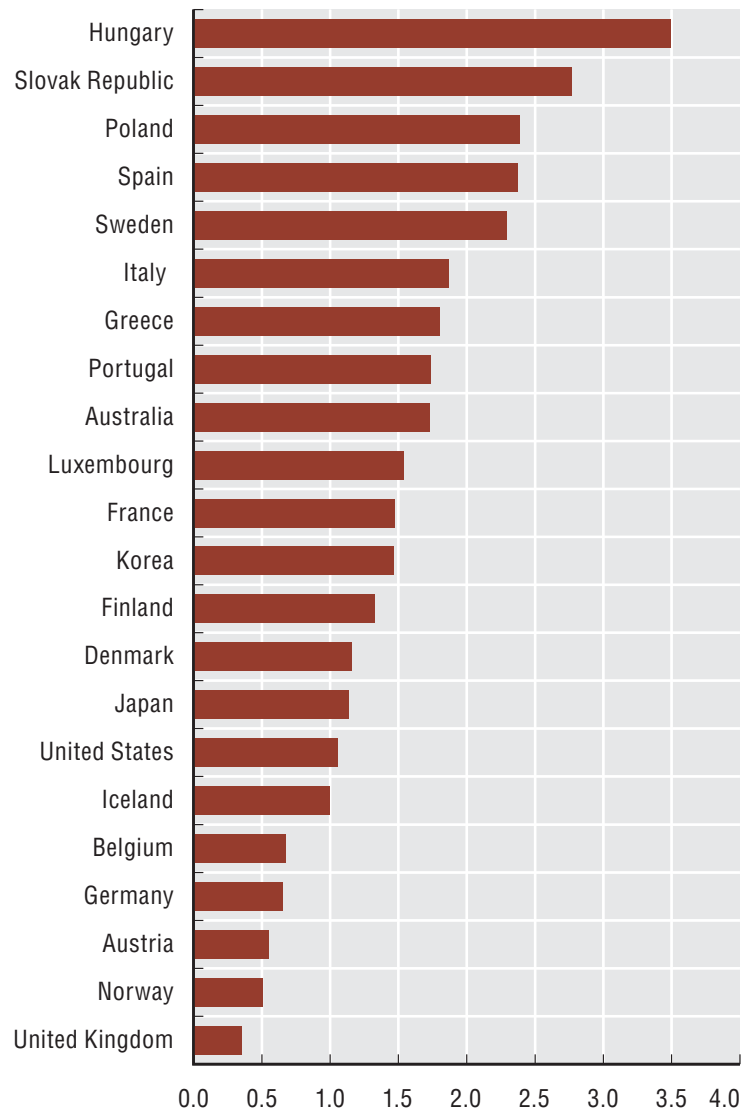

StatLink तiाs< http://dx.doi.org/10.1787/742013061504

\section{R\&D intensity (GERD/GDP), 2007 or} latest available year

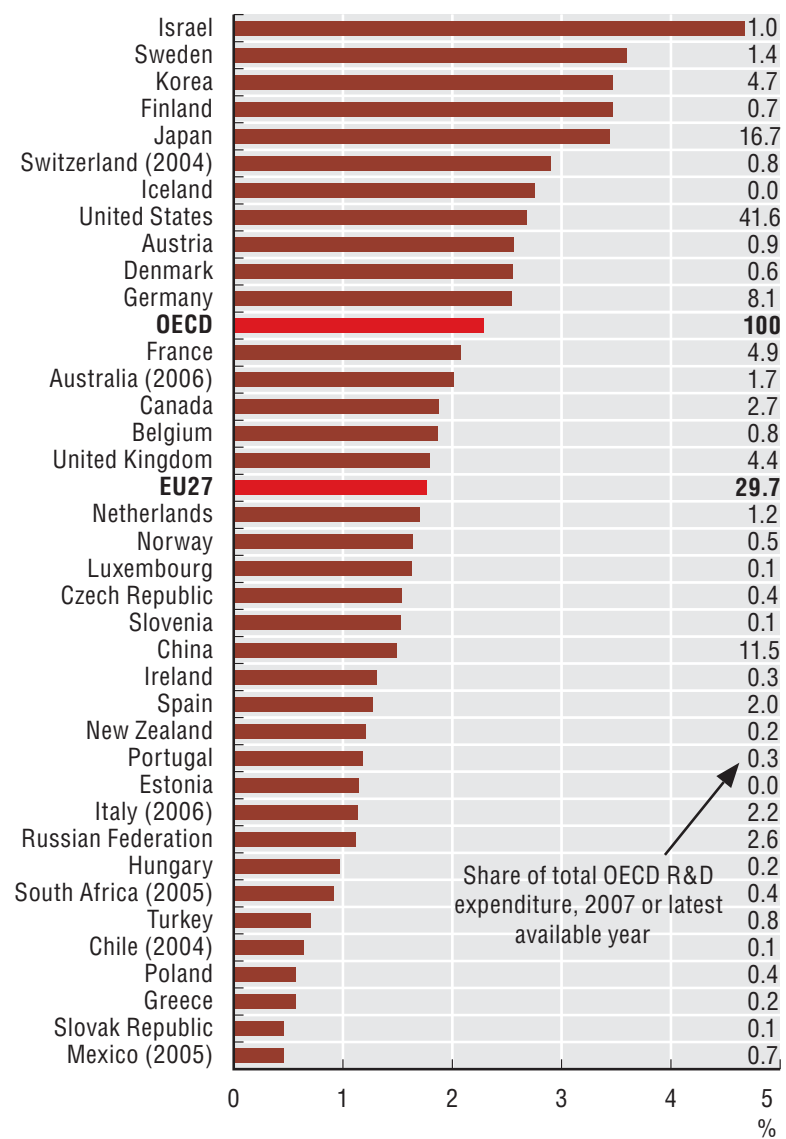

StatLink ला/s http://dx.doi.org/10.1787/742024553847 
The business enterprise sector remains the main source of R\&D funding in most OECD countries, accounting for around two-thirds of the total in 2007. Its role differs sharply across countries, from over three-quarters in Japan and Luxembourg to less than $35 \%$ in Greece and Poland. In recent years, its role has increased slightly in the main OECD regions to $55 \%$ in the EU and $66 \%$ in the United States.

$R \& D$ financed by the business enterprise sector is also the component most affected by the business cycle: over 1982-2007, the observed variations in the OECD area were significantly larger than the variations in total R\&D. This suggests that the current crisis will affect business-financed R\&D most strongly.

In the OECD area, business funding of R\&D has been growing on average at a faster pace than government-financed R\&D over the last 25 years. Following the economic upturns after 1993 and 2002-03, businessfunded R\&D growth picked up much more rapidly than government-funded R\&D. Both sources of financing moved in parallel from 1982 to 1987, and they moved in opposite directions in 1988-89 and 2001-02.

Based on a measure of "responsiveness", businessfinanced R\&D appears more volatile than other sources of financing in most countries. However, in Austria, Ireland, Italy and Portugal the financing of $R \& D$ by businesses is more stable than financing from other sources. In these countries, the current crisis may result in a decrease in R\&D financing by government unless recent stimulus packages focused on R\&D are implemented, like in the case of Portugal.

\section{$R \& D$ performance and funding}

The R\&D effort (expenditure and personnel) is usually broken down among four sectors of performance: business enterprise, higher education, government and private non-profit institutions serving households (PNP). This breakdown is largely based on the System of National Accounts, but higher education is viewed as a special sector, owing to the important role played by universities and similar institutions in the performance of $R \& D$.
$R \& D$ has various sources of financing. Five are generally taken into account: the four R\&D-performing sectors mentioned above and funds from "abroad". Flows of funds are measured using performance-based reporting on the funds received by a unit, organisation or sector for the performance of intramural R\&D. What is therefore measured are direct transfers of resources used to carry out R\&D; other government provisions to encourage R\&D, such as tax concessions, payment of bonuses for R\&D, exemption from taxes and tariffs on R\&D equipment, etc., are excluded. For purposes of international comparisons, public general university funds (GUF) are included in the subtotal for government funds. These are the funds allocated by higher education establishments to R\&D from the general grant in support of their overall research and teaching activities which they receive from the Ministry of Education or the corresponding provincial or local authorities.

When assessing the contributions of the different sectors to R\&D performance and the changes over time, it is important to take account of changes in methods and breaks in series, as well as national practices. For example, the transfer of publicsector organisations to the private sector would reduce the government sector's contribution and increase that of the business sector. In the United States, funds from abroad are included with financing by the business enterprise sector.

Responsiveness is measured as the estimated elasticity of business enterprise-financed GERD to total GERD. The estimation is based an OLS regression on the first-order differences of natural logs. Only coefficients significant at 10\% level and below are reported.

\section{Source}

OECD, Main Science and Technology Indicators Database, June 2009.

\section{Going further}

OECD (2002), Frascati Manual: Proposed Standard Practice for Surveys on Research and Experimental Development, OECD, Paris, www.oecd.org/sti/frascatimanual. 


\section{RESPONDING TO THE ECONOMIC CRISIS}

1.4. Financing $R \& D$ during a recession

R\&D growth over the business cycle by source of financing, OECD area, 1982-2007

Average annual real growth rate, percentage

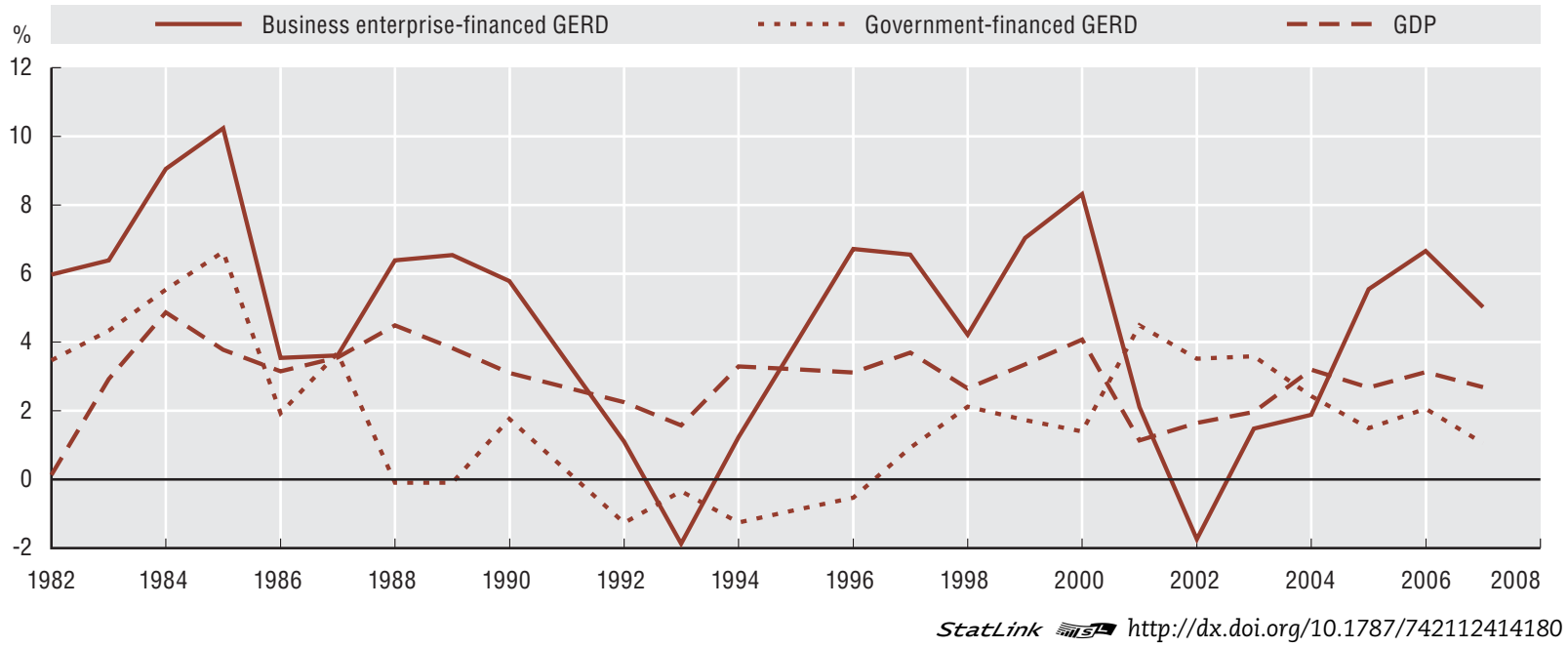

\section{Responsiveness of business-financed R\&D} to the business cycle, 1981-2007

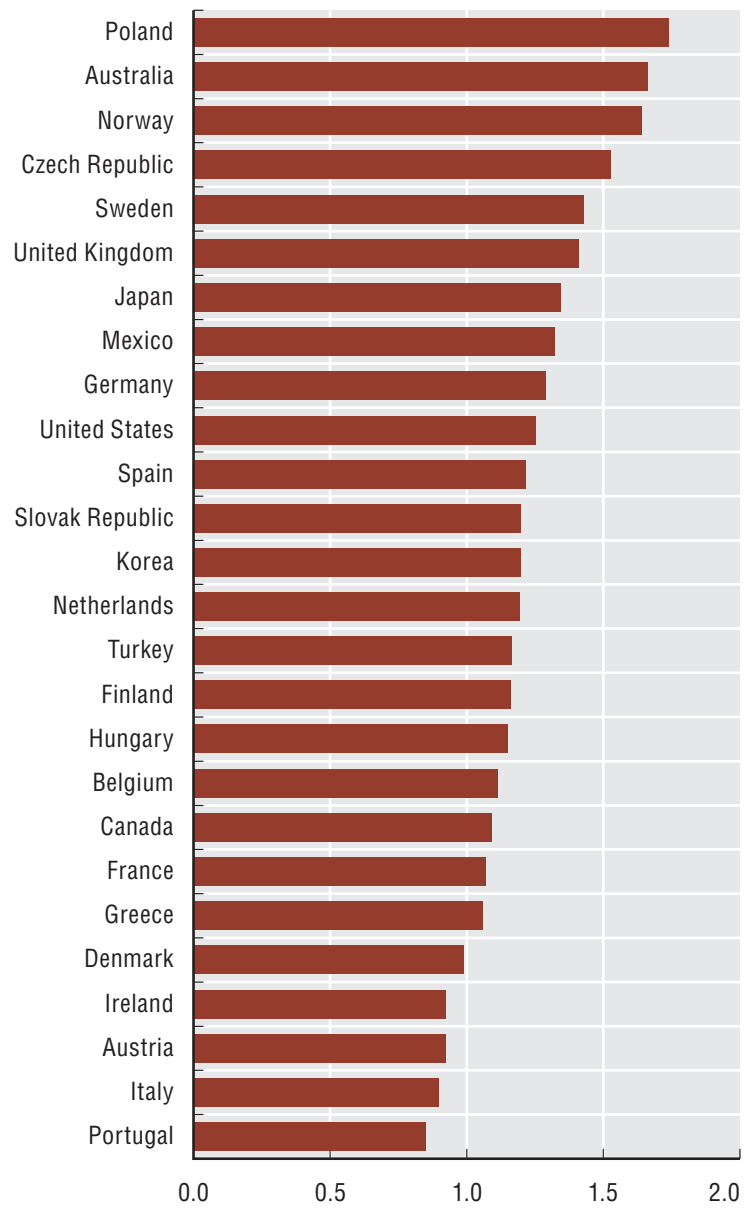

R\&D by source of financing, 2007

As a percentage of the national total

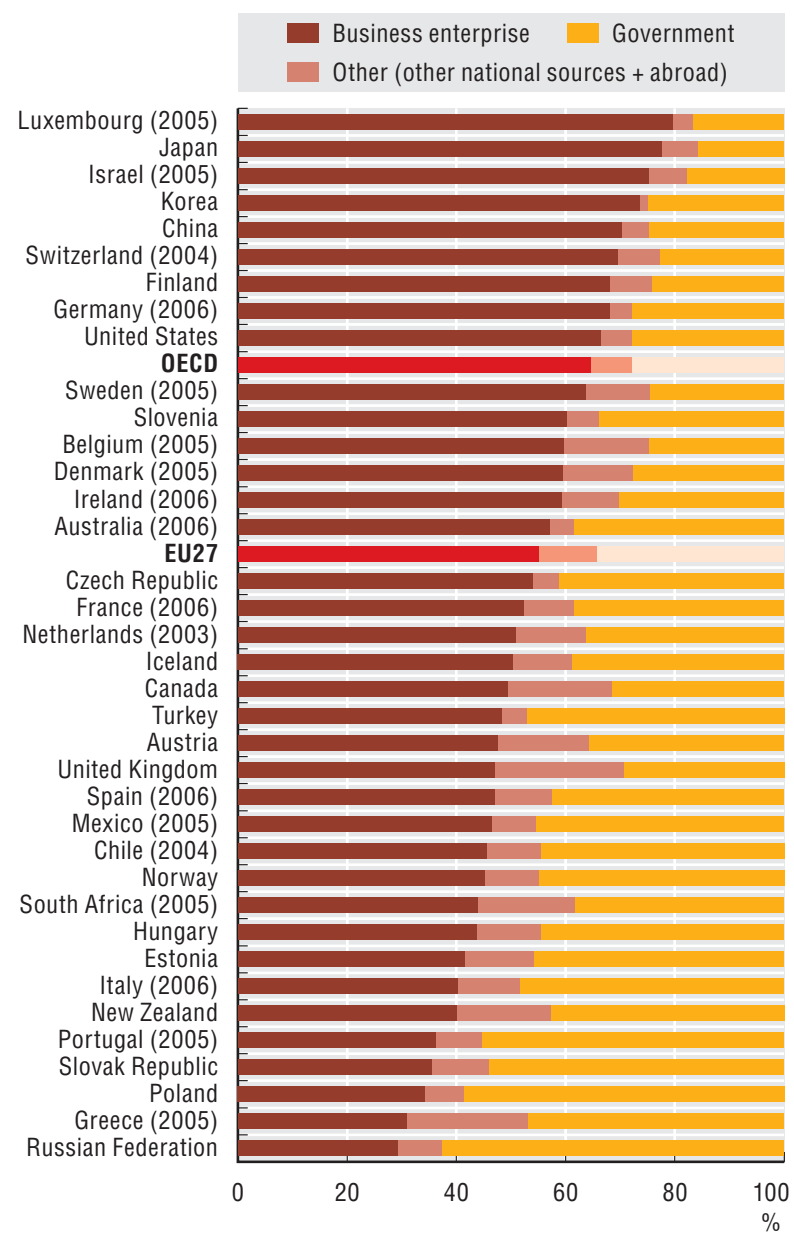

StatLink Allst http://dx.doi.org/10.1787/742104412330 


\section{RESPONDING TO THE ECONOMIC CRISIS}

\subsection{Trends in business R\&D}

Business enterprise R\&D (BERD) accounts for the bulk of research and development (R\&D) activity in OECD countries in terms of both performance and funding. In 2007, R\&D performed by the business sector reached USD 616.8 billion (in current PPP), or close to $70 \%$ of total R\&D. The United States accounted for around $43 \%$ of OECD-area BERD. The EU and Japan accounted for $27 \%$ and $19 \%$, respectively.

Between 1997 and 2007, OECD-area BERD grew by USD 160 billion (in PPP of 2000). The United States accounted for almost $40 \%$ of the growth, and Japan for around 20\%. In 2007 BERD in China reached USD 74 billion (in current PPP), or about $45 \%$ of BERD in the EU, up from around $7 \%$ ten years earlier.

Among OECD countries, Iceland, Portugal and Turkey experienced strong growth of BERD during the last decade, in excess of $10 \%$ a year. Outside the OECD area, both China and Estonia had growth rates above $20 \%$ a year in real terms. The Slovak Republic is the only country among those surveyed to have experienced a decline of BERD in real terms during the period (almost $10 \%$ per year).

In the three main OECD regions, business R\&D intensity ( $R \& D$ expenditure relative to value added in industry) increased from the mid-1990s to 2000. Since then, it has risen strongly in Japan (to $3.7 \%$ in 2007), but remained stable in the European Union (around $1.8 \%$ ). In the United States, after a drop in the early 2000s (2.8\% in 2004), it climbed to $3.1 \%$ in 2007. Business R\&D intensity is well above the OECD average of $2.4 \%$ in all Nordic countries except Norway, but particularly in Sweden (4.5\%) and Finland (4.0\%).

\section{Business R\&D}

Business enterprise expenditure on R\&D (BERD) covers $R \& D$ activities carried out in the business sector by performing firms and institutes, regardless of the origin of funding. While the government and higher education sectors also carry out $R \& D$, industrial $R \& D$ is most closely linked to the creation of new products and production techniques, as well as to a country's innovation efforts. The business enterprise sector includes:

- All firms, organisations and institutions whose primary activity is production of goods and services for sale to the general public at an economically significant price.

- The private and not-for-profit institutions mainly serving them.

When assessing changes in BERD over time, it is necessary to take account of changes in methods and breaks in series, notably in terms of the extension of survey coverage, particularly in the services sector, and the privatisation of publicly owned firms.

\section{Source}

OECD, Main Science and Technology Indicators Database, June 2009.

\section{Going further}

OECD (2002), Frascati Manual: Proposed Standard Practice for Surveys on Research and Experimental Development, OECD, Paris, www.oecd.org/sti/frascatimanual. 
Business R\&D intensity trends by area, 1993-2007 $B E R D$ as a percentage of value added in industry

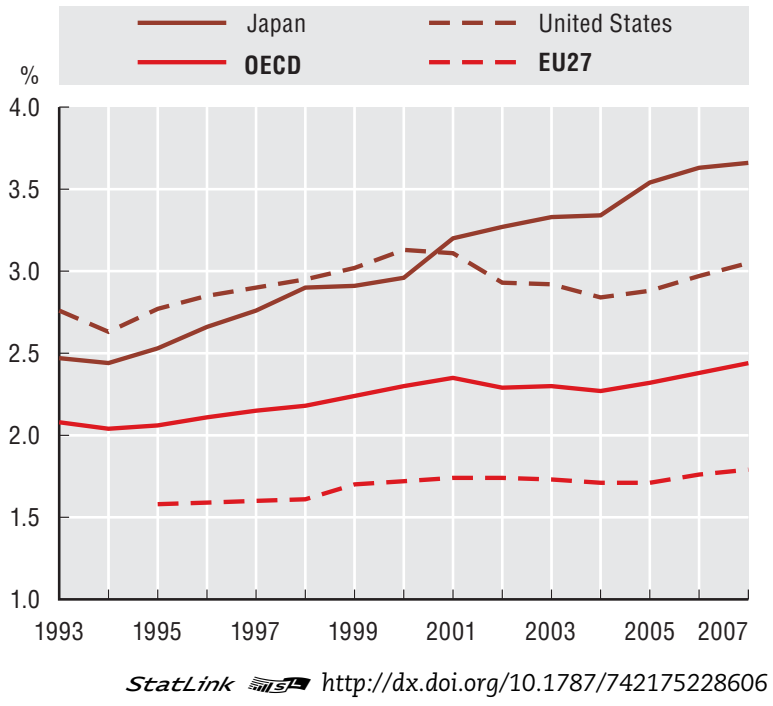

Business R\&D intensity, 2007

$B E R D$ as a percentage of value added in industry

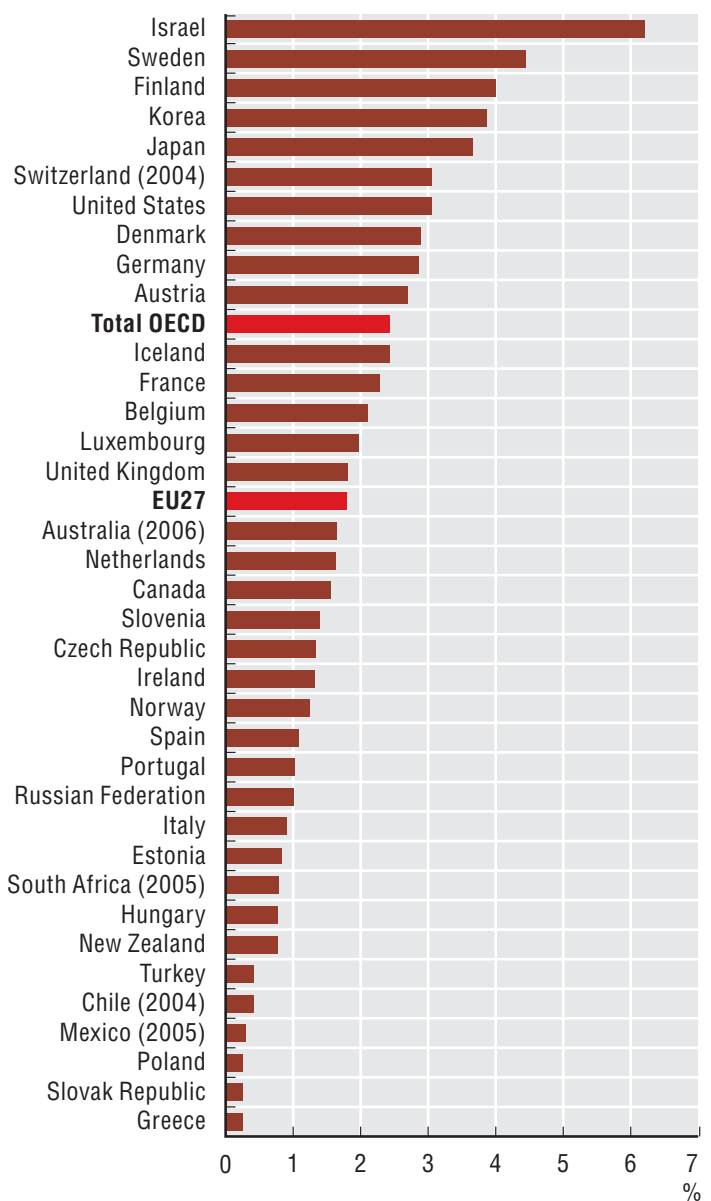

StatLink Niाsस http://dx.doi.org/10.1787/742227210404
Business R\&D by area, 1993-2007

Billions of USD PPP of 2000
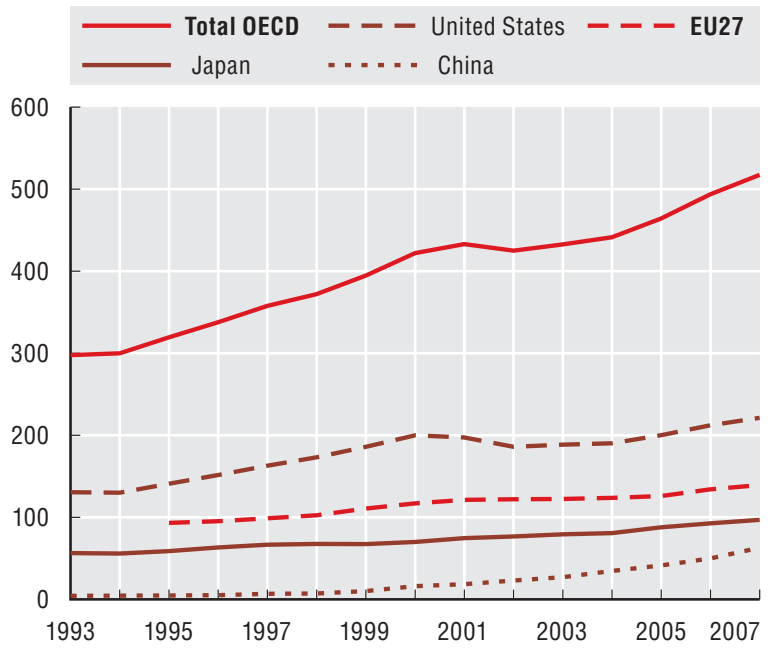

StatLink (AाIs http://dx.doi.org/10.1787/742222770463

Growth of business R\&D, 1997-2007

Average annual real growth rate in percentage

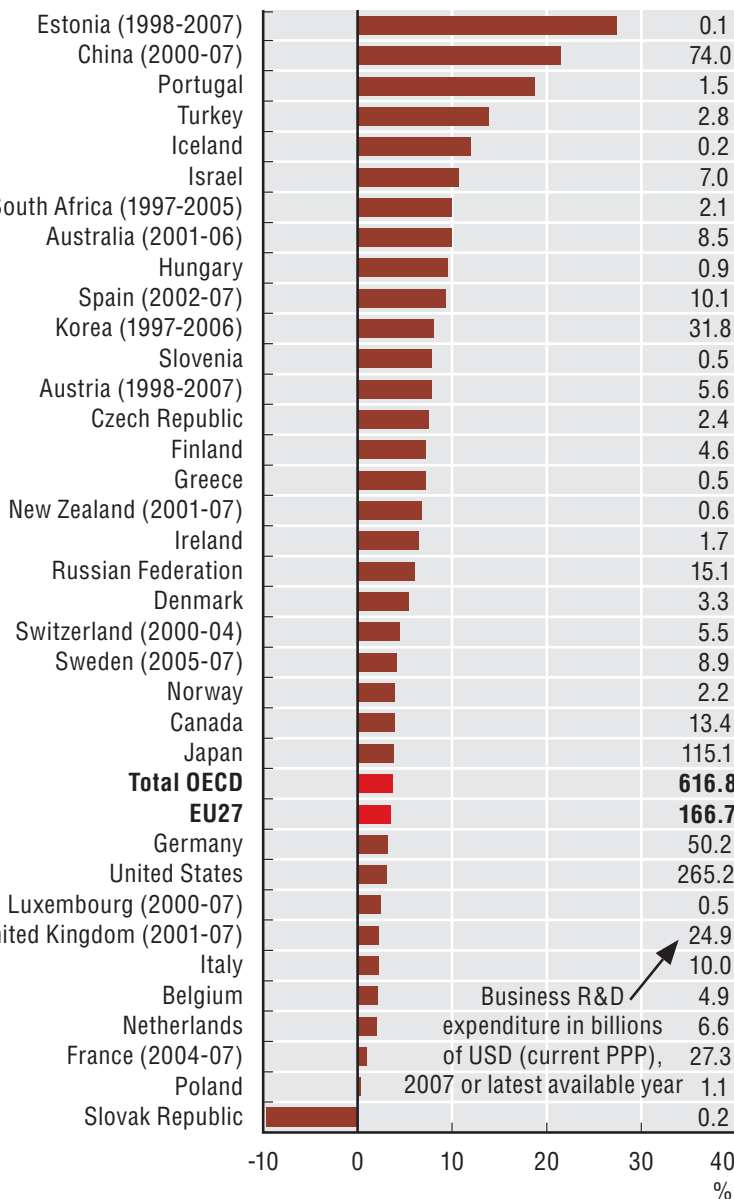

StatLink AiाsL $h t t p: / / d x . d o i . o r g / 10.1787 / 742168543605$ 


\section{RESPONDING TO THE ECONOMIC CRISIS}

\subsection{Business R\&D by technology intensity}

Manufacturing industries can be grouped into four categories according to their research and development (R\&D) intensity: high, medium-high, mediumlow and low technology. In the OECD area since the early 1990s, high-technology industries had on average stronger growth of $R \& D$ expenditure than other manufacturing industries, particularly in the mid1990s and up to the bursting of the Internet bubble after 2000.

In 2006, OECD area high-technology industries accounted for more than $52 \%$ of total manufacturing R\&D. They accounted for over $67 \%$ of total manufacturing R\&D in the United States and for $45 \%$ and $42 \%$ in the European Union and Japan, respectively.

Manufacturing R\&D expenditure is highly skewed towards high-technology industries in Finland, Hungary, Ireland and the United States (more than two-thirds of manufacturing BERD). Medium-hightechnology industries account for around $60 \%$ of manufacturing BERD in the Czech Republic and Germany. Australia, Greece and Norway are the only OECD countries in which medium-low and low-technology industries account for more than $30 \%$. This indicator does not take into account the fact that in some countries, the ranking of industries by $R \& D$ intensity might be different from that of the OECD average.

\section{Technology classification}

Medium-low-technology: Coke, refined petroleum products and nuclear fuel (ISIC 23), Rubber and plastics products (ISIC 25), Other non-metallic products (ISIC 26), Basic metals and fabricated metal products (ISIC 27-28), Building and repairing of ships and boats (ISIC 351).

Low-technology: Food products, beverages and tobacco (ISIC 15-16), Textiles, textile products, leather and footwear (ISIC 17-19), Wood and products of wood and cork (ISIC 20), Pulp, paper, paper products, printing and publishing (ISIC 21-22), Manufacturing not elsewhere classified and recycling (ISIC 36-37).
Manufacturing industries are classified according to technology intensity using the ISIC Rev. 3 breakdown of activity. The classification is based on a ranking which uses data on $R \& D$ expenditure divided by value added, and R\&D expenditure divided by production for 12 OECD countries during the period 1991-99.

High-technology: Pharmaceuticals (ISIC 2423), Office, accounting and computing machinery (ISIC 30), Radio, television and communication equipment (ISIC 32), Medical, precision and optical instruments, watches and clocks (ISIC 33).

Medium-high-technology: Chemicals excluding pharmaceuticals (ISIC 24 less 2423), Machinery and equipment not elsewhere classified (ISIC 29), Electrical machinery and apparatus not elsewhere classified (ISIC 31), Motor vehicles, trailers and semi-trailers (ISIC 34), Railroad equipment and transport equipment not elsewhere classified (ISIC 352 plus 359).

\section{Source}

OECD, ANBERD Database, June 2009.

\section{Going further}

OECD, (2002), Frascati Manual: Proposed Standard Practice for Surveys on Research and Experimental Development, OECD, Paris, www.oecd.org/sti/frascatimanual.

OECD (2009), Research and Development in Industry ANBERD 1990-2007, OECD, Paris.

\section{Figure notes}

The EU aggregate includes Austria, Belgium, the Czech Republic, Denmark, Finland, France, Germany, Hungary, Italy, the Netherlands, Poland, Spain, Sweden and the United Kingdom. 


\section{RESPONDING TO THE ECONOMIC CRISIS}

\subsection{Business R\&D by technology intensity}

Changes in R\&D over the business cycle by technological intensity, OECD 1988-2006 Average annual real growth rate in percentage

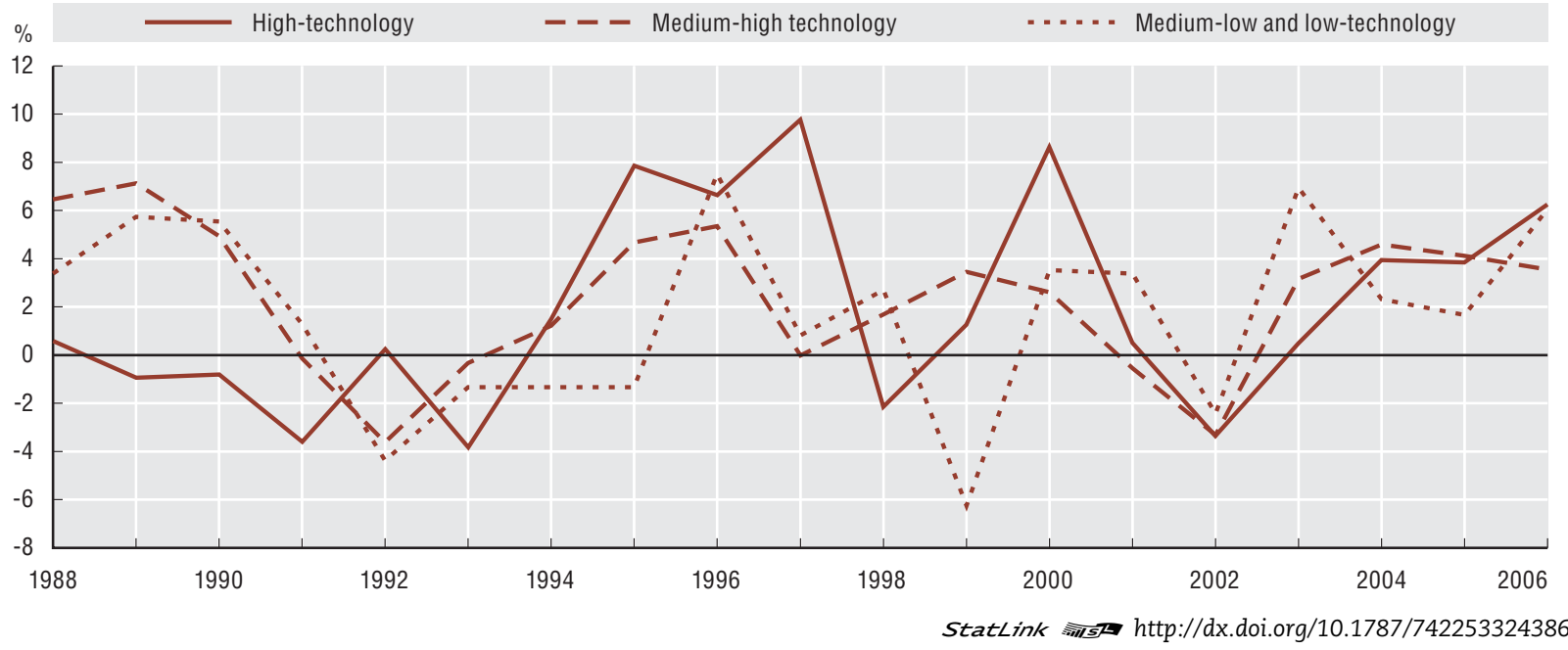

Business R\&D in the manufacturing sector by technological intensity, 2006 As a percentage of manufacturing BERD
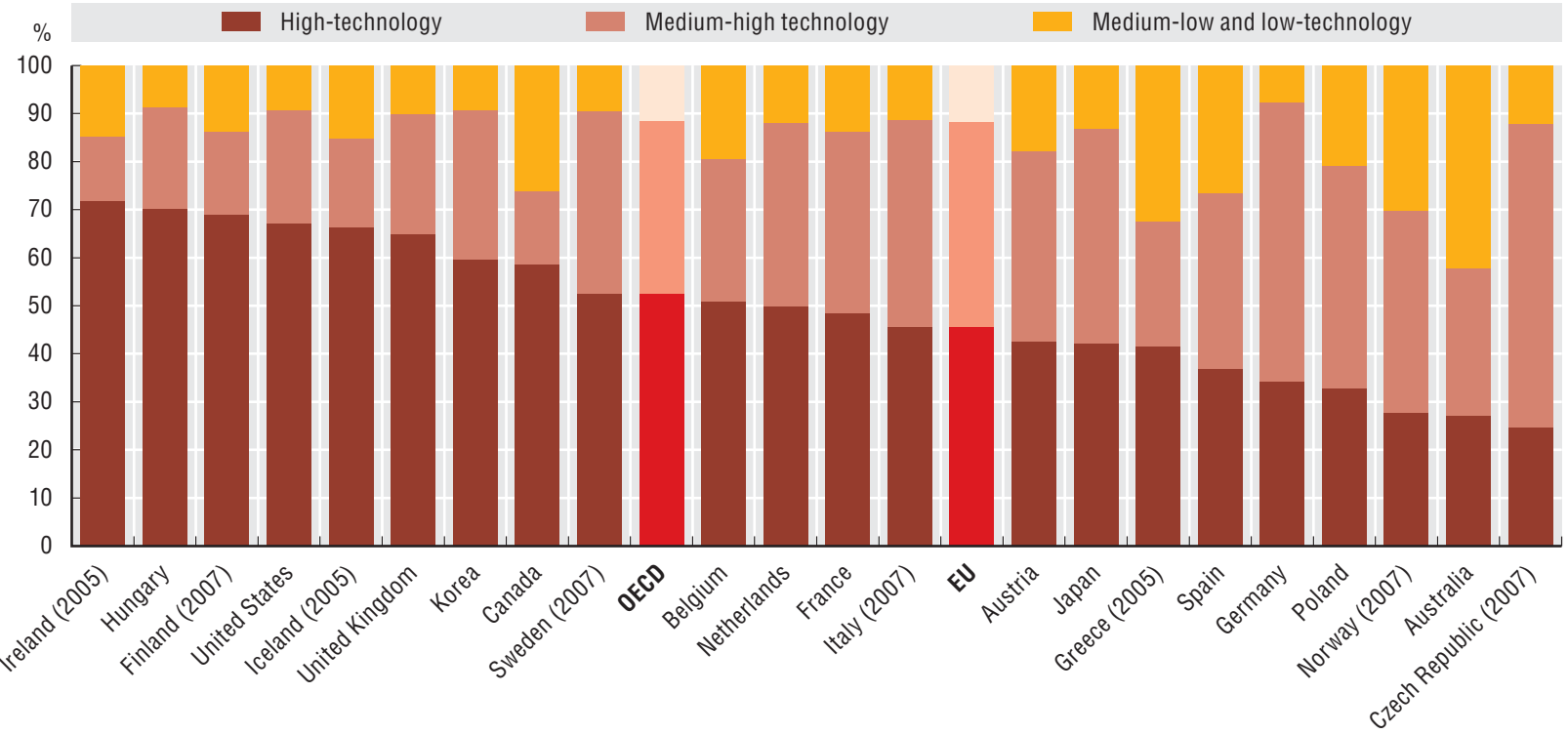
Small and medium-sized firms (SMEs) play an important role in innovation. They are a constant source of technological change and competitive pressure for large firms, which are compelled to innovate to maintain their technological edge. The credit crunch created by the current crisis is likely to affect SMEs severely, owing to their typically limited access to finance.

The effects of the recession on business research and development (R\&D) expenditure are also likely to be stronger in smaller OECD economies, where the share of R\&D performed by SMEs (defined here as firms with fewer than 250 employees) is generally greater than in larger economies. In 2007, SMEs accounted for a large share of business R\&D in New Zealand (73\%), Greece (60\%), the Slovak Republic (57\%), Norway $(50 \%)$, Spain $(49 \%)$, and Ireland (46\%). In the larger EU countries, their share is less than $20 \%$, and in the United States it is around $15 \%$. Japan has one of the lowest shares among OECD countries, with only $6.4 \%$.

Small firms (those with fewer than 50 employees) account for a significant share of business R\&D (over $20 \%$ ) in Greece, Ireland, and Spain, and more than $45 \%$ in New Zealand.

The impact of the crisis on the innovative activities of SMEs also depends on the government financing of business R\&D, which differs greatly among OECD countries. In Hungary, Portugal, the Slovak Republic and Slovenia, SMEs receive $75 \%$ or more of government-financed R\&D. In Belgium, Hungary, Slovenia and Switzerland, more than $40 \%$ of governmentfinanced R\&D goes to firms with fewer than 50 employees. The United Kingdom, France and the United States are the countries in which the greatest share of government-financed business R\&D is directed to large firms.

\section{Classification by size}

The classification of firms by size follows the recommendations of the 2002 Frascati Manual (para. 183). Small firms are defined as those with "fewer than 50 employees" and medium-sized firms as those with "50 to 249 employees". This definition is consistent with the size classification adopted by the European Commission for SMEs.

\section{Source}

OECD, Main Science and Technology Indicators Database, June 2009.

\section{Going further}

OECD (2002), Frascati Manual: Proposed Standard Practice for Surveys on Research and Experimental Development, OECD, Paris, www.oecd.org/sti/frascatimanual.

\section{Figure notes}

Small firms (fewer than 50 employees): for the United States, 5-49 employees; for Luxembourg, the Netherlands and Sweden, 10-49 employees. Mediumsized firms (50-249 employees): for Japan, fewer than 299 employees. 


\section{RESPONDING TO THE ECONOMIC CRISIS}

1.7. Business R\&D by firm size

Share of business R\&D by size class of firms, 2007

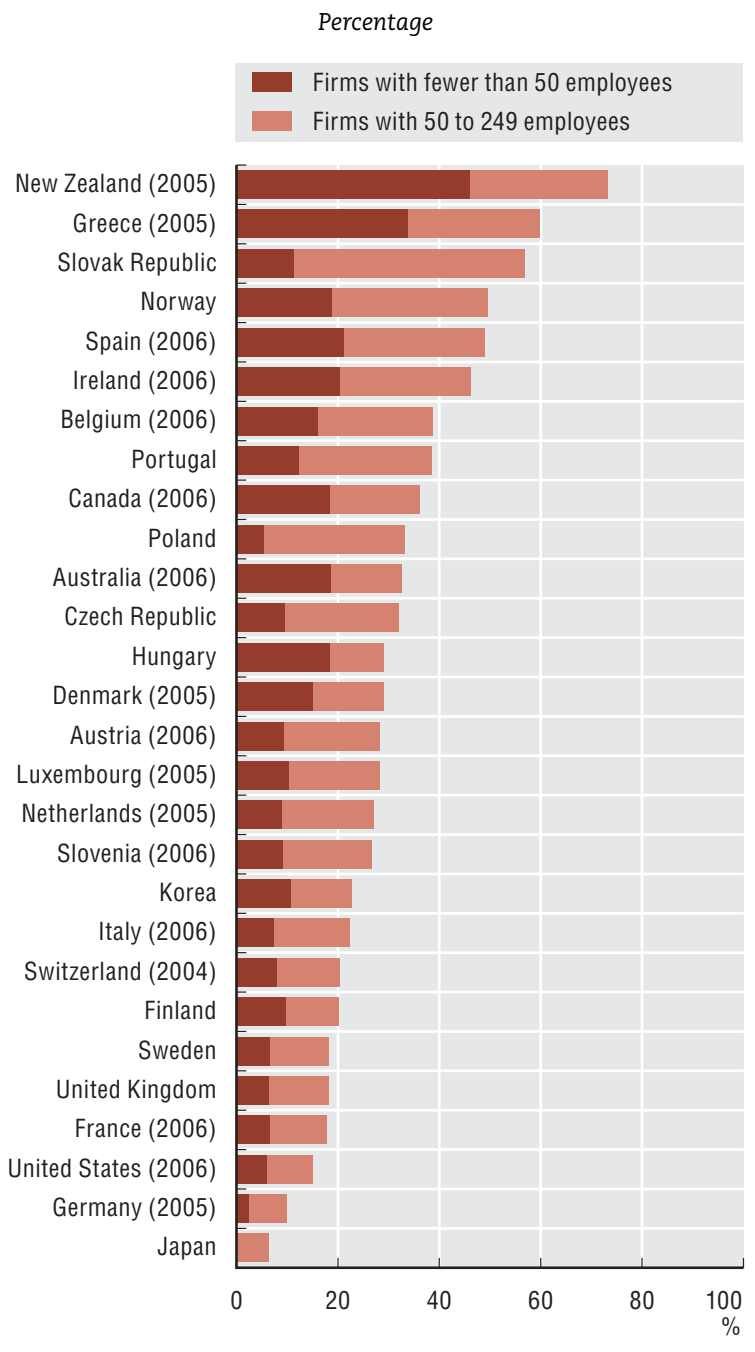

StatLink AाIs http://dx.doi.org/10.1787/742335760410
Share of government-financed business R\&D by size class of firms, 2007

Percentage

Firms with fewer than 50 employees

Firms with 50 to 249 employees

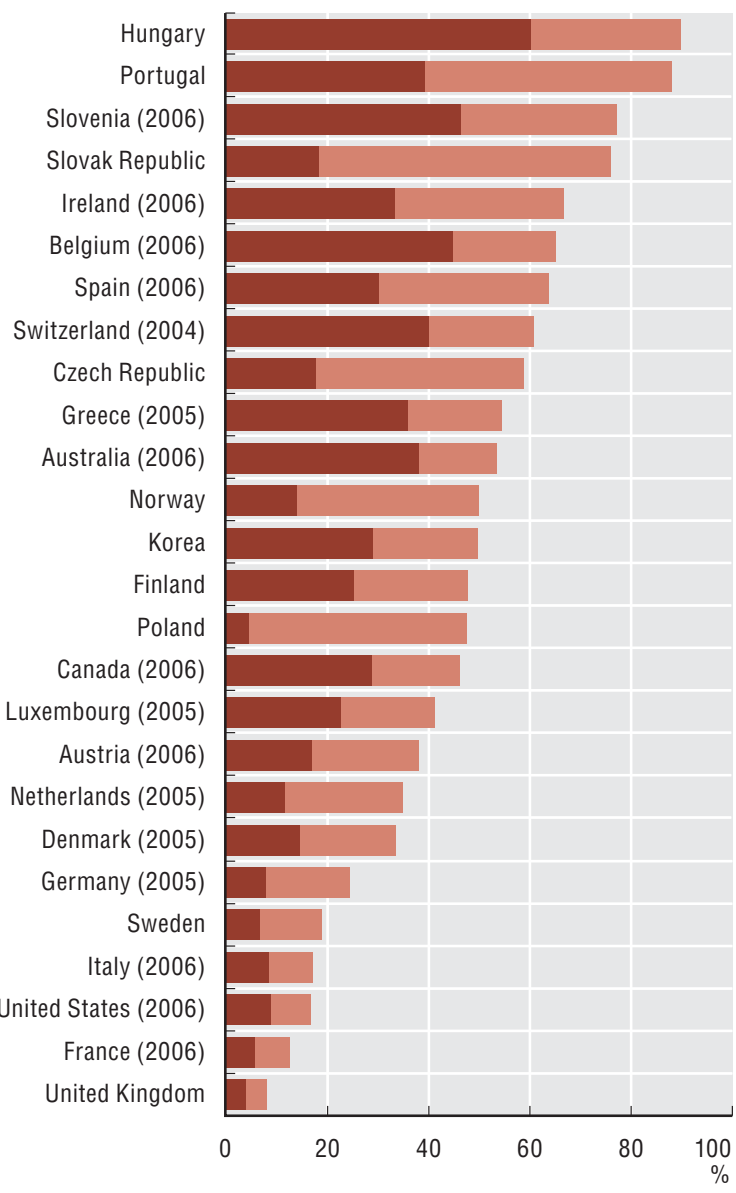

StatLink AाIsय http://dx.doi.org/10.1787/742376005261 
Patents provide a uniquely detailed source of information on the inventive activity of countries. Historically, research and development (R\&D) expenditures and patent filings have moved in parallel with gross domestic product (GDP) and slowed markedly during the economic downturns of the early 1990s and early 2000s. Patenting is more rapidly affected by the economic situation than R\&D expenditures funded by the business sector. Provisional data for 2008 show a significant slowdown of patenting activity in most countries.

The number of triadic patent families almost doubled over the last 20 years, in spite of the slowdown in the early 2000s. In 2007, the OECD estimated these at nearly 52000 . The United States, Japan and Germany are the three most inventive countries, followed by Korea and France. A significant upsurge occurred in Asia, with average growth of $33 \%$ in China and $20 \%$ in India and Korea from 2000.

There is a strong positive correlation between the number of triadic patent families and industryfinanced expenditures on R\&D: the more a country spends on R\&D, the higher the propensity to patent. The Netherlands has the strongest patent intensity of all OECD countries (240 triadic families per billion USD of R\&D funded by industry), followed by Switzerland (186), Japan (164) and Germany (163). Emerging economies such as Brazil and China have a small number of patents relative to $R \& D$.

\section{Triadic patent families}

Patents filed at a given patent office provide a rich source of data but have some statistical limitations. First, domestic applicants tend to file more patents in their home country than nonresident applicants, an effect known as "home bias". Second, indicators based on a single patent office are influenced by factors other than technology, such as patenting procedures, trade flows, proximity, etc. Finally, the value distribution of patents within a single patent office is skewed: many patents are of low value and a few are of extremely high value. Simple patent counts would give equal weight to all patents.

The OECD triadic patent families improve the quality and the international comparability of patent indicators. They are defined as a set of patents taken at the European Patent Office (EPO), the Japan Patent Office (JPO) and the US Patent and Trademark Office (USPTO) that protect a same invention. Since only patents applied for in all three are included, home advantage and influence of geographical location are eliminated. Moreover, patents included in the family are typically of higher value: patentees only take on the additional costs and delays of extending protection to other countries if they deem it worthwhile.

To reflect the inventive performance of countries, triadic patent families are counted according to the earliest priority date (first patent application worldwide), the inventor's country of residence, and fractional counts. Owing to the time lag between the priority date and the availability of information, data from 2000 onwards are OECD estimates based on more recent patent series ("nowcasting").

\section{Sources}

OECD, Patent Database and R\&D Database, June 2009.

EPO Worldwide Statistical Patent Database (PATSTAT), April 2009.

\section{Going further}

OECD (2008), "Compendium of Patent Statistics", www.oecd.org/sti/ipr-statistics.

OECD (2009), "Policy Reponses to the Economic Crisis: Investing in Innovation for Long-Term Growth", www.oecd.org/dataoecd/59/45/42983414.pdf.

OECD (2009), OECD Patent Statistics Manual, OECD, Paris.

\section{Figure notes}

"Triadic" patent families refer to patents filed at the European Patent Office (EPO), the US Patent and Trademark Office (USPTO) and the Japan Patent Office (JPO) which protect the same invention. Gross domestic expenditure on R\&D (GERD) is measured as millions of USD (2000) using purchasing power parities, lagged by one year. 


\section{RESPONDING TO THE ECONOMIC CRISIS}

\subsection{Patent intensity over the business cycle}

\section{Changes in patenting over the business cycle}

Annual growth rates, OECD area

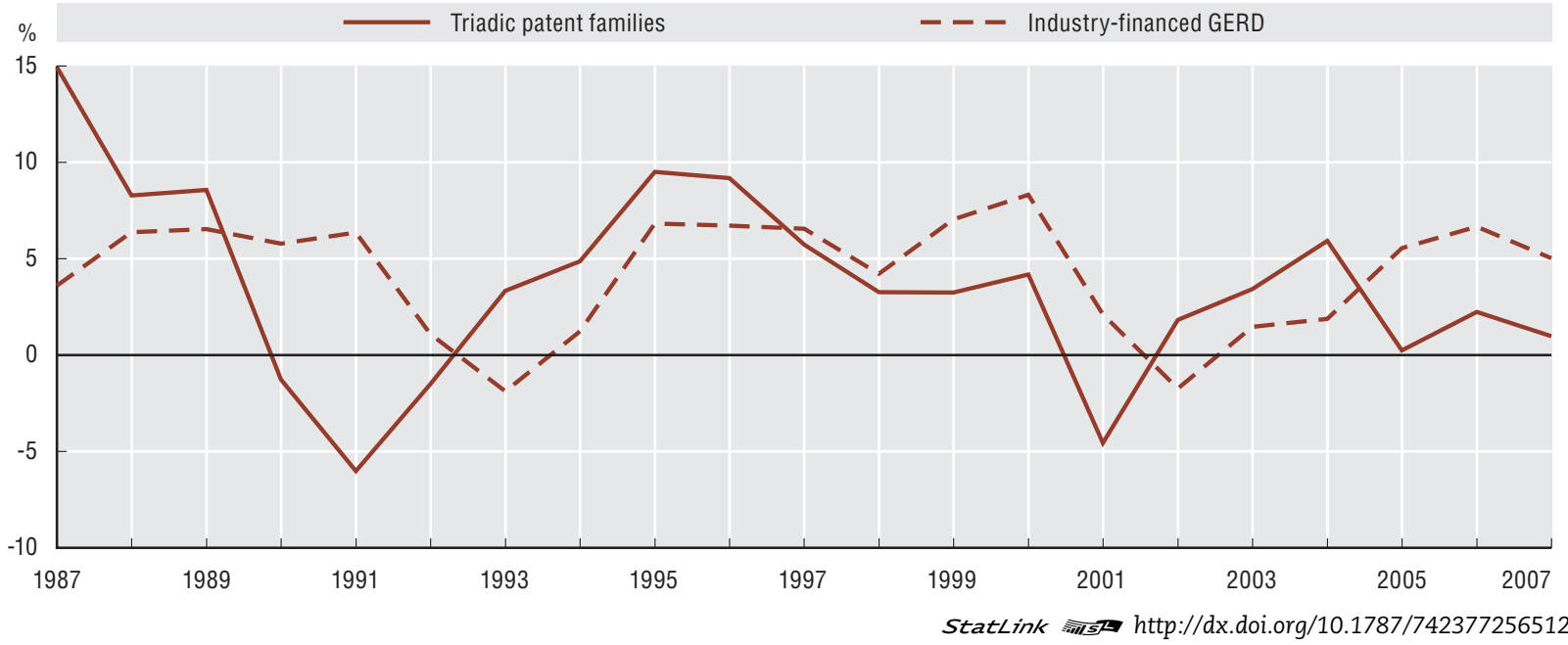

"Triadic" patent families and industry-financed R\&D

Average for 2005-07 or closest available years

Triadic patent families (log)

100000

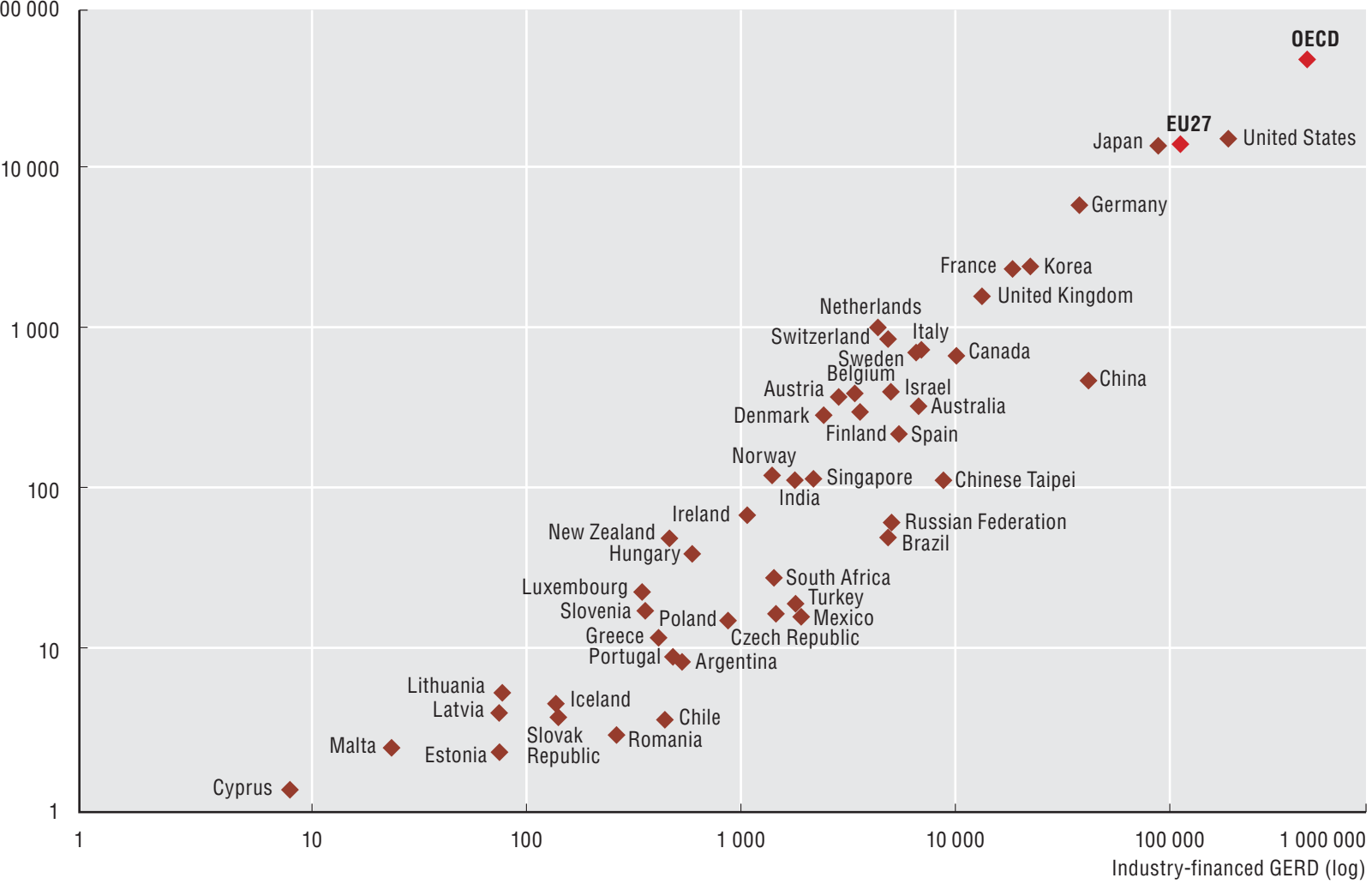

StatLink AाIsस http://dx.doi.org/10.1787/742418686226 


\subsection{Trademarks over the business cycle}

Trademark data are a possible source of information on innovative activity. Firms use them in practice to launch new products on the market in order to signal novelty, and to appropriate the benefits of their innovations. It has been shown that the number of trademark applications is highly correlated to other innovation indicators. Trademarks can then complement the other indicators. As their perimeter of applications is very broad, they can convey information not only on product innovations, but also on marketing innovation and innovations in the service sectors. One advantage of using trademarks as an innovation indicator is that the data relating to trademark applications are publicly available immediately after the filing. Trademark-based indicators can then provide up-to-date information on the level of innovative activity.

The most recent data show that trademarking activity has been strongly affected by the economic crisis. There has been a decline in trademarks filed at the United States Patent and Trademark Office (USPTO) from mid-2007, since when the year-on-year growth rate has fallen continuously. It turned negative in mid-2008 and stabilised around $-20 \%$ at the end of the year. At the beginning of 2009, it started to rise again, although it remains negative and below $-10 \%$.

This decline applies both to service and good trademarks, yet the crisis has affected more severely the services, which year-on year growth rate was sensibly higher than goods in 2007 and passes below in mid-2008. Innovation in the finance and insurance sectors has been particularly affected, trademark applications in those sectors have significantly started to decline from the beginning of 2007, reaching a year-on-year growth rate of nearly $-30 \%$ in the end of 2008.

Both the United States and the European Union have experienced a decline in trademark applications. Their growth rates started to decline in mid-2007 and became negative in mid-2008. The growth rate of applications from the United States started to rise again in the beginning of 2009 although it is still negative, but it continued to drop for applications from European Union. This difference can be explained by a delay in the foreign applications at the USPTO due to the system of priority rights.

\section{Trademarks}

As most economic indicators, trademark counts are affected by seasonal effects, which make analyses of short-term trends difficult. For this reason, year-on-year growth rates of trademark applications are used here. For example, December, which is a month of lower activity, is compared with December of the previous year. The year-on-year growth rate provides a general trend, and accounts for irregularities of the economic cycle.

Besides, 3 period moving averages of the number of trademark applications are used to smooth out the volatility of the growth rates. The indicators presented here are the year-on-year growth rate applied to the moving average period 3 of the monthly trademark applications at USPTO.

\section{Sources}

USPTO Trademark BIB ACE Database (Cassis), April 2009.

USPTO Trademark Electronic Search System (TESS), September 2009.

\section{Going further}

Millot, V. (2009), “Trademarks as an Indicator of Product and Marketing Innovations", OECD Science, Technology and Industry Working Papers 2009/6, OECD, Paris, www.oecd.org/sti/working-papers.

\section{Figure notes}

Growth rates are calculated on three months moving average of the total number of applications received by the USPTO.

Goods (resp. services) represent trademark applications designating only goods (resp. service) classes; finance and insurance represent trademark applications designating class 036 of the International Classification of Goods and Services. 


\section{RESPONDING TO THE ECONOMIC CRISIS}

1.9. Trademarks over the business cycle

Year-on-year growth rate of trademark applications at USPTO

Moving average period 3

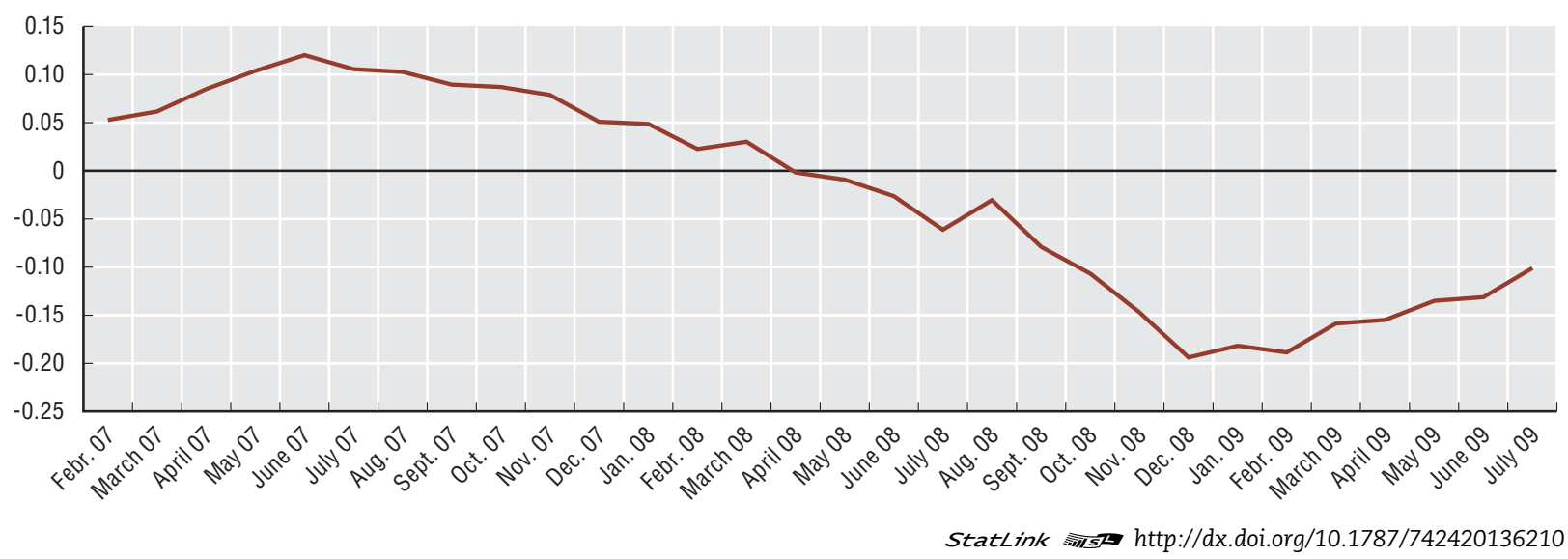

Year-on-year growth rate of trademark applications at USPTO, by product type Moving average period 3

L Goods $\quad$ - - - Services $\quad . . .$. .. Finance and insurance

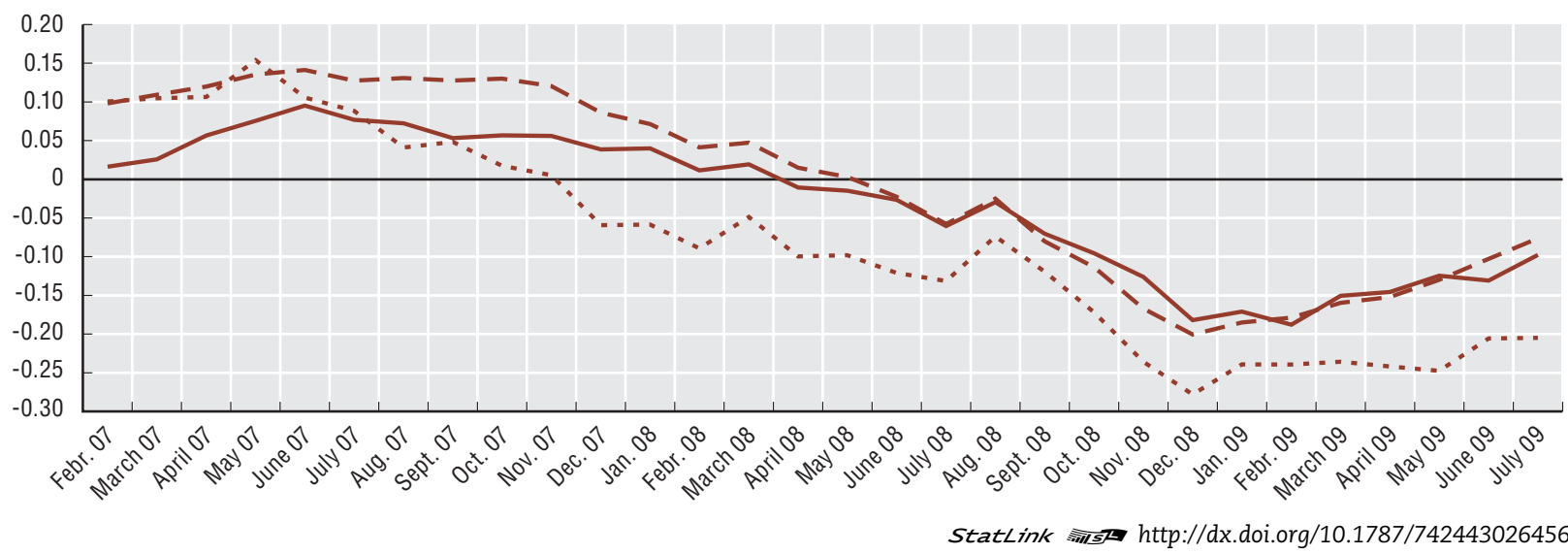

Year-on-year growth rate of trademark applications at USPTO, by region of origin of the applicant Moving average period 3

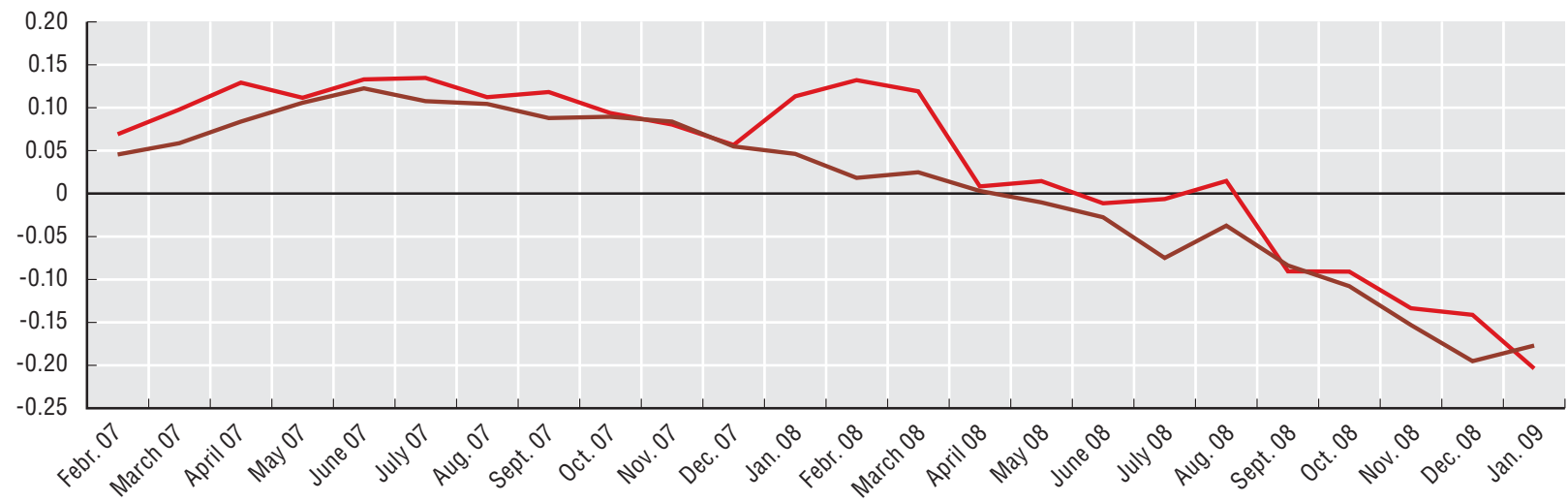


Researchers are central to the research and development (R\&D) system. Since the early 1980s, business researchers have grown faster than total industrial workers. However, they have also been more vulnerable to economic downturns, such as those at the beginning and the end of the 1990s and in the early 2000s. A significant slowdown in the growth of researchers can be expected as a result of the current recession. This can weaken the capability of firms and countries to perform R\&D.

In 2006, some 4 million researchers were engaged in R\&D in the OECD area, or about 7.4 researchers per 1000 employees, a significant increase from the 1997 level of 6.2 per 1000 . Among the major OECD regions, Japan had the largest number of researchers relative to total employment, followed by the United States and the European Union. However, around $36 \%$ of all OECD researchers reside in the United States, 33\% in the European Union and 18\% in Japan. In 2007, the R\&D intensity of Finland, Sweden, Iceland, Japan and the United States, in terms of both researchers and expenditure, was substantially above the OECD average.

While the government and the higher education sectors mainly conduct basic and applied research, R\&D in industry is more closely linked to the creation of new products and production techniques and to a country's innovation effort. In 2006, around 2.6 million researchers (about $65 \%$ of the total) were employed by the business sector in the OECD area. However, whereas four out of five researchers work in businesses in the United States and two out of three in Japan, only one out of two do so in the European Union. Business researchers exceed 10 per 1000 employees in Finland, Sweden, Japan and the United States; they number 6 per 1000 in France and Germany (close to the OECD average), and 4 per 1000 in the United Kingdom (close to the EU average).

Mexico, Turkey, Poland and the Slovak Republic have fewer than 1 researcher per 1000 employees in industry. In these countries, the business sector plays a much smaller role in the national R\&D system than the higher education and government sectors.

Growth in the number of business researchers is most dynamic in smaller OECD economies. In Portugal,
Turkey and Greece, business researchers increased by more than $12 \%$ annually over the past decade. In China and South Africa, numbers of business researchers have also progressed strongly at an average annual rate of $15 \%$ and $19 \%$, respectively.

\section{Researchers}

Researchers are defined as professionals engaged in the conception and creation of new knowledge, products, processes, methods and systems and are directly involved in the management of projects. The number of researchers is here expressed in full-time equivalent (FTE). A person working half-time on R\&D is counted as 0.5 person-year in FTE. FTE includes staff engaged in R\&D during the course of a particular year. FTE data are a true measure of the volume of research conducted by a country' researchers. The business enterprise sector covers researchers carrying out R\&D in firms and business enterprise sector institutes.

\section{Source}

OECD, Main Science and Technology Indicators Database, May 2009.

\section{Going further}

OECD (2002), Frascati Manual: Proposed Standard Practice for Surveys on Research and Experimental Development, OECD, Paris, www.oecd.org/sti/frascatimanual.

\section{Figure notes}

For the United States: the number of researchers is underestimated owing to the exclusion of military personnel in the government sector; data for 2000-07 are OECD estimates. 


\section{RESPONDING TO THE ECONOMIC CRISIS}

1.10. Trends in researchers

Changes in business researchers over the business cycle, OECD, 1981-2007

Business enterprise researchers and industrial employment, annual growth rates

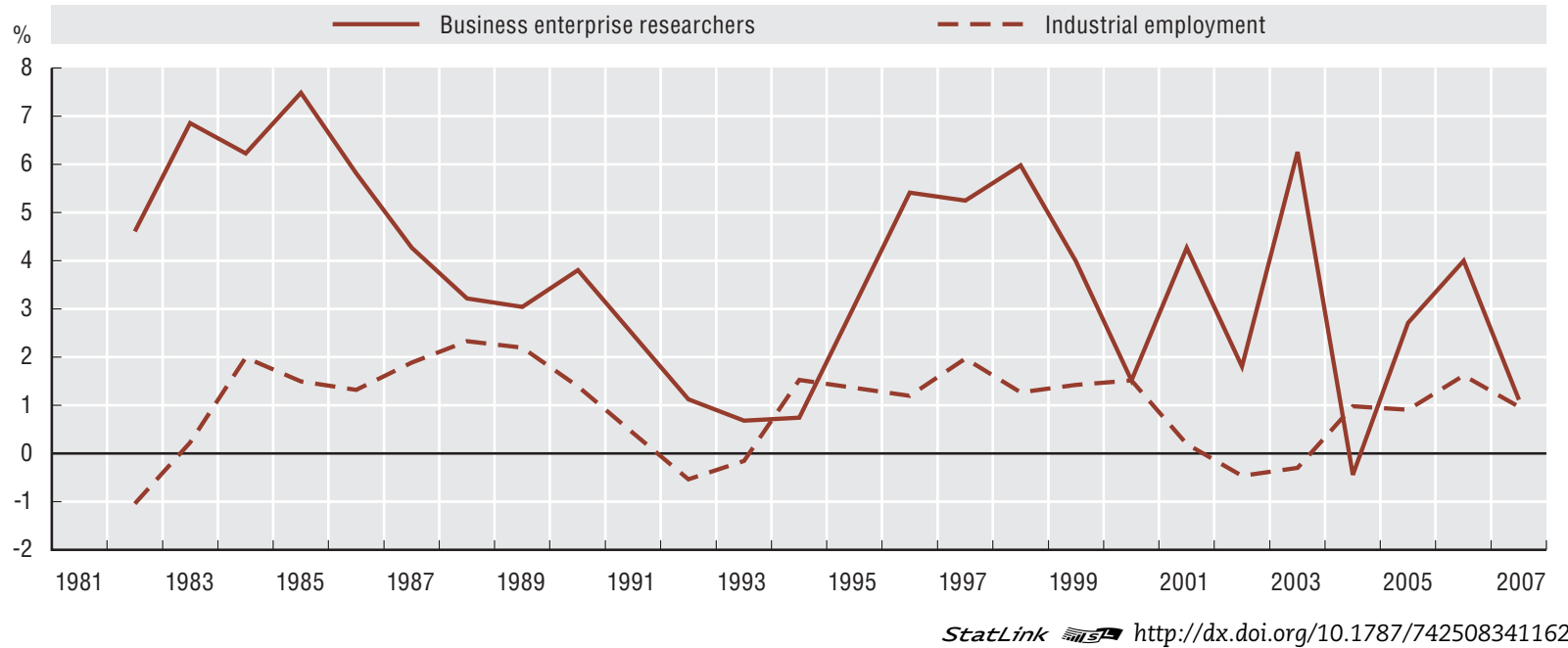

Researchers, 2007

Per 1000 total employment

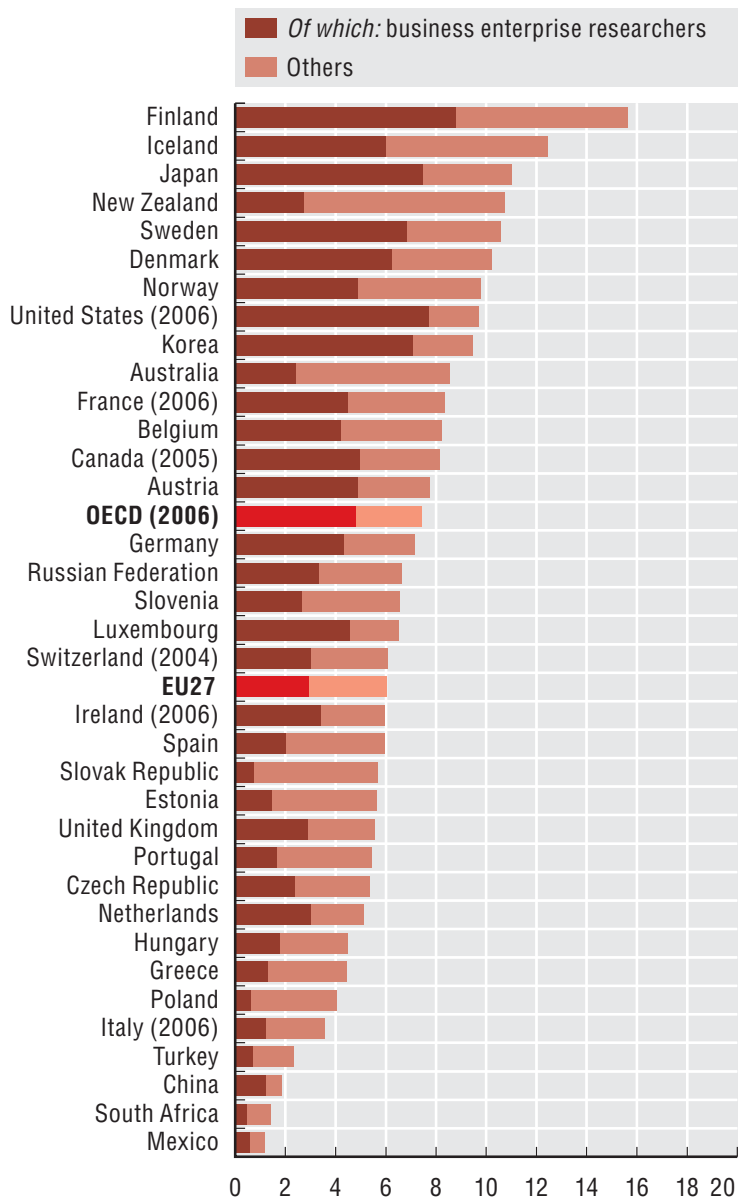

StatLink काजि http://dx.doi.org/10.1787/742515411553
Growth of business researchers, 1997-2007

Average annual growth rate

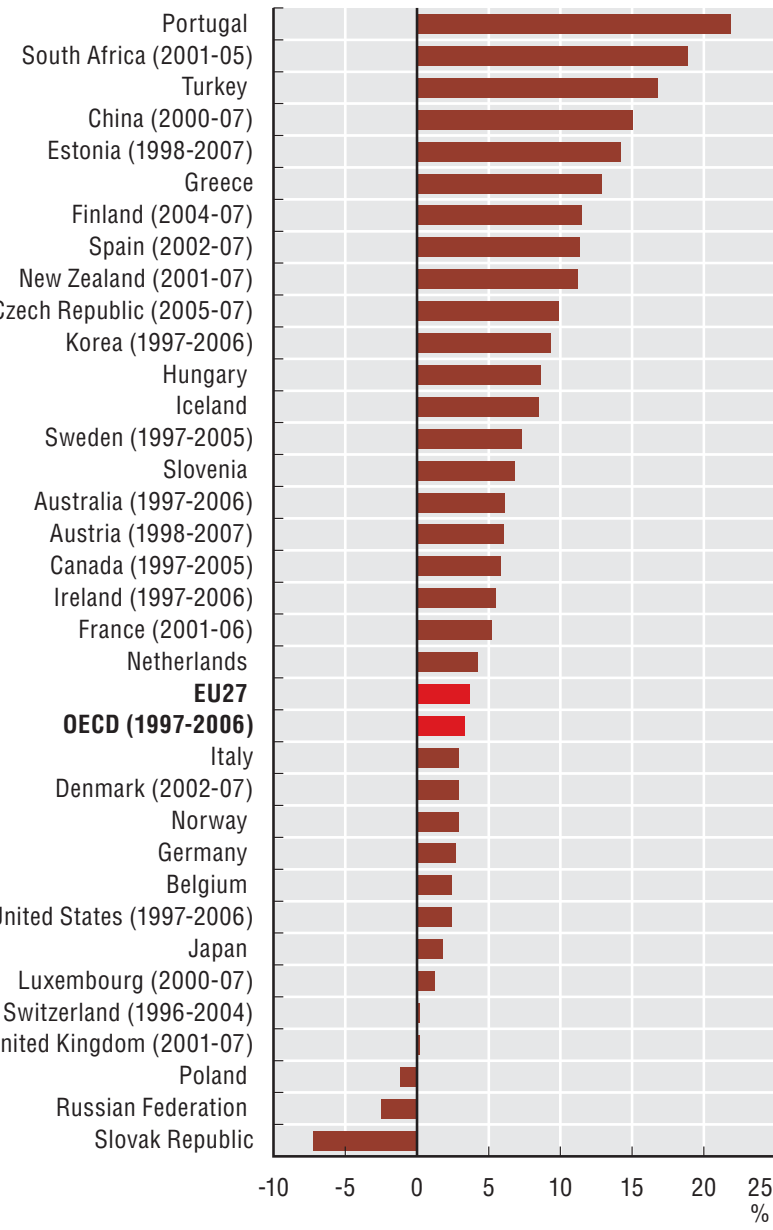

StatLink तiाs $h t t p: / / d x . d o i . o r g / 10.1787 / 742528481768$ 
Foreign direct investment (FDI) provides the recipient country with access to new technologies and generates knowledge spillovers for domestic firms and additional investment in research and development (R\&D). FDI flows as a percentage of gross domestic product (GDP) are also a measure of the degree of a country's integration in the global economy. Crises have a variable impact on global FDI flows. While some national crises have sometimes seen a rise in FDI inflows, more general crises such as in the 1930s or 1970s and many national ones have seen sharp drops in outflows or inflows. FDI inflows to G7 countries dropped by $25 \%$ in 2008 . In the first quarter of 2009, the decrease accelerated in Canada $(-97 \%)$, Germany $(-67 \%)$, Italy $(-41 \%)$, Japan $(-59 \%)$ and the United States (-63\%). FDI inflows to the United Kingdom more than doubled in the first quarter of 2009, back to the same level as the previous year.

In absolute terms, the United States is both the largest foreign investor and the largest recipient of FDI in the OECD area. However, it is only sixth among the G7 countries for the value of FDI relative to GDP. The United Kingdom and France are first and second, respectively.

Some OECD countries have relatively high ratios for both inward and outward flows of FDI. In the Benelux countries, some of these flows are largely due to the activities of special-purpose entities and holding companies established by multinationals to finance and manage their cross-border investment. Owing to the methodology currently used, a significant share of the transactions of such entities is included in FDI statistics.

Iceland, Hungary, Belgium and Switzerland invest on average more than $10 \%$ of GDP in non-resident enterprises. Hungary, Belgium and Iceland receive on average FDI corresponding to more than $10 \%$ of their GDP.

\section{Foreign direct investment}

Direct investment flows are transactions between a direct investor in one economy and a direct investment enterprise in another economy, and among affiliated direct investment enterprises that are in a direct investment relationship, other than those that are resident in the same economy. Direct investment flows are recorded on a directional basis: i) as resident direct investment abroad (outflows); or ii) nonresident direct investment in the reporting economy (inflows). Direct investment financial flows are composed of equity capital, reinvested earnings (and undistributed branch profits) and other capital.
Equity capital comprises: i) equity in branches; ii) all shares in subsidiaries and associates (except non-participating preference [preferred] shares, which are treated as debt securities and included under direct investment, other capital); and iii) other capital contributions, including non-cash acquisitions of equity (such as through the provision of capital equipment).

Reinvested earnings and undistributed branch profits comprise, in proportion to equity held, direct investors' shares of i) earnings that foreign subsidiaries and associated enterprises do not distribute as dividends (reinvested earnings), and ii) earnings that branches and other unincorporated enterprises do not remit to direct investors (undistributed branch profits).

Other capital: covers the borrowing or lending of funds between i) direct investors resident in one economy and their subsidiaries, branches, and associates resident in other economies; and ii) enterprises within a group of related direct investment enterprises that are resident in different economies. The instruments covered include loans, debt securities, suppliers' (trade) credits, financial leases, and non-participating preference [preferred] shares which are treated as debt securities.

\section{Source}

International Monetary Fund Balance of Payments Statistics, June 2009.

\section{Going further}

OECD (2005), Measuring Globalisation: OECD Handbook on Economic Globalisation Indicators, OECD, Paris. 


\section{RESPONDING TO THE ECONOMIC CRISIS}

1.11. Foreign direct investment flows

FDI outflows from G7 countries, 1992-2008 and Q1 2009

As a percentage of GDP

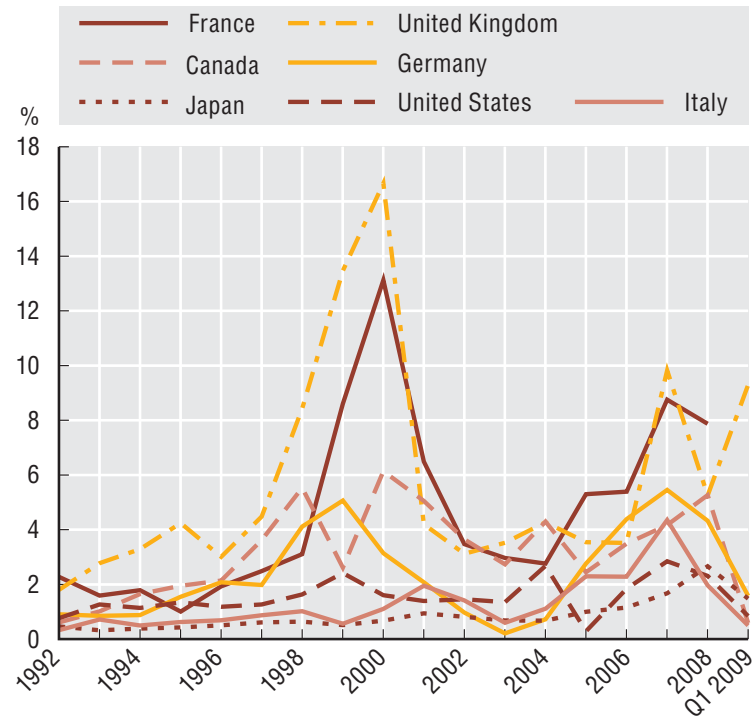

StatLink काज्य http://dx.doi.org/10.1787/742554345446

FDI outflows from OECD countries, average 2003-08 As a percentage of GDP

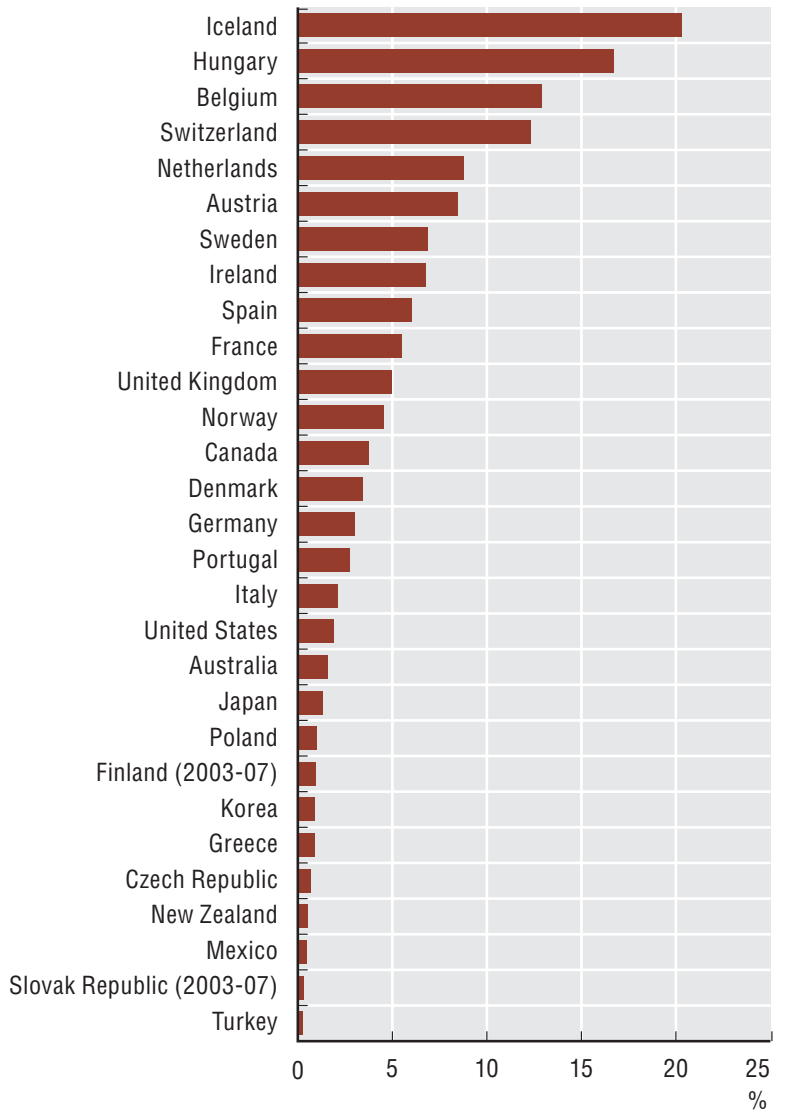

StatLink AाIs http://dx.doi.org/10.1787/742584077541
FDI inflows to G7 countries, 1992-2008 and Q1 2009

As a percentage of GDP
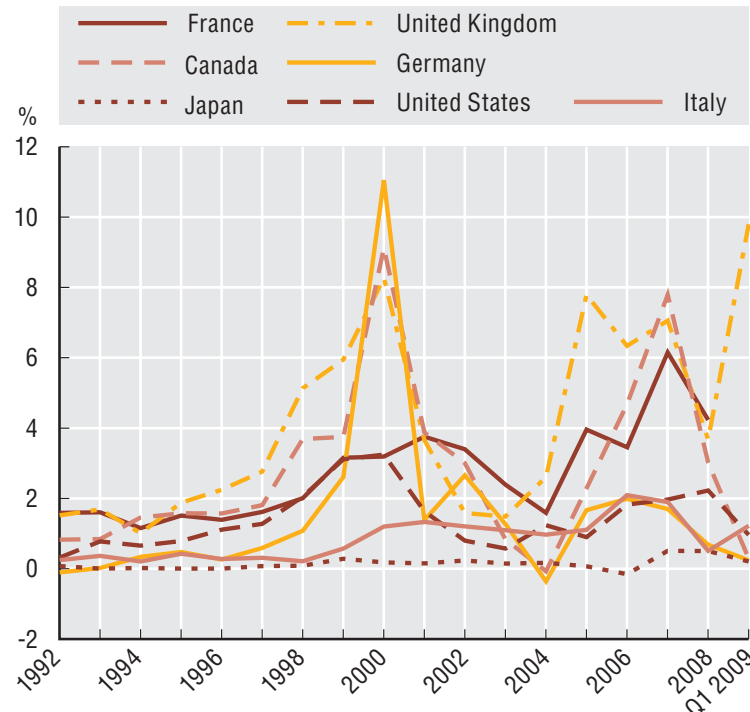

StatLink काज्ञ http://dx.doi.org/10.1787/742556111401

FDI inflows to OECD countries, average 2003-08

As a percentage of GDP

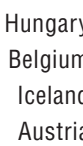

Czech Republic

Slovak Republic (2003-07)

Switzerland

United Kingdom

Netherlands

Sweden

Poland

France

Spain

Canada

New Zealand

Finland (2003-07)

Portugal

Mexico

Australia

Turkey

Denmark

United States

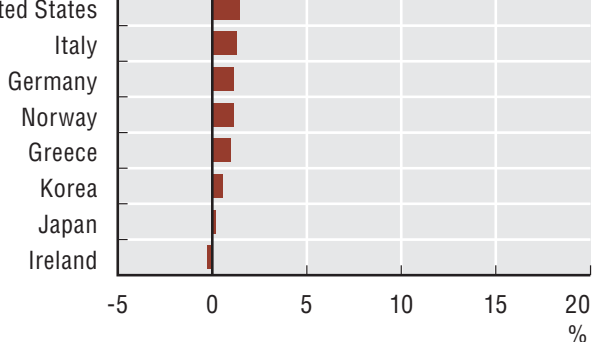

StatLink ताs $h$ ttp://dx.doi.org/10.1787/742584558022 
Foreign affiliates contribute to a host country's international competitiveness through several channels. They provide access to new markets and new technologies for domestic suppliers and buyers along the value chain, generate knowledge spillovers for domestic firms, and invest a higher share of their revenue in research and development (R\&D).

Over 1996-2006, trends in employment of foreign affiliates in the manufacturing sector have roughly paralleled total manufacturing employment in OECD countries. However, employment of foreign affiliates dropped further in the aftermath of the ICT crisis in early 2000 and has not since caught up. If this trend is maintained in the current crisis, manufacturing jobs losses would be larger in foreign affiliates than in domestic enterprises.

Employment under foreign control in Norway, Italy and the United States has especially followed trends in total manufacturing employment. In these three countries, manufacturing employment of foreign affiliates is likely to be more affected than in other countries. In Japan, foreign affiliates' employment has been less responsive to the employment cycle in manufacturing, but in any case, the weight of foreign affiliates in employment is so small as to be negligible.

\section{The concepts of influence and control}

The basic criterion for determining whether an investment is a direct investment is its capacity to exert "influence" on company management. The notion of influence is reflected, in statistical terms, in the holding of more than $10 \%$ of the ordinary shares or voting rights, while any investment below $10 \%$ is considered to be portfolio investment. The notion of influence does not allow for collecting data on the activities of multinational enterprises in a coherent and effective manner, whence the need to resort to the notion of "control".

The notion of control implies the ability to appoint a majority of administrators empowered to direct an enterprise, to guide its activities and determine its strategy. In most cases, this ability can be exercised by a single investor holding more than $50 \%$ of the shares with voting rights. The notion of control allows all of a company's activities to be attributed to the controlling investor. This means that a company's employees are all attributed to the controlling investor and the investor's country of residence.
Data on the activity of multinationals use the notion of "control" to a greater degree than the notion of "influence". Influence implies attributing production, value added, the number of employees and other variables according to shareholders' percentage stake in the enterprise, and it is the "financial" aspect that predominates. In the case of control, it is the "power to take decisions" and "decide corporate strategy" that comes first.

The term "foreign affiliate" is restricted to affiliates under foreign control. Accordingly, the geographical origin of a foreign affiliate is the country of residence of the ultimate controller. An investor (company or individual) is considered to be the investor of ultimate control if it is at the head of a chain of companies and controls directly or indirectly all the enterprises in the chain without itself being controlled by any other company or individual.

\section{Source}

OECD, calculations based on AFA database, July 2009.

\section{Going further}

OECD (2005), Measuring Globalisation: OECD Handbook on Economic Globalisation Indicators, OECD, Paris.

\section{Figure notes}

Aggregate OECD includes the Czech Republic, Finland, France, Germany, Hungary, Ireland, Italy, Japan, Luxembourg, the Netherlands, Norway, Poland, Portugal, the Slovak Republic, Spain, Sweden, Switzerland, the United Kingdom and the United States.

Responsiveness is measured as the estimated elasticity of foreign affiliates' manufacturing employment to total manufacturing employment. The estimation is based on an OLS regression on the first-order differences of natural logs. Only coefficients significant at the $10 \%$ level and below are reported. 


\section{RESPONDING TO THE ECONOMIC CRISIS}

\subsection{Trends in the employment of foreign affiliates}

Changes in foreign affiliates' manufacturing employment over the business cycle, OECD, 1996-2006 Annual growth rate, percentage

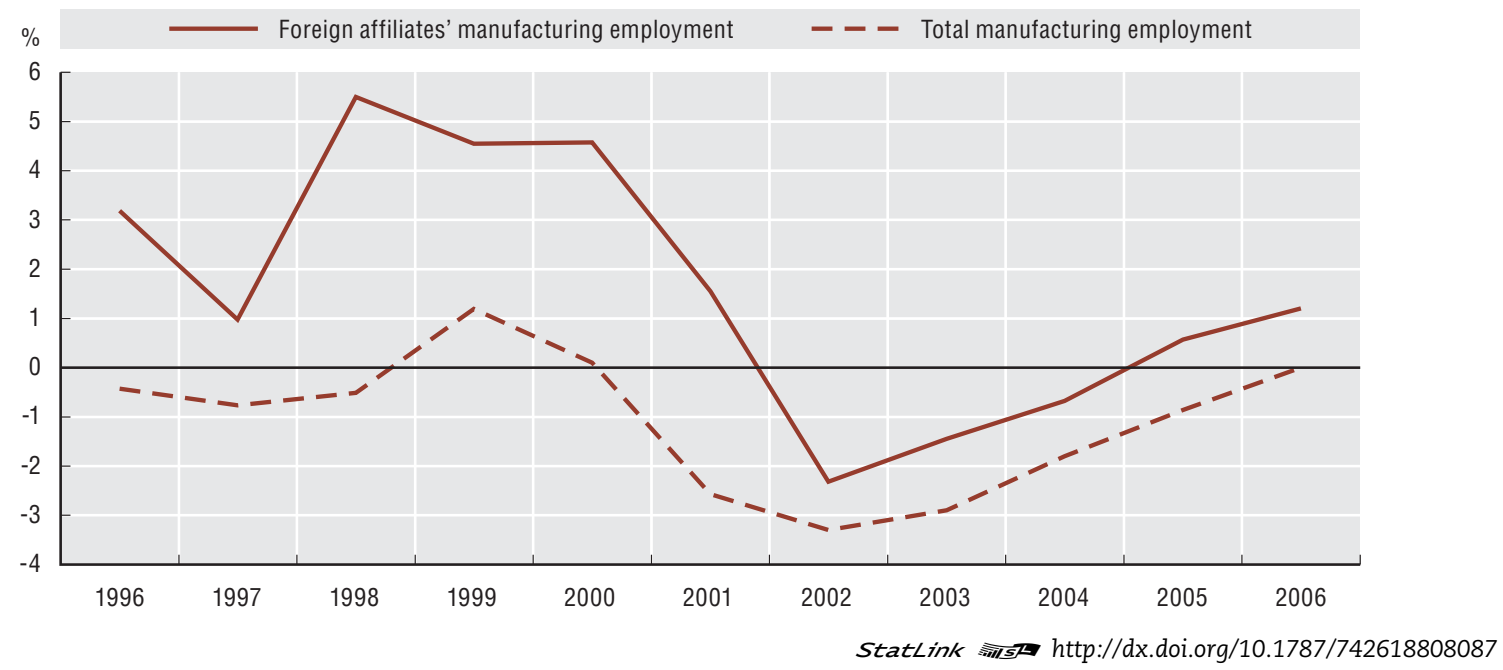

Responsiveness of foreign affiliates' manufacturing employment to the business cycles, 1996-2006

Percentage

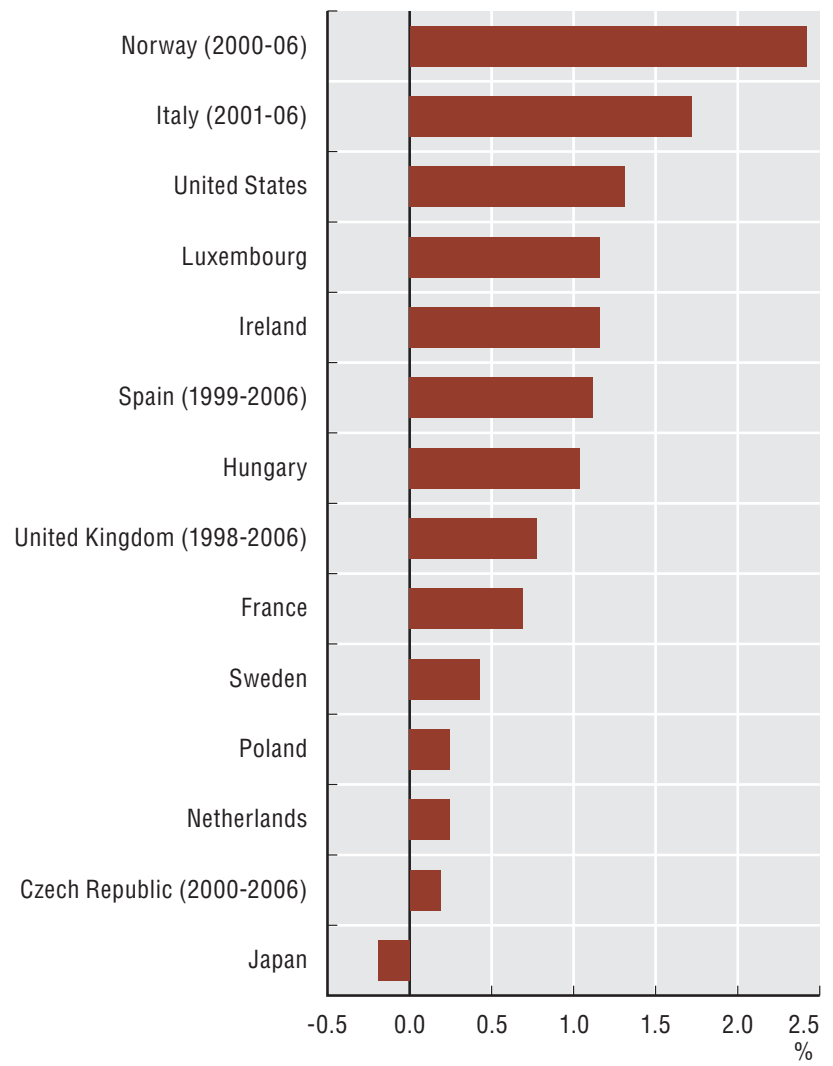

StatLink काज्ञा $h$ ttp://dx.doi.org/10.1787/742627775615 
Labour productivity is a key economic indicator commonly used to measure economic performance. It is closely associated with standards of living. In most OECD countries, labour productivity tends to increase over economic booms and decrease during recessions.

Trend patterns for value added and labour productivity growth in OECD countries have been roughly similar over 1981-2007, with growth in value added nonetheless showing larger fluctuations. Over the period, the range for growth of value added in the OECD area was from $0.3 \%$ to $5.0 \%$ while that for growth of labour productivity was from 1.1 to $3.1 \%$. Both growth in labour productivity and growth in value added experienced a steep decline in 1982 , reaching $1.1 \%$ and $0.3 \%$, respectively, but grew fairly rapidly thereafter. During the first half of the 1990s, labour productivity grew faster than production, owing to a slowdown in the growth in hours worked. It was then dampened somewhat before collapsing to $1.3 \%$ in 1998 , at the time of the financial crisis which affected Korea, among other Asian countries. Labour productivity growth recovered shortly thereafter to around $2.7 \%$, led by rapid output growth, but dropped again to $1.7 \%$ during the recession in 2001. Right after the beginning of the new millennium, productivity growth in the OECD area accelerated noticeably but from 2004, it declined more rapidly than growth of value added to $1.7 \%$ in 2007.

A breakdown of labour productivity growth between manufacturing and services indicates that much of the OECD labour productivity growth cycle has been driven by the manufacturing sector. Over 1981-2007, the growth cycles for labour productivity in manufacturing and services were broadly similar to the cycle at the level of the total economy, but the cycle was smoother for services than for manufacturing, with growth ranging from $0.4 \%$ to $2.3 \%$ and $1.1 \%$ to $7.1 \%$, respectively.

A look at the detail by country shows that the current crisis is likely to affect some nations more than others. Over 1981-2007, Italy, Japan and Norway appear to have been more responsive to the business cycle. If this pattern is maintained, the current crisis is likely to affect labour productivity severely in these countries. In contrast, the United Kingdom and Spain were less responsive to the economic cycle. In these countries, therefore, the crisis is likely to result in a smaller decrease in labour productivity.

\section{Labour productivity}

Labour productivity is defined as the volume of output divided by the volume of labour input. For the indicator presented here, the output measures used are value added volumes from the OECD STAN Database and the labour input measures are estimates of total hours worked derived from STAN and the OECD Productivity Database. STAN annual hours worked series by industry were extended using OECD Productivity estimates of annual hours worked at the total economy level and adjusted using the employment structure by industry from STAN. To calculate value added for the OECD area, STAN value-added volumes were converted using the purchasing power parities for the total gross domestic product, available in the OECD Annual National Accounts Database. Series have not been adjusted for cyclical effect.

\section{Sources}

OECD, STAN Database for Structural Analysis, www.oecd.org/sti/stan.

OECD, Productivity Database, www.oecd.org/statistics/productivity.

\section{Going further}

OECD (2008), "Compendium of Productivity Indicators", www.oecd.org/statistics/productivity/compendium.

Ahmad, N. et al. (2003), "Comparing Labour Productivity Growth in the OECD Area: The Role of Measurement", OECD Science, Technology and Industry Working Papers 2003/14, OECD, Paris, www.oecd.org/sti/working-papers.

OECD (2001), Measuring Productivity: OECD Manual on Measurement of Aggregate and Industry-level Productivity Growth, OECD, Paris,

www.oecd.org/dataoecd/59/29/2352458.pdf.

\section{Figure notes}

OECD aggregate includes 15 countries for which the time-period covered in STAN Database was optimal: Belgium, Canada, Denmark, Finland, France, Germany, Iceland, Italy, Japan, Korea, the Netherlands, Norway, Spain, the United Kingdom and the United States.

Responsiveness is measured as the estimated elasticity of labour productivity to value added. The estimation is based on an OLS regression on the first-order differences of natural logs. Only coefficients significant at the 10\% level and below are reported. 


\section{RESPONDING TO THE ECONOMIC CRISIS}

\subsection{Labour productivity growth over the business cycle}

Labour productivity growth in OECD, 1981-2007

Annual growth rate, percentage

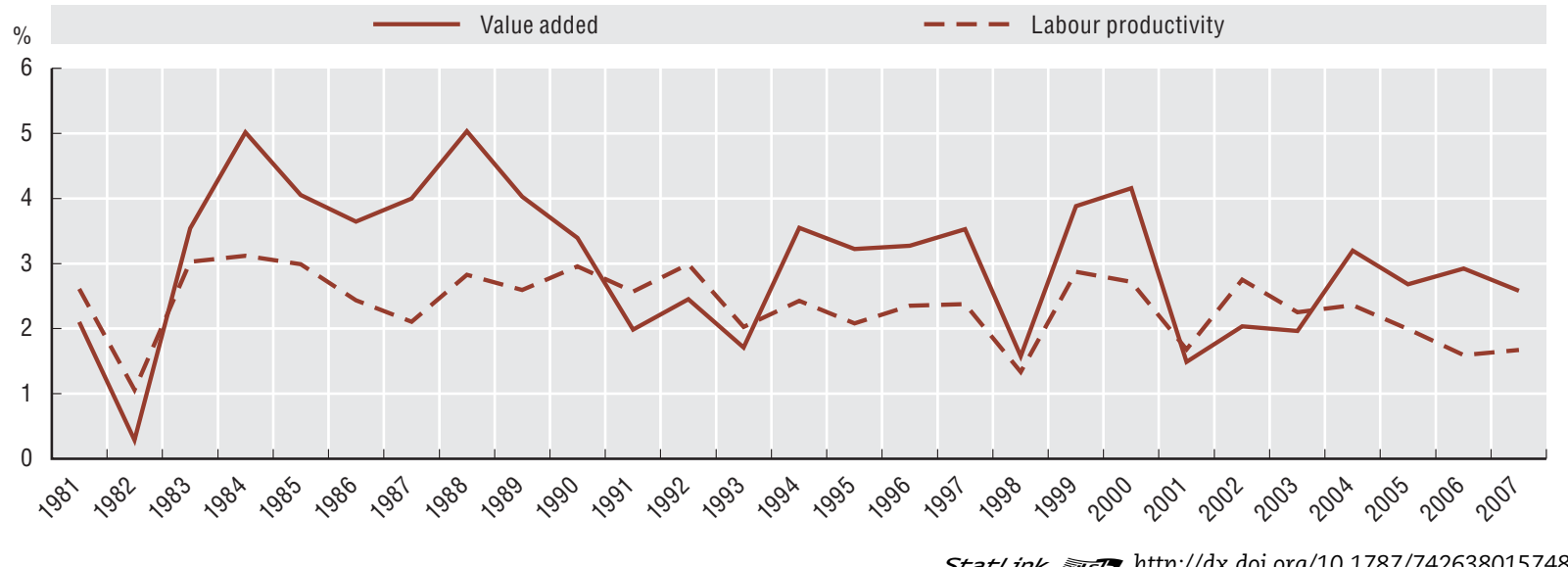

Labour productivity growth in OECD by industry, 1981-2007

Annual growth rate, percentage

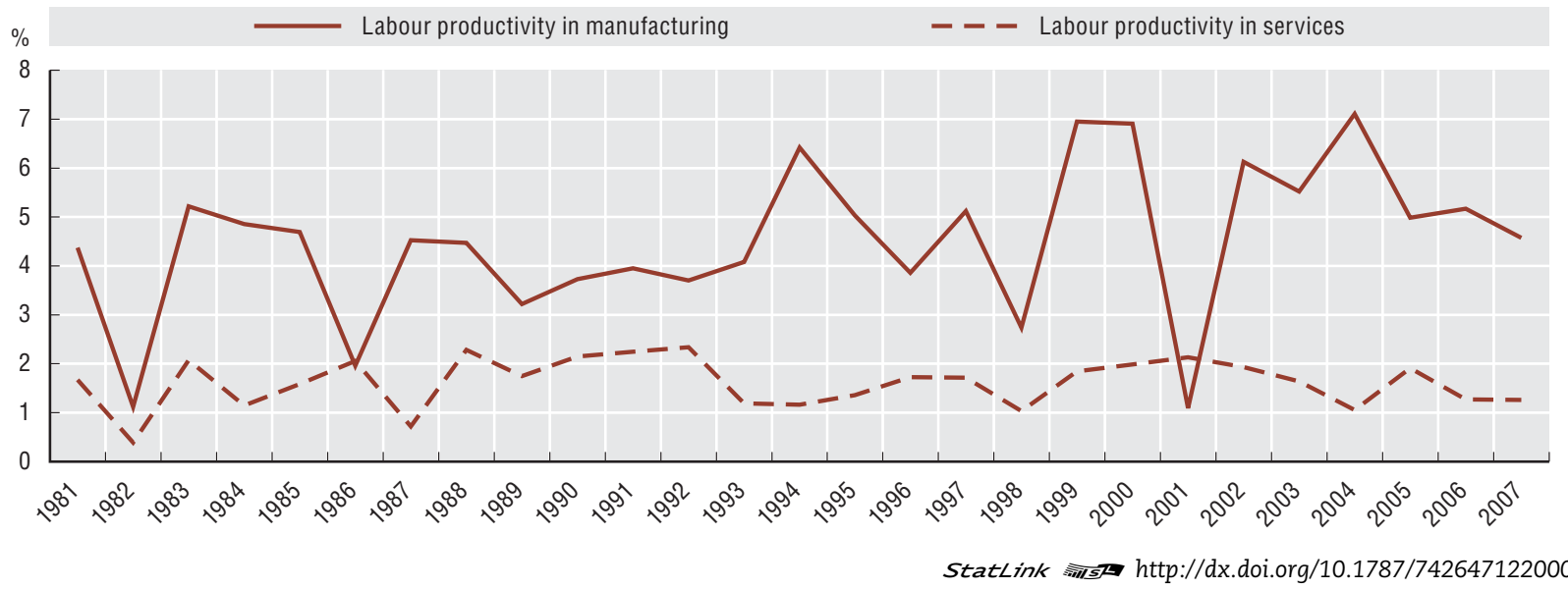

Responsiveness of labour productivity to the business cycle, 1981-2007

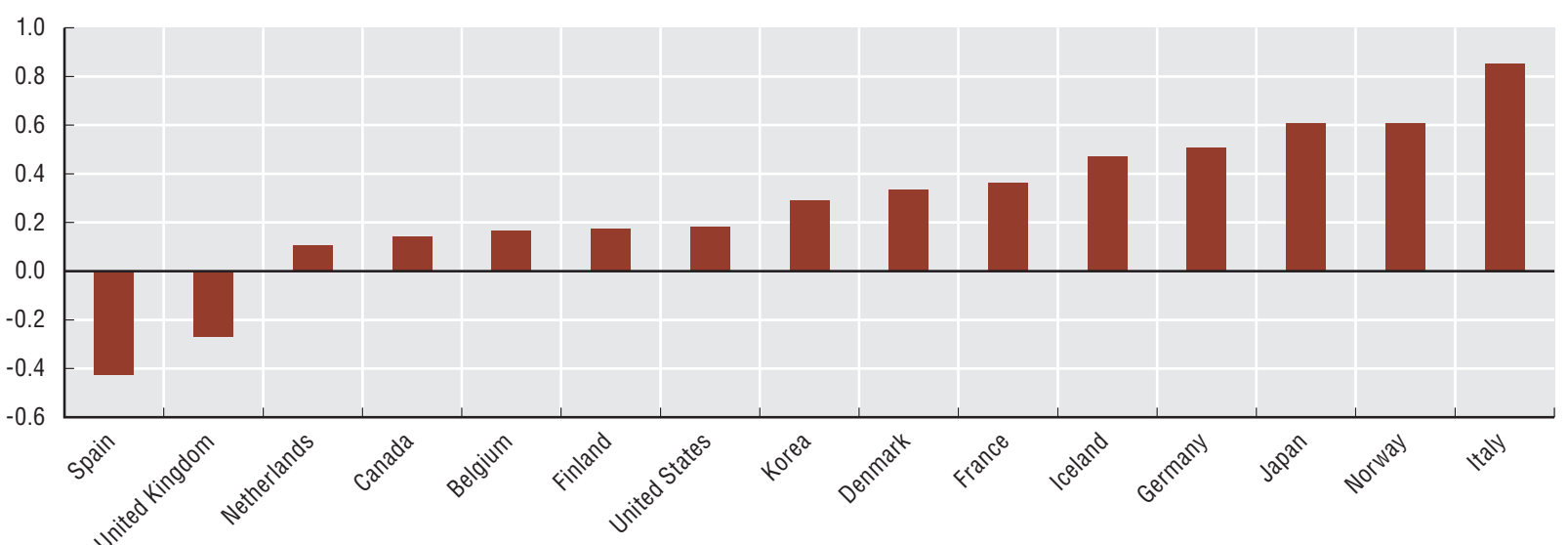


Investment in physical capital is important for growth. It is a way to expand and renew the capital stock and enable new technologies to enter the production process.

Information and communication technology (ICT) has been the most dynamic component of investment from 1985 to 2000 but then started to decrease, following the bursting of the dot com bubble. The OECD average growth rate of ICT investment dropped from $15.3 \%$ in 2000 to $-7.6 \%$ in 2002 and remained below the growth rate of total non-residential investment since then. In 2007, ICT investment is estimated to grow faster than total investment but the current economic cycle raises concerns on whether this trend will be confirmed.

ICT investment accounts for a considerable share of total fixed non-residential investment. In 2005-07, it represented between $20-25 \%$ in Sweden, the United Kingdom, the United States, Belgium, Denmark, Finland, the Netherlands and Switzerland. Software has been the fastest-growing component of ICT investment, reaching $52 \%$ in Belgium, $43 \%$ in Denmark, $41 \%$ in Australia and exceeding 30\% in Austria, Germany, Greece, Ireland, Japan, Portugal and the Netherlands.

Communications equipment was the major component of ICT investment in Portugal (55\%) and Greece (49\%). Information technology (IT) equipment was the major component in France (70\%), Finland (62\%) and Sweden (60\%).

\section{Investment in ICT}

Correct measurement of investment in ICT in both nominal and volume terms is crucial for estimating the contribution of ICT to economic growth and performance. Data availability and measurement of ICT investment based on national accounts (SNA 93) vary considerably across OECD countries, especially as regards measurement of investment in software, deflators applied, breakdown by institutional sector and temporal coverage. In the national accounts, expenditure on ICT products is considered investment only if the products can be physically isolated (i.e. ICT embodied in equipment is considered not as investment but as intermediate consumption). This means that ICT investment may be underestimated and the order of magnitude of the underestimation may differ depending on how intermediate consumption and investment are treated in each country's accounts.
In particular, it is only very recently that expenditure on software has been treated as capital expenditure in the national accounts, and methodologies still vary considerably across countries. The difficulties for measuring software investment are also linked to the ways in which software can be acquired, e.g. via rental and licences or embedded in hardware. Moreover, software is often developed on own account. To tackle the specific problems relating to software in the context of the SNA 93 revision of the national accounts, a joint OECD-EU Task Force on the Measurement of Software in the National Accounts has developed recommendations concerning the capitalisation of software. These are now being implemented by OECD member countries.

\section{Sources}

OECD, Database on Capital Services, July 2009.

OECD, Productivity Database,

www.oecd.org/statistics/productivity/compendium.

\section{Going further}

Lequiller, F. et al. (2003), "Report of the OECD Task Force on Software Measurement in the National Accounts", OECD Statistics Working Paper 2003/1, OECD, Paris.

Ahmad, N. (2003), "Measuring Investment in Software", OECD Science, Technology and Industry Working Papers, 2003/6, OECD, Paris, www.oecd.org/sti/working-papers.

Schreyer, P., P.E. Bignon and J. Dupont (2003), “OECD Capital Services Estimates: Methodology and a First Set of Results", OECD Statistics Working Paper 2003/6, OECD, Paris.

\section{Figure notes}

Growth rates of ICT and fixed non-residential investment in 2007 are estimates.

ICT equipment is defined here as computer and office equipment and communication equipment; software includes both purchased and own account software. Software investment in Japan is likely to be underestimated, owing to methodological differences. 


\section{RESPONDING TO THE ECONOMIC CRISIS}

\subsection{ICT investment over the business cycle}

Growth of ICT and total fixed non-residential investment, OECD 1985-2007

Annual growth rate - current PPP US dollars

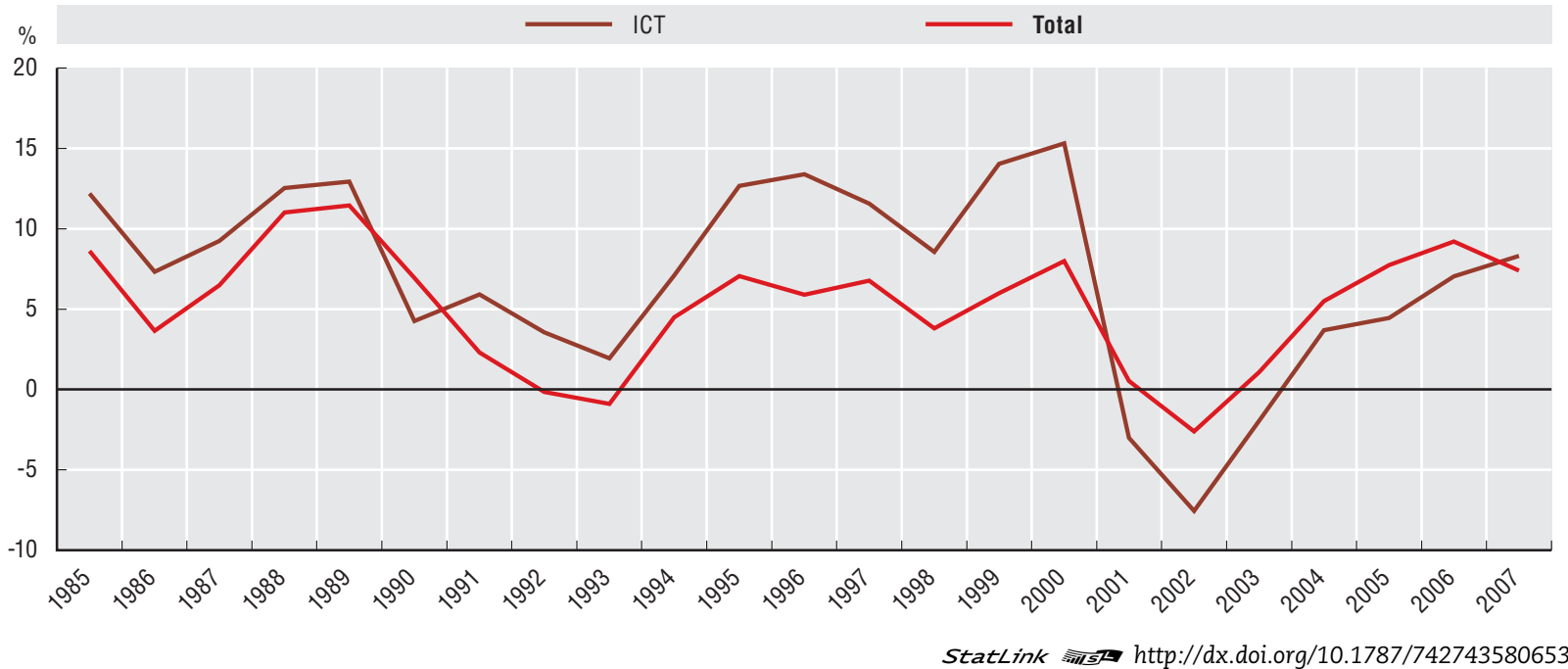

ICT investment by asset in OECD countries, 2007

Percentage of non-residential gross fixed capital formation, total economy

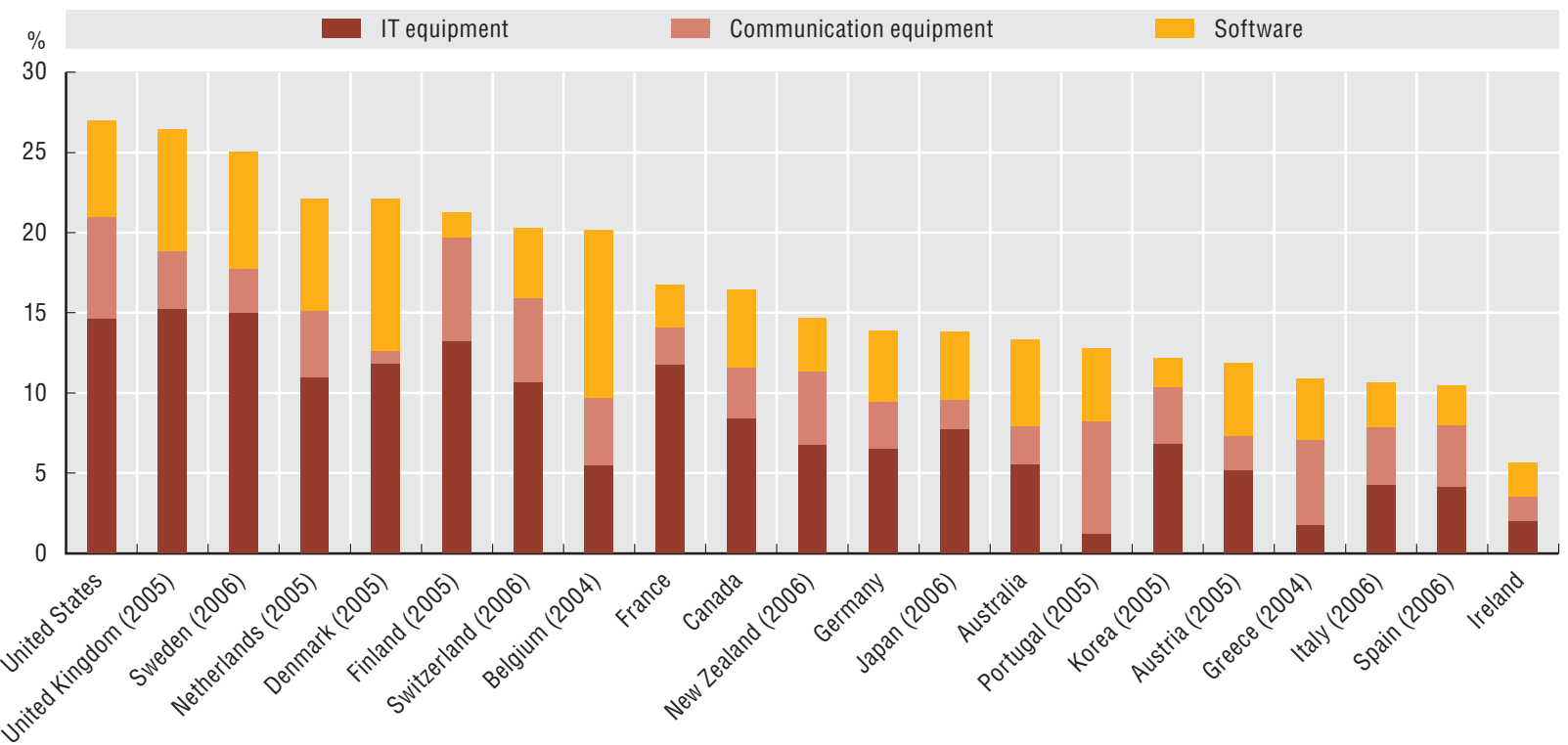

StatLink 게s/4 $h t t p: / / d x . d o i . o r g / 10.1787 / 742752646584$ 

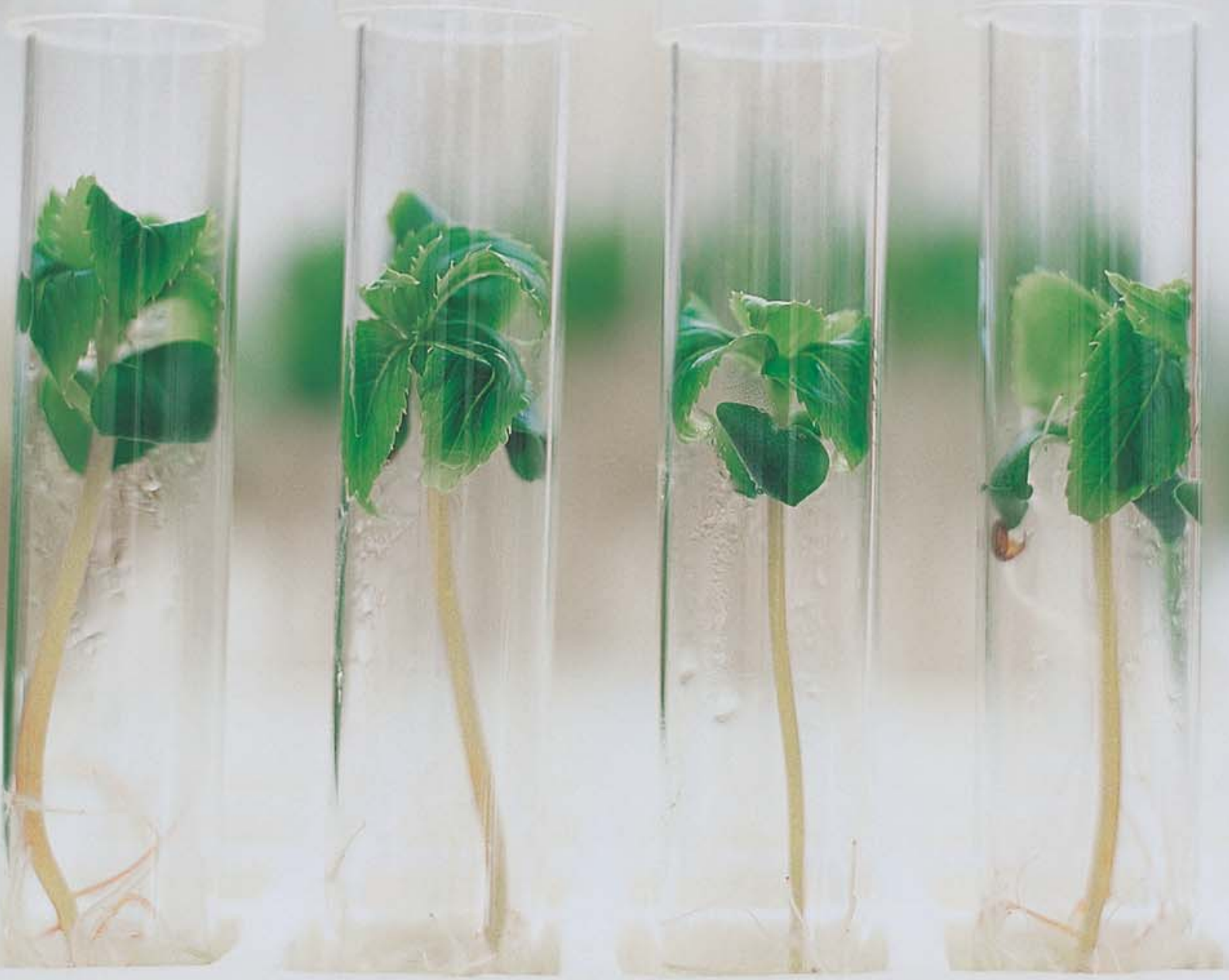

flina $(128)$ Gewing 


\section{TARGETING NEW GROWTH AREAS}

2.1. Patents in environment-related technologies ............ 52

2.2. Environmental sciences ......................... 54

2.3. Telecommunication networks ................... 56

2.4. Health-related R\&D . . . . . . . . . . . . . . . . . . . . 58

2.5. Health-related patents $\ldots \ldots \ldots \ldots \ldots \ldots \ldots \ldots \ldots \ldots \ldots \ldots \ldots$

2.6. Biotechnology R\&D . . . . . . . . . . . . . . . . . . 62

2.7. Public-sector biotechnology R\&D.................... 64

2.8. Biotechnology patents.......................... 66

2.9. Biosciences .................................... 68

2.10. Nanotechnology patents....................... 70

2.11. Nanosciences ................................ 72

2.12. Government R\&D budgets $\ldots \ldots \ldots \ldots \ldots \ldots \ldots \ldots \ldots \ldots \ldots \ldots$

2.13. Public-private cross-funding of R\&D $\ldots \ldots \ldots \ldots \ldots \ldots \ldots \ldots$

2.14. Tax treatment of R\&D .......................... 78

2.15. Collaboration by innovating firms................ 80 
Investment in "clean" technologies can help achieve a wide range of environmental objectives, from mitigating climate change to controlling air and water pollution, to enhancing resource efficiency in general. Patents in renewable energy technologies or in techniques for controlling pollution and waste contribute to the development of clean technologies.

Renewable energy and air pollution control are the most dynamic groups of environmental technologies among patent applications filed under the Patent Co-operation Treaty (PCT). The number of patented inventions in renewable energy $(+20 \%)$ and air pollution control $(+12 \%)$ increased more rapidly than total patents $(+11 \%)$ between 1996 and 2006. These are technologies that are more closely related to profitability and stringent regulation than solid waste and water pollution. In most countries, the proportion of renewable energy patents has more than doubled, on average, although the volume remains low (1 098 patents in 2006). As a consequence, the shares of water pollution control and solid waste management patents decreased significantly.

For all environment-related technologies, the largest number of patents resulted from European research: more than $30 \%$ of patented inventions had EU inventors in the mid-2000s. The United States and Japan contributed shares of between $18 \%$ and $26 \%$ in the four technological areas. The BRIICS countries (Brazil, Russian Federation, India, Indonesia, China, South Africa) are also substantially involved in waste management, water pollution control and renewable energy. Among European countries, Denmark is highly specialised in the development of wind energy technologies.

\section{Environmental patents}

The International Patent Classification system (IPC, 8th edition) was used to identify classes that matched environmental technologies more closely. Keyword searches in the patent document were also conducted to find patents embedding technology specific to a particular field. The focus here is on selected environmental technologies:

Air pollution control/abatement: B01D $\left[46 /{ }^{*}, 47 / /^{*}, 49 /{ }^{*}\right.$, 50/*,51/*, D53/(34-36, 48-52, 54-58, 60, 62, 64, 66, 68-70,72)], B03C3/*, C10L10/(02,06), C21B $/ / 22$, $\mathrm{C} 21 \mathrm{C} 5 / 38, \mathrm{~F} 01 \mathrm{~N}\left[3 /^{*}, 5 /^{*}, 7 /^{*}, 9 /^{*}, 11 /{ }^{*}\right], \mathrm{F} 23 \mathrm{~B} 80 /^{*}$, F23C9/*, F23J15/*, F23G7/06, F27B1/18, G08B21/ (12-14).

Water pollution control (water and wastewater management): B63J4/*, $\mathrm{CO2F}\left[1 / /^{*}, 3 /{ }^{*}, 7 /^{*}, 9 /^{*}, 11 /^{*}\right]$, $\mathrm{C} 05 \mathrm{~F} 7 /{ }^{*}, \mathrm{C} 09 \mathrm{~K} 3 / 32, \mathrm{E} 02 \mathrm{~B} 15 /(04,06,10), \mathrm{E03B} 3 /^{*}$, E03C1/12, E03F.
Solid waste management: A23K1/(06,08,10), A43B(1/12, 21/14), A61L11/*, B03B9/06, B09B, B09C, B22F8/*, B27B33/20, В29B $\left[17 /{ }^{*}, 7 / 66\right]$, В30B9/ 32, B62D67, B65F, B65H73/00, C04B[7/24-30, 11/ 26,18/04-10, 33/132-138], C05F9/*, C08J11/*, C09K11/01, C10G1/10, C10L[5/(46,48)], C10M175/*, C22B [7/*, 19/(28,30),25/06], D01B5/08,D01G[11/*, 19/22], D21B1/(08-10,32), D21C5/02, D21H17/01, $\mathrm{E} 01 \mathrm{H}\left[6 /{ }^{*}, 15 /^{*}\right]$, F23G $\left[5 /{ }^{*}, 7 / *\right]$

Renewable energy:

- Wind: F03D

- Solar: F03G6/*, F24J2/*,E04D13/18, H01L[27/142, 31/(04-078), 51/(42-48)], H02N6/*

- Geothermal: F24J3/*, F03G[4/*, 7/04]

- Ocean: F03B13/(10-26), F03G7/05, E02B9/08

- Hydro power: $\left\{\right.$ E02B9/*, F03B $\left[3 /{ }^{*}, 7 / /^{*}, 13 / 06-08\right.$, $\left.\left.15 /^{*}\right]\right\}+$ NOT $\{$ F03B13/(10-26), F03G7/05, E02B9/08 $\}$

- Biomass: C10L5/40-48,F01K25/14,F02B43/08, $\mathrm{F} 23 \mathrm{G} 5 / 46, \mathrm{C} 10 \mathrm{~L}\left[1 /^{*}, 3 /^{*}, 5 /^{*}\right]+\left\{\mathrm{B} 09 \mathrm{~B}\left[1 /^{*}, 3 /^{*}\right]\right.$, F23G $[5 / *, 7 / *]\},\left\{\mathrm{F} 01 \mathrm{~K} 27 / /^{*}, \mathrm{~F} 02 \mathrm{G} 5 /^{*}\right.$, F25B27/02 $\}+$ $\left\{\mathrm{F} 23 \mathrm{G}\left[5 /^{*}, 7 /^{*}\right\}\right.$

For further details on the IPC, 8th edition, www.wipo.int/classifications/ipc/ipc8/?lang=en.

\section{Source}

OECD, Patent Database, June 2009, www.oecd.org/sti/ipr-statistics.

\section{Going further}

Johnstone, N., I. Hascic and D. Popp (2008), "Renewable Energy Policies and Technological Innovation: Evidence Based on Patent Counts", NBER Working Paper Series, N.13760.

Johnstone, N., I. Hascic and P. Scapecchi (2009), "Environmental Policy Stability and Innovation in Environmental Technologies", Social Science Research Network Working Paper, 30 March, http://ssrn.com/abstract=1370336.

OECD (2008), Environmental Policy, Technological Innovation and Patents, OECD, Paris.

OECD (2009), OECD Patent Statistics Manual, OECD, Paris.

\section{Figure notes}

Data relate to patent applications filed under the PCT, at international phase, designating the European Patent Office (EPO). Patent counts are based on the priority date, the inventor's country of residence and fractional counts. 


\section{TARGETING NEW GROWTH AREAS}

\subsection{Patents in environment-related technologies}

Patents in selected environmental technologies

As a percentage of total PCT patent applications

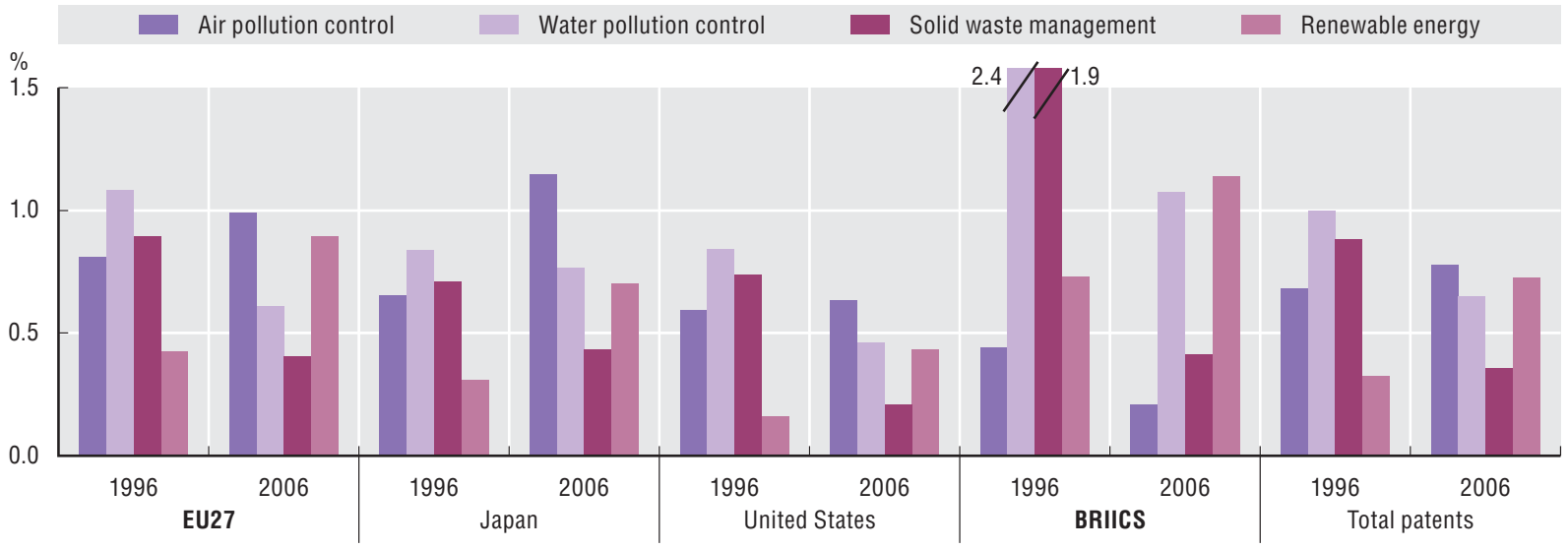

StatLink क्ञाs http://dx.doi.org/10.1787/742753678785

Share of countries in environmental technology patents filed under PCT

Top 25 countries, 2004-06
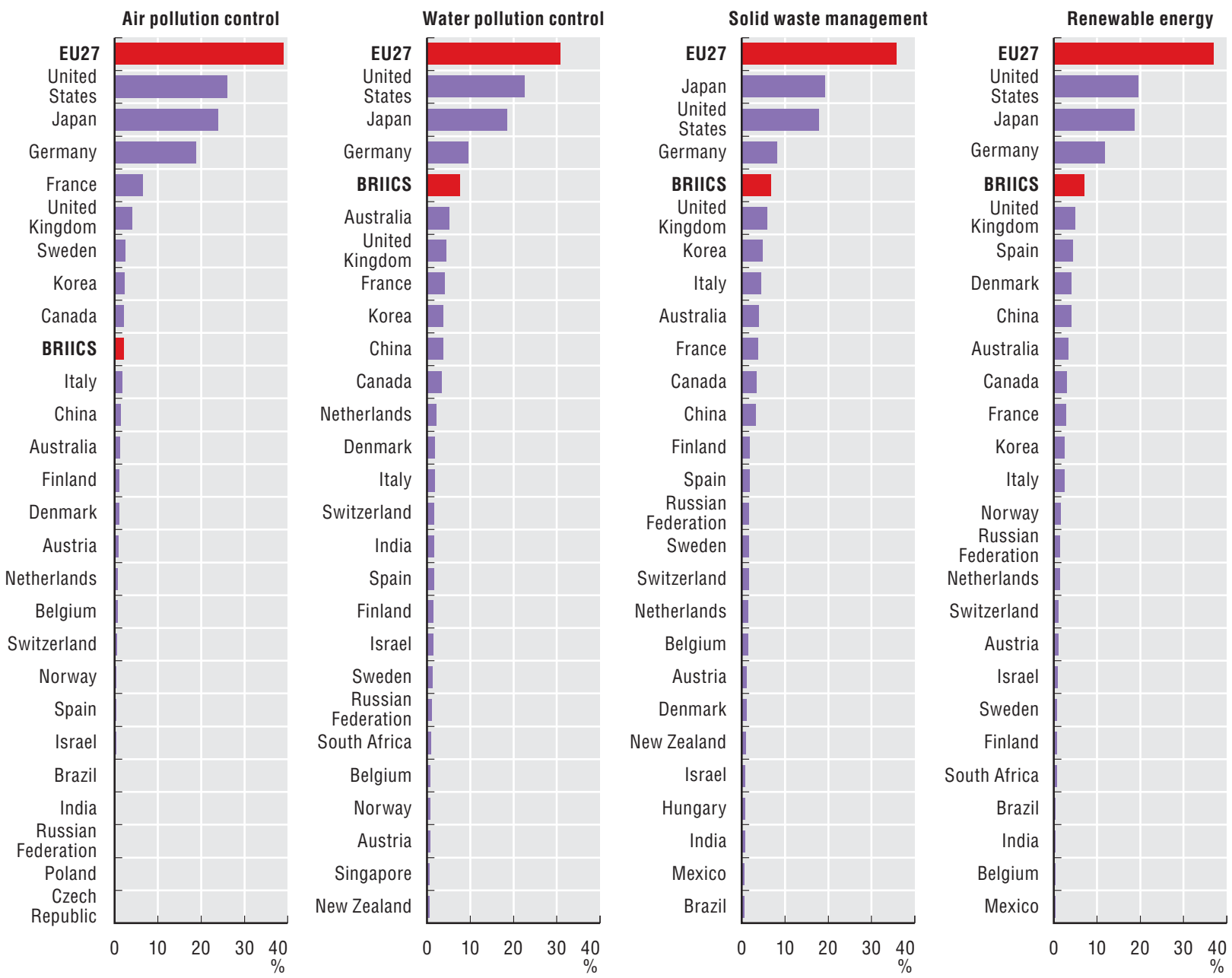

StatLink तiाs http://dx.doi.org/10.1787/742754285081 


\section{TARGETING NEW GROWTH AREAS}

\subsection{Environmental sciences}

Research in environmental sciences can help achieve a wide range of environmental objectives, from mitigating climate change to controlling air and water pollution, to enhancing biodiversity. Core scientific articles identify the most influential contributions to research. Citations to core articles in environmental sciences provide a measure of research activity in this field.

Environmental sciences include three main research areas: climate change, air and chemical pollutants, and biodiversity. The average annual growth rate in citations to core articles in climate change $(20.0 \%)$ and biodiversity (18.5\%) exceeds the rate for the total number of citations to all scientific articles (15.8\%) between 2002 and 2007. However, citations to core articles in air and chemical pollutants grew more slowly (14\%). These trends show the increasing influence of research in climate change and biodiversity in recent years.

Research activities show a clear orientation towards environmental sciences in a minority of OECD countries. Seven report a share of citations above the world average in air and chemical pollutants, ten in climate change, and eleven in biodiversity.

The United States has the largest relative share in air and chemical pollutants and in climate change, while Denmark has the largest relative share in biodiversity. The United Kingdom ranks second in climate change and biodiversity and Sweden in air and chemical pollution. Switzerland is third in all three areas.

In China, Italy, Japan and Spain the share of citations to environmental sciences is below the world average in all areas.

\section{Environmental research}

Clusters of articles with similar research subjects were identified via co-citation analysis. Co-citation is a form of citation in which a set of articles is simultaneously cited by other articles. A total of 64958 highly cited articles, i.e. the top $1 \%$ of cited articles in the database from 2001 to 2006, were clustered on the basis of cocitation relationship. The co-citation analysis identifies three areas of environmental science in which there has been active research in recent years: climate change, air and chemical pollutants, and biodiversity.

Research on climate change consists, for example, of research on the global carbon cycle, the North Atlantic Oscillation and the paleoclimate. The impact of increasing greenhouse gases on global climate is extensively studied.
Research on air and chemical pollutants appears to be another important domain. It models generation and diffusion processes of aerosols and air pollutants and studies their impact on climate. It also covers aquatic pollution by toxic chemical compounds and environmental pollution caused by persistent organic pollutants.

Biodiversity is defined as the diversity of living organisms from all sources, including, among others, terrestrial, marine and other aquatic ecosystems and their ecological systems. This includes diversity within species, between species and among ecosystems.

\section{Source}

OECD calculations, based on Scopus Custom Data, Elsevier, July 2009.

\section{Going further}

Igami, M. and A. Saka (2007), "Capturing the Evolving Nature of Science, the Development of New Scientific Indicators and the Mapping of Science", OECD Science,Technology and Industry Working Papers 2007/1, OECD, Paris, www.oecd.org/sti/working-papers.

\section{Figure notes}

The average annual growth rate of the number of citations to core articles is based on the year of publication of citing articles.

Calculation of a country's share is based on the address of the institution to which the authors belong, and fractional counts.

Only countries with a share of core articles over $1 \%$ are included.

A country's relative share in core articles is calculated by dividing the country's share in core articles by the country's share in all articles in all scientific fields. 
Trends in citations to core articles in selected environmental sciences, 2002-07

Average annual growth rate in the number of citations to core articles

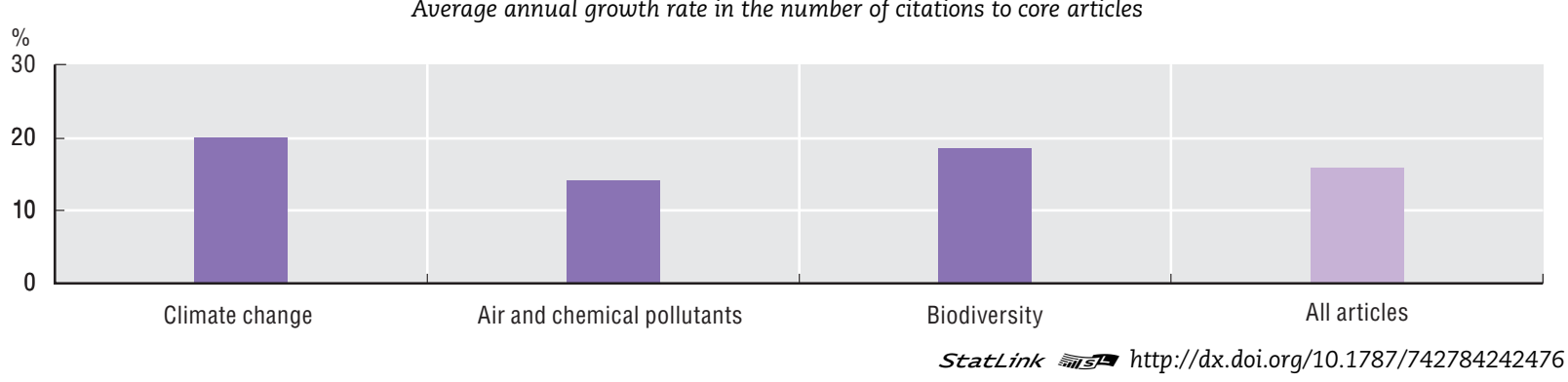

Countries' relative share in core articles in climate change, 2001-06

Ratio of the country's share in core articles to its share in all fields

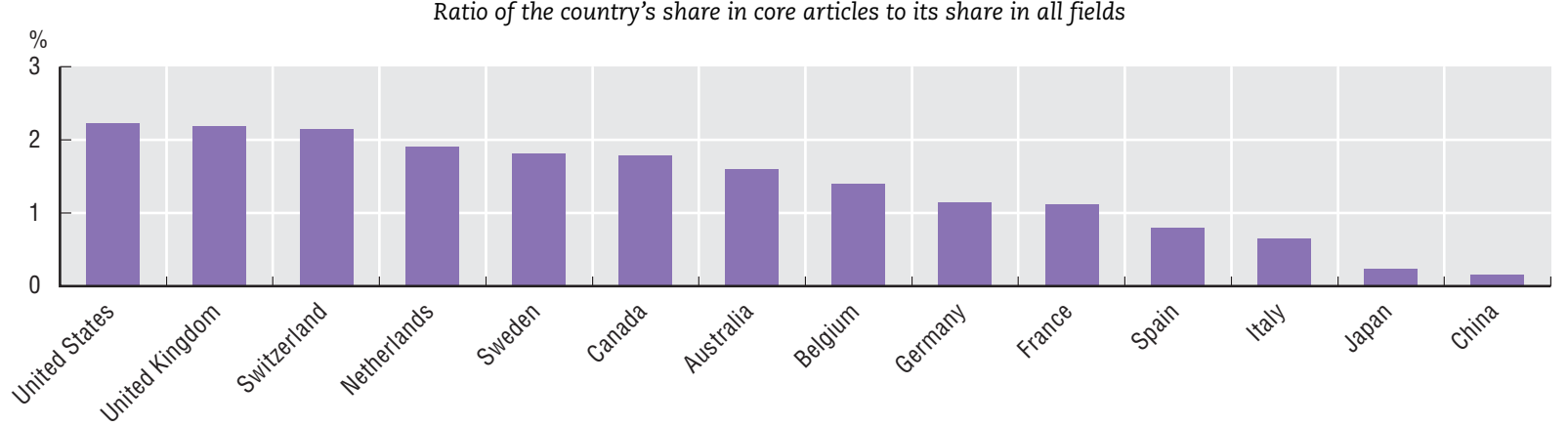

StatLink sils http://dx.doi.org/10.1787/742808880801

Countries' relative share in core articles in air and chemical pollutants, 2001-06

Ratio of the country's share in core articles to its share in all fields

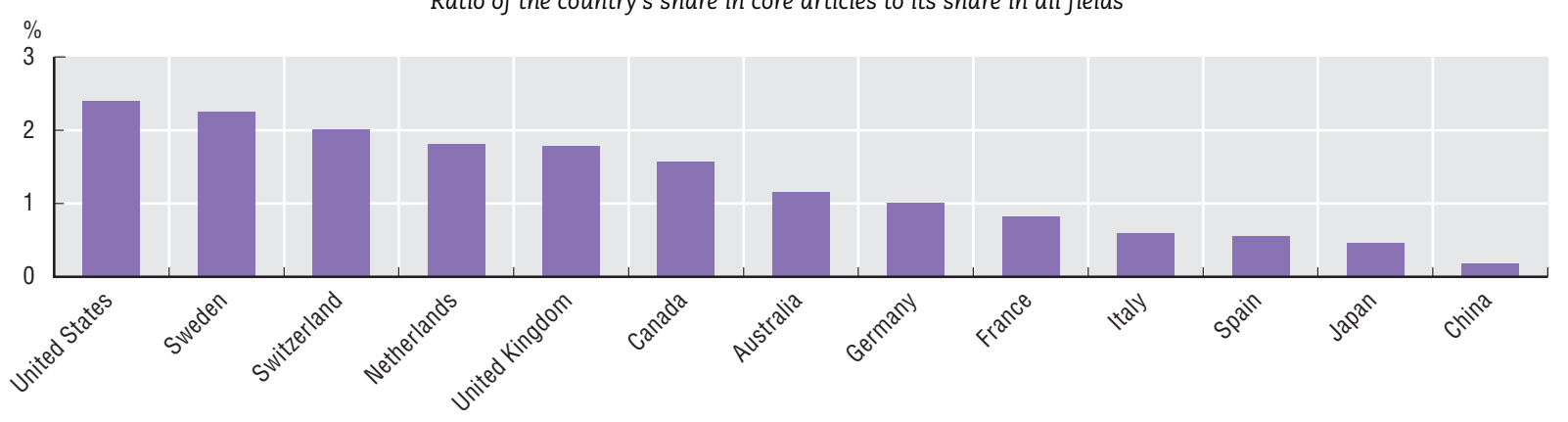

StatLink काISL http://dx.doi.org/10.1787/742848400728

Countries' relative share in core articles in biodiversity, 2001-06

Ratio of the country's share in core articles to its share in all fields

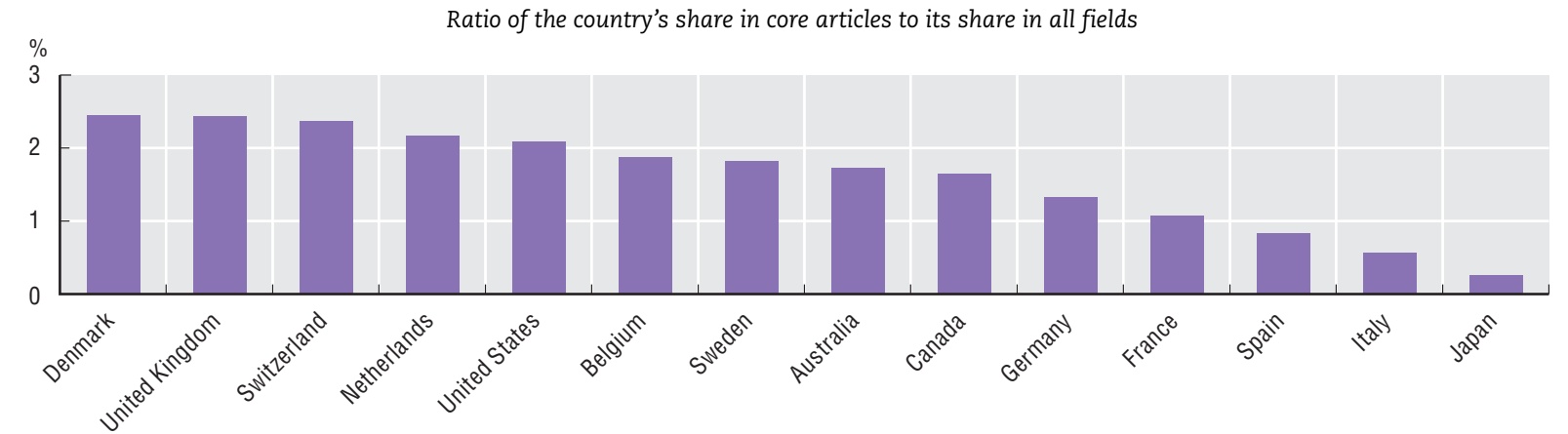


Broadband Internet and mobile phones have dramatically increased opportunities for long-distance communications and often now replace face-to-face interaction. Information can now be transmitted at any time and from anywhere via e-mail, conference calls, and virtual meetings. Improved communication channels can reduce commuting and business travel and thus the impact of productive activities on the environment. Telecommunication networks, therefore, are an important infrastructure for green growth.

Since 2005, the two major growth areas in telecommunication networks have been mobile and broadband. Mobile subscriptions grew at an annual rate of $10 \%$ over $2005-07$, bringing the number of OECD-area mobile subscriptions to 1.14 billion by 2007 . Over the same period, the number of fixed telephone access paths (analogue + ISDN lines) declined by 3.4\% a year. Together, communications access paths grew at an annual rate of $7.4 \%$. The number of broadband subscribers has grown by $22.3 \%$ a year since 2005 , and this has helped protect fixed line operators from much more dramatic losses. It has also increased the value of cable networks around the world.

The total number of communications paths (fixed, mobile, and broadband) in the OECD area reached 1.6 billion in 2007 for just over 1 billion inhabitants. Mobile and broadband accounted for $74 \%$ of all communication subscriptions in 2007 (61\% for mobile and $13 \%$ for broadband). Standard phone lines have dropped to $26 \%$. This is a dramatic turnaround from 2000 when fixed line subscribers outnumbered mobile subscribers. Mobile's effective penetration rate is 96.1 subscribers per 100 inhabitants. Italy has the highest penetration rate with 151 subscribers per 100 inhabitants. Only nine countries had less than one subscription per person.

In 2005 , dial-up connections still accounted for $40 \%$ of fixed Internet connections but by 2007 they accounted for only $10 \%$. In Korea dial-up has practically disappeared and now accounts for fewer than two out of every 1000 Internet connections. DSL is the leading broadband technology, accounting for $60 \%$ of all broadband subscriptions in December 2008. Cable represents $28 \%$ and fibre-based connections $10 \%$. The remaining $2 \%$ of connections are fixed-wireless, satellite and broadband over power lines. At the end of 2008 there were 22.4 broadband subscribers per 100 inhabitants in the OECD area.

\section{Telecommunication networks}

In the past, the penetration of standard access lines provided a reasonable indication of the extent to which basic telecommunication connections were available to users. Today, the take-up of ISDN (integrated services digital network) in most OECD countries has made this indicator inappropriate. A measure is the penetration of telecommunication paths, including those made possible by ISDN. To appreciate overall telecommunication penetration rates across the OECD area, it is also increasingly necessary to take into account the development of mobile communication networks and of broadband Internet access. The two leading technologies currently used to provide high-speed Internet access are digital subscriber lines (DSL) and cable modem. Other broadband connections include satellite broadband Internet access, fibreto-home Internet access, Ethernet LANs (local areas networks), and fixed wireless access. The data for broadband subscribers include business and residential connections.

A significant shift in fixed broadband technologies occurred in 2008. In June of that year, Japan and Korea became the first two countries to have more fibrebased subscriptions than either DSL or cable.

\section{Source}

OECD (2009), OECD Communications Outlook, OECD, Paris, www.oecd.org/sti/telecom/outlook.

\section{Going further}

OECD, Telecommunications Database, 2009.

OECD, Broadband Statistics, www.oecd.org/sti/ict/broadband.

OECD, ICT Key Indicators, www.oecd.org/sti/ICTindicators.

\section{Figure notes}

Fixed communication access paths = analogue lines + ISDN lines + DSL + cable modem + fibre/LAN . 


\section{TARGETING NEW GROWTH AREAS}

Communication access per 100 inhabitants, 2007

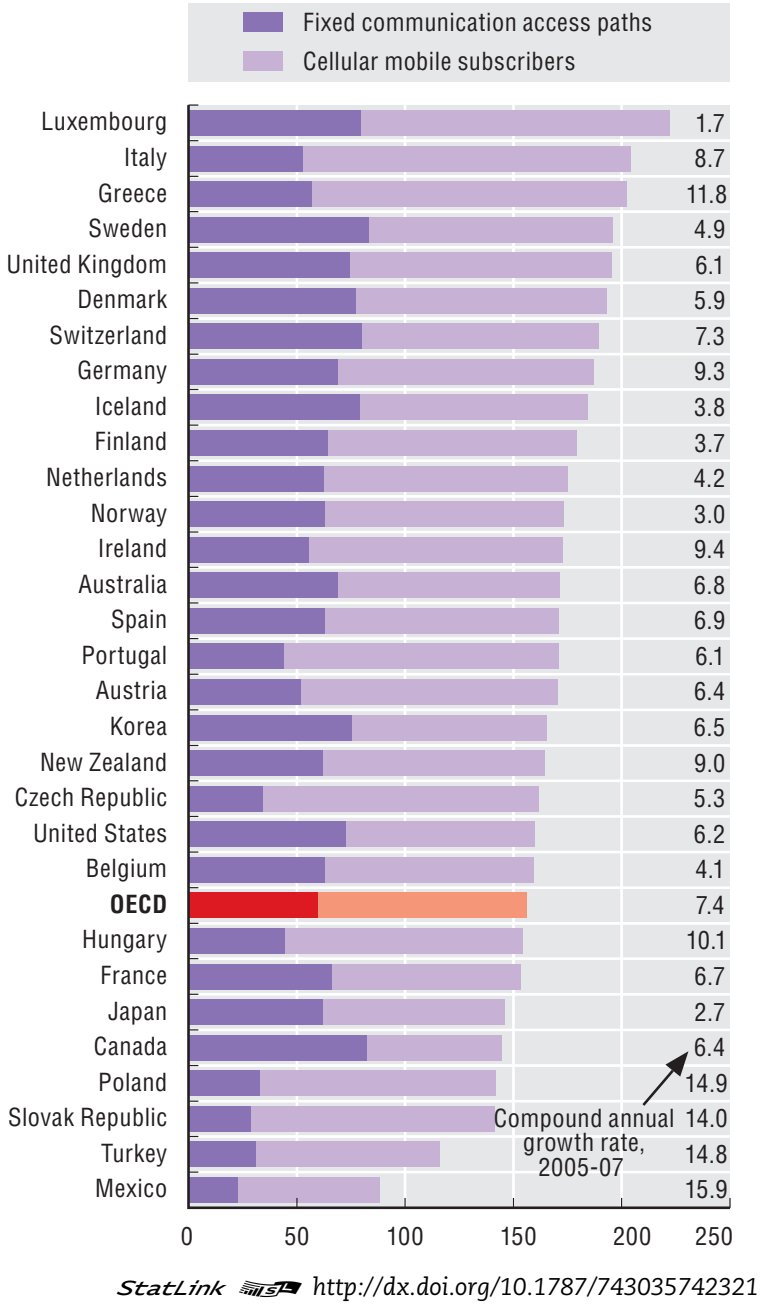

Broadband subscribers in OECD countries, per 100 inhabitants, by technology, December 2008
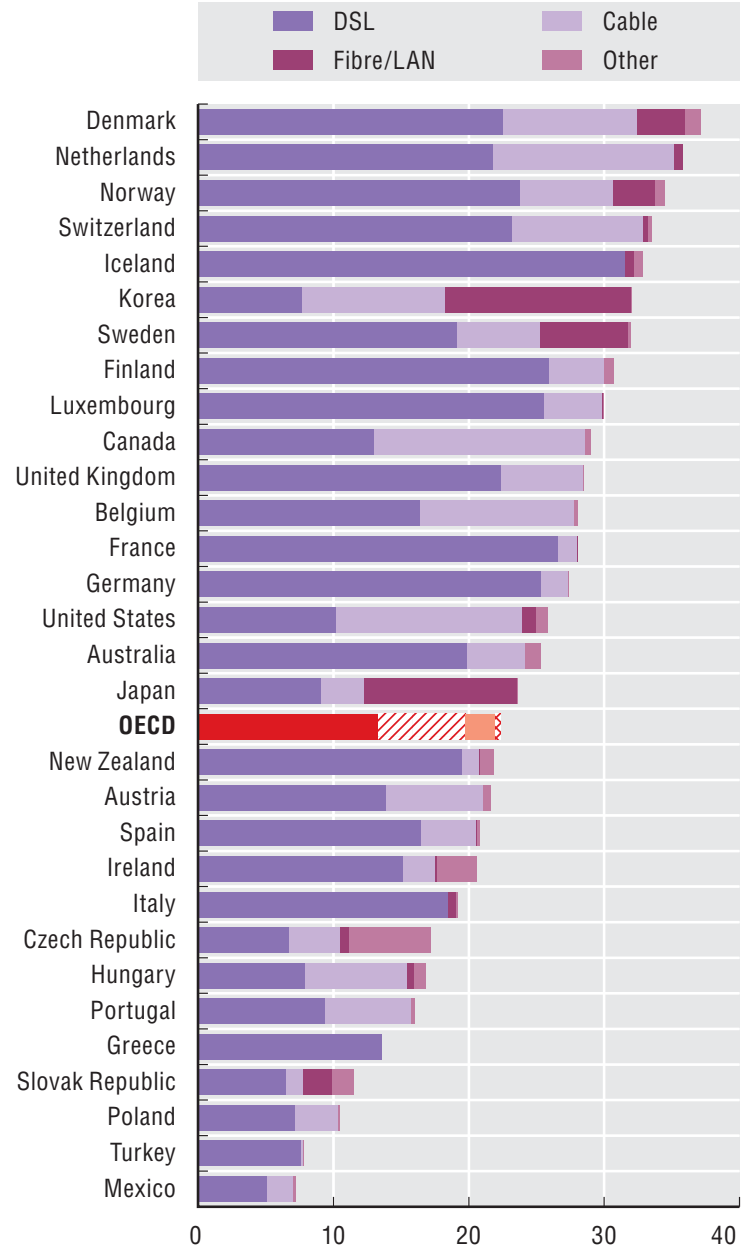

StatLink ans (nttp://dx.doi.org/10.1787/743043842747 
Ageing is one of the major challenges facing OECD societies and economies in the next decades. Innovation can help to meet this challenge, by improving the performance of health systems and reducing their costs. Health-related research and development (R\&D) provides a useful indicator of innovative efforts in this field.

In OECD countries in 2008, direct government support of health-related R\&D based on government budget appropriations for R\&D (GBAORD) was about $0.11 \%$ of their combined GDP. Direct support for health-related R\&D represented over $0.22 \%$ of gross domestic product (GDP) in the United States, far above the levels for the European Union $(0.05 \%$ in 2006$)$ and Japan $(0.03 \%$ in 2008). Since 2000, it has decreased only in Sweden.

The data on direct support for health-related R\&D suggest that the United States accounts for around three-quarters of the OECD total. However, when data from additional GBAORD categories are used to adjust for institutional differences in the funding of health $\mathrm{R} \& \mathrm{D}$, the picture changes. The United States is no longer an outlier: health-related $R \& D$ budgets relative to GDP approach that of the United States in a number of countries, notably owing to the important contribution of funding of medical science (through general university funds and non-oriented research). Sweden, with a relatively modest direct government budget for health-related $R \& D$ as a percentage of GDP, is a case in point.

Another indicator often used as a component of health-related R\&D is R\&D expenditure by the pharmaceutical industry. In 2006, it represented around $0.3 \%$ of GDP in Belgium, Sweden, the United States and the United Kingdom, and reached almost $0.5 \%$ in Denmark.

The share of pharmaceutical R\&D in business sector R\&D (BERD) is above $20 \%$ in Belgium, Denmark, Ireland and the United Kingdom, and over $40 \%$ in Hungary. While the ratio of pharmaceutical R\&D to GDP is low in the Netherlands, Poland and Spain (less than $0.1 \%$ ), this sector accounts for a significant share of total business sector R\&D in the three countries (more than 10\%).

\section{Public funding of health R\&D}

Health-related R\&D is difficult to measure owing to institutional complexity and diversity; it may be publicly or privately funded and be carried out in firms, universities, hospitals and private non-profit institutions. The government budget appropriations or outlays for R\&D (GBAORD) can be broken down by socioeconomic objectives, such as the protection and improvement of public health, as defined by the Frascati Manual (OECD, 2002).

The GBAORD health category is used here as a proxy for total central government funding of health-related R\&D. However, this category only covers programmes for which health is the primary objective. Furthermore, the classification of programme and institutional funding depends on how governments present their $R \& D$ priorities as well as on the formal mandate of the institutions concerned. Arrangements for funding R\&D in hospitals also vary among countries.

To address some of the limitations mentioned above and to provide a more complete picture of health-related R\&D, funding of medical sciences via non-oriented research and general university funds are included when available as are other relevant funds, notably general support for R\&D in hospitals.

\section{Sources}

OECD, R\&D Database, May 2009.

OECD, ANBERD Database, June 2009.

\section{Going further}

OECD (2002), Frascati Manual: Proposed Standard Practice for Surveys on Research and Experimental Development, OECD, Paris, www.oecd.org/sti/frascatimanual.

\section{Figure notes}

Growth rate for 2000-07 for Spain, Portugal, Greece, Slovenia, Belgium and Israel; 2000-06 for OECD, United Kingdom, Canada, EU27, Mexico and Switzerland; 2001-08 for Denmark; 2002-07 for Estonia; 2002-08 for the Czech Republic; 2004-07 for Poland; and 2005-08 for Norway.

"Advancement of knowledge" comprises non-oriented R\&D and general university funds, and "Other" includes other relevant national and international categories. 


\section{TARGETING NEW GROWTH AREAS}

Health R\&D in GBAORD as a percentage of GDP, 2008

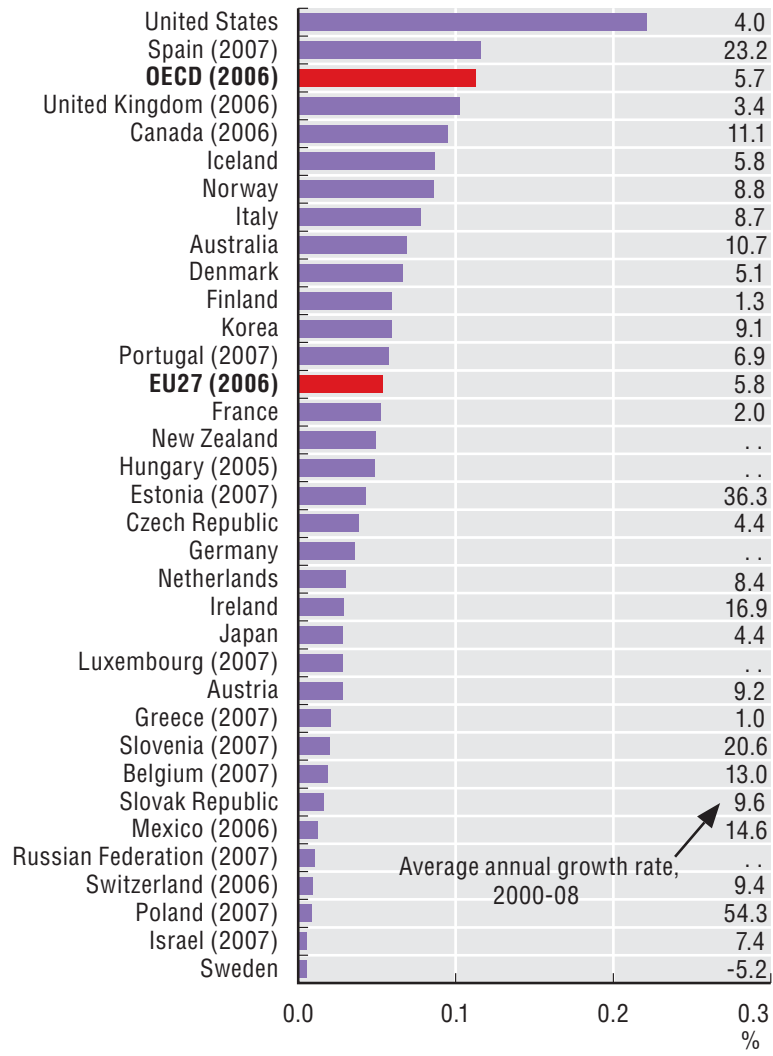

StatLink AाISL http://dx.doi.org/10.1787/743056803871

\section{Direct and indirect government support for health-related R\&D, 2008}

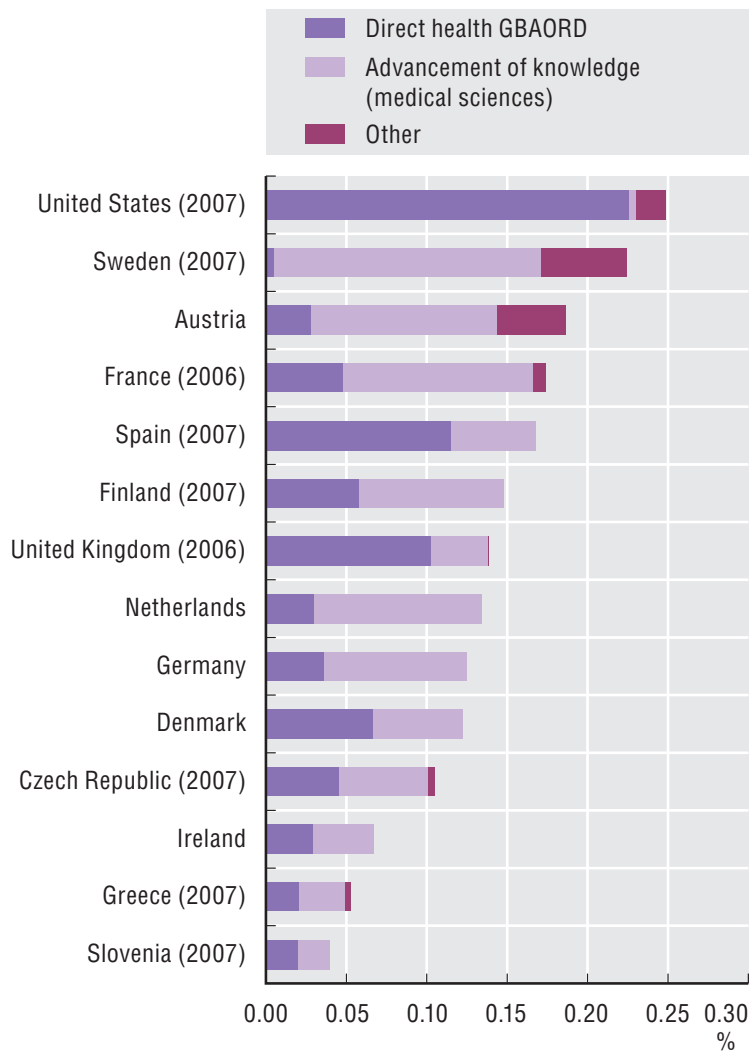

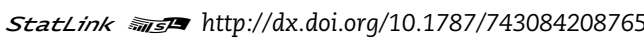

R\&D in the pharmaceutical industry as a percentage of BERD and of GDP, 2006

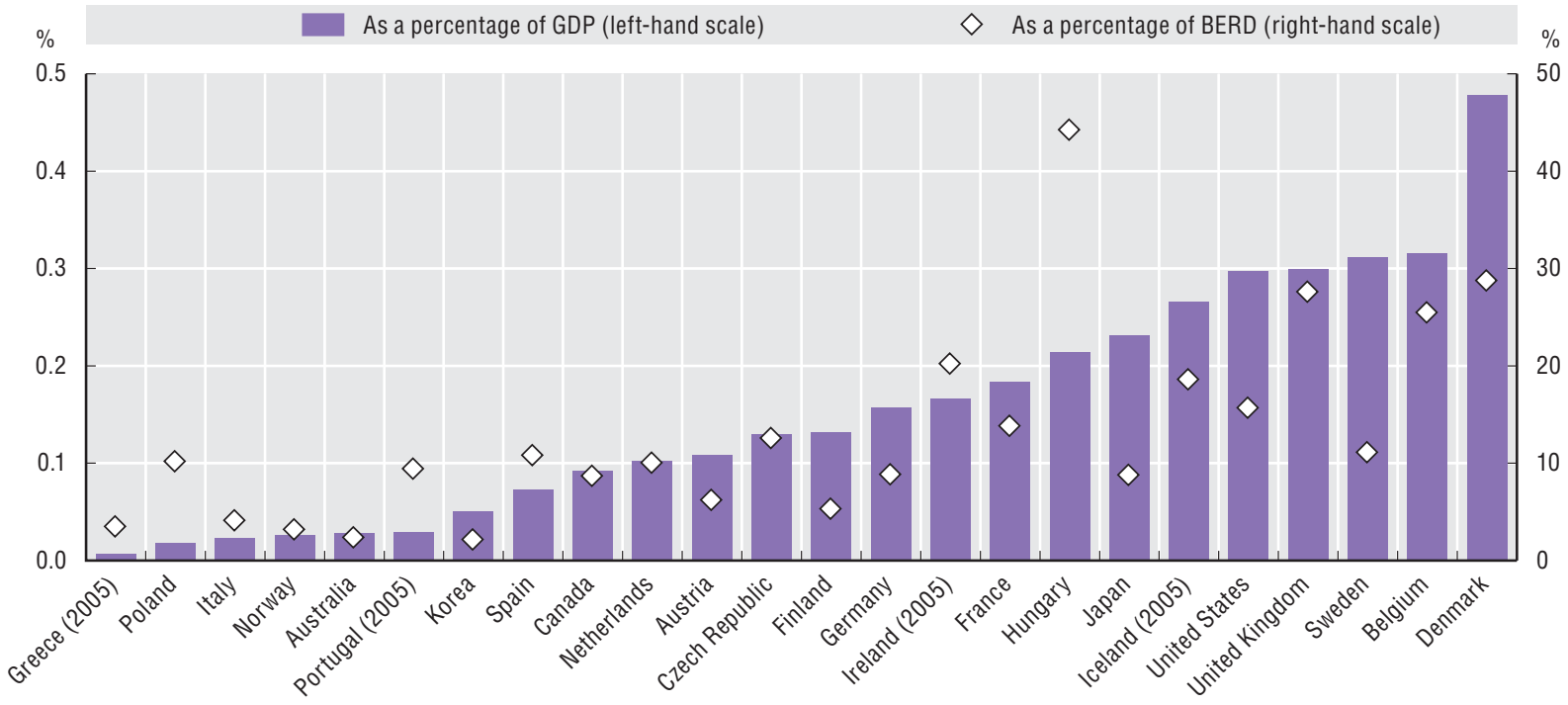




\section{TARGETING NEW GROWTH AREAS}

\subsection{Health-related patents}

General health expenditures have risen relentlessly over the past decades in line with the increased costs of medical equipment and the ageing of the population in most OECD countries. Innovations in medical technologies and pharmaceuticals have followed the trend but remain unevenly distributed worldwide.

From 1996 to 2006, the number of patents in medical technologies increased at an average rate of $11 \%$ a year, at the same pace as the total number of patents under the Patent Co-operation Treaty (PCT). Patent applications in pharmaceuticals registered growth of $7 \%$ over the period. In relative terms, the share of patents in pharmaceuticals decreased in most countries' patent portfolios, from $11 \%$ in 1996 to $8 \%$ in 2006. In the BRIICS countries (Brazil, Russian Federation, India, Indonesia, China, South Africa) the share of patents relating to pharmaceuticals increased by two percentage points, whereas the share of medical technology patents declined by half from the levels of 1996.

In 2004-06, the United States accounted for almost half of patented inventions in medical technologies, twice as many as the European Union. Israel accounted for $2.7 \%$ of patents in medical technologies, twice its share in total patents (1.3\%). Additionally, the United States had more than $42 \%$ of pharmaceutical patents in the mid-2000s. China and India together accounted for nearly $5 \%$ of patents in pharmaceuticals over the period.

\section{Health-related patents}

Patents in health-related technologies were identified using the 2008 revision of the technology classification originally developed by the Fraunhofer ISI and the Observatoire des Sciences et des Technologies (OST), in co-operation with the French patent office (INPI), to enable country comparisons (Schmoch, 2008). The research was performed using the codes of 8th edition of the International Patent Classification (IPC).

- Medical Technology: A61[B, C, D, F, G, H, J, L, M, N], H05G. "Medical technology is generally associated with high technology. However, a large part of the class A61 refers to less sophisticated products and technologies such as operating tables, massage devices, bandages, etc. These less complex sub-fields represent a large number of patent applications, and the total field is the second largest of the suggested classification with 6.3 per cent of all applications in 2005."

- Pharmaceuticals: A61K NOT A61K8/*. “(...) this field refers to an area of application, not a technology. However, the key sub-class $A 61 \mathrm{~K}$ is primarily organized by technologies (e.g., medicinal preparations containing inorganic active ingredients...). Cosmetics are explicitly excluded from the field; these represent about 10 per cent of all applications classified in A61K."

For further details on the IPC, 8th edition, www.wipo.int/classifications/ipc/ipc8/?lang=en.

\section{Source}

OECD, Patent Database, June 2009, www.oecd.org/sti/ipr-statistics.

\section{Going further}

OECD (2009), OECD Patent Statistics Manual, OECD, Paris.

Schmoch, U. (2008), "Concept of a Technology Classification for Country Comparisons, Final Report to the World Intellectual Property Organisation (WIPO)", www.wipo.int/export/sites/www/ipstats/en/statistics/ patents/pdf/wipo_ipc_technology.pdf.

\section{Figure notes}

Data relate to patent applications filed under the PCT, at international phase, designating the European Patent Office (EPO). Patent counts are based on the priority date, the inventor's country of residence and fractional counts. 


\section{TARGETING NEW GROWTH AREAS}

\section{Health-related patents}

As a percentage of total PCT patent applications

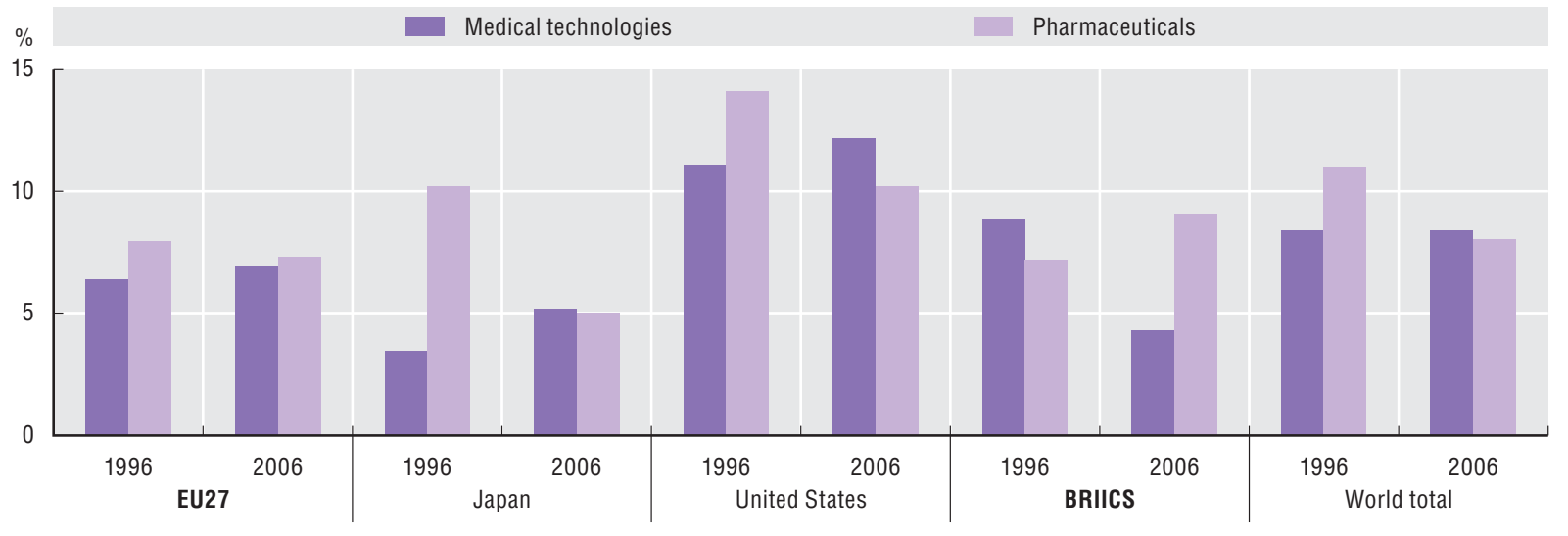

StatLink तiाsय $h t t p: / / d x . d o i . o r g / 10.1787 / 743200258672$

Share of countries in health-related patents filed under PCT, 2004-06
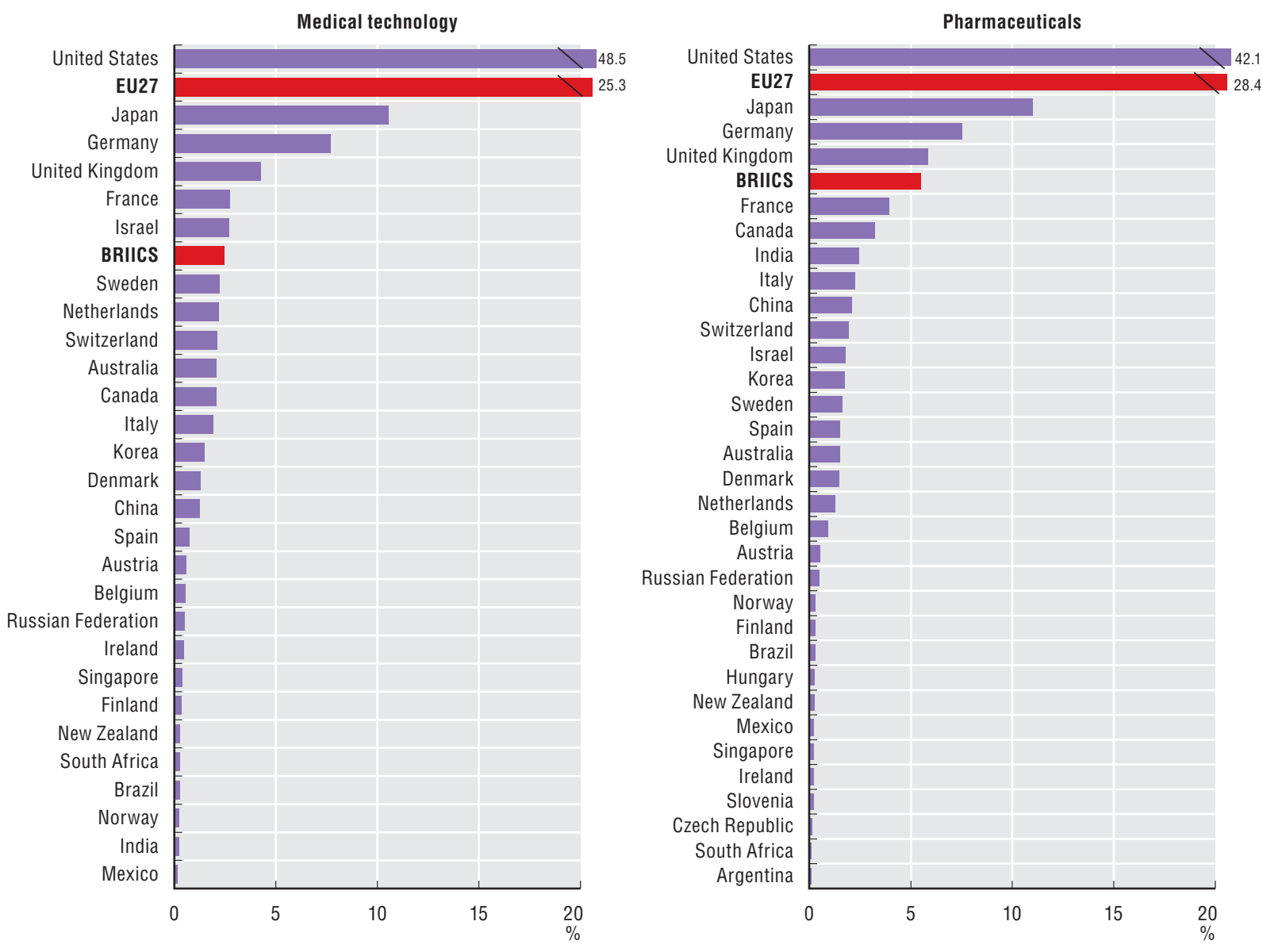

StatLink तiाsय http://dx.doi.org/10.1787/743274071177 
Recent advances in the life sciences are proving the prediction that this will be the century of biotechnology. In two to three decades, new treatments and drugs, genetically modified foods, biologically controlled production processes, new materials, biologically based computing and many other applications may well be part of our everyday lives, improving health, the environment, and industrial, agricultural and energy production.

Data on business sector expenditure for biotechnology research and development (R\&D) performed within the country are available for 17 OECD countries and two non-member countries. However, data on biotechnology R\&D expenditure are not available for Denmark, Japan and the United Kingdom, countries which have substantial business sector capabilities in biotechnology.

Business sector expenditure on biotechnology R\&D is highest in the United States (USD 25101 million current PPP). This represents $75 \%$ of firms' total biotechnology $R \& D$ expenditures in the 19 countries for which data are available.

Total business expenditure on biotechnology R\&D as a share of total business sector R\&D expenditure is an indicator of a research focus on biotechnology. The average share for the 19 countries is $6.14 \%$. Eight countries have an above-average focus on biotechnology R\&D. It accounts for $21.7 \%$ of all business sector R\&D in Ireland, followed by Belgium (13.1\%), Canada (11.1\%) and the United States (10.4\%).

An alternative measure of research focus on biotechnology is biotechnology R\&D intensity, defined as biotechnology R\&D expenditure as a share of total value added of the industry sector. The average share for the 19 countries is $0.12 \%$. Seven countries have aboveaverage biotechnology R\&D intensities. The United States leads with $0.31 \%$, followed by Switzerland $(0.28 \%)$, Ireland $(0.27 \%)$, Belgium $(0.26 \%)$ and Sweden $(0.24 \%)$.

The share of total biotechnology R\&D (in all sectors) performed in the services sector is available for biotechnology R\&D firms in 13 countries. It ranges from $2 \%$ in Belgium to $86 \%$ in France, with an average of $41 \%$ for the 13 countries. In the United States, $73 \%$ of all biotechnology R\&D firms are in the non-manufacturing sector, but only $27 \%$ of all biotechnology R\&D is attributed to the non-manufacturing sector (which includes services, mining, construction and utilities). In Switzerland, $75 \%$ of all biotechnology R\&D is performed outside the services sector.

Although most biotechnology firms have fewer than 50 employees, most biotechnology R\&D is performed by large firms with over 250 employees. For the United States and France, the two countries spending the most on biotechnology R\&D, some $75 \%$ of all biotechnology $R \& D$ is performed by large biotechnology R\&D firms.

\section{Biotechnology firms}

Biotechnology firms can be broken down into three types:

1. Biotechnology firm: a firm engaged in biotechnology using at least one biotechnology technique (as defined in the OECD list-based definition of biotechnology techniques) to produce goods or services and/or to perform biotechnology R\&D. Some firms may be large, with only a small share of total economic activity attributable to biotechnology.

Two subgroups of biotechnology firms are largely defined by the data collection method.

2. Dedicated biotechnology firm: a firm whose main activity involves the application of biotechnology techniques to produce goods or services and/or to perform biotechnology R\&D.

3. Biotechnology R\&D firm: a firm that performs biotechnology R\&D. Dedicated biotechnology R\&D firms, a subset of this group, are firms that devote $75 \%$ or more of their total R\&D to biotechnology R\&D.

The data available on firm type depends on the way biotechnology data are collected.

\section{Source}

OECD (2009), "OECD Biotechnology Statistics 2009", www.oecd.org/dataoecd/4/23/42833898.pdf.

\section{Going further}

OECD (2005), "A Framework for Biotechnology Statistics", www.oecd.org/dataoecd/5/48/34935605.pdf.

\section{Figure notes}

Data for Slovenia are underestimated.

The services sector is defined as non-manufacturing for the United States. Biotechnology R\&D firms for the United States, Switzerland and Norway. Data for Ireland are underestimated.

Small biotechnological firms refer to dedicated biotechnology firms only for Germany and Canada. Small biotechnological firms refer to biotechnological firms with fewer than 100 employees in Switzerland and to all biotechnology firms in Poland. 
Total biotechnology R\&D expenditures in the business sector, 2006

Millions of USD PPP
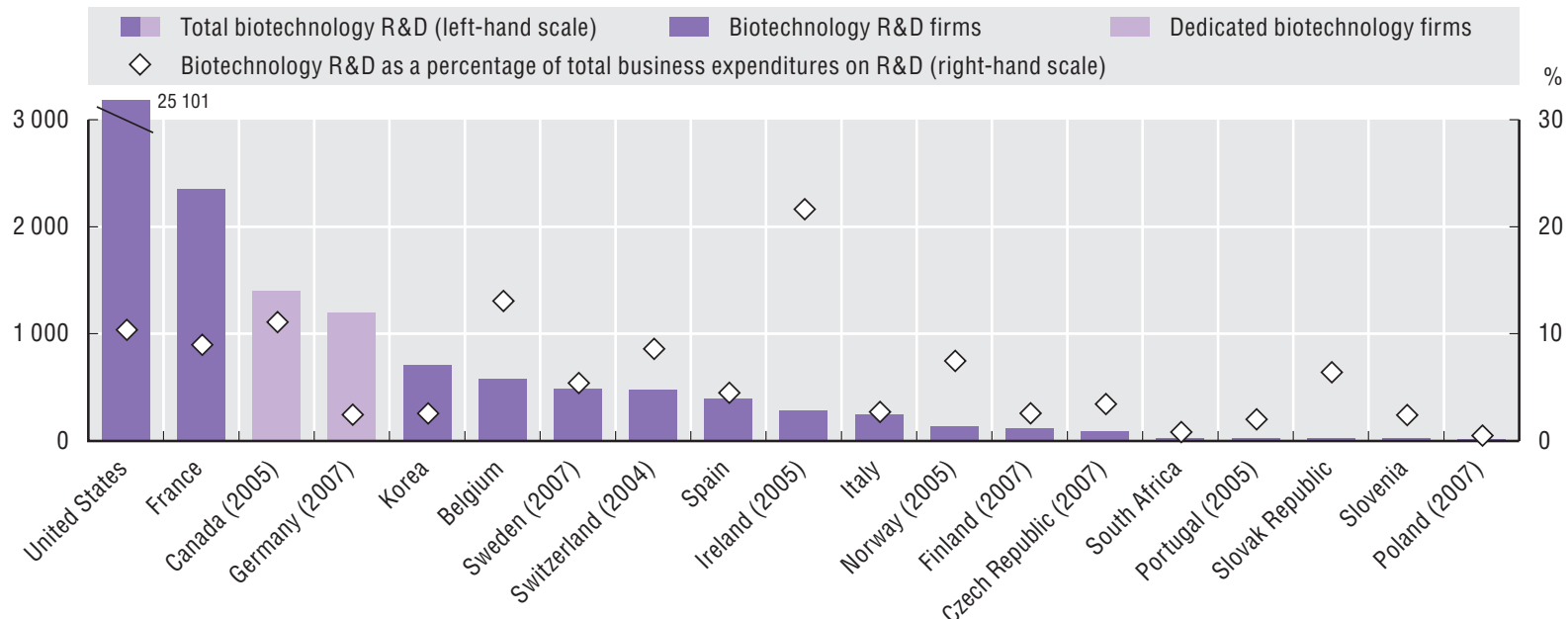

Biotechnology R\&D intensity, 2006

Biotechnology R\&D as a percentage of industry value added

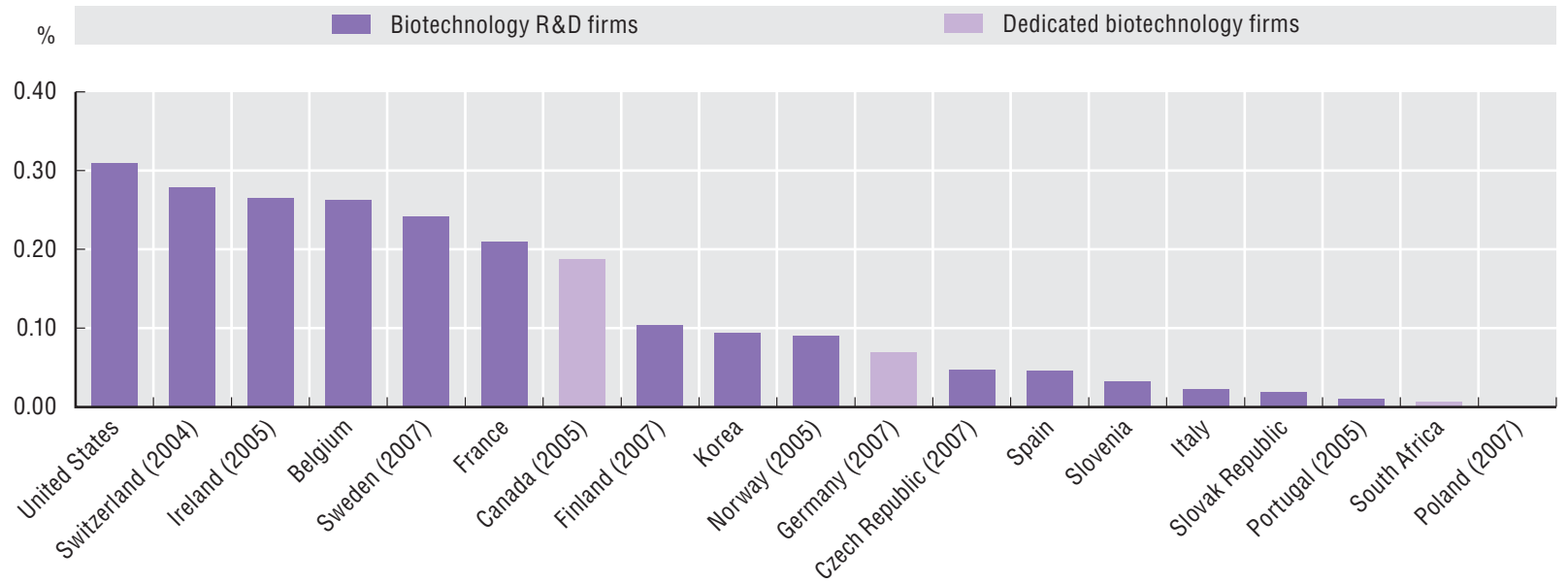

StatLink ताइस http://dx.doi.org/10.1787/743376071204

Percentage of biotechnology R\&D performed in the services sector by dedicated biotechnology R\&D firms, 2006

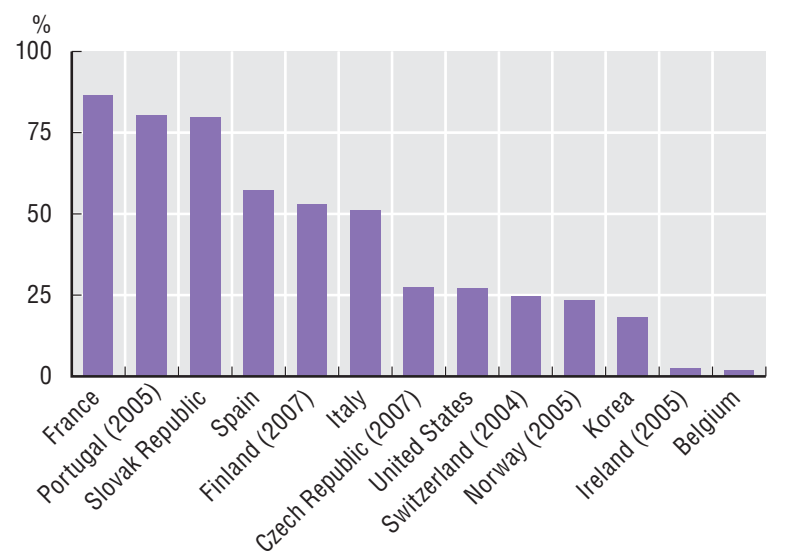

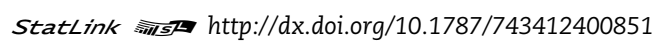

Percentage of biotechnology R\&D performed by small biotechnology R\&D firms, 2006

Firms with fewer than 50 employees

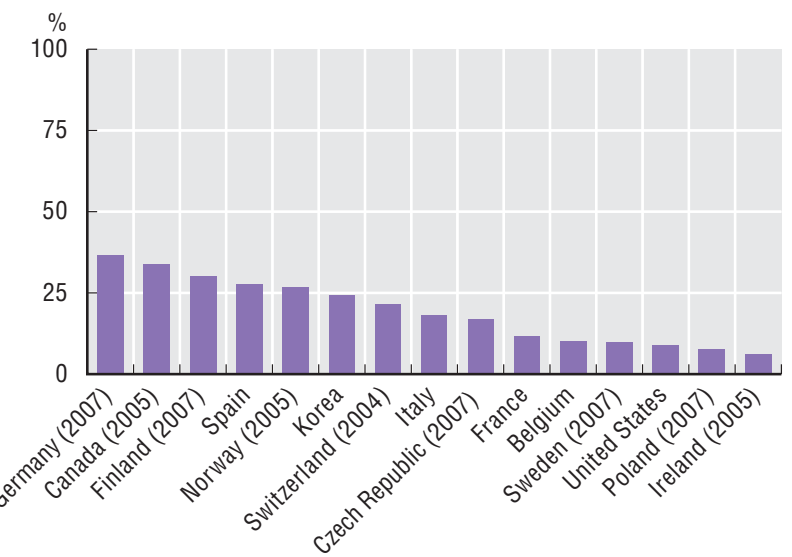

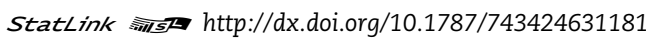




\section{TARGETING NEW GROWTH AREAS}

\subsection{Public-sector biotechnology R\&D}

Biotechnological techniques, materials and devices may - together with other technologies such as information technology, bioinformatics and nanotechnologies - transform the way a host of products are designed, manufactured and used. This may provide significant opportunities for sustainable growth in both developed and developing countries. It can also lead to far-reaching changes in economic activity and society and to some complex policy challenges.

Biotechnology R\&D can be performed in the public sector (government research institutes or higher education institutions), by the business sector, and by the private non-profit sector. Public-sector biotechnology $\mathrm{R} \& \mathrm{D}$ is defined as the sum of government and higher education biotechnology R\&D.

Public funding of biotechnology R\&D provides a measure of the importance governments place on biotechnology. In some countries, it is substantial.

Data on public expenditure on biotechnology R\&D are available for seven countries. Among these, Korea leads with USD 1446.8 million PPP, followed by Spain (USD 1022.8 million PPP) and Canada (USD 677.9 million PPP).

The share of biotechnology in all public R\&D expenditures is highest in Korea, at $18.7 \%$, followed by Spain (14.8\%), Norway (7.7\%) and Canada (6.7\%).

Data on public biotechnology R\&D as a share of total biotechnology R\&D expenditure are available for six countries. The share is highest in Poland, at $85 \%$, followed by Spain (67.8\%) and Korea (60.9\%).

\section{Public funding of biotechnology R\&D}

The two main types of government programmes to support biotechnology research are direct funding of research by the public sector and direct (research grants) and indirect (tax deductions for research expenditures) funding of research by the private sector. Government funding of public and private biotechnology research can be substantial. Indicators of public funding of biotechnology research include basic data on public R\&D spending on biotechnology and intermediate output measures of public biotechnology research, such as patenting by public research institutes and citations of public research papers.

The OECD is working on establishing guidelines for measuring public-sector biotechnology R\&D funding. Recommendations for collecting statistics on public R\&D funding were beyond the scope of the 2005 version of the Framework for Biotechnology Statistics. However, such statistics are seen as highly relevant to policy decisions and represent a future extension of the development of statistical standards.

\section{Source}

OECD (2009), “OECD Biotechnology Statistics 2009", OECD, Paris, www.oecd.org/dataoecd/4/23/42833898.pdf.

\section{Going further}

OECD (2005), "A Framework for Biotechnology Statistics", OECD, Paris, www.oecd.org/dataoecd/5/48/34935605.pdf. 
Biotechnology R\&D expenditures by the public sector, millions of USD PPP, 2006

Government and higher education biotechnology R\&D

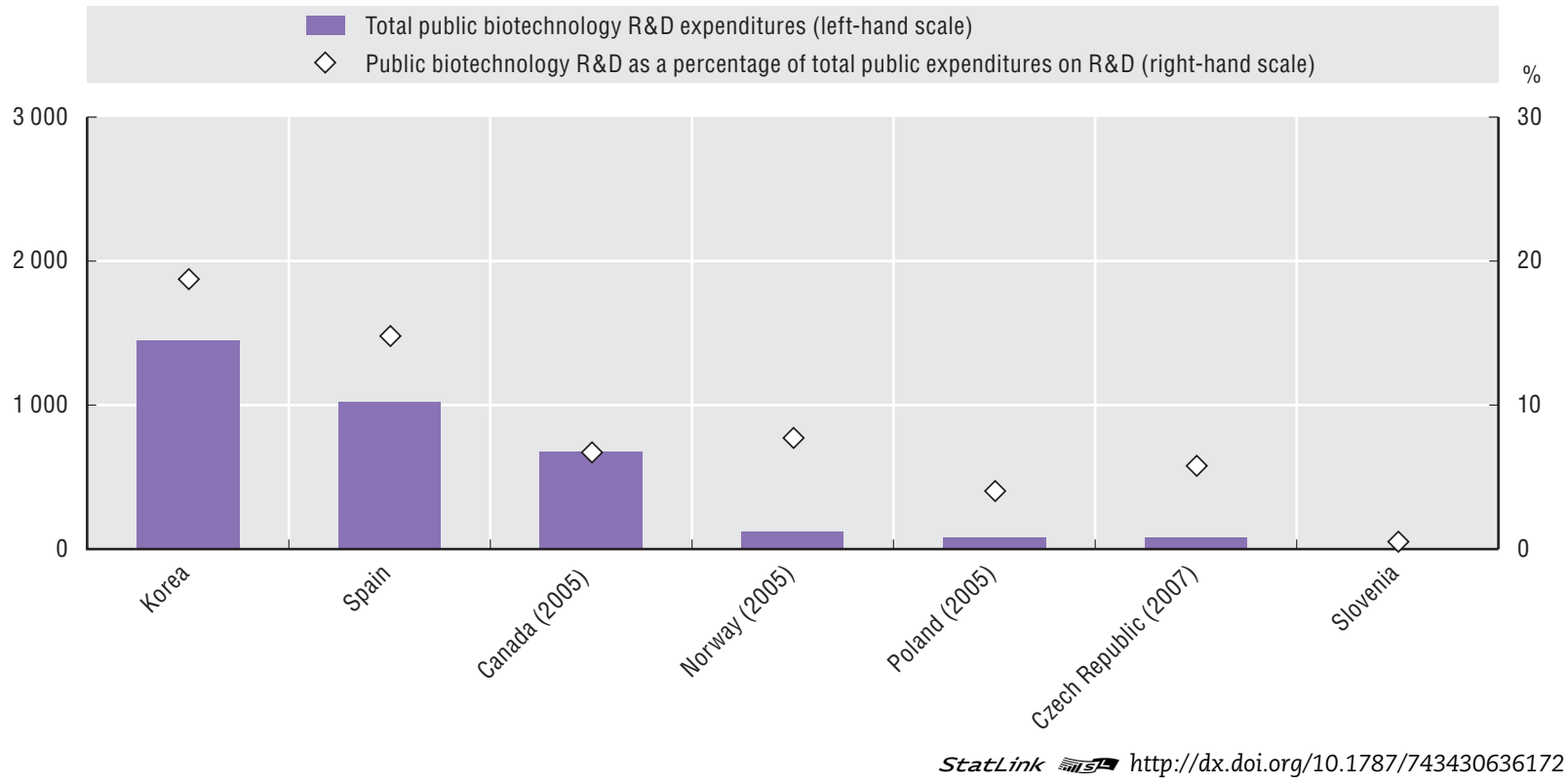

Public biotechnology R\&D expenditures, 2006

As a percentage of total expenditures on biotechnology $R \& D$

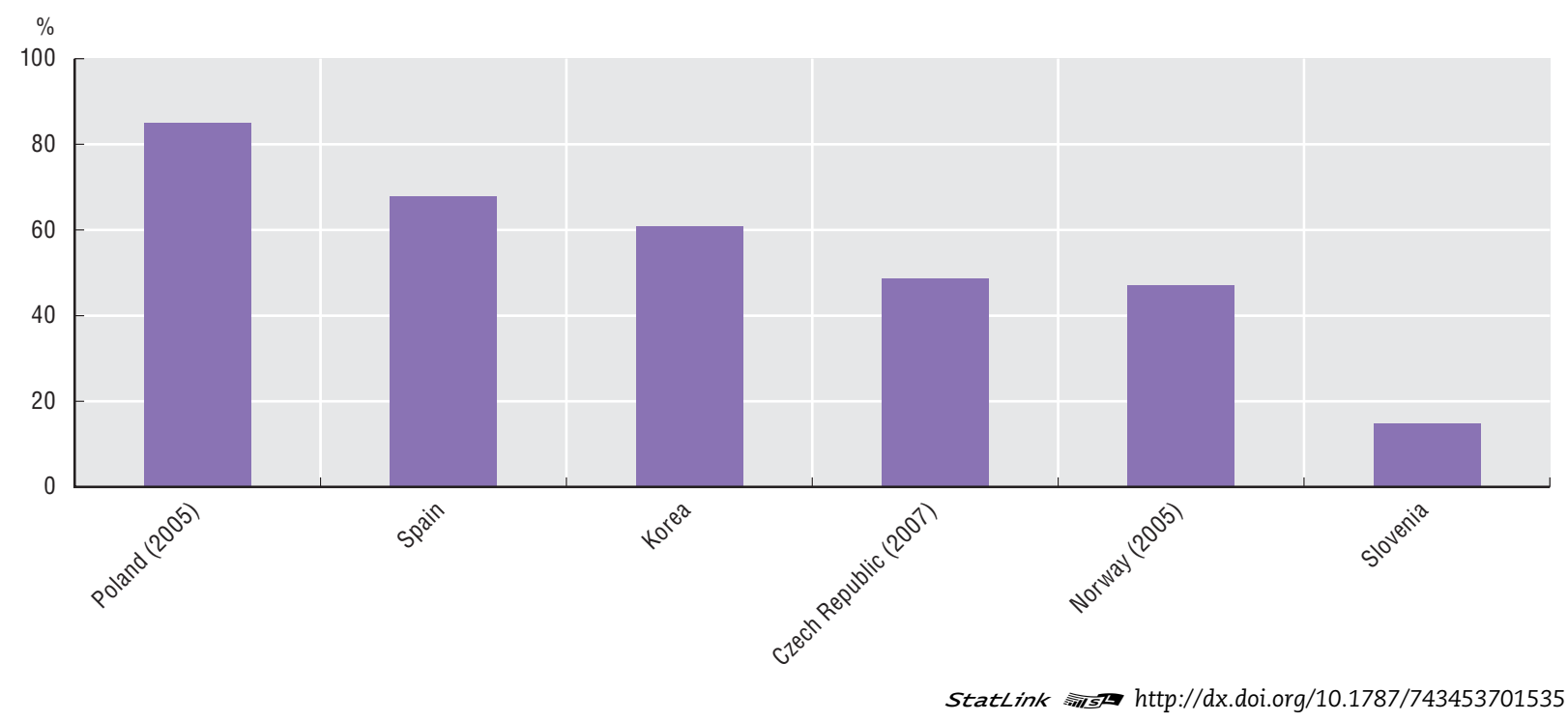




\section{TARGETING NEW GROWTH AREAS}

\subsection{Biotechnology patents}

Biotechnology and genetics research have received extensive investment from both the public and private sectors, with a growing impact on health care. Advances in medical genetics promise faster and better diagnosis as well as a new generation of targeted therapies.

After steady growth in the 1990s, the number of biotechnology patent applications filed under the Patent Co-operation Treaty (PCT) decreased from more than 11800 in 2000 to 9481 in 2006, at an average rate of $-3.6 \%$ a year between 2000 and 2006, compared to an increase of $20.4 \%$ over $1995-2000$. Conversely, the total number of PCT patent applications increased by an average of $6.5 \%$ a year over $2000-06$. As a result, the relative weight of biotechnology in all international patent filings decreased between the mid-1990s and the early 2000s in many countries. On average, biotechnology patents represented $6.7 \%$ of countries' patent portfolios over 2004-06, compared to $10.6 \%$ in the mid-1990s.

The surge in biotechnology patents in the late 1990s was partly due to patent applications pertaining to the human genome. The recent decrease raises concerns that more stringent criteria on the patenting of genetic inventions may discourage further research and reduce access to the benefits of the technology.

The United States accounted for $43.5 \%$ of all biotechnology PCT patent applications in 2006. Japan and Germany followed with shares of 11.6 and $6.7 \%$, respectively. Nearly $4 \%$ of all biotechnology patents were developed by inventors in the BRIICS countries (Brazil, Russian Federation, India, Indonesia, China, South Africa), notably China (1.9\%), India (0.9\%) and the Russian Federation (0.8\%).

Denmark remains the most active country in biotechnology patenting with $15.8 \%$ of biotechnology patents in total patents. This is more than twice the share of biotechnology patents in all patent applications between 2004 and 2006 for all countries combined. Belgium, Singapore and Canada also have a strong revealed technological advantage in biotechnology, with more than $10 \%$ of their patent portfolio dedicated to biotechnology.

\section{Biotechnology patents}

Biotechnology patents are identified using the International Patent Classification (IPC) system: one or several classification codes are attributed to the patent during the examination process. For emerging technologies, however, a specific category or class may not yet be part of the patent classification system, which means that some biotechnology patent applications may be missed.

The $8^{\text {th }}$ edition of the IPC is used to identify patents in the biotechnology sector. IPC classes selected include areas such as transgenic vertebrates, invertebrates and plants; methods, processes and testing; bioinformatics; biological materials, etc. These are: A01H1/00, A01H4/00, A61K38/00, A61K39/00, A61K48/00, C02F3/34, $\operatorname{Co7G}(11 / 00,13 / 00,15 / 00), \operatorname{Co7K}(4 / 00,14 / 00,16 / 00$, $17 / 00,19 / 00), C 12 \mathrm{M}, \mathrm{C} 12 \mathrm{~N}, \mathrm{C} 12 \mathrm{P}, \mathrm{C} 12 \mathrm{Q}, \mathrm{C} 12 \mathrm{~S}$, G01N27/327, G01N33/(53* 54* $55^{*}, 57^{*}, 68,74,76$, $78,88,92)$.

Source: The definition remains provisional; its coverage is being discussed in the framework of the OECD Working Party on Biotechnology. For further details on the IPC classes (IPC, 8th edition), www.wipo.int/classifications/ipc/ipc8/?lang=en.

\section{Source}

OECD, Patent Database, June 2009, www.oecd.org/sti/ipr-statistics.

\section{Going further}

OECD (2009), “OECD Biotechnology Statistics 2009", ww.oecd.org/dataoecd/4/23/42833898.pdf.

OECD (2009), OECD Patent Statistics Manual, OECD, Paris.

\section{Figure notes}

Data relate to patent applications filed under the PCT, at international phase, designating the European Patent Office (EPO). Patent counts are based on the priority date, the inventor's country of residence and fractional counts.

The revealed technological advantage indicator is calculated as the share of biotechnology in a country's patents relative to the share of biotechnology in total patents. Only countries with more than 250 patents during the periods are included in the figure. 


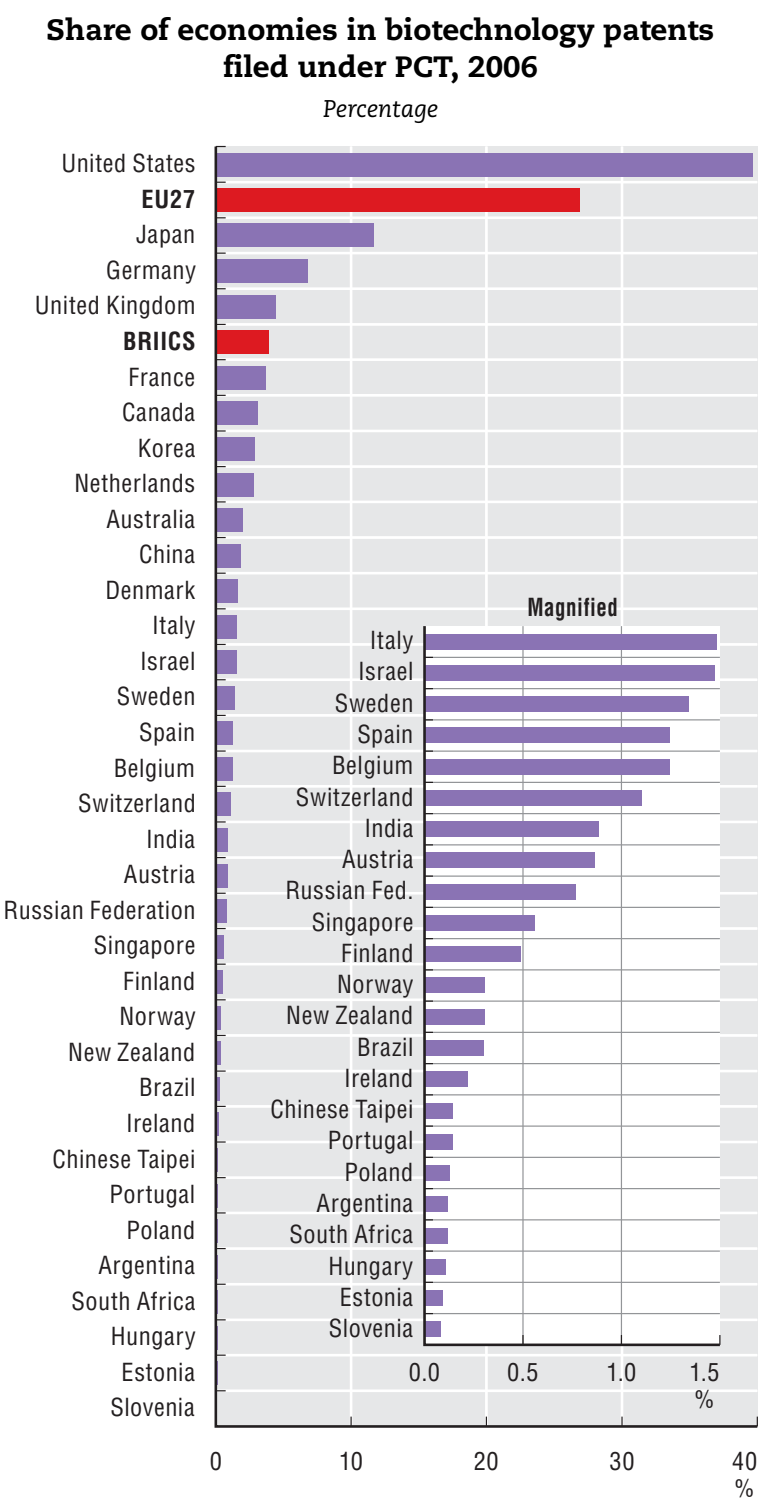

StatLink काज्ञ http://dx.doi.org/10.1787/743548442486

\section{Revealed technological advantage in biotechnology \\ PCT patent applications}

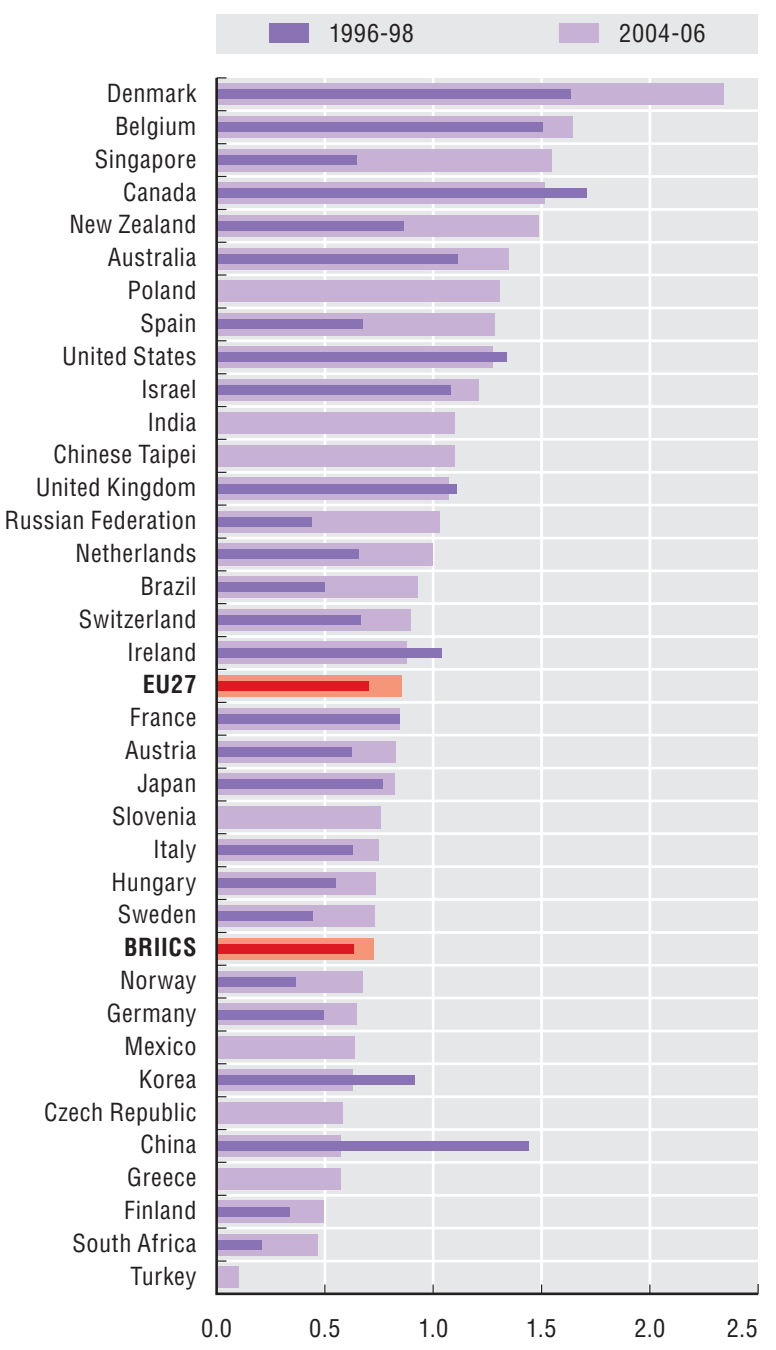

StatLink कीजस http://dx.doi.org/10.1787/743558060332 
Recent advances in biosciences can help achieve a wide range of economic and social objectives, improving health, the environment, and industrial, agricultural and energy production. Core scientific articles identify the most influential contributions to research. Citations to core articles in biosciences provide a measure of research activity in this field.

Bioscience covers a wide variety of scientific fields. Among them, four are increasingly multidisciplinary: brain research, genomics, regenerative medicine and plant science research.

Research activities show a clear orientation towards biosciences in a minority of OECD countries. Eight report a share of citations above the world average in brain research, genomics or regenerative medicine and eleven in plant science research.

The United States and Switzerland have the largest relative share in all four research areas. The United Kingdom ranks third in brain research and genomics, the Netherlands in regenerative medicine, and Denmark in plant science research.

In China, Italy, Japan and Spain the share of citations to biosciences is below the world average in all four areas.

\section{Research in biosciences}

Clusters of articles with similar research subjects were identified via co-citation analysis. Cocitation is a form of citation in which a set of articles is simultaneously cited by other articles. A total of 64958 highly cited articles, i.e. the top $1 \%$ of cited articles in the database from 2001 to 2006 , were clustered on the basis of co-citation relationship. The co-citation analysis identifies four areas of biosciences in which there has been active research in recent years: brain research, genomics, regenerative medicine and plant science research.

Brain research has a long history and is particularly active these days, with diverse research methods. A typical example of brain research is functional neuro-imaging, which measures different aspects of brain function.
Genomics refers to the study of the genomes of organisms. Intense efforts are made to determine the entire DNA sequence of organisms and to carry out genetic mapping at a fine scale. Genomics is developing stronger ties with fields such as chemistry, physics, computer science, mathematics and clinical medicine.

Regenerative medicine using stem cells is attracting attention in a broad research community. Research activities in this area are expected to progress in directions beyond regenerative medicine, such as the development of new pharmaceuticals.

Plant science research is opening up new possibilities through its convergence with traditional sciences, such as agronomics, and new research fields, such as biosciences.

\section{Source}

OECD calculations, based on Scopus Custom Data, Elsevier, July 2009.

\section{Going further}

Igami, M. and A. Saka (2007), "Capturing the Evolving Nature of Science, the Development of New Scientific Indicators and the Mapping of Science", OECD Science, Technology and Industry Working Papers 2007/1, OECD, Paris, www.oecd.org/sti/working-papers.

\section{Figure notes}

The average annual growth rate of the number of citations to core articles is based on the year of publication of the citing articles.

Calculation of a country's share is based on the address of the institution to which the authors belong, and fractional counts.

Only countries with a share of core articles over $1 \%$ are included.

A country's relative share in core articles is calculated by dividing the country's share in core articles by the country's share in all articles in all scientific fields. 
Trends in core articles in biosciences, 2002-07

Average annual growth rate in the number of citations to core articles

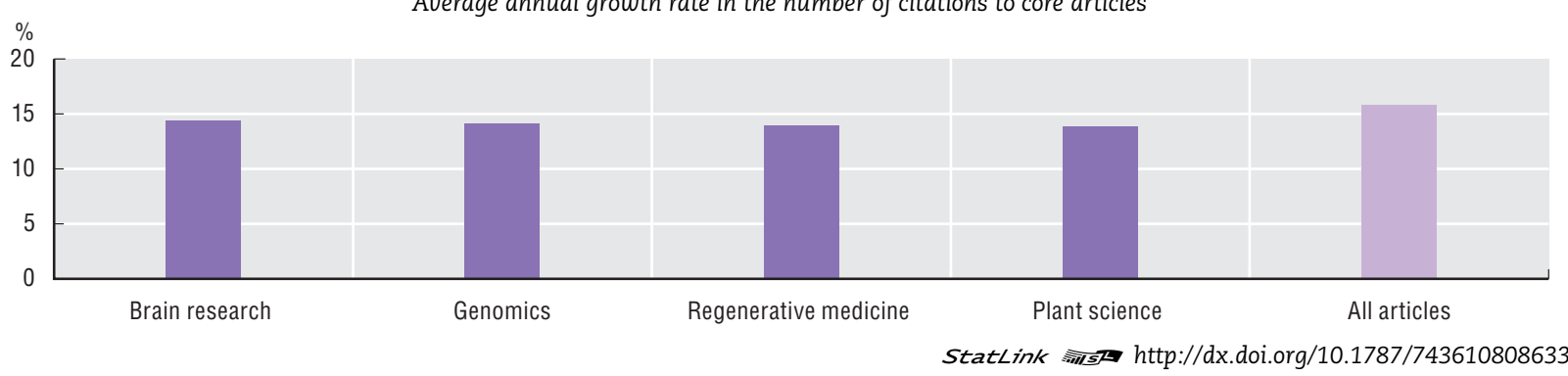

Countries' relative share in core articles in genomics, 2001-06

Ratio of the country's share in core articles to its share in all fields

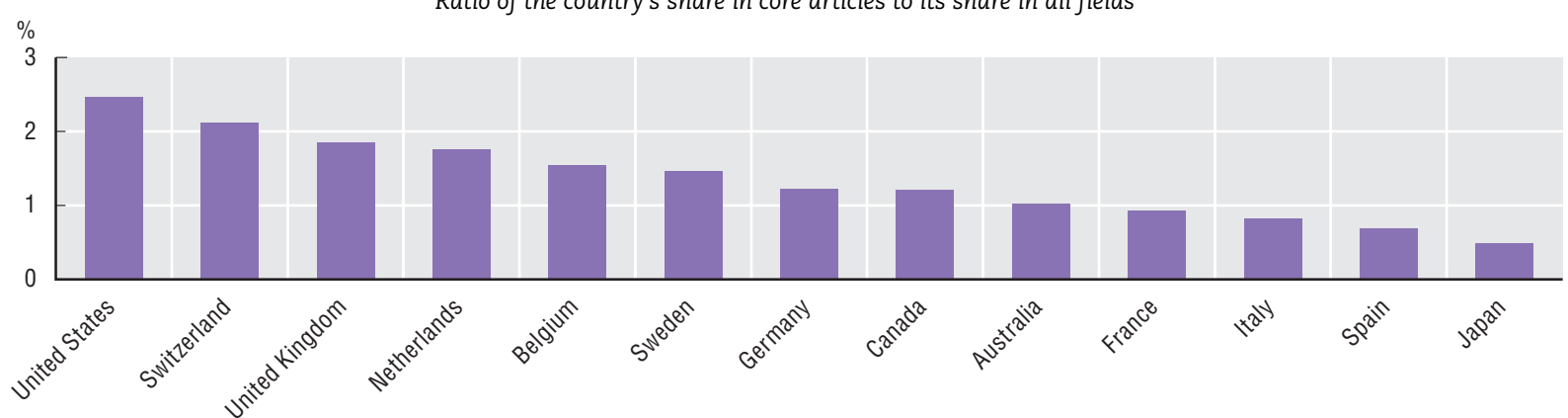

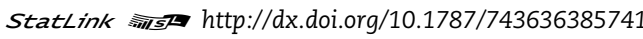

Countries' relative share in core articles in regenerative medicine, 2001-06

Ratio of the country's share in core articles to its share in all fields

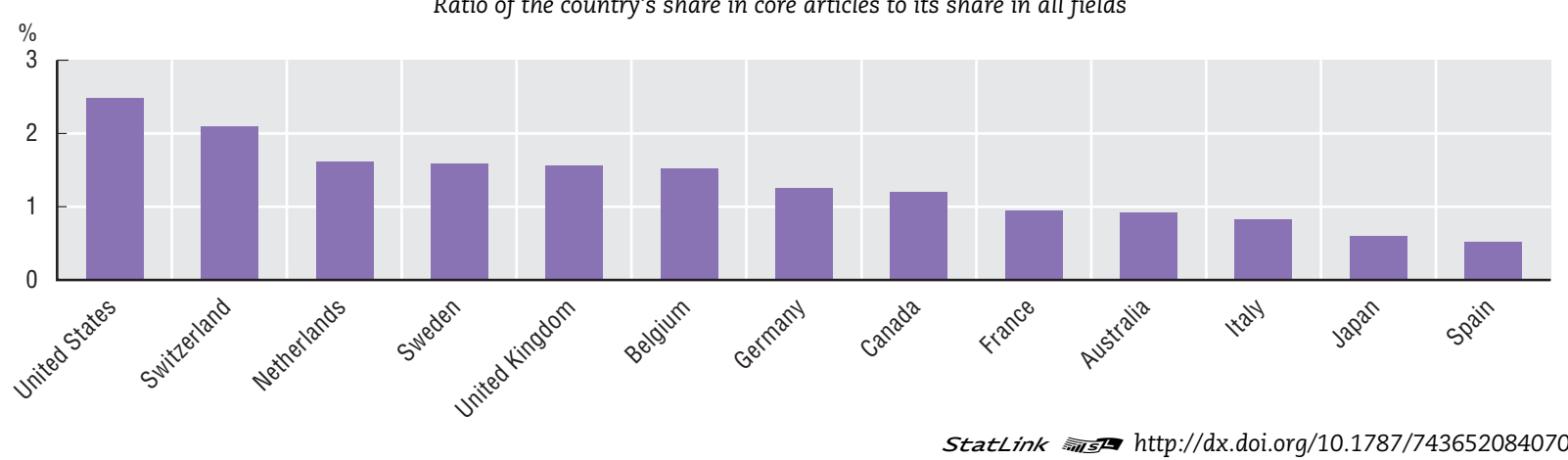

Countries' relative share in core articles in plant science research, 2001-06

Ratio of the country's share in core articles to its share in all fields

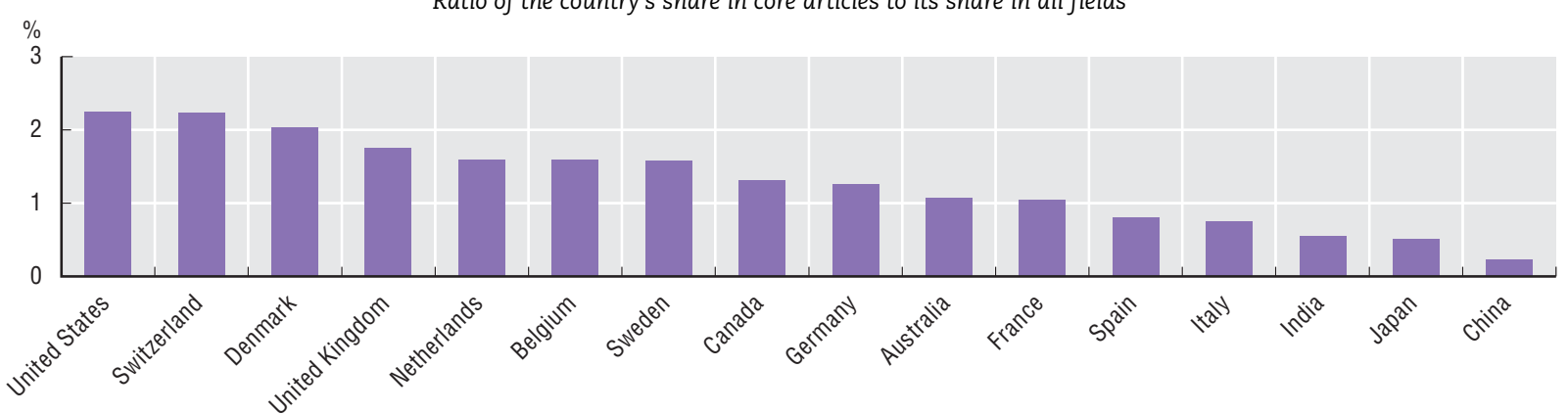




\section{TARGETING NEW GROWTH AREAS}

\subsection{Nanotechnology patents}

Nanotechnology - the science of the very small - is likely to have a major economic and social impact in the years ahead. It may help further miniaturise information technology devices, resolve fundamental questions related to the immune system, accelerate advances in genomics and contribute to the generation of renewable energy.

Inventive activities in nanotechnology have risen substantially since the end of the 1990 s. At $16.5 \%$, the average annual growth rate in nanotechnology patents filed under the Patent Co-operation Treaty (PCT) surpassed that of overall PCT patents (11\%) between 1996 and 2006. Most countries report a significant increase in their shares of nanotechnology in total national patenting since the late 1990s, although activity remains relatively limited (1.1\% of total patents on average). Singapore is the country most specialised in nanotechnology with respect to relative patenting activity: its proportion of nanotechnology patents is nearly three times the average share of nanotechnology patents in all patents over 2004-06.

During the same period, more than two-thirds of nanotechnology patents originated from the United States (43\%), Japan (17\%) and Germany (10\%). Korea has also broadly invested in nanotechnology and ranks fourth in producing nanotechnology patents (3.7\%).

\section{Nanotechnology patents}

Reflecting the increasing interest and importance of nanotechnology in patents, the United States Patent and Trademark Office (USPTO), the European Patent Office (EPO), and the Japan Patent Office (JPO), have made intense efforts to improve their respective classification systems and collect all nanotechnology-related patents in a single patent class. Nanotechnology patents presented in this section were identified via the EPO using the following definition:

"The term nanotechnology covers entities with a controlled geometrical size of at least one functional component below $100 \mathrm{~nm}$ in one or more dimensions susceptible to make physical, chemical or biological effects available which are intrinsic to that size. It covers equipment and methods for controlled analysis, manipulation, processing, fabrication or measurement with a precision below $100 \mathrm{~nm}$."

Identification of nanotechnology patents is a complex task. A nanotechnology working group (NTWG) was created by the EPO in 2003. At first, it worked on the definition of nanotechnology in order to follow trends in nanotechnology patents. Then it identified nanotechnology patents through keyword searches, consultations with nanotechnology experts in the EPO, and peer reviews by external experts. Patent applications from 15 countries or organisations were analysed. As a consequence of these endeavours, about 90000 out of 20 million patent or non-patent literature documents were tagged to class Y01N.

Nanotechnology patent applications were further categorised into six fields of application by the OECD, i.e. "Electronics", "Optoelectronics", "Medicine and biotechnology", "Measurements and manufacturing", "Environment and energy", and "Nanomaterials", based on the International Patent Classification (IPC).

\section{Source}

OECD Patent Database, June 2009, www.oecd.org/sti/ipr-statistics.

\section{Going further}

Igami, M. and T. Okazaki (2007), "Capturing Nanotechnology's Current State of Development via Analysis of Patents", OECD Science, Technology and Industry Working Papers 2007/4, OECD, Paris,

www.oecd.org/sti/working-papers.

OECD (2009), OECD Patent Statistics Manual, OECD, Paris.

Scheu, M., et al. (2006), "Mapping Nanotechnology Patents: The EPO Approach", World Patent Information 28, pp. 204-211.

\section{Figure notes}

Data relate to patent applications filed under the PCT, at international phase, designating the European Patent Office. Patent counts are based on the priority date, the inventor's country of residence and fractional counts. BRIICS refers to Brazil, the Russian Federation, India, Indonesia, China and South Africa.

The revealed technological advantage indicator is calculated as the share of nanotechnology in a country's patents relative to share of nanotechnology in total patents. Only countries with more than 250 patents during the periods are included in the figure. 


\section{TARGETING NEW GROWTH AREAS}

\subsection{Nanotechnology patents}

\section{Share of economies in nanotechnology patents filed under PCT, 2004-06}

Percentage

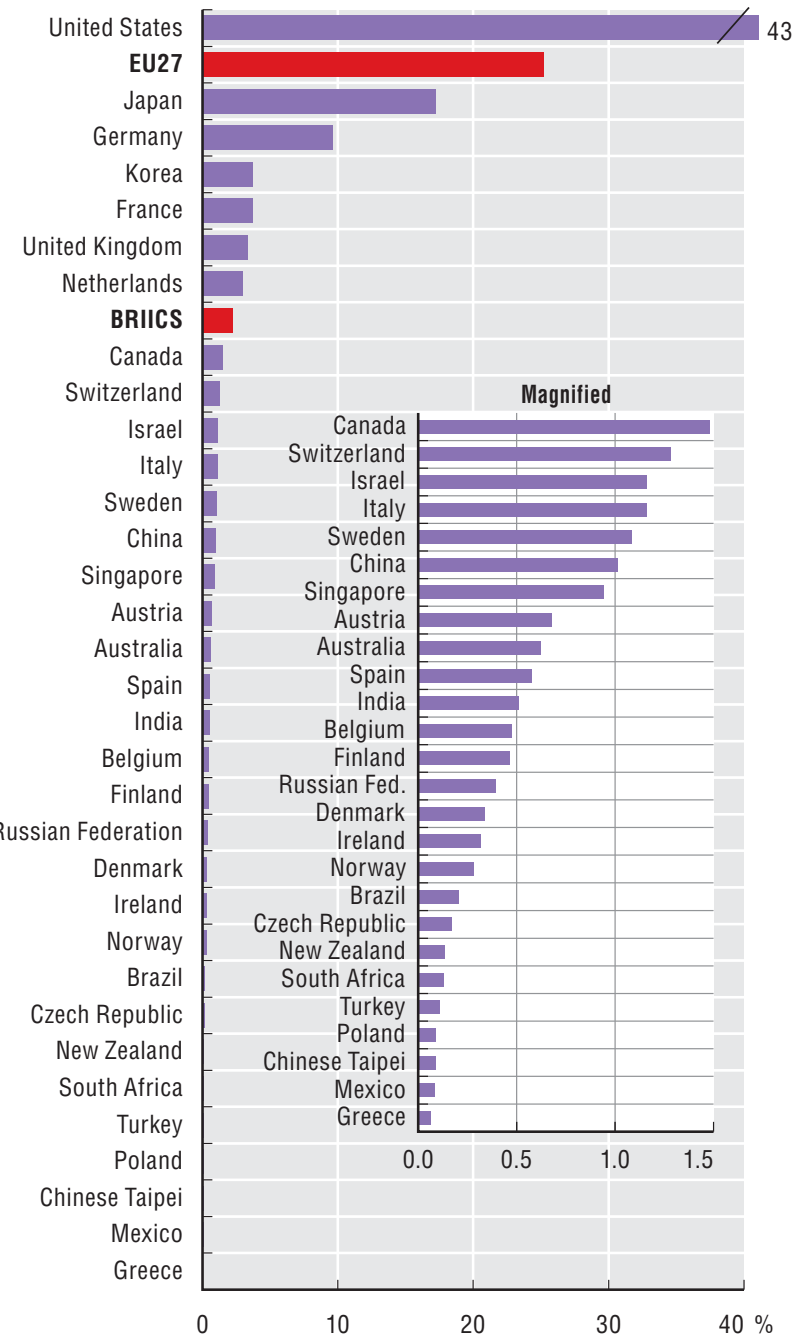

StatLink काजि http://dx.doi.org/10.1787/743710614871

\section{Revealed technological advantage in nanotechnology}

PCT patent applications

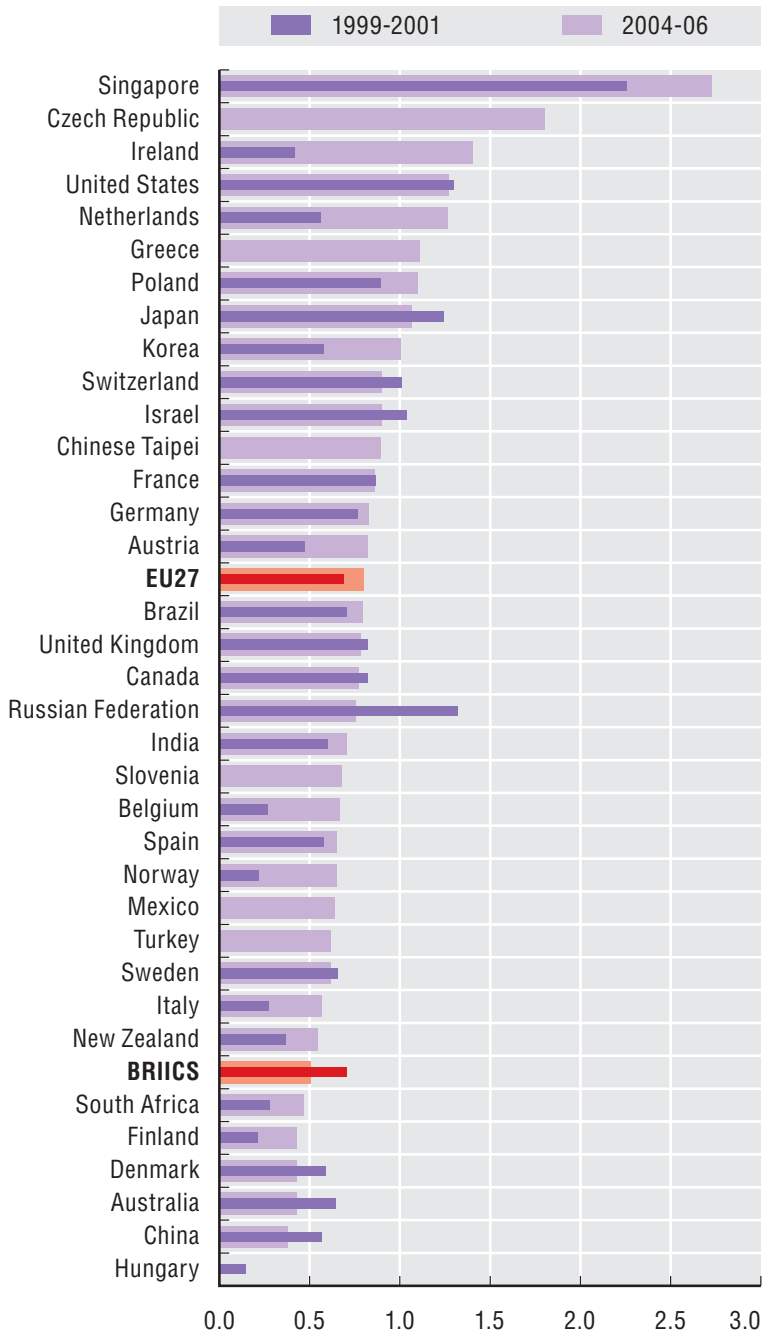

StatLink ants http://dx.doi.org/10.1787/743727147336

\section{Trends in nanotechnology patents by field of application}

World total

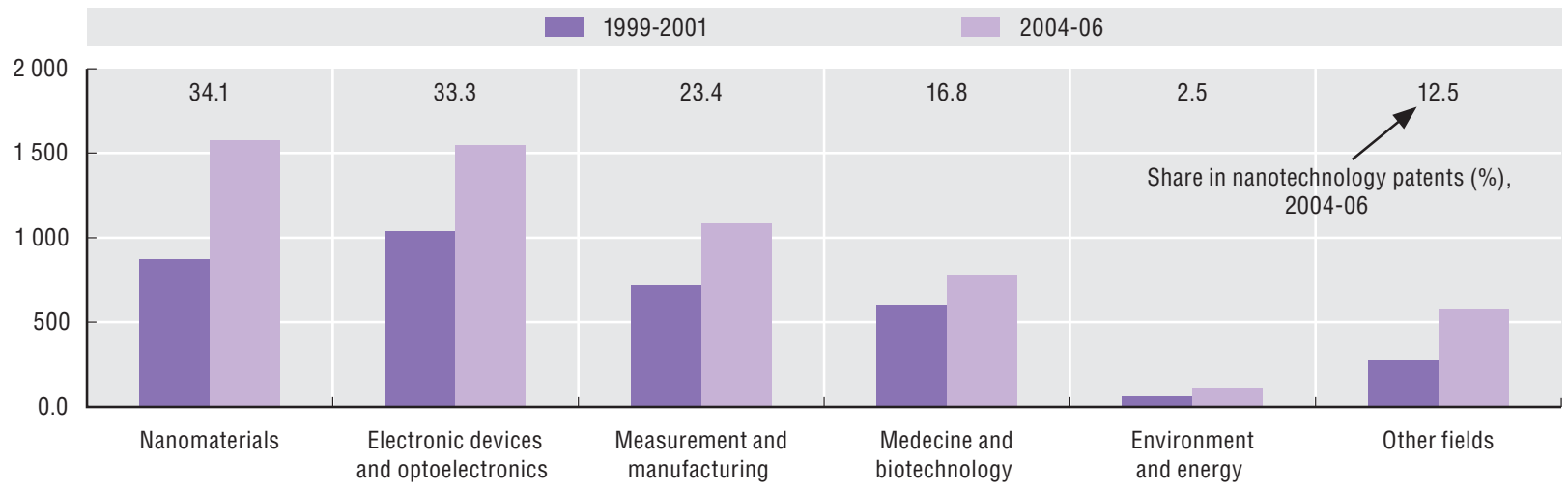

StatLink काज़ http://dx.doi.org/10.1787/743854706424 
Nanosciences can help achieve a wide range of economic and social objectives, from solving fundamental questions related to the immune system, to accelerating advances in genomics and contributing to the generation of renewable energy. Core scientific articles identify the most influential contributions to research. Citations to core articles in nanosciences provide a measure of research activity in this field.

Nanosciences include three main research areas: chemical synthesis, superconductivity and quantum computing, and nano materials and devices. The number of citations to core articles in nano materials and devices (25.0\%) and superconductivity and quantum computing $(17.8 \%)$ has increased more rapidly than the total number of citations (15.8\%) between 2002 and 2007. Citations to core articles in chemical synthesis have been growing at a slightly slower rate (15.2\%). These trends show the increasing influence of research in nanosciences in recent years.

Research activities show a clear specialisation in nanosciences in a minority of OECD countries. Seven countries report a share of citations above the world average in chemical synthesis, eight in superconductivity and quantum computing, and eight in nano materials and devices.

Singapore has the largest relative share in all three areas, particularly in nano materials and devices, and Switzerland ranks second. The United States ranks third in chemical synthesis and nano materials and devices and Germany in superconductivity and quantum computing. This indicates that the last two countries have not only a relative advantage but also a substantial influence in nanoscience, as they are the largest producers of scientific articles.

In China, India, Italy and Spain, the share of citations to nanosciences is below the world average in all three areas.

\section{Research in nanosciences}

Clusters of articles with similar research subjects were identified via co-citation analysis. Co-citation is a form of citation in which a set of articles is simultaneously cited by other articles. A total of 64958 highly cited articles, i.e. the top $1 \%$ of cited articles in the database from 2001 to 2006, were clustered on the basis of co-citation relationship.

Nanoscience is a new field, and it has as yet no established definition. The co-citation analysis identifies three main areas in which there has been active research in recent years: chemical synthesis, superconductivity and quantum computing, and nano materials and devices.

Of these three areas, chemical synthesis has a long history in chemistry, which still has a vast unexplored field. Superconductivity and quantum computing is an area that combines concrete application and the study of basic laws of physics, and it is attracting the attention of many researchers. Nano materials and devices have possibilities of wide-range application and are the focus of strategic research in many countries.

\section{Source}

OECD calculations, based on Scopus Custom Data, Elsevier, July 2009.

\section{Going further}

Igami, M. and A. Saka (2007), "Capturing the Evolving Nature of Science, the Development of New Scientific Indicators and the Mapping of Science", OECD Science, Technology and Industry Working Papers 2007/1, OECD, Paris, www.oecd.org/sti/working-papers.

\section{Figure notes}

The average annual growth rate of the number of citations to core articles is based on the year of publication of the citing articles.

Calculation of a country's share is based on the address of the institution to which the authors belong and fractional counts.

Only countries with a share of core articles over $1 \%$ are included.

A country's relative share in core articles is calculated by dividing the country's share in core articles by the country's share in all articles in all scientific fields. 
Trends in core articles in selected nanoscience, 2002-07

Average annual growth rate in citations to core articles

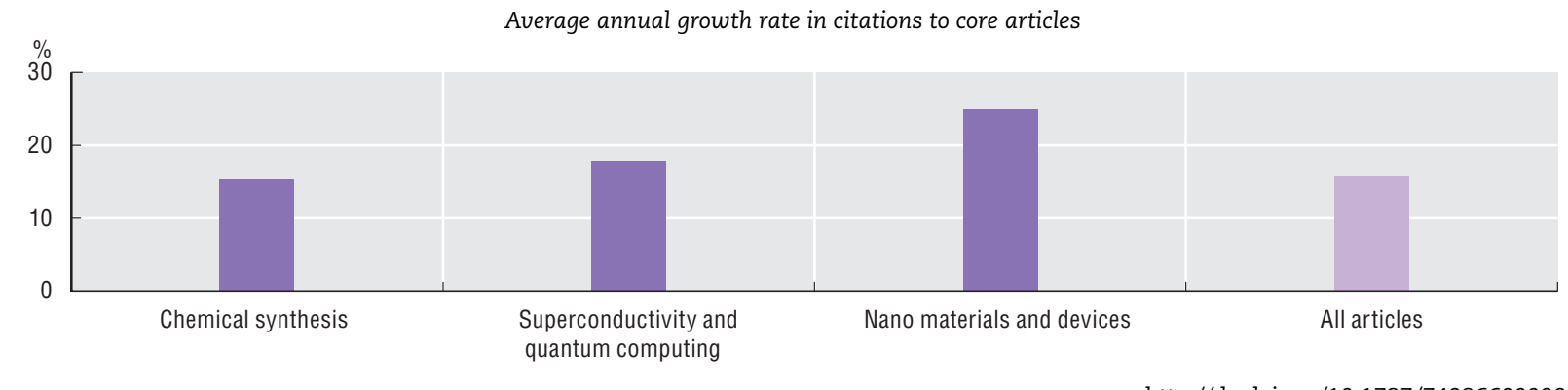

StatLink काजस http://dx.doi.org/10.1787/743866000335

Countries' relative share in core articles in chemical synthesis, 2001-06

Ratio of the country's share in core articles to its share in all fields

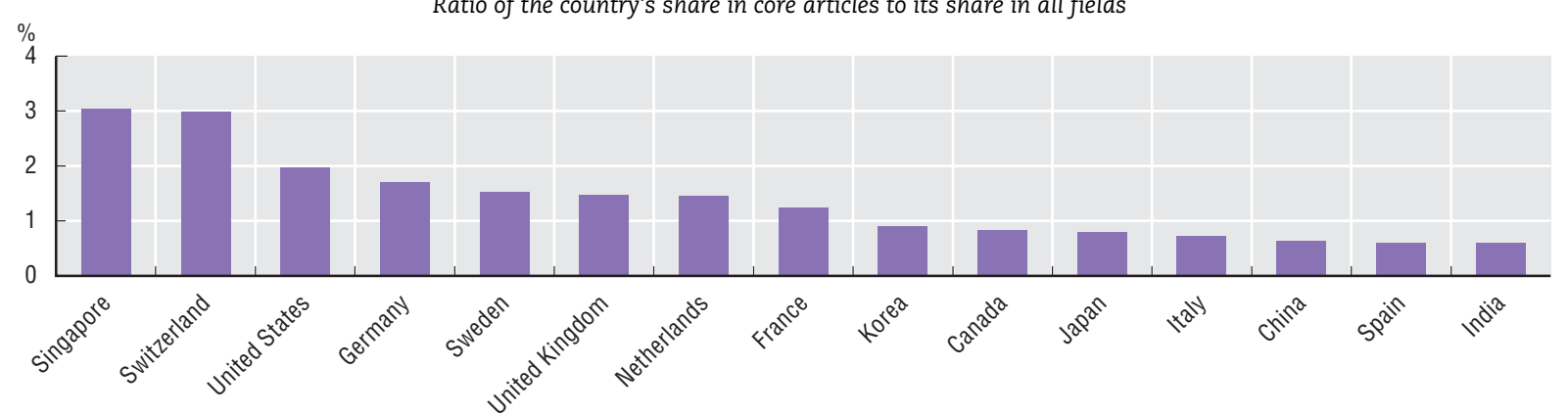

StatLink क्ञाज http://dx.doi.org/10.1787/743886181846

Countries' relative share in core articles in superconductivity and quantum computing, 2001-06

Ratio of the country's share in core articles to its share in all fields

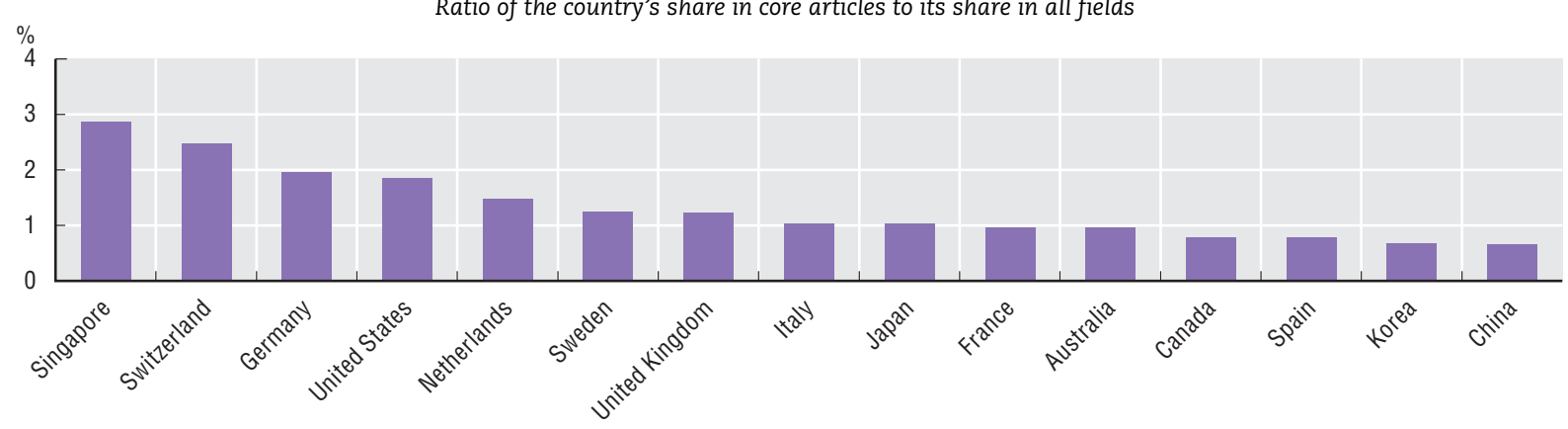

StatLink काIst http://dx.doi.org/10.1787/744032055334

Countries' relative share in core articles in nano materials and devices, 2001-06

Ratio of the country's share in core articles to its share in all fields

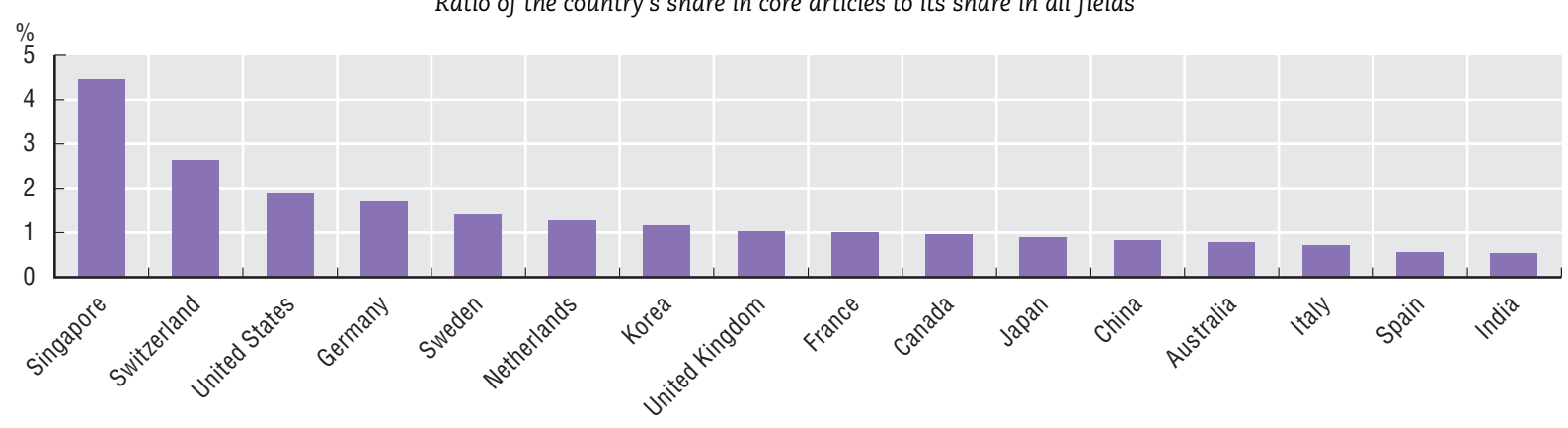

StatLink काISL http://dx.doi.org/10.1787/744114222585 


\section{TARGETING NEW GROWTH AREAS}

\subsection{Government R\&D budgets}

Public policy can play an important role in orienting innovation efforts towards the solution of global challenges. Government R\&D budgets (GBAORD) provide an indication of the relative importance of various socioeconomic objectives, such as defence, health and the environment, in public R\&D spending.

Government R\&D budgets as a share of gross domestic product (GDP) are the largest in Spain, Portugal and the United States. In the United States defence accounts for $57 \%$ of total government R\&D budget in 2008. France comes second with almost 30\%, followed by the United Kingdom with $24 \%$. Sweden and Spain also have significant defence R\&D budgets (more than 10\% of GBAORD), although their relative share has declined slightly in recent years.

Together with Portugal and Spain, Finland, Denmark and Iceland have the largest government $R \& D$ budgets for civil programmes as a share of GDP in 2008.

In many countries, GBAORD has not increased in line with GDP. In the OECD area Spain is currently the leader in terms of GBAORD as a share of GDP, at $1.08 \%$ in 2007. The United States and Portugal are the only other OECD countries where the share exceeds $1 \%$. Iceland has seen a significant drop in the ratio of GBAORD to GDP in the last few years (from 1.4\% in 2005 to $0.9 \%$ in 2008), mainly owing to strong growth in GDP.

In the OECD area between 2000 and 2006, government R\&D budgets grew on average by $3.8 \%$ a year (in real terms). In Luxembourg the R\&D budget grew by more than $20 \%$ a year between 2000 and 2007. Spain and Ireland have both had growth rates exceeding 10\% a year since 1998. France is the only OECD country whose government R\&D budget decreased in real terms in the last decade, by around $0.4 \%$ a year. Growth of GBAORD has been modest in the EU27 region, averaging $2.4 \%$ a year since 1998 , compared to $2.9 \%$ in Japan and $4.2 \%$ in the United States.

\section{GBAORD}

GBAORD (government budget appropriations or outlays for R\&D) measures the funds committed by the federal/central government for R\&D to be carried out in one of the four sectors of performance business enterprise, government, higher education, private non-profit - at home or abroad (including by international organisations). The data are usually based on budgetary sources and reflect the views of the funding agencies. They are generally considered less internationally comparable than the performer-reported data used in other tables and graphs but have the advantage of being more timely and reflecting current government priorities, as expressed in the breakdown by socioeconomic objectives.

A first distinction can be made between defence programmes, which are concentrated in a small number of countries, and civil programmes, which can be broken down as follows:

- Economic development: agriculture, fishery, forestry; industry; energy; and infrastructure and general planning of land use.

- Health and environment: protection and improvement of human health, control and care of the environment, exploration and exploitation of the Earth.

- Education and society: education; culture, recreation, religion and mass media; and political and social systems, structure and processes.

- Exploration and exploitation of space.

- Non-oriented research.

- Research financed from general university funds (GUF): the estimated R\&D content of block grants to universities.

It should be noted that the series for Japan excludes the R\&D content of military procurement. In the United States, general support for universities is the responsibility of state governments and therefore GUF is not included in total GBAORD.

\section{Sources}

OECD, Main Science and Technology Indicators Database, June 2009.

OECD, R\&D Database, June 2009.

\section{Going further}

OECD (2002), Frascati Manual: Proposed Standard Practice for Surveys on Research and Experimental Development, OECD, Paris, www.oecd.org/sti/frascatimanual. 


\section{TARGETING NEW GROWTH AREAS}

\subsection{Government R\&D budgets}

Defence and civil R\&D budgets, 2008

GBAORD as a percentage of GDP

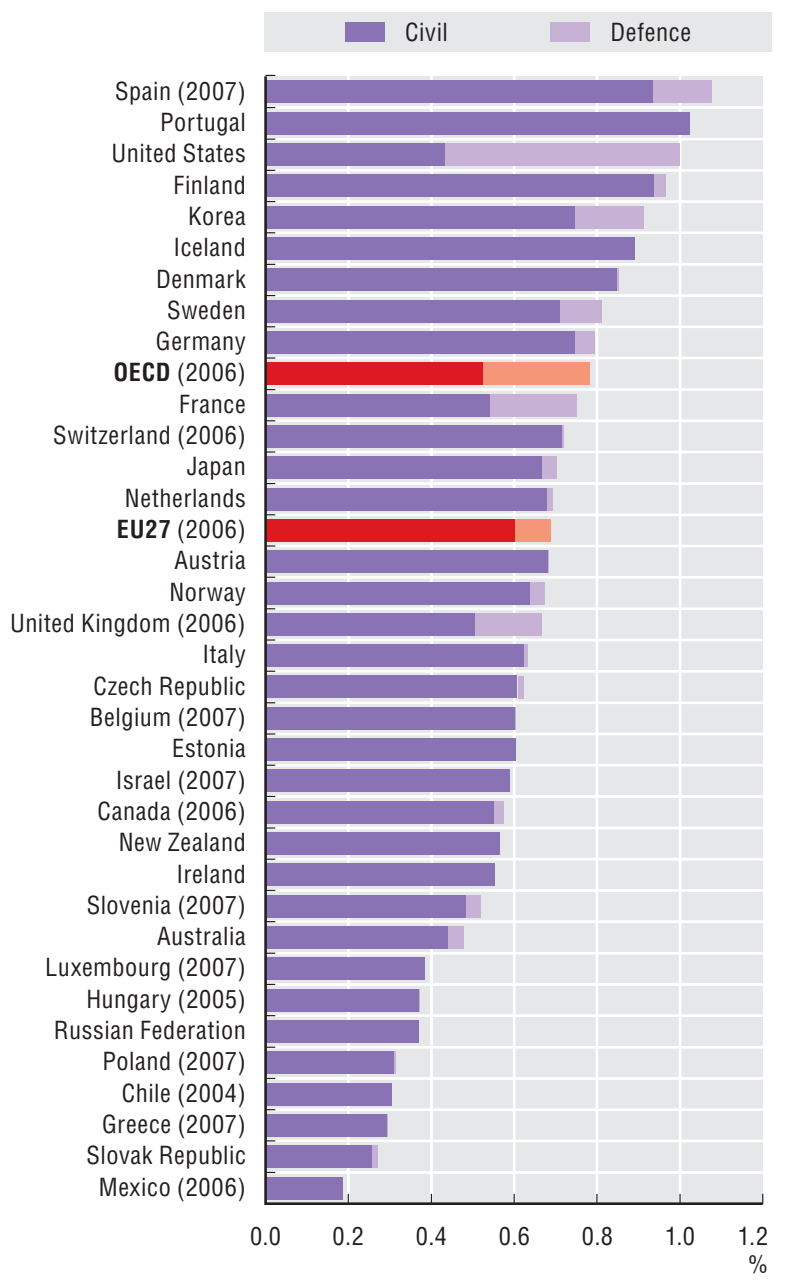

StatLink काज़ http://dx.doi.org/10.1787/744138547871

\section{Change in government R\&D budgets, 1998-2008}

Average annual real growth rate

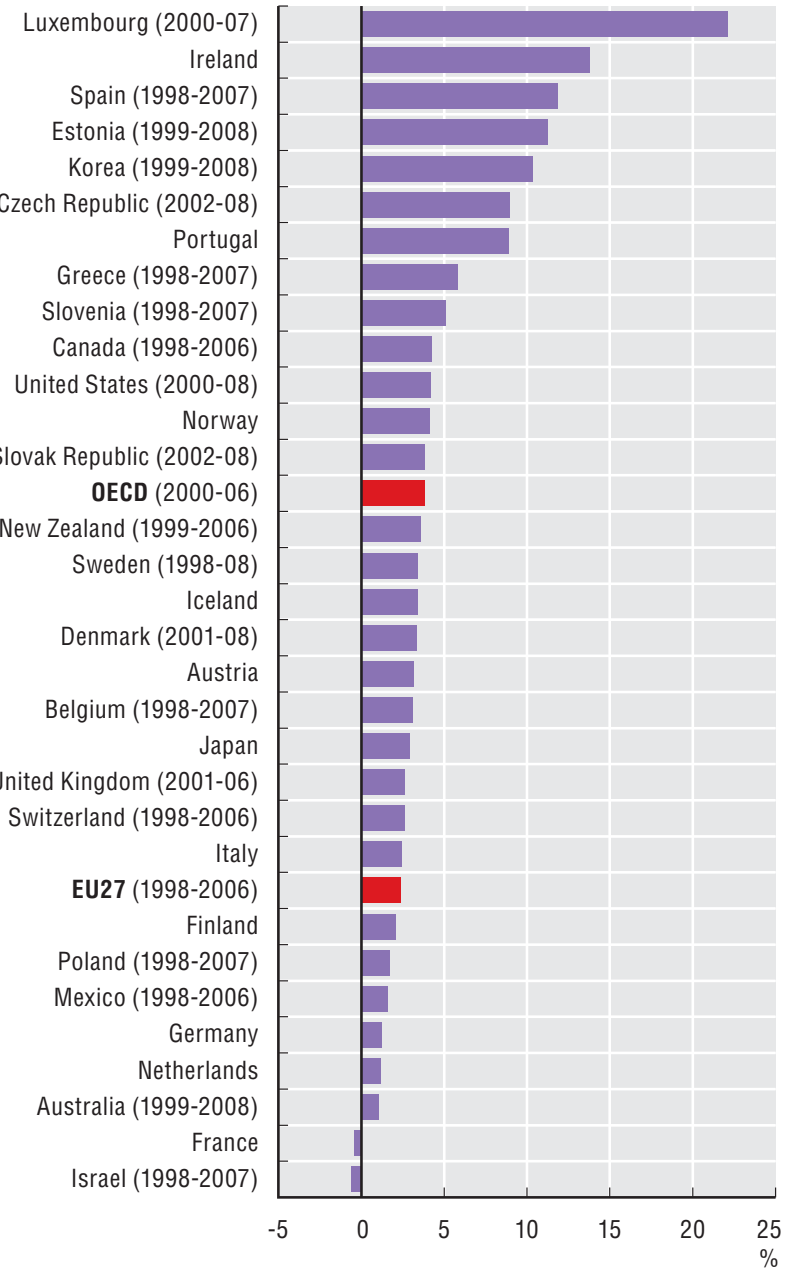

StatLink 에sस http://dx.doi.org/10.1787/744138670205 
Public and business research are complementary inputs for innovation. Research in the business sector is closely linked to the creation of new products and production techniques, but public research is important for funding and performing basic research that does not lead immediately to commercial returns. Public research also supports business sector research via knowledge spillovers.

Direct financial flows between government and the business enterprise sector for R\&D are one way to track interactions between government and industry in science and innovation. On average, around $7 \%$ of research and development (R\&D) performed in the business sector is financed by direct government funds. The share has tended to decrease in almost all countries in recent years. It is still high in the Russian Federation (55\%) but is less than $15 \%$ in all OECD countries. This pattern is consistent with the increasing adoption of other policy instruments to stimulate innovation, such as R\&D tax incentives.

Likewise, business funds an important share of the R\&D performed in the higher education and government sectors, with an OECD area average of 5.3\% in 2006. This share has tended to increase in around half of all OECD countries: in the EU27, companies financed $7.4 \%$ of all R\&D performed in public institutions and universities, compared to only $3.2 \%$ in the United States and $2.2 \%$ in Japan. Ireland, Mexico and Portugal have the smallest shares of business-funded R\&D performed in the higher education and government sectors.

Over the last decade, the share of business-funded R\&D in the higher education and government sectors increased significantly in Germany, Hungary, Israel and the Russian Federation. The opposite trend is evident in Ireland, Mexico, Slovenia and South Africa. Despite increases in many countries, business still funds less than $8 \%$ of $R \& D$ performed in public institutions and universities in most large OECD economies.

High values for both indicators in the Russian Federation and Poland suggest strong ties between the private and public sectors in terms of direct cross-funding of $R \& D$ activities. In contrast, the values for both are very low for Japan and Denmark.

\section{R\&D performance in government and higher education}

Measures of R\&D performance in the higher education sector are often based on estimates by national authorities and evaluation methods are periodically revised. Moreover, certain national characteristics may strongly influence $R \& D$ performance by the government and higher education sectors.
US figures for these sectors are underestimated. Government-sector R\&D covers only federal government activities, not those of individual state and local governments; and since 1985 figures for researchers exclude military personnel in the government sector. In the higher education sector, R\&D in the humanities is not included, and since 1991 capital expenditures have been excluded.

In Korea, the higher education sector is probably greatly underestimated until 2007 owing to the exclusion of $R \& D$ in the social sciences and humanities.

Certain transfers of public agencies to private enterprise, as in the case of the privatisation of Swisscom (Switzerland) in 1998, and the partial privatisation of the Defence Evaluation and Research Agency (DERA) in the United Kingdom in 2001, have had the effect of reducing $R \& D$ performed in the government sector and increasing it in the business enterprise sector.

Conversely, for the United States, in 2005 following a survey of the federally funded research and development centres (FFRDCs), it was determined that FFRDC R\&D belongs in the government sector rather than in the sector of the FFRDC administrator as previously reported. This R\&D expenditure was therefore reclassified from the other three performing sectors to the government sector and data were revised historically.

\section{Source}

OECD, R\&D Database, June 2009.

\section{Going further}

OECD (2002), Frascati Manual: Proposed Standard Practice for Surveys on Research and Experimental Development, OECD, Paris, www.oecd.org/sti/frascatimanual.

\section{Figure notes}

Government-financed R\&D in business: Austria and Estonia 1998; Switzerland, Luxembourg and China 2000; South Africa 2001.

Business-funded R\&D in the higher education and government sectors: Australia, Austria and Switzerland 1998; Luxembourg and China 2000; and South Africa 2001. For Luxembourg: government sector only. For Switzerland: higher education sector only. 


\section{TARGETING NEW GROWTH AREAS}

\subsection{Public-private cross-funding of R\&D}

\section{Government-financed R\&D in business, 2007}

As a percentage of $R \& D$ performed in the business sector

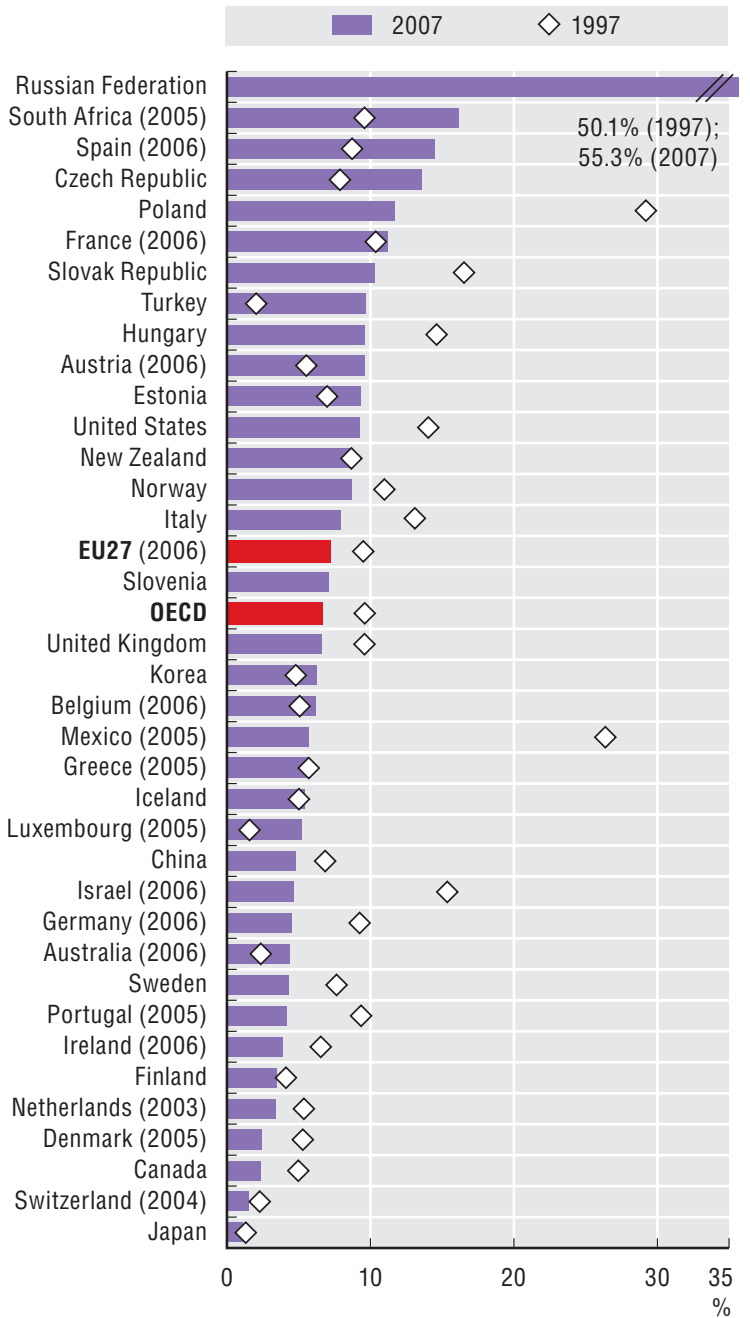

StatLink AाIsय http://dx.doi.org/10.1787/744175470435

\section{Business-funded R\&D in the higher education and government sectors, 2007}

As a percentage of $R \& D$ performed in these sectors (combined)

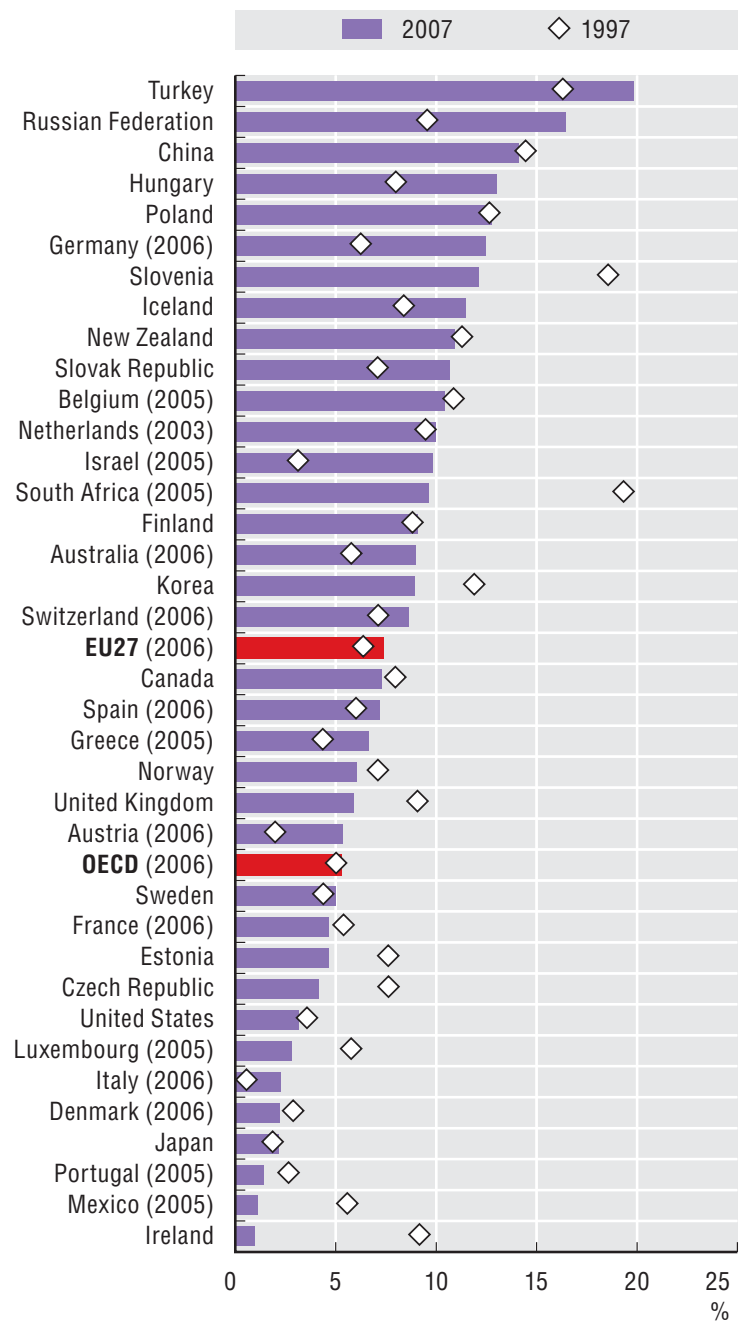

StatLink ला15L http://dx.doi.org/10.1787/744214163561 
Research and development (R\&D) tax concessions are extensively used by OECD countries as an indirect way of encouraging business R\&D expenditures. Special tax treatment for R\&D expenditures includes immediate write-off of current R\&D expenditures and various types of tax relief, such as tax credits or allowances against taxable income. Depreciation allowances are a third type.

The amount of tax subsidy for $R \& D$ is calculated as 1 minus the $B$ index (Warda, 2001). The $B$ index is defined as the present value of before tax income necessary to cover the initial cost of R\&D investment and to pay corporate income tax, so that it is profitable to perform research activities.

In 2008, 21 OECD countries had R\&D tax credits, up from 18 in 2004. It is an increasingly popular measure among OECD and non-OECD governments. France and Spain provide the largest subsidies and make no distinction between large and small firms. Canada and the Netherlands continue to be significantly more generous to small firms than to large ones. Emerging economies are also implementing these policy instruments to encourage R\&D investments. Brazil, India, South Africa and China provide a generous and competitive tax environment for investment in R\&D.

Tax subsidies for R\&D by large firms increased significantly between 1999 and 2008 in France and Norway, and to a lesser extent in Italy, Portugal, the United Kingdom, Belgium and Japan. Elsewhere, the tax subsidy rate remained stable, except in Mexico and Denmark, where it decreased. Italy showed the largest decrease in tax subsidies for $R \& D$ for small and medium-sized enterprises. The scheme introduced in New Zealand in 2008 was discontinued in 2009.

\section{The $B$ index}

Algebraically, the $B$ index is equal to the after-tax cost of an expenditure of USD 1 on R\&D divided by one minus the corporate income tax rate. The after-tax cost is the net cost of investing in $\mathrm{R} \& \mathrm{D}$, taking into account all the available tax incentives.

$$
B \text { index }=\frac{(1-A)}{(1-\tau)}
$$

where $A=$ the net present discounted value of depreciation allowances, tax credits and special allowances on R\&D assets; and $\tau=$ the statutory corporate income tax rate (CITR). In a country with full write-off of current R\&D expenditure and no R\&D tax incentive scheme, $A=\tau$, and consequently $B=1$. The more favourable a country's tax treatment of R\&D, the lower its $B$ index.
The $B$ index is a unique tool for comparing the generosity of the tax treatment of R\&D in different countries. However, its computation requires some simplifying assumptions. It should therefore be examined together with a set of other relevant policy indicators. Furthermore, its "synthetic" nature does not allow for distinguishing the relative importance of the various policy tools it takes into account (e.g. depreciation allowances, special R\&D allowances, tax credit, CITR). B indexes have been calculated under the assumption that the "representative firm" is taxable and may enjoy the full benefit of the tax allowance or credit. For incremental tax credits, calculation of the B index implicitly assumes that $R \& D$ investment is fully eligible for the credit and does not exceed the ceiling if there is one. Some detailed features of R\&D tax schemes (e.g. refunding, carry-back and carry-forward of unused tax credit, or flow-through mechanisms) are therefore not taken into account.

The effective impact of the R\&D tax allowance or credit on the after-tax cost of R\&D is affected by the level of the CITR. An increase in the CITR reduces the $B$ index only in those countries with the most generous R\&D tax treatment. If tax credits are taxable, the effect of the CITR on the $B$ index depends only on the level of the depreciation allowance. If the latter is over $100 \%$ for the total R\&D expenditure, an increase in the CITR will reduce the $B$ index. For countries with less generous $R \& D$ tax treatment, the $B$ index is positively related to the CITR.

\section{Source}

Warda, J. (2009), “An Update of R\&D Tax Treatment in OECD Countries and Selected Emerging Economies, 2008-2009", mimeo.

\section{Going further}

OECD (2008), OECD Science, Technology and Industry Outlook, OECD, Paris, www.oecd.org/sti/outlook.

Warda, J. (2001), "Measuring the Value of R\&D Tax Treatment in OECD Countries", STI Review No. 27: Special Issue on New Science and Technology Indicators, OECD, Paris. 
Tax subsidy rate for USD 1 of R\&D, large firms and SMEs, 2008

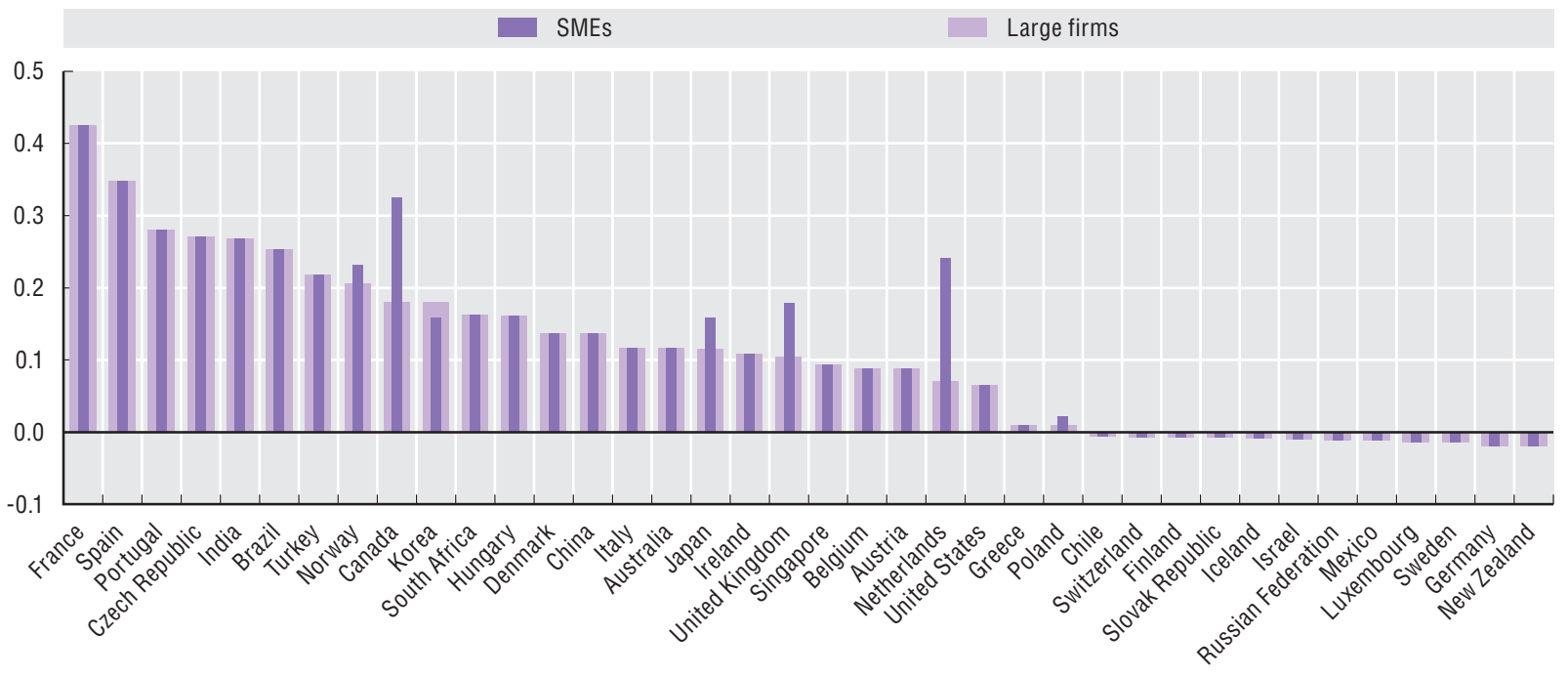

StatLink त्ञाs http://dx.doi.org/10.1787/744214584778

Change in the tax subsidy rate for USD 1 of R\&D, large firms and SMEs, between 1999 and 2008

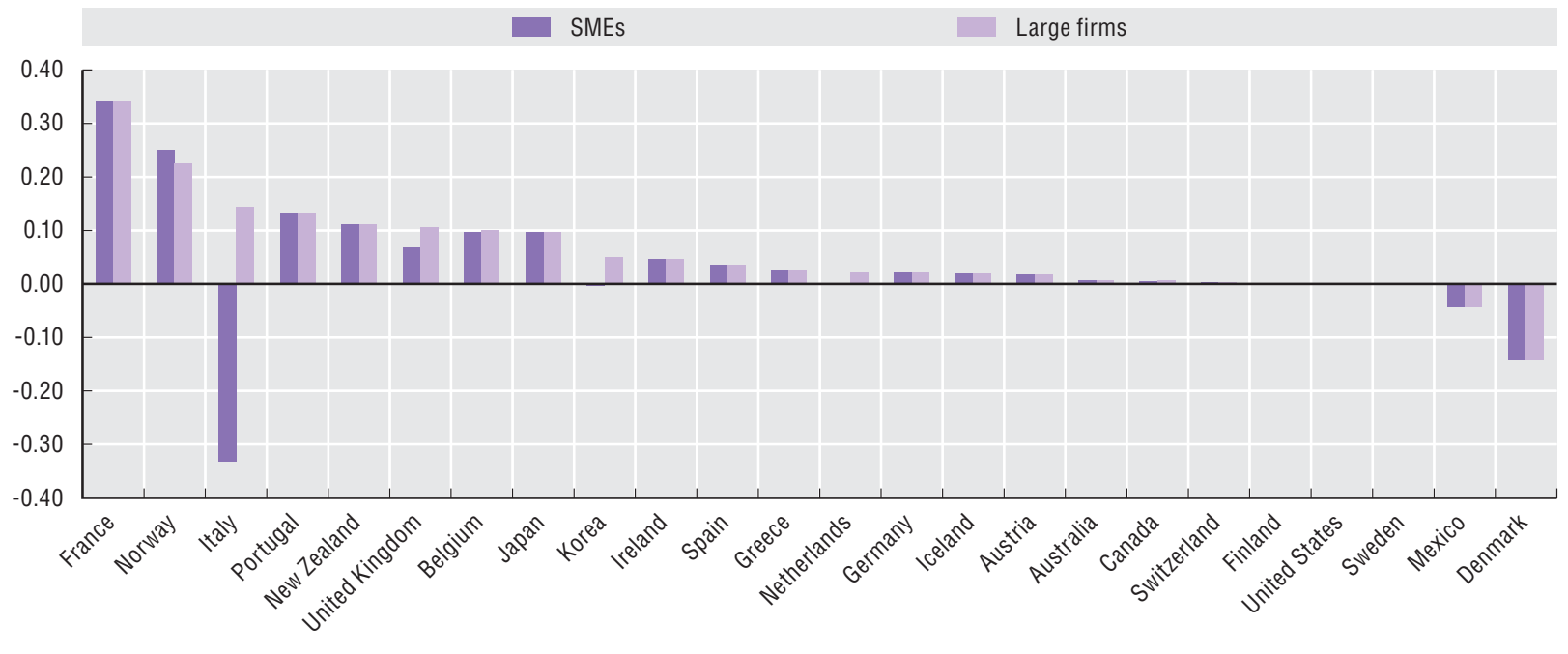

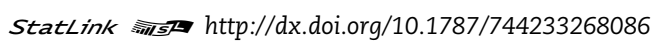




\section{TARGETING NEW GROWTH AREAS}

\subsection{Collaboration by innovating firms}

Collaboration is an important part of the innovation activities of many firms. It involves "active participation in joint innovation projects with other organisations" (Oslo Manual, 2005), but excludes pure contracting out of work. Collaboration can involve the joint development of new products, processes or other innovations with customers and suppliers, as well as horizontal work with other enterprises or public research bodies.

During 2004-06, large firms were significantly more likely to collaborate on innovation than small and medium-sized enterprises (SMEs). Among SMEs, the rate of collaboration is fairly similar across countries (between $10 \%$ and $20 \%$ of all firms in two-thirds of the countries surveyed), but it varies widely for large firms. More than half of all large firms collaborated on innovation in Austria, Belgium, Estonia, Finland and Slovenia, while less than one in four did so in Australia, Italy, Turkey and the United Kingdom.

Collaboration with public research organisations (higher education or government research institutes) can be an important source of knowledge transfer for the innovation activities of firms. Here again, large firms are much more active than SMEs, and show much more cross-country variation. However, this indicates only the existence of some sort of collaboration, not its type or intensity.

In almost all countries, there is more collaboration with higher education institutions than with government research centres. For large firms, co-operation with the former is most prevalent in Austria, Finland, Greece and Slovenia (over 35\%), and with the latter in Austria, Belgium, Finland and Slovenia (over 20\%).

Among SMEs, collaboration on innovation with both higher education and government institutions was below $10 \%$ in all countries, except Finland.

\section{Measuring innovation in firms}

Innovation surveys are increasingly used to better understand the role of innovation in economic growth as well as its determinants and the characteristics of innovative firms. Since 1992, the Oslo Manual has provided a harmonised framework - including coherent concepts and tools - for undertaking comparable large-scale surveys of this type. While previous editions of the Manual emphasised technological product and process (TPP) innovation, the latest (3rd) edition (OECD/Eurostat, 2005) extends the scope of such surveys to marketing and organisational innovations and places new emphasis on the role of linkages (including collaboration) in innovation. Although cross-country comparability of innovation surveys based on the Oslo Manual is generally good and improving, certain differences may affect comparisons between CIS (Community Innovation Survey) and non-CIS countries, such as sectoral coverage, size thresholds, sampling methods and the unit of analysis. In addition, countries differ in terms of filtering innovators/non-innovators, i.e. whether firms identified as non-innovators early in the questionnaire are asked to answer subsequent questions.

\section{Sources}

Eurostat, CIS-2006 (NewCronos), June 2009.

National data sources.

\section{Going further}

OECD and Eurostat (2005), Oslo Manual: Guidelines for Collecting and Interpreting Innovation Data, 3rd edition, OECD, Paris, www.oecd.org/sti/oslomanual.

\section{Figure notes}

France: manufacturing only.

New Zealand: SMEs are firms with 10-99 employees. 
Firms collaborating on innovation activities by size, 2004-06

As a percentage of all firms

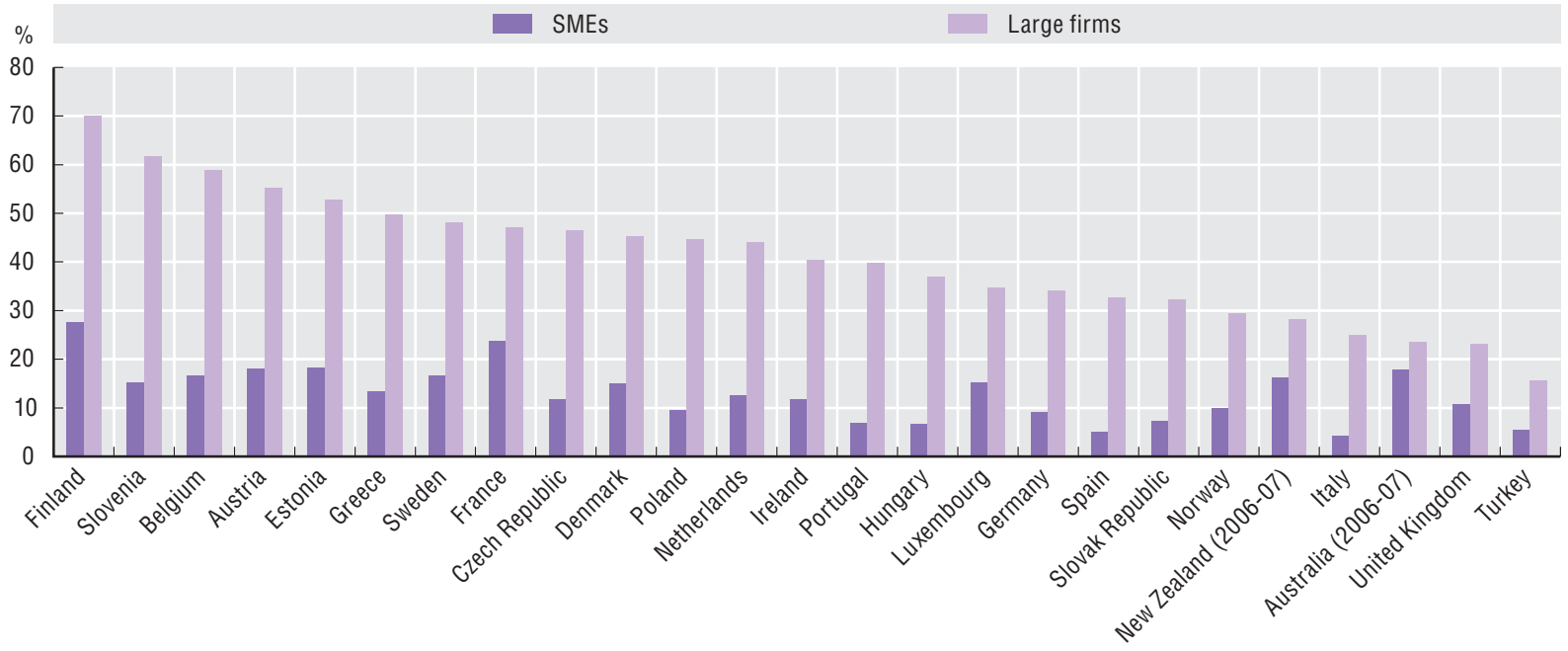

StatLink AाISL http://dx.doi.org/10.1787/744255302518

Firms collaborating on innovation with higher education institutions by size, 2004-06

As a percentage of all firms

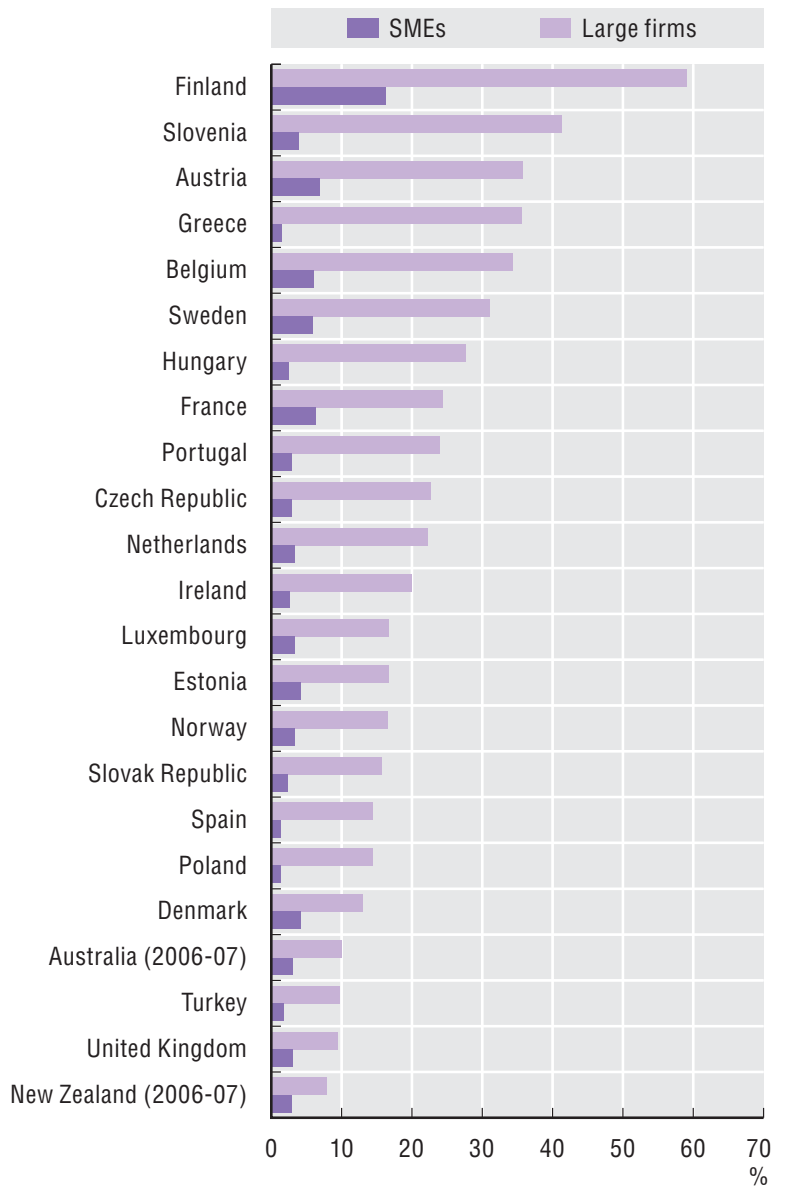

StatLink लाISL http://dx.doi.org/10.1787/744256247635
Firms collaborating on innovation with government research institutes by size, 2004-06

As a percentage of all firms

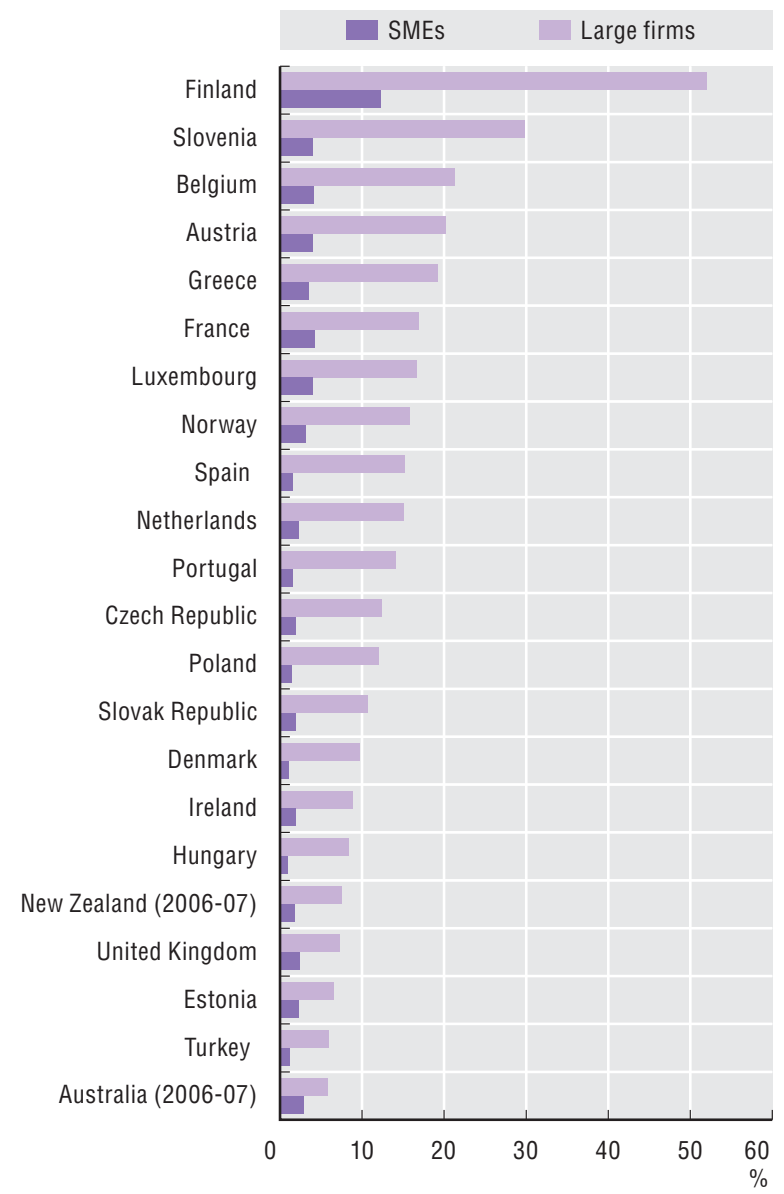

StatLink ताISL http://dx.doi.org/10.1787/744317448007 


\section{COMPETING IN THE WORLD ECONOMY}

3.1. International trade............................ 84

3.2. International trade by technology intensity $\ldots \ldots \ldots \ldots \ldots . . \ldots 6$

3.3. Manufacturing trade balance by technology intensity........ 88

3.4. International trade in ICT goods and services............ 90

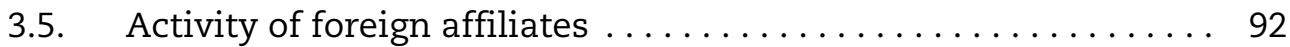

3.6. Electronic commerce........................... 94

3.7. Innovation and firm performance.................. 96

3.8. Innovation within companies $\ldots \ldots \ldots \ldots \ldots \ldots \ldots \ldots \ldots$

3.9. Non-technological innovation ....................... 100

3.10. Product and marketing innovation using trademarks ........ 102

3.11. Internet access and use by businesses . . . . . . . . . . . . . . . . 104

3.12. Entrepreneurship ........................... 106 


\section{COMPETING IN THE WORLD ECONOMY}

\subsection{International trade}

The value of their international trade in goods and services reflects countries' integration into the world economy. Small countries are generally more integrated: their exports tend to be in a limited number of sectors and they need to import more goods and services to satisfy domestic demand than larger countries. Size, however, is not the only determinant of trade integration. Other factors help explain differences across countries: geography, history, culture, (trade) policy, the structure of the economy (especially the weight of non-tradable services), re-exports and the presence of multinational firms (intra-firm trade).

The average ratio of exports and imports to gross domestic product (GDP), in constant prices of 2007, increased between 1997 and 2007 in all OECD countries. In 2007, it was over $160 \%$ in Luxembourg and very high in Belgium, the Slovak Republic, Estonia, Hungary, as well as the Czech Republic. In contrast, it was less than $20 \%$ in Japan, the United States and Brazil, owing in part to their larger size.

Traditionally, international trade in goods has been the principal channel for economic integration. Over the past 20 years, however, other forms of transactions have become prevalent (e.g. foreign direct investment, portfolio investment) as firms increasingly implement global strategies and capital movements are liberalised.

In 2007, the average trade-to-GDP ratio of goods in the OECD area was $19.2 \%$, up from $17.3 \%$ in 1997 , an increase very similar to that for total trade. The ratio was above $60 \%$ in the Slovak Republic, Belgium, the Czech Republic, Hungary and Estonia.

As a share of GDP in 2007, average trade in services in the OECD area only accounted for around 5.4\% of GDP. Luxembourg and Ireland had the highest values. In
Luxembourg, financial services played a dominant role in exports, and in Ireland, technology payments were a very important component of total imports.

\section{The trade-to-GDP ratio}

The most frequently used indicator of the importance of international transactions relative to domestic transactions is the trade-to-GDP ratio, which is the average share of exports and imports of goods and services in GDP.

The trade-to-GDP ratio is often called the trade openness ratio. However, the term "openness" to international competition may be somewhat misleading. In fact, a low ratio does not necessarily imply high (tariff or non-tariff) obstacles to foreign trade, but may be due to the factors mentioned above, especially size and geographic remoteness from potential trading partners.

\section{Sources}

OECD, National Accounts Database, June 2009. International Monetary Fund, June 2009.

\section{Going further}

OECD (2005), Measuring Globalisation: OECD Handbook on Economic Globalisation Indicators, OECD, Paris. 
Total exports and imports, 2007

Average, as a percentage of GDP

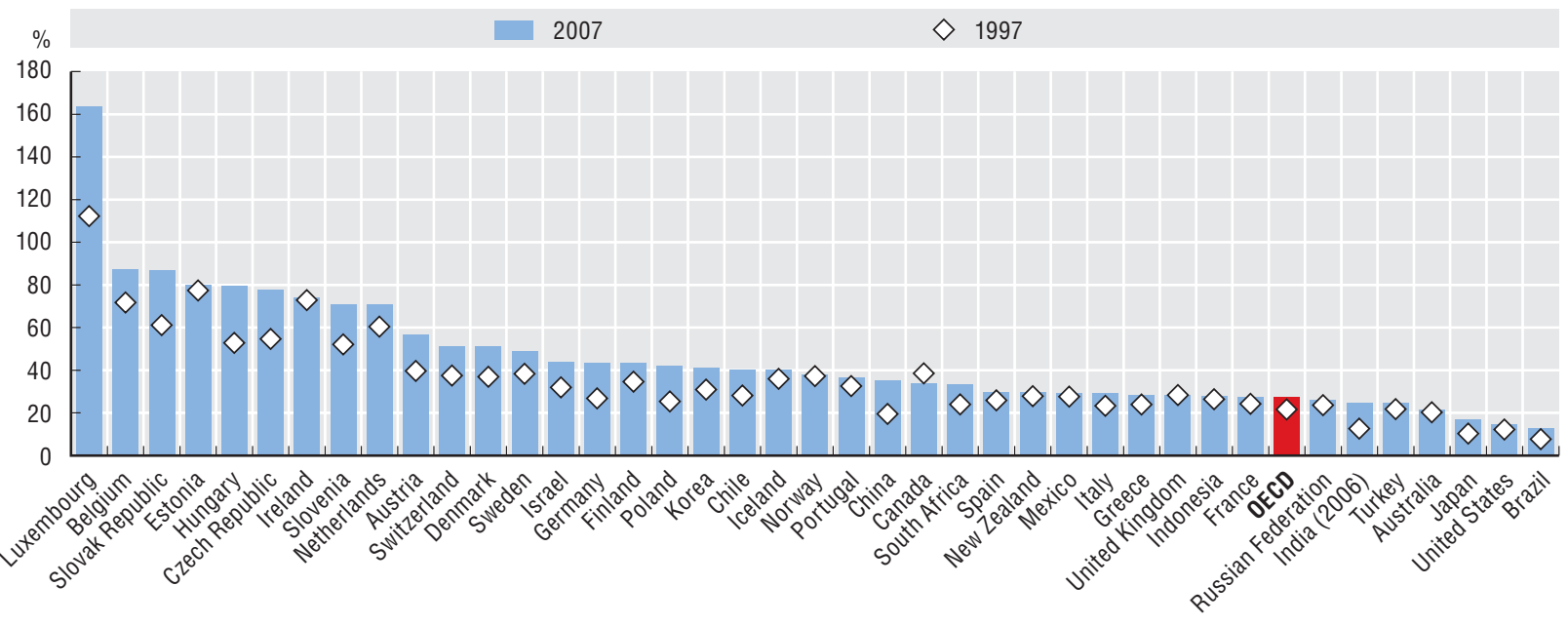

StatLink लाাs< http://dx.doi.org/10.1787/744325750814

Exports and imports of goods, 2007

Average, as a percentage of GDP

$$
\diamond 1997
$$

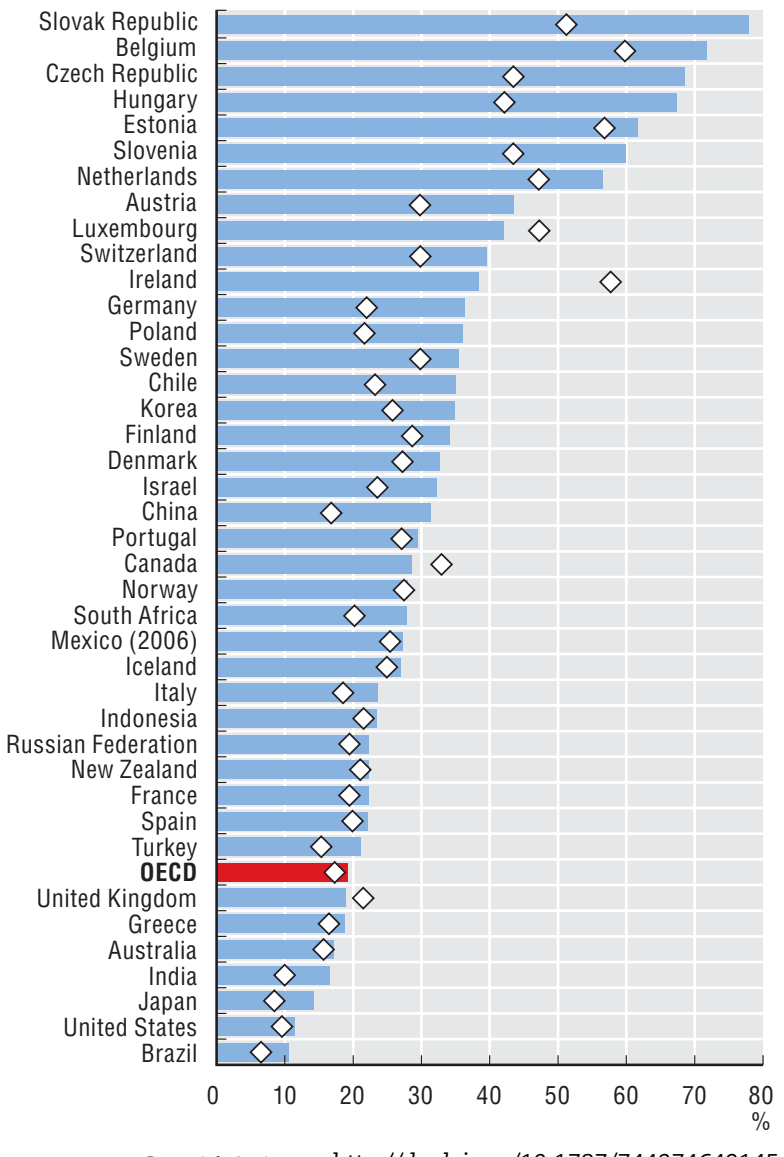

StatLink AाISL http://dx.doi.org/10.1787/7443746642145
Exports and imports of services, 2007

Average, as a percentage of GDP

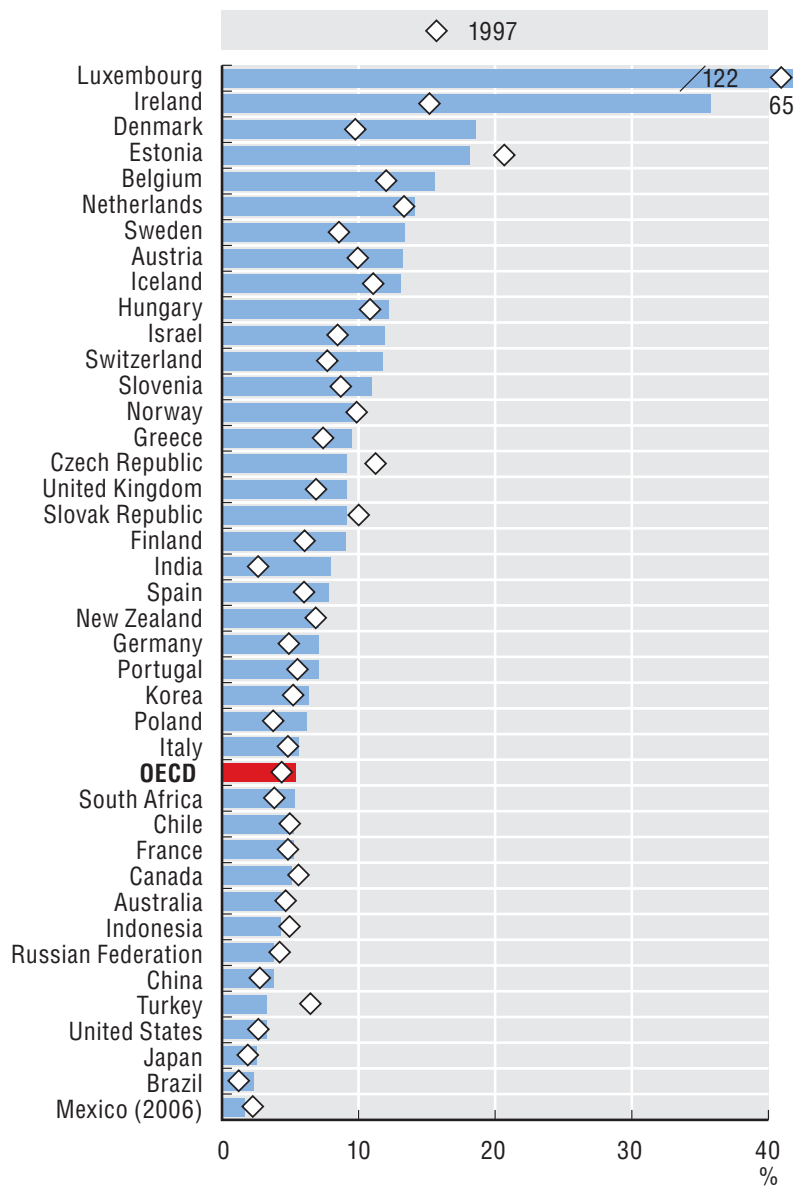

StatLink काजद http://dx.doi.org/10.1787/744425588570 
High-technology goods have been among the most dynamic components of international trade over the last decade. A country's ability to compete in hightechnology markets is therefore important to its overall competitiveness in the world economy.

An analysis of trends in technology intensity show that in the OECD area, trade in manufacturing was mostly driven by high-technology industries over the second half of the 1990s and up to the beginning of 2005. In 2001, the strong downturn in information and communication technology (ICT) trade affected trade in most technology industries, but recovery was fairly rapid. From 2005, the value of trade in high-technology manufactures started to slow. In 2007 it stood at broadly the same level as medium-high-technology manufactures. Over the same period, trade in medium-low-technology manufactures rose sharply. The notable increase in the value of trade in medium-low-technology manufactures was due in part to the recent significant increases in commodity prices for oil, petroleum products and basic metals, particularly the metals required for the manufacture of ICT goods. However, in terms of shares, medium-low-technology manufactures ranked third and accounted for $20 \%$ of total manufacturing trade in 2007; high-technology manufactures and medium-high-technology manufactures accounted for $23 \%$ and $39 \%$, respectively.

High-technology manufacturing contributes strongly to the growth of global manufacturing. Between 1997 and 2007, high-technology exports grew substantially faster than medium-high-technology exports in most countries, and notably in the Slovak Republic, Iceland and the Czech Republic, where they represented about 1.5 times the value of medium-high-technology exports. They grew at somewhat under $30 \%$ in China and by about $15 \%$ in Brazil. Over the period, growth in exports of hightechnology goods outstripped growth in total manufacturing except in most OECD accession countries (Chile, Estonia, Israel, Russian Federation, Slovenia), Sweden and Japan.

In 2007, exports were particularly oriented towards high- and medium-high-technology manufactures in Ireland, Japan, Hungary, Switzerland, Mexico and the United States. China's exports were significantly higher than the OECD average, with high- and medium-hightechnology exports accounting for about $60 \%$ of its total manufacturing exports.

\section{Trade by technology intensity}

OECD methodological work classifies manufacturing industries in four categories of technological intensity: high, medium-high, medium-low and low technology. This classification is based on indicators of (direct as well as indirect) technological intensity which reflect to some degree "technology-producer" or "technology-user" aspects.

To analyse international trade flows by technological intensity requires attributing each product to a specific industry. However, products which belong to a high-technology industry do not necessarily have only high-technology content. Likewise, some products in industries of lower technological intensity may incorporate a high degree of technological sophistication. No detailed data are available for services at present. Therefore the indicators presented here only relate to manufacturing industries.

\section{Source}

OECD, STAN Bilateral Trade Database, www.oecd.org/sti/btd. OECD, STAN Indicators Database, www.oecd.org/sti/stan/indicators.

\section{Going further}

Hatzichronoglou, T. (1997), "Revision of the High Technology Sector and Product Classification", OECD Science, Technology and Industry Working Papers 1997/2, OECD, Paris.

OECD (2005), Measuring Globalisation: OECD Handbook on Economic Globalisation Indicators, OECD, Paris.

OECD (2007), Staying Competitive in the Global Economy: Moving Up the Value Chain, OECD, Paris.

Pilat, D. et al. (2006), "The Changing Nature of Manufacturing in OECD Countries", OECD Science, Technology and Industry Working Papers 2006/9, OECD, Paris.

\section{Figure notes}

OECD manufacturing trade by technology intensity: OECD manufacturing trade is calculated as the average value of total OECD exports and imports of goods. The OECD aggregate excludes Luxembourg for which data are only available from 1999.

Growth of high- and medium-high-technology exports: the OECD and EU aggregates exclude Luxembourg for which data are only available from 1999.

Share of high- and medium-high-technology in manufacturing exports: the OECD and EU aggregates exclude Luxembourg for which data are only available from 1999. Underlying data for China include exports to Hong Kong (China). 


\section{COMPETING IN THE WORLD ECONOMY}

\subsection{International trade by technology intensity}

\section{OECD manufacturing trade by technology intensity}

Index $1997=100$

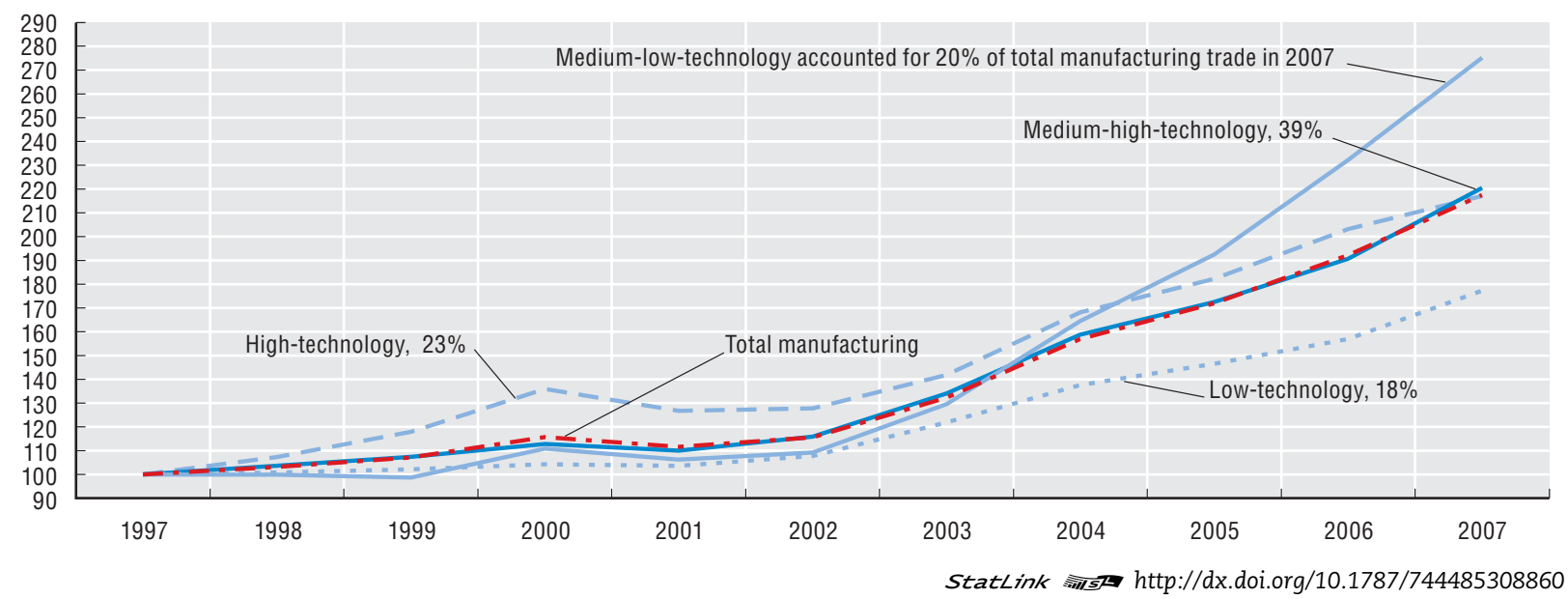

Growth of high- and medium-high-technology exports, 1997-2007

Average annual growth rate, percentage

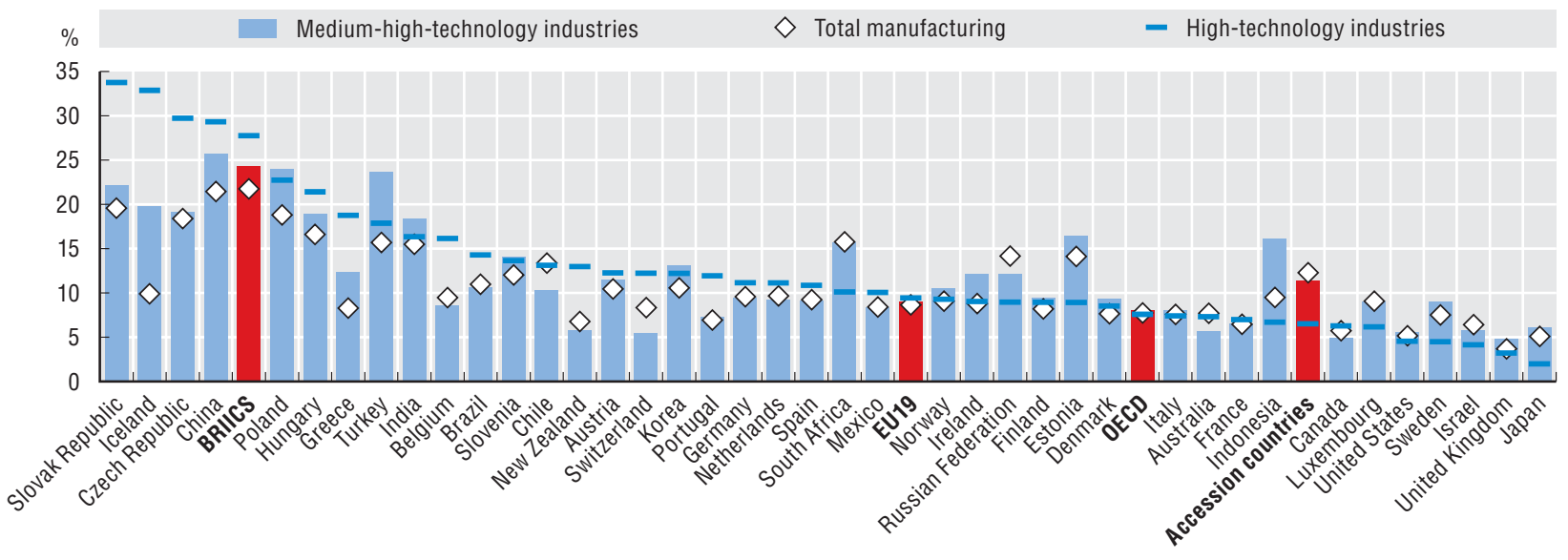

StatLink AाIS http://dx.doi.org/10.1787/744504213850

Share of high- and medium-high-technology in manufacturing exports, 2007 Percentage

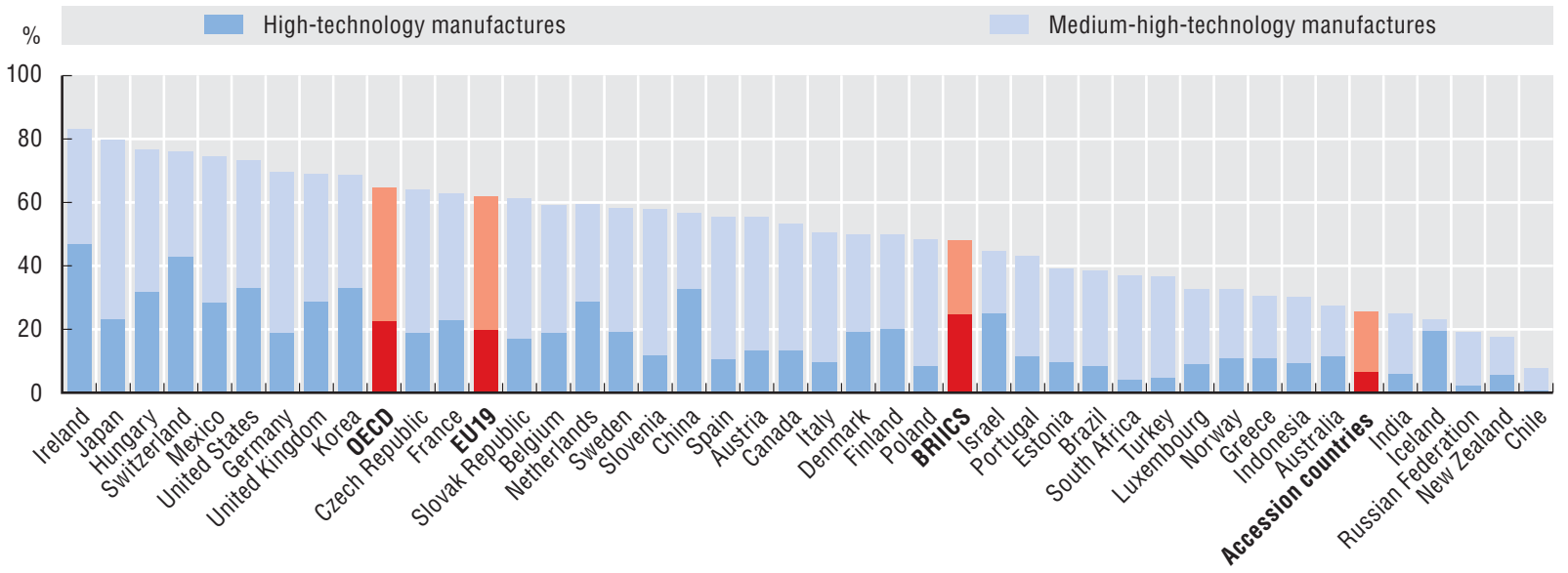

StatLink AाIs/ http://dx.doi.org/10.1787/744513042674 
The manufacturing trade balance reveals an economy's structural strengths and weaknesses in terms of technological intensity. It indicates whether an industry performs relatively better (or worse) than total manufacturing and can be interpreted as an indicator of revealed comparative advantage that is based on countries' trade specialisation.

In 2007, only 11 OECD countries and 2 non-members (Israel and Slovenia) show a strong comparative advantage in trade in high-technology manufactures. As in previous years, Switzerland had a trade surplus of over $7 \%$, followed by Ireland with $5 \%$. Trade in hightechnology industries represented around 3\% of total manufacturing trade in the United States, Mexico and Korea. In Israel and Slovenia the trade surplus was $2 \%$ and $1 \%$, respectively. Most countries' comparative advantage in trade in high-technology industries changed little between 1997 and 2007, although there were notable exceptions. It rose by 6 percentage points in Iceland, by 4 percentage points in Switzerland and in South Africa, and by 2 percentage points in Brazil. Over the same period, it dropped by 5 percentage points in Japan and by 3 percentage points in India and in China.

Between 1997 and 2007, the picture was somewhat different for trade in medium-high-technology industries. In particular, more countries had a strong comparative advantage in 2007. As in previous years, Japan led with a surplus of $15 \%$, followed by Germany and Ireland with $7 \%$ and 5\%, respectively. In 2007, Slovenia was the only non-OECD country to have not only a fairly strong comparative advantage of $2 \%$ in trade in medium-high technologies but also to benefit from an increase of 4 percentage points in its contribution to the manufacturing trade balance. Over 1997-2007, the contribution of trade in medium-high-technology industries increased by 13 percentage points in Indonesia, 11 percentage points in Turkey and 6 percentage points in China, despite negative contributions to their overall manufacturing trade balance. In 2007, much of the manufacturing trade balance of these countries relied on the positive contribution of low-technology industries.

\section{Contributions to the trade balance}

The contribution to the manufacturing trade balance is calculated as follows:

$\left(\mathrm{X}_{\mathrm{i}}-\mathrm{M}_{\mathrm{i}}\right)-(\mathrm{X}-\mathrm{M})^{*}\left[\left(\mathrm{X}_{\mathrm{i}}+\mathrm{M}_{\mathrm{i}}\right) /(\mathrm{X}+\mathrm{M})\right]$, where $\left(X_{\mathrm{i}}-\mathrm{M}_{\mathrm{i}}\right)$ is the observed manufacturing sector trade balance and $(X-M)^{*}\left[\left(X_{i}+M_{j}\right) /(X+M)\right]$ is the theoretical trade balance.

A positive value for an industry $i$ indicates a structural surplus, while a negative value indicates a structural deficit. The indicator is expressed as a percentage of total manufacturing trade in order to eliminate business cycle variations.

\section{Sources}

OECD, STAN Bilateral Trade Database, www.oecd.org/sti/btd.

OECD, STAN Indicators Database, www.oecd.org/sti/stan/indicators.

\section{Going further}

Hatzichronoglou, T. (1997), "Revision of the High Technology Sector and Product Classification", OECD Science, Technology and Industry Working Papers 1997/2, OECD, Paris.

OECD (2005), Measuring Globalisation: OECD Handbook on Economic Globalisation Indicators, OECD, Paris.

OECD (2007), Staying Competitive in the Global Economy: Moving Up the Value Chain, OECD, Paris.

Pilat, D. et al. (2006), "The Changing Nature of Manufacturing in OECD Countries", OECD Science, Technology and Industry Working Papers 2006/9, OECD, Paris.

\section{Figure notes}

Underlying data for China include trade with Hong Kong, China.

Changes in contribution to the manufacturing trade balance refer to 1999-2007 for Luxembourg, to 2000-07 for South Africa and to 2000-07 for the BRIICS (Brazil, Russian Federation, India, Indonesia, China and South Africa). 
Contribution of high-technology industries to the manufacturing trade balance, 2007

As a percentage of manufacturing trade

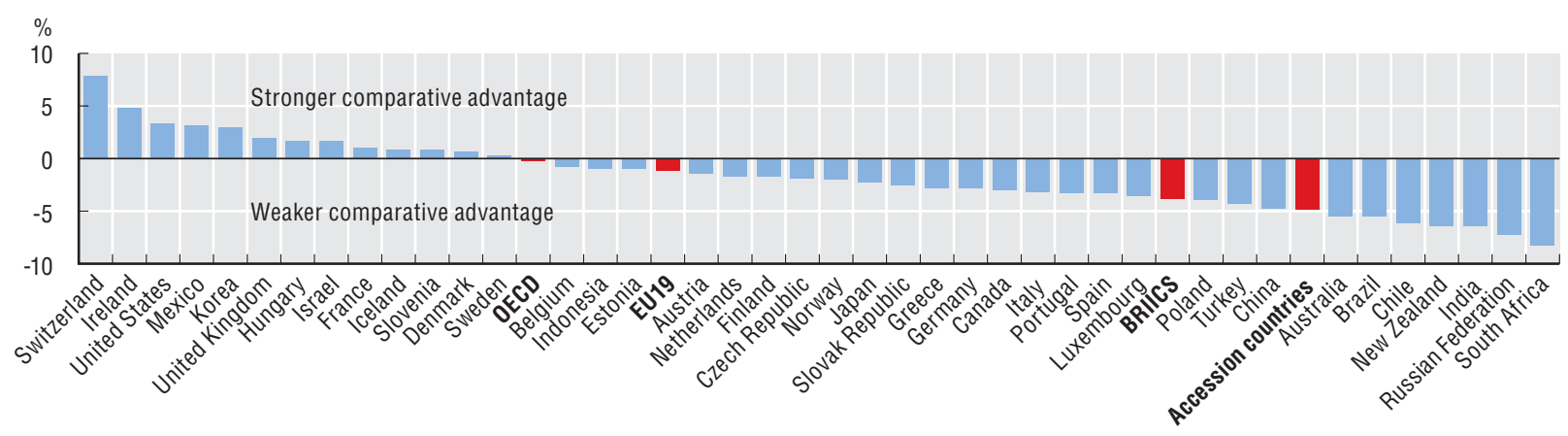

StatLink AाIsL http://dx.doi.org/10.1787/744524463556

Change in contribution to the manufacturing trade balance: high-technology industries, 1997-2007

As a percentage of manufacturing trade

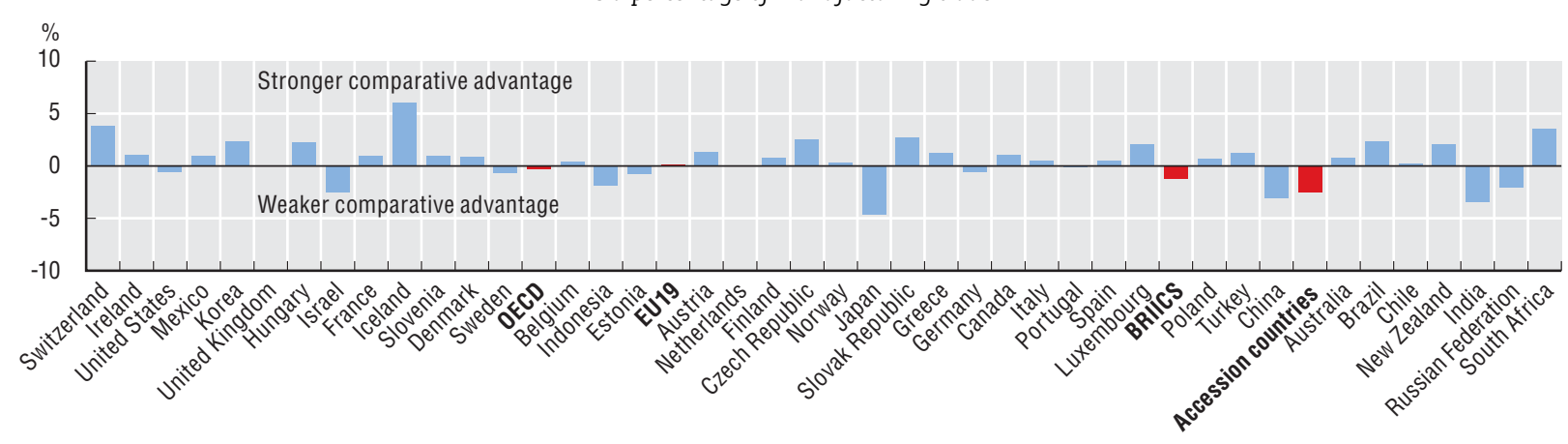

StatLink तोड़ा $h$ ttp://dx.doi.org/10.1787/744542886012

Contribution of medium-high-technology industries to the manufacturing trade balance, 2007

As a percentage of manufacturing trade

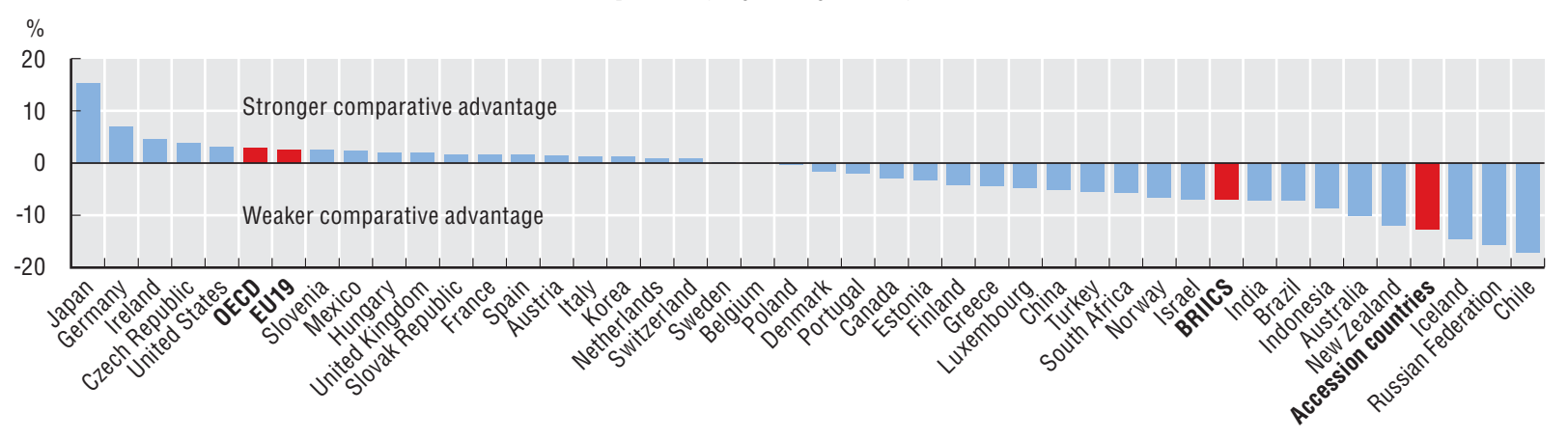

StatLink काIs $h$ ttp://dx.doi.org/10.1787/744586031377

Change in contribution to the manufacturing trade balance: medium-high-technology industries, 1997-2007 As a percentage of manufacturing trade

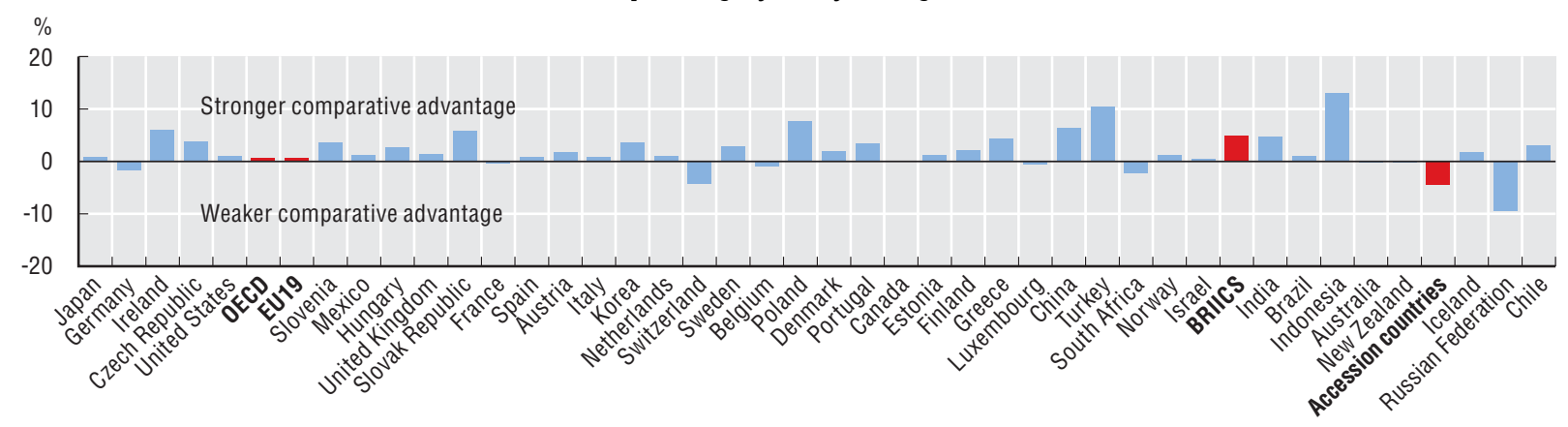

StatLink काIst http://dx.doi.org/10.1787/744600432311 
Information and communication (ICT) goods and services have been among the most dynamic components of international trade over the last decade. Global trade in ICT goods (the sum of exports and imports) expanded strongly to USD 3.7 trillion in 2007. However, the share of OECD ICT trade in total world ICT trade has decreased steadily from $75 \%$ in 1997 to $52 \%$ in 2007 owing to a rapid rise in trade from non-OECD Asian countries.

In 2007 , ICT goods trade accounted for $11 \%$ of total trade within the OECD area. China has been the world's largest ICT goods exporter since 2004 with exports growing by 30\% a year from 1996 to almost USD 360 billion in 2007. The United States was the largest importer of ICT goods with USD 273 billion. In Europe, Germany is the largest exporter and importer of ICT goods.

Only 8 of the 30 OECD countries had a positive trade balance in ICT-related goods in 2007. Korea has the greatest trade surplus in ICT goods (almost $6 \%$ of total trade and over $26 \%$ of the country's total merchandise exports).

The majority of OECD countries showed a positive trade balance in ICT-related services. In 2007, the leading OECD exporter of ICT-related services was Ireland with USD 30.2 billion. The United States (USD 22.7 billion) and Germany were the largest OECD importers. With respect to computer and information services, India was the largest exporter in 2006 at USD 29 billion.

\section{ICT goods and services trade}

The ICT commodities trade list is defined according to the OECD definition (OECD, 2009) based on the 2002 version of the World Customs Organization's Harmonized System (HS). However it is difficult to compare values of OECD ICT goods trade in 2007 with earlier years owing to the new HS classification, adopted in 2007, differing radically from earlier revisions. The OECD Working Party on Indicators for the Information Society (WPIIS) is developing a correspondence between the HS 2002 and the HS 2007 for ICT goods. Efforts are also required to quantify and adjust for the impact of Missing Trader Intra-Community (MTIC) VAT Fraud from the mid-2000s which mainly affected the movements of ICT goods within the EU.

The ICT goods trade balance indicator is calculated as ICT exports minus ICT imports divided by total trade (exports plus imports). Data are at current prices.
Data on telecommunications and computer and related services are estimated within a Balance of Payments (BPM 5) framework and cannot be compared to data on trade in ICT goods based on customs returns and related surveys. It is therefore not possible to calculate indicators of overall trade in ICT goods and services.

\section{Sources}

OECD, International Trade by Commodity Statistics (ITCS) Database, 2009.

OECD, Statistics on International Trade in Services Database, 2009.

\section{Going further}

OECD (2009), "Information Economy Product Definitions Based on the Central Product Classification (Version 2)", Mimeo.

OECD (2009), "Guide to Measuring the Information Society", www.oecd.org/sti/measuring-infoeconomy/guide.

OECD (2008), OECD Information Technology Outlook, OECD, Paris, www.oecd.org/sti/ito.

\section{Figure notes}

OECD ICT trade includes trade in copying machines and related parts to maximise the consistency of 2007 data with that for earlier years. The 2007 revision of HS groups together office printers (in the ICT good definition) with photocopiers (not in the current ICT list) whereas previous versions of HS classified them separately. Also, ICT trade does not include UK trade in "Transmit-receive apparatus for radio, TV, etc." due to uncertainties concerning the impact of MTIC VAT Fraud on UK Trade Statistics.

Data for EU15 exclude intra-EU trade.

When interpreting the magnitude of China's exports of ICT goods one should bear in mind the high volume of its imports of ICT parts and components for assembly into ICT final products for export. Export data for China includes exports to Hong Kong that are subsequently re-exported back to China.

No data on ICT services exports are available for Greece in 2007. For Mexico and Switzerland, they refer to communications only. Telecommunication services include postal services. 


\section{COMPETING IN THE WORLD ECONOMY}

\subsection{International trade in ICT goods and services}

OECD trade in ICT goods, 1997-2007

Index: $1997=100$

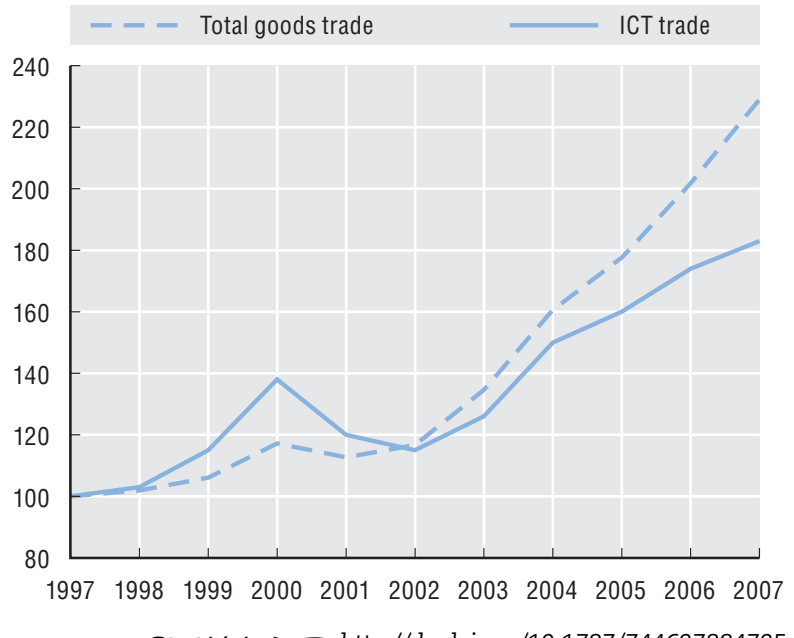

StatLink काजि http://dx.doi.org/10.1787/744637884735

ICT goods trade balance, 2007

Share of total goods trade

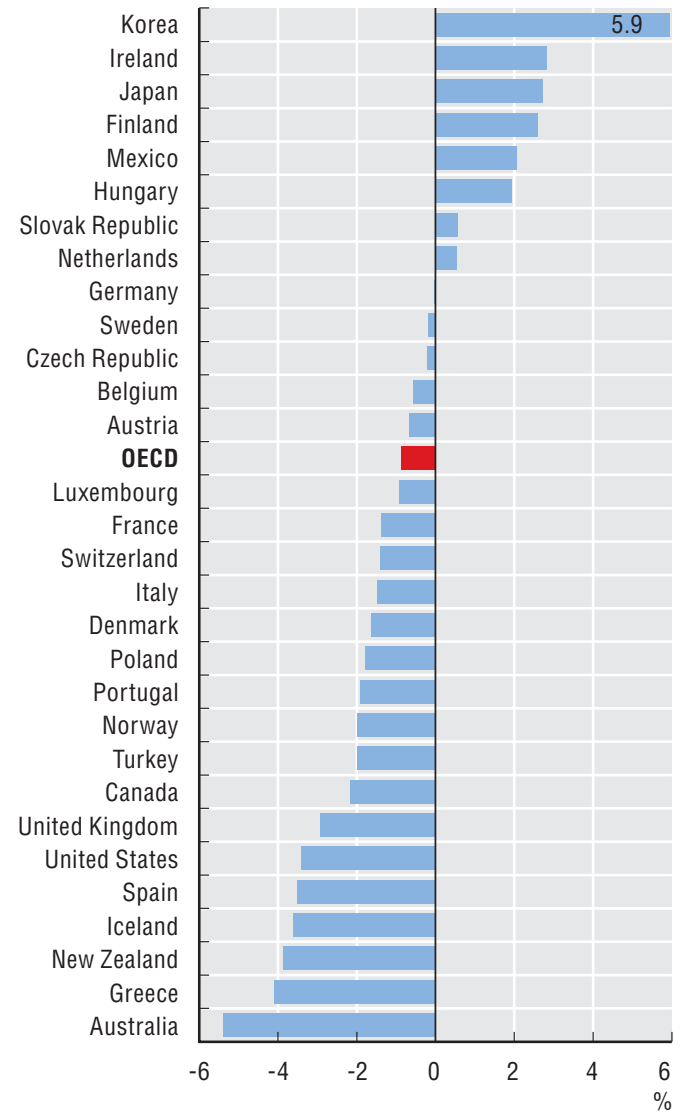

StatLink काज् http://dx.doi.org/10.1787/744730088214
Top exporting economies of ICT goods, 1997-2007

USD billions in current prices

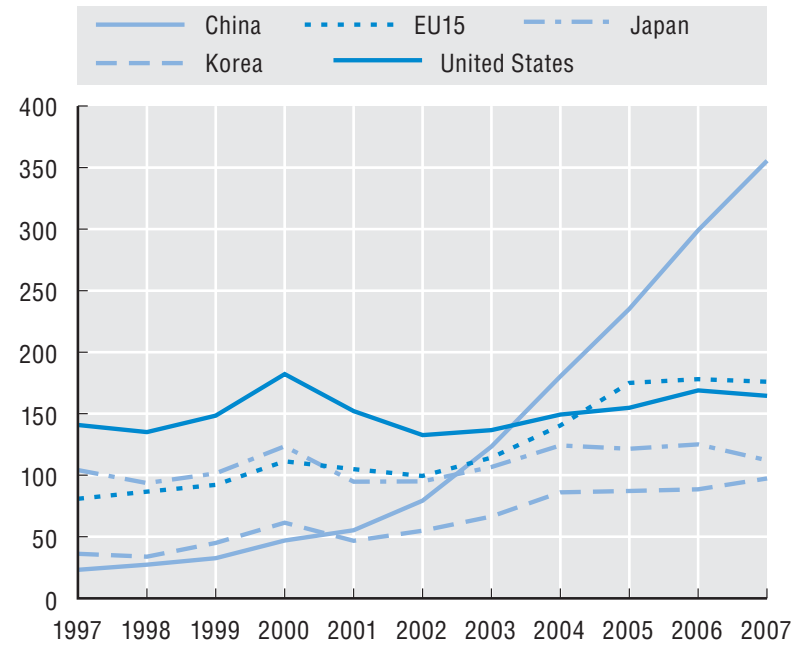

StatLink Ais $h$ Atp://dx.doi.org/10.1787/744650503541

OECD exporters of ICT services, 2007

USD billions in current prices

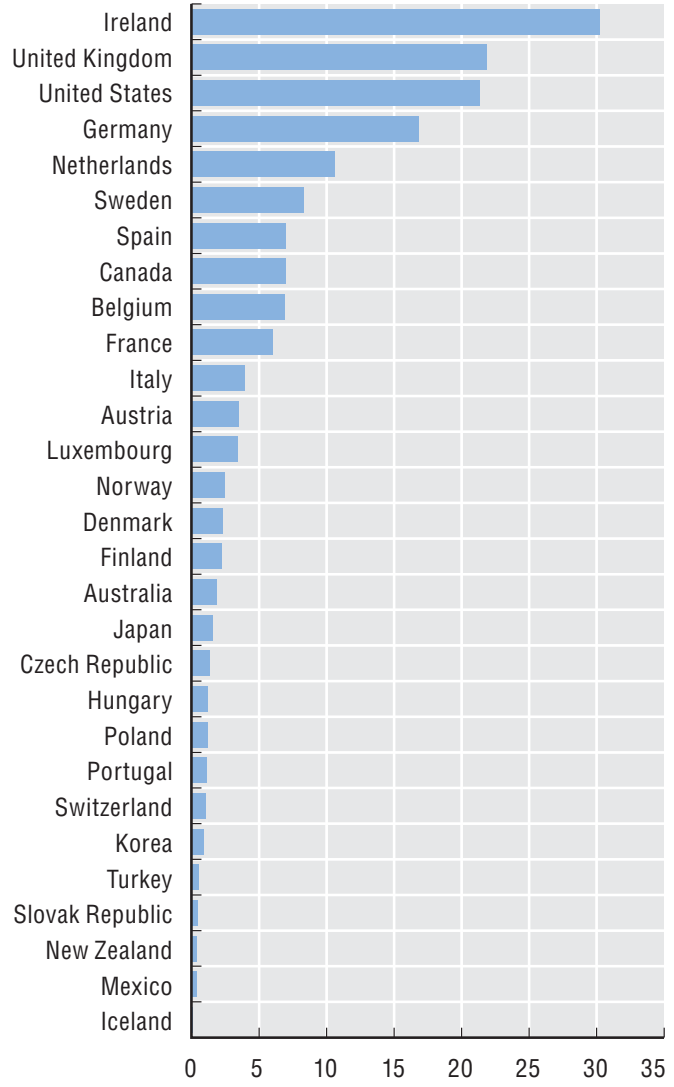

StatLink ताsस http://dx.doi.org/10.1787/744782707770 
Foreign affiliates contribute to a host country's international competitiveness through several channels. They provide access to new markets and new technologies for domestic suppliers and buyers along the value chain, generate knowledge spillovers for domestic firms, and invest a higher share of their revenue in research and development (R\&D).

In 2006, the share of firms under foreign control in total turnover of the manufacturing sector varied from about $80 \%$ in Ireland to $3 \%$ in Japan. It exceeded $50 \%$ in the Slovak Republic, Hungary, Belgium, the Czech Republic and Canada.

Manufacturing employment under foreign control in OECD countries generally follows the same pattern as turnover although the share in total employment is lower because foreign direct investment is more capitalthan labour-intensive. Countries differ, however: for example, the share of turnover under foreign control is greater in the Netherlands than in France while employment under foreign control is about the same.

In services, the share of turnover under foreign control is over 30\% in Ireland, the Czech Republic, Belgium, the Slovak Republic, Sweden, Poland and Hungary. For employment, it ranges from over $20 \%$ in Ireland, the Slovak Republic and Sweden to less than 5\% in the United States.

In all countries except Finland, the share of turnover of foreign affiliates is greater for manufacturing than for services. In terms of employment, penetration of foreign affiliates seems more evenly distributed between services and manufacturing in Finland, Switzerland, Norway, Italy and Portugal. The largest differences are in Hungary, Belgium, the Slovak Republic, Ireland and the Czech Republic.

\section{Turnover and employment in foreign affiliates}

\section{The share of foreign affiliates in turnover}

Output differs from turnover because it includes changes in stocks of finished goods and work in progress and because of differences in the measurement of activities involving trade or financial intermediation. Turnover covers gross operating revenues less rebates, discounts and returns. It should be measured exclusive of consumption and turnover (sales) taxes on consumers and value-added taxes. Turnover generally presents fewer collection difficulties and thus is likely to be more widely available than value added. Also unlike value added, turnover indicates the extent to which affiliates under foreign control are used to deliver outputs originating in the affiliates themselves or in other firms.

\section{The share of foreign affiliates in employment}

Employment should normally be measured as the number of persons on the payrolls of affiliates under foreign control. Employment data are sometimes converted to full-time equivalent (FTE), part-time workers being counted according to time worked. Employment data can be used to determine the share of affiliates under foreign control in host country employment or to help determine the extent to which employment by affiliates under foreign control complements or substitutes for domestic (home country) employment by parent companies or other domestic firms. The share of affiliates under foreign control in host country employment may reflect the importance of foreign direct investment in maintaining or creating employment in a compiling country. However, this information is not sufficient to evaluate the net job creation of foreign investment in the compiling countries.

\section{Source}

OECD, AFA Database, May 2009

OECD, FATS Database, May 2009.

\section{Going further}

OECD (2005), Measuring Globalisation: OECD Handbook on Economic Globalisation Indicators, OECD, Paris.

\section{Figure notes}

Turnover of foreign affiliates in services does not include: Financial intermediation (ISIC 65 to 67) in all countries except the Czech Republic, France, Poland and the Slovak Republic; Community, social and personal services (ISIC 80 to 93) in Austria, Finland, France, Germany, the Netherlands, Norway, Portugal, Spain and the United Kingdom.

Employment of foreign affiliates in services does not include: Financial intermediation (ISIC 65 to 67) in all countries except Belgium, the Czech Republic, France, Italy, Poland, the Slovak Republic and Switzerland; Community, social and personal services (ISIC 80 to 93) in Austria, France, Germany, Hungary, the Netherlands, Norway, Portugal, Spain and Switzerland. 


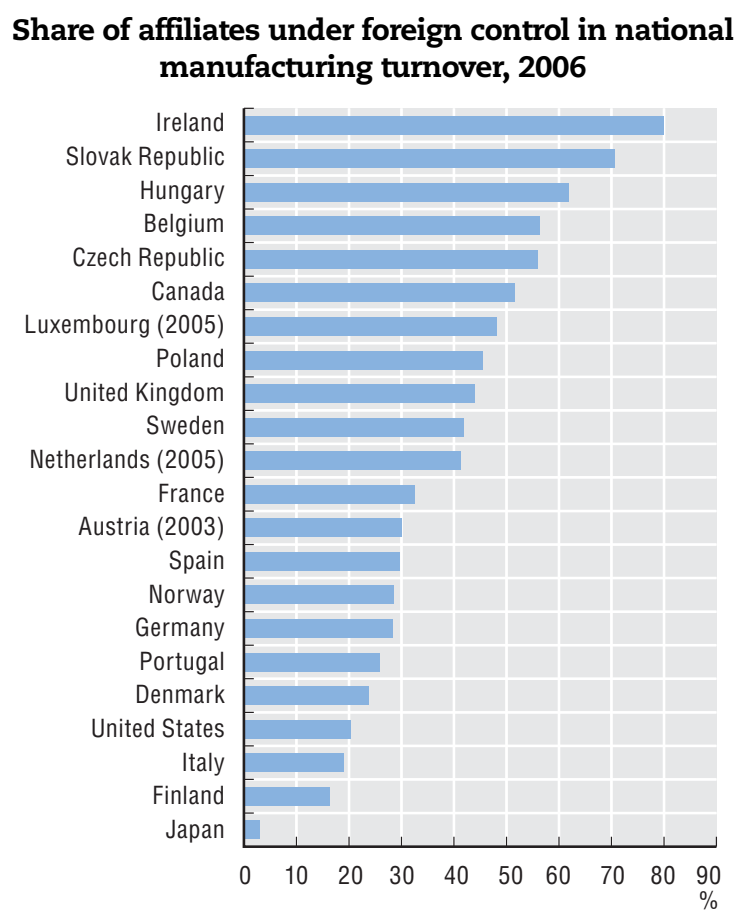

StatLink तils http://dx.doi.org/10.1787/744815206331

\section{Share of affiliates under foreign control in national services turnover, 2006}

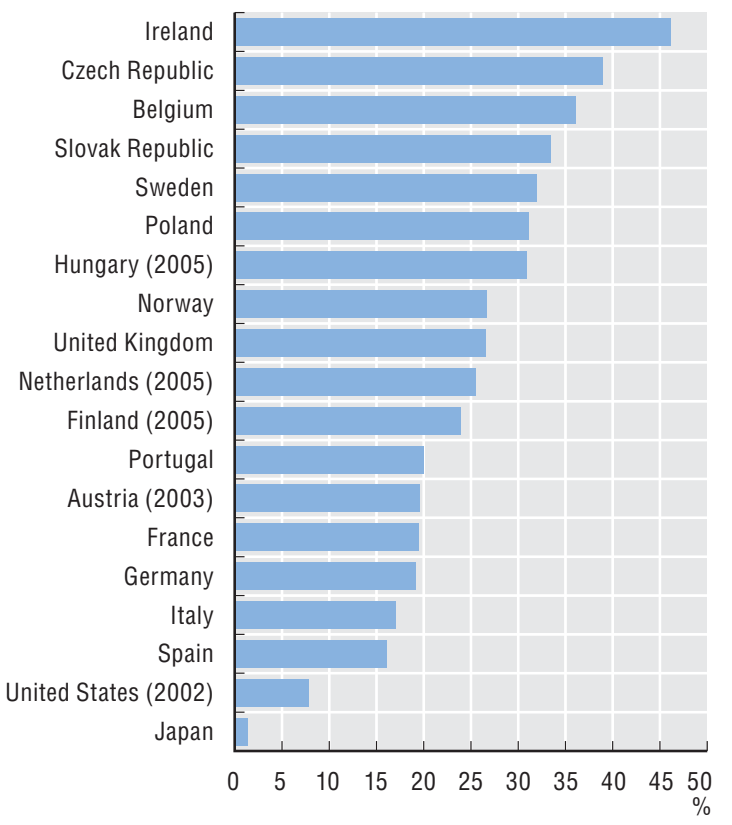

StatLink काजद http://dx.doi.org/10.1787/744833585705

\section{Share of affiliates under foreign control in national manufacturing employment, 2006}

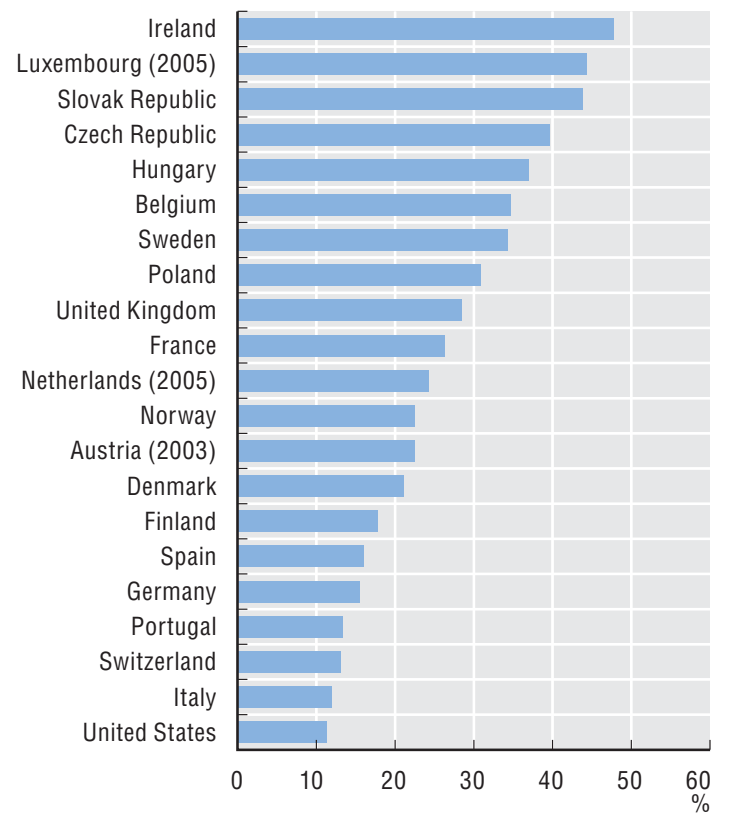

StatLink क्ञाज http://dx.doi.org/10.1787/744816206437

\section{Share of affiliates under foreign control in national services employment, 2006}

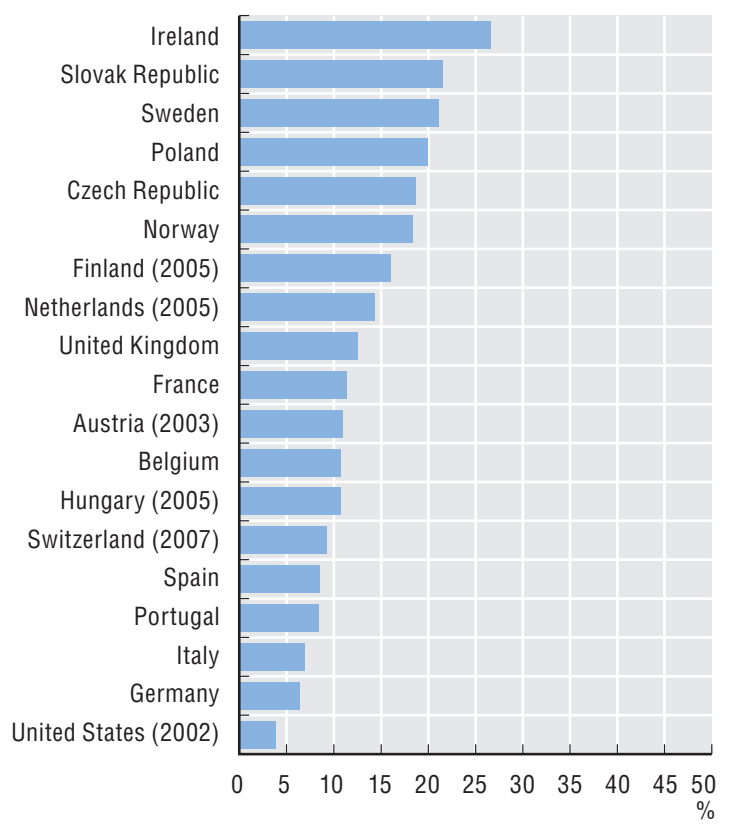

StatLink ताISL http://dx.doi.org/10.1787/745013282212 
The Internet is redefining relations between businesses and consumers, enabling companies to sell their products and services around the globe on an unprecedented scale. Shoppers can buy online at their convenience at any time and from anywhere. Ecommerce therefore allows firms around the world to compete in the global marketplace, at lower costs.

Use of the Internet to sell goods or services varies across industries and countries. In OECD countries, on average, over $33 \%$ of all businesses (with 10 or more employees) use the Internet for purchasing and about $17 \%$ for selling goods or services.

Over half of all businesses in Australia, Canada, Germany, Ireland, New Zealand and Switzerland purchase via the Internet. Approximately one-third of all businesses in Australia, New Zealand and the United Kingdom sell goods or services via the Internet.

Canada and Korea show the largest differences between the shares of businesses selling and purchasing over the Internet. Large differences coincide with exceptionally high use of Internet purchasing and, generally, a below-average level of Internet selling.

In most European countries, the volume of Internet and other e-commerce sales transactions (including over proprietary electronic data interchange) is increasing as a percentage of total turnover. In 2008, Norway, Denmark, the United Kingdom and Ireland reported the highest shares.

\section{Measuring electronic commerce}

OECD defines an Internet commerce transaction as "the sale or purchase of goods or services, whether between businesses, households, individuals, governments, and other public or private organisations, conducted over the Internet".

The goods or services are ordered over the Internet, but the payment or ultimate delivery of the good or service may be conducted on or off line. The OECD suggests including: orders received or placed on any Internet application used in automated transactions such as web pages, extranets and other applications that run over the Internet (such as electronic data interchange [EDI] over the Internet), or over any other webenabled application regardless of how the web is accessed (mobile phone, TV set, etc.). It suggests excluding orders received or placed by telephone, facsimile or conventional e-mail. A broader electronic commerce transaction may be conducted over any computer-mediated network (including the Internet). The OECD suggests including: orders received or placed on any online application used in automated transactions such as Internet applications, EDI over proprietary networks, Minitel or interactive telephone systems. It should be noted that differences exist in the statistical treatment of e-commerce by countries.

\section{Sources}

OECD, ICT Database, May 2009.

Eurostat Community Survey on ICT Usage in Enterprises, May 2009.

\section{Going further}

OECD (2008), "The Future of the Internet Economy: A Statistical Profile", www.oecd.org/dataoecd/44/56/40827598.pdf. OECD (2009), "Guide to Measuring the Information Society 2009", www.oecd.org/sti/measuring-infoeconomy/guide.

\section{Figure notes}

The definition of Internet selling and purchasing varies between countries, with some explicitly including orders placed by conventional e-mail (e.g. Australia and Canada) and others explicitly excluding them (e.g. Ireland, the United Kingdom and some other European countries). Most countries explicitly use the OECD concept of Internet commerce, that is, goods or services ordered over the Internet but payment and/or delivery may be off line. For Australia, Internet income results from orders received via the Internet or the web for goods or services, where an order is a commitment to purchase.

Total sales via the Internet or other networks during the reference year, excluding VAT. 
Internet selling and purchasing for total industry, 2008

Percentage of businesses with 10 or more employees

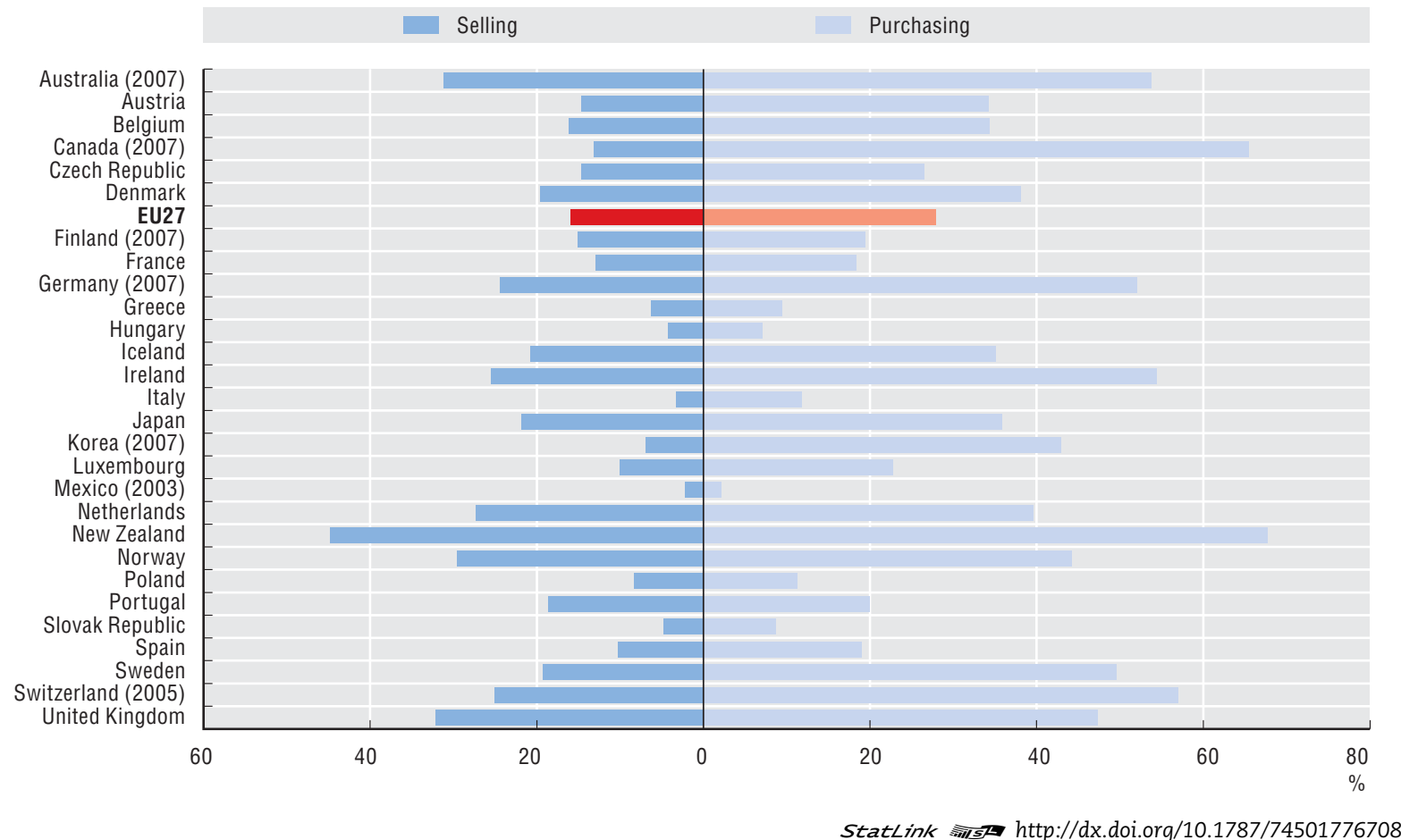

Percentage of enterprises' total turnover from e-commerce, 2008

As a percentage of total enterprise turnover

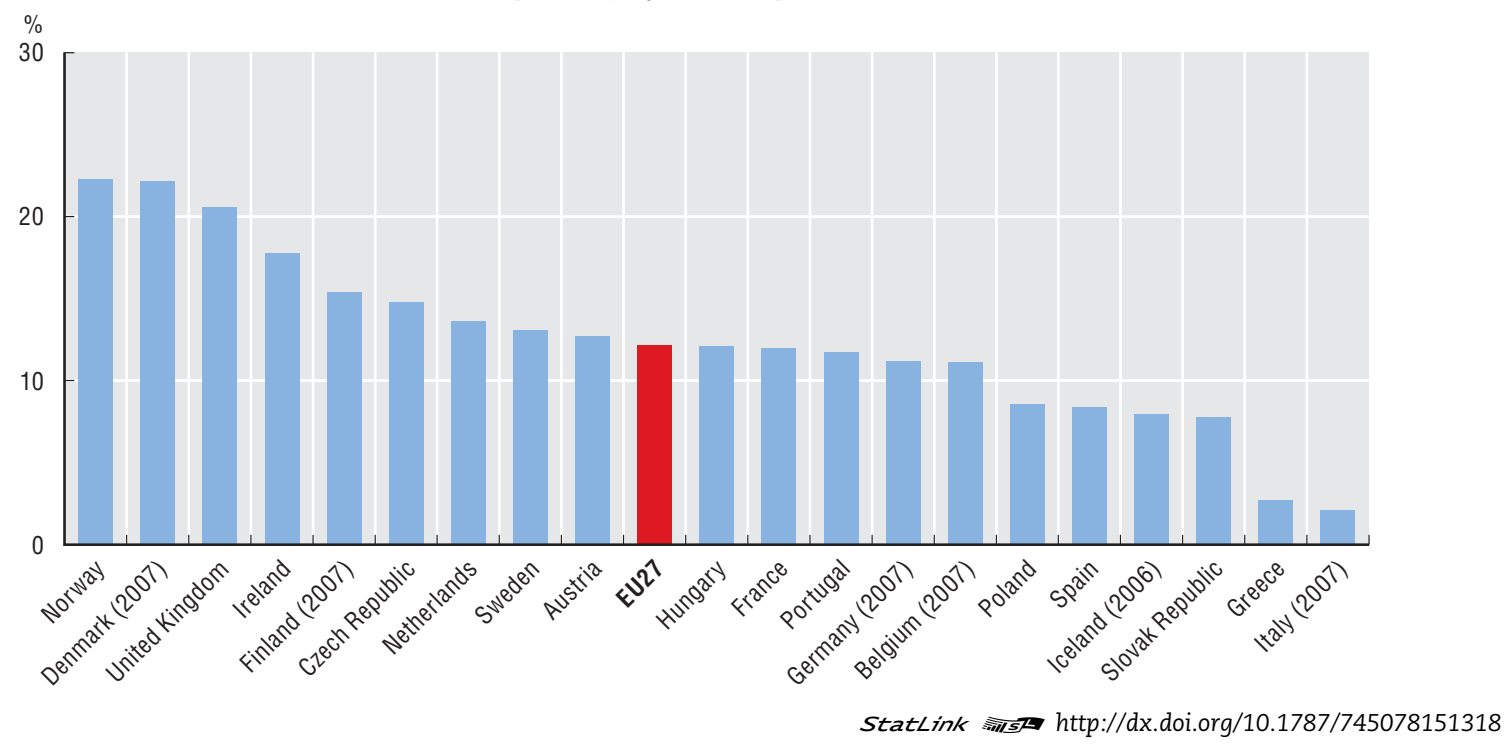




\section{COMPETING IN THE WORLD ECONOMY}

\subsection{Innovation and firm performance}

Innovations have different degrees of novelty. A firm's introduction of an innovation developed elsewhere can have a significant impact on its performance, but being an adopter is different from developing an innovation in house, especially if it is new to the market or to the world.

Large firms tend to introduce more "novel" innovations than small and medium-sized enterprises (SMEs). For product innovation, more than $50 \%$ of all large firms introduced a new-to-market innovation in Austria, Belgium, France, Greece and Luxembourg, while less than $25 \%$ did so in Hungary, Norway, Poland, the Slovak Republic, Turkey and the United Kingdom.

Overall, SMEs are less likely to introduce novel innovations. Again, there are differences across countries. Within Europe, SMEs in France, Luxembourg and Sweden had a significantly higher propensity to introduce new-to-market product innovations than those in Hungary and Poland.

The share of turnover from new-to-market product innovations can be used as an indicator of the impact of innovation at the firm level. However, the data should be interpreted with caution as some firms may find this difficult to estimate. In most countries differences between SMEs and large firms in this respect are not very significant. However, in Germany the share of turnover from such innovations was on average more than four times higher for large firms than for SMEs. In Norway and Portugal, the relative share of turnover from new-to-market product innovations was significantly higher for SMEs than for large firms.

\section{Measuring novelty and the diffusion of innovations}

By definition, all innovation must contain a degree of novelty. The Oslo Manual distinguishes three relevant concepts: new to the firm, new to the market and new to the world. The first concept covers the diffusion of an existing innovation to a firm (the innovation may have already been implemented by other firms, but is new to the firm). Firms that first develop innovations (new to market or new to world) can be considered as drivers of the process of innovation. Many new ideas and knowledge originate from these firms, but the economic impact of the innovations will depend on their adoption by other firms. Information on the degree of novelty can be used to identify the developers and adopters of innovations, to examine patterns of diffusion and to identify market leaders and followers. In addition, innovation surveys often collect information on the developer of an innovation. This is different from questions on the degree of novelty as enterprises may develop innovations that have already been implemented by others. It therefore indicates how innovative enterprises are, but not necessarily how novel their innovations are.

\section{Sources}

Eurostat, CIS-2006 (New Cronos), June 2009.

National data sources.

\section{Going further}

OECD and Eurostat (2005), Oslo Manual: Guidelines for Collecting and Interpreting Innovation Data, 3rd edition, OECD, Paris, www.oecd.org/sti/oslomanual.

\section{Figure notes}

France: manufacturing only.

New Zealand: SMEs are firms with 10-99 employees. 


\section{Firms with new-to-market product innovations by size, 2004-06}

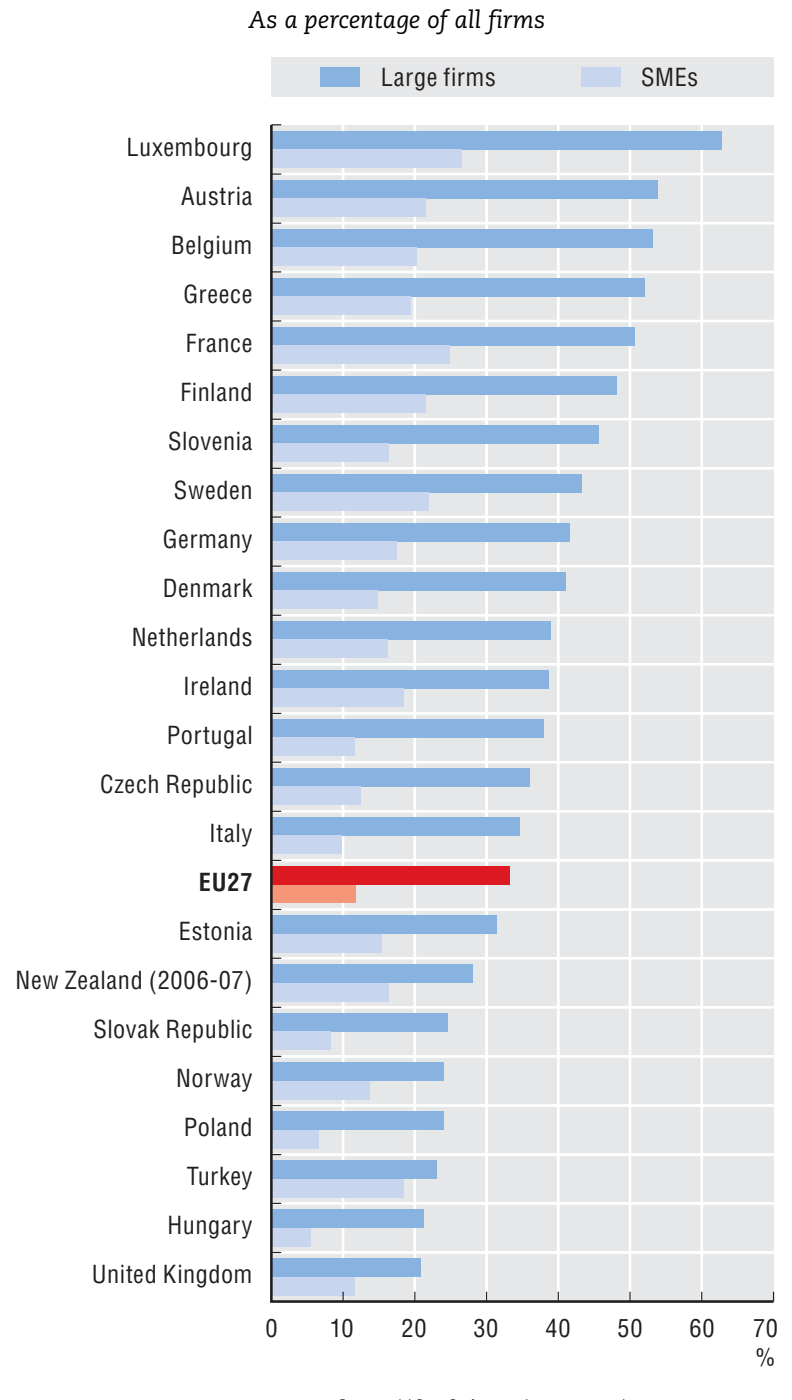

StatLink ला1s http://dx.doi.org/10.1787/745082412270

\section{Share of 2006 turnover due to new-to-market product innovations introduced in 2004-06, by firm size}

As a percentage of turnover (for innovation-active firms)

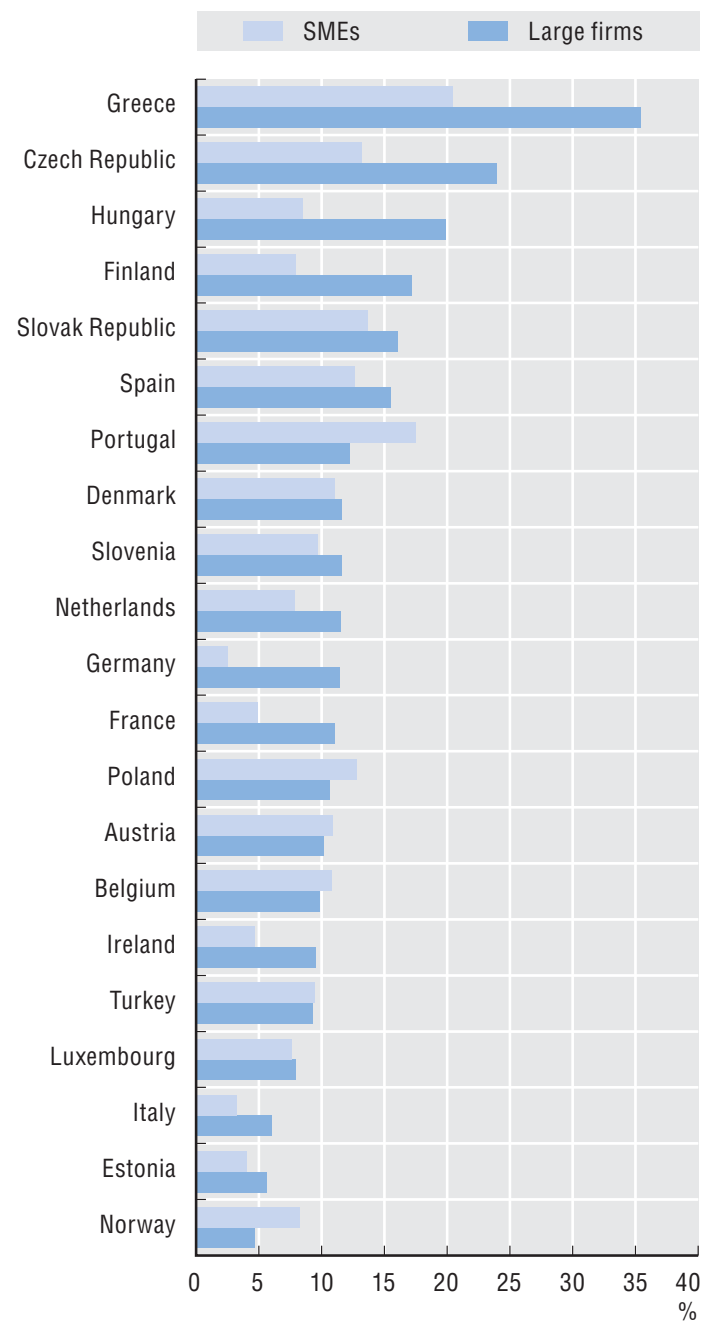

StatLink क्ञाज http://dx.doi.org/10.1787/745137085070 


\section{COMPETING IN THE WORLD ECONOMY}

To understand how diffusion of new technologies takes place, and to produce a more complete picture of how innovative a firm is, innovation surveys collect data on whether the innovation was developed within or outside the firm, and to what extent the firm interacted with other parties during the process.

Data on innovations mainly developed within a firm (so-called "in-house innovators") confirm that small and medium-sized enterprises (SMEs) tend to be "adopters" more frequently than large firms. In more than half of the countries surveyed, $40 \%$ or more of all large firms had developed during 2004-06 an in-house product innovation, and around $20 \%$ of all SMEs.

The pattern is similar for in-house process innovations. The highest rates (over 40\%) were for large firms in Australia, Belgium, Estonia, France, Germany, Ireland and Luxembourg. For these countries the rates for SMEs were around $20 \%$ to $25 \%$.

In terms of sectors, manufacturing firms tend to undertake more in-house innovation than services firms, for both products and processes. However, in Luxembourg in-house process innovators were more prevalent among service firms.

In most countries, there is less sectoral difference in terms of firms' propensity to innovate in house for processes than for products. This confirms that in most countries, product innovation is still more prevalent among manufacturing firms than process innovation (Australia is an exception).

\section{Defining innovation}

The latest (3rd) edition of the Oslo Manual defines innovation as the implementation of a new or significantly improved product (good or service), or process, a new marketing method, or a new organisational method in business practices, workplace organisation or external relations. This implicitly identifies the following four types:

- Product innovation: the introduction of a good or service that is new or significantly improved with respect to its characteristics or intended uses. This includes significant improvements in technical specifications, components and materials, incorporated software, user friendliness or other functional characteristics.

- Process innovation: the implementation of a new or significantly improved production or delivery method. This includes significant changes in techniques, equipment and/or software.

- Marketing innovation: the implementation of a new marketing method involving significant changes in product design or packaging, product placement, product promotion or pricing.

- Organisational innovation: the implementation of a new organisational method in the firm's business practices, workplace organisation or external relations.

The first two types are traditionally more closely related to technological innovation (also referred to as TPP innovation). Firms are considered innovative if they have implemented an innovation during the period under review (the observation period is usually two to three years).

\section{Sources}

Eurostat, Community Innovation Survey (CIS) 2006 (NewCronos), June 2009.

National data sources.

\section{Going further}

OECD and Eurostat (2005), Oslo Manual: Guidelines for Collecting and Interpreting Innovation Data, 3rd edition, OECD, Paris, www.oecd.org/sti/oslomanual.

\section{Figure notes}

France: manufacturing only.

New Zealand: SMEs are firms with 10-99 employees. 
In-house product innovators by size, 2004-06 As a percentage of all firms

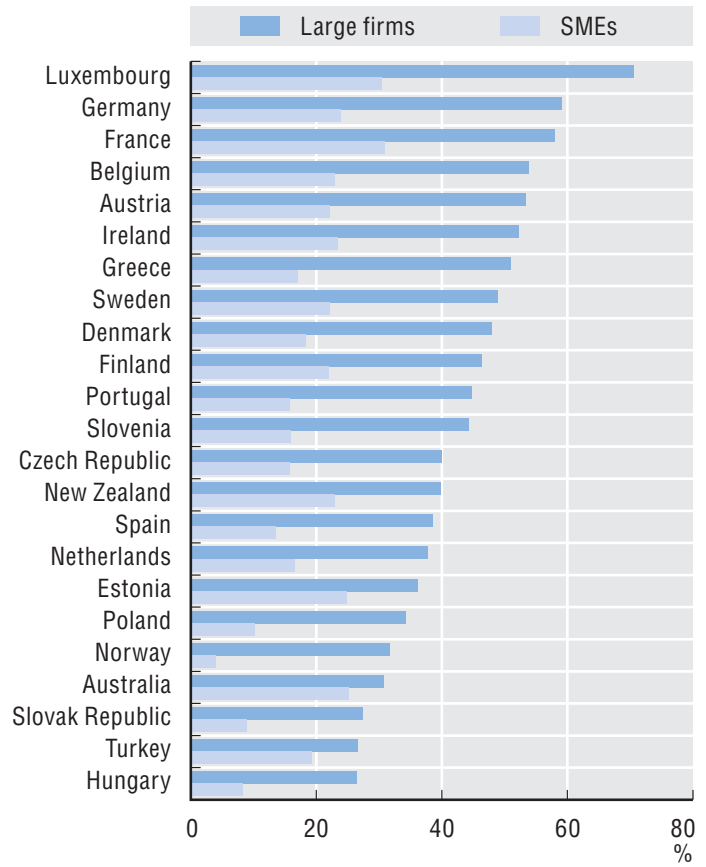

StatLink ना1s http://dx.doi.org/10.1787/745147353337

\section{In-house product innovators by sector, 2004-06} As a percentage of all firms

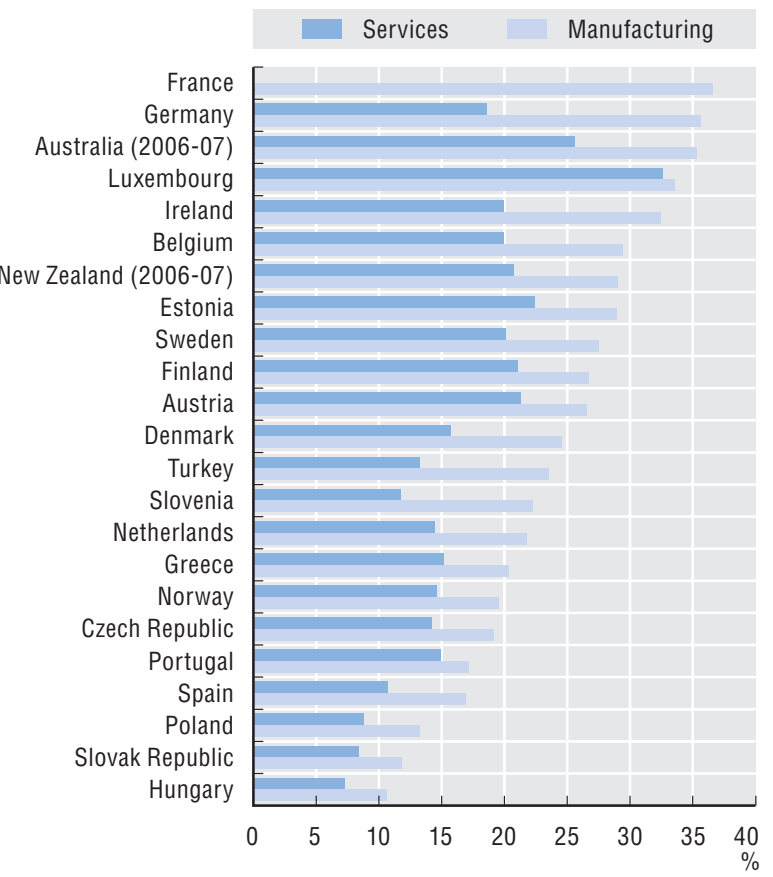

StatLink बाग http://dx.doi.org/10.1787/745227131530
In-house process innovators by size, 2004-06

As a percentage of all firms

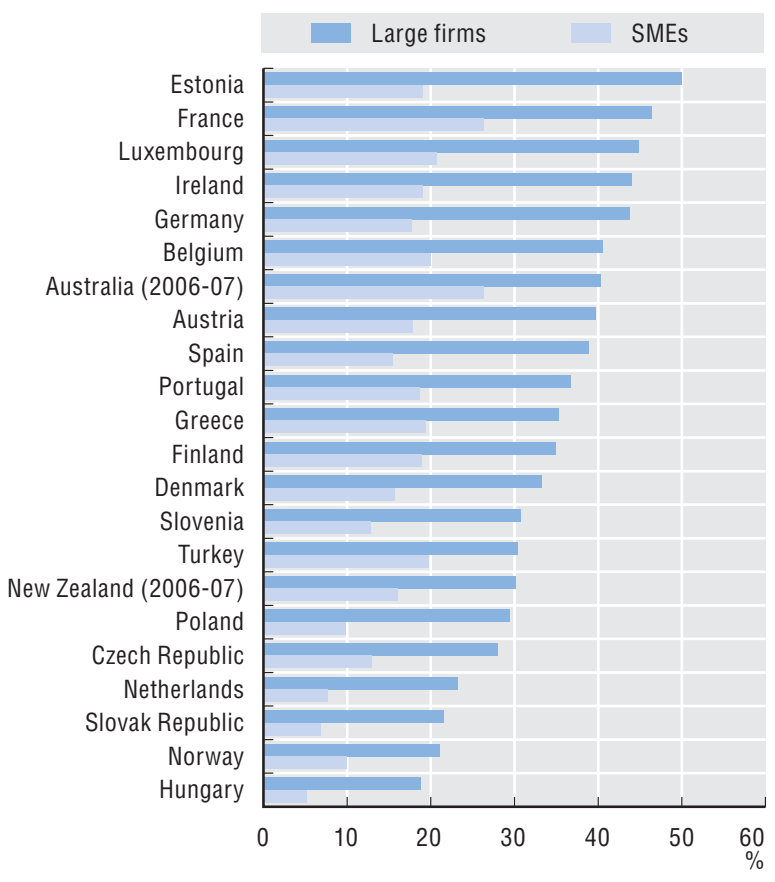

StatLink काISL http://dx.doi.org/10.1787/745187300120

In-house process innovators by sector, 2004-06 As a percentage of all firms

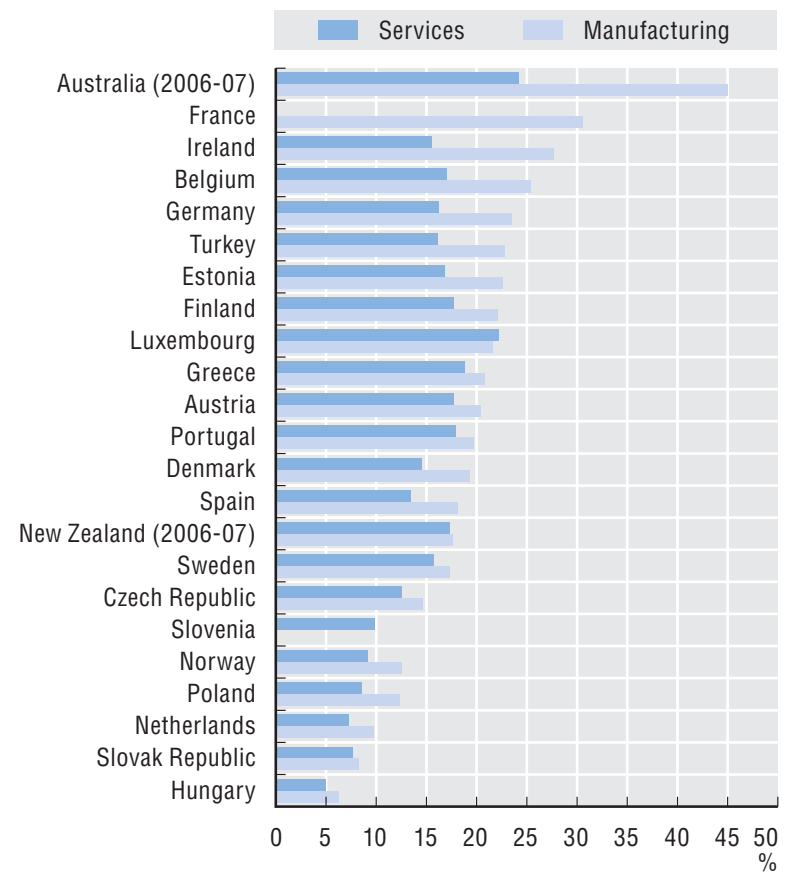

StatLink AाISL http://dx.doi.org/10.1787/745256621152 
Innovation has both technological and non-technological aspects. The commercialisation of new products often requires the development of new marketing methods. Similarly, a new production technique will increase productivity only if is supported by changes in organisation. Marketing and organisational innovations, therefore, are important dimensions of many firms' innovation activities, particularly in services.

Non-technological innovation is significantly more prevalent among large firms than among small and medium-sized enterprises (SMEs), although the gap is less pronounced in Australia, New Zealand and Turkey.

Sectoral differences with regard to the introduction of non-technological innovations do not appear very marked in most countries. However, the rates of nontechnological innovation are significantly higher in manufacturing in Germany and Slovenia, and somewhat higher in services in Luxembourg, New Zealand and Portugal.

\section{Marketing and organisational innovations}

In the 2005 edition of the Oslo Manual, two new types of innovation that can be considered "nontechnological" were identified for the purpose of innovation surveys. They contrast with product and process innovations, which are considered more closely dependent on technology, and are defined as follows:

- A marketing innovation is the implementation of a new marketing method involving significant changes in product design or packaging, product placement, product promotion or pricing.

- An organisational innovation is the implementation of a new organisational method in a firm's business practices, workplace organisation or external relations.

Countries have begun to include these categories in their innovation surveys although the information collected is usually less detailed than for product and process innovation. Examples include:

\section{Marketing innovations}

- The implementation of a significant change in the design of a furniture line to give it a new look and widen its appeal.

- First introduction of direct selling or exclusive retailing.
- First introduction of a method for varying the price of a good or service according to the demand for it.

\section{Organisational innovations}

- First introduction of management systems for general production or supply operations such as supply chain management, business reengineering, lean production, quality management system.

- First establishment of formal or informal work teams to improve access to and sharing of knowledge from different departments, such as marketing, research and production.

- First use of outsourcing of research or production.

\section{Sources}

Eurostat, CIS-2006 (NewCronos), June 2009.

National data sources.

\section{Going further}

OECD and Eurostat (2005), Oslo Manual: Guidelines for Collecting and Interpreting Innovation Data, 3rd edition, OECD, Paris, www.oecd.org/sti/oslomanual.

\section{Figure notes}

Non-technological innovators include firms that introduced a marketing and/or an organisational innovation, except for Slovenia (organisational innovations only).

France: manufacturing only.

New Zealand: SMEs are firms with 10-99 employees. 


\section{COMPETING IN THE WORLD ECONOMY}

3.9. Non-technological innovation

Non-technological innovators by size, 2004-06 As a percentage of all firms

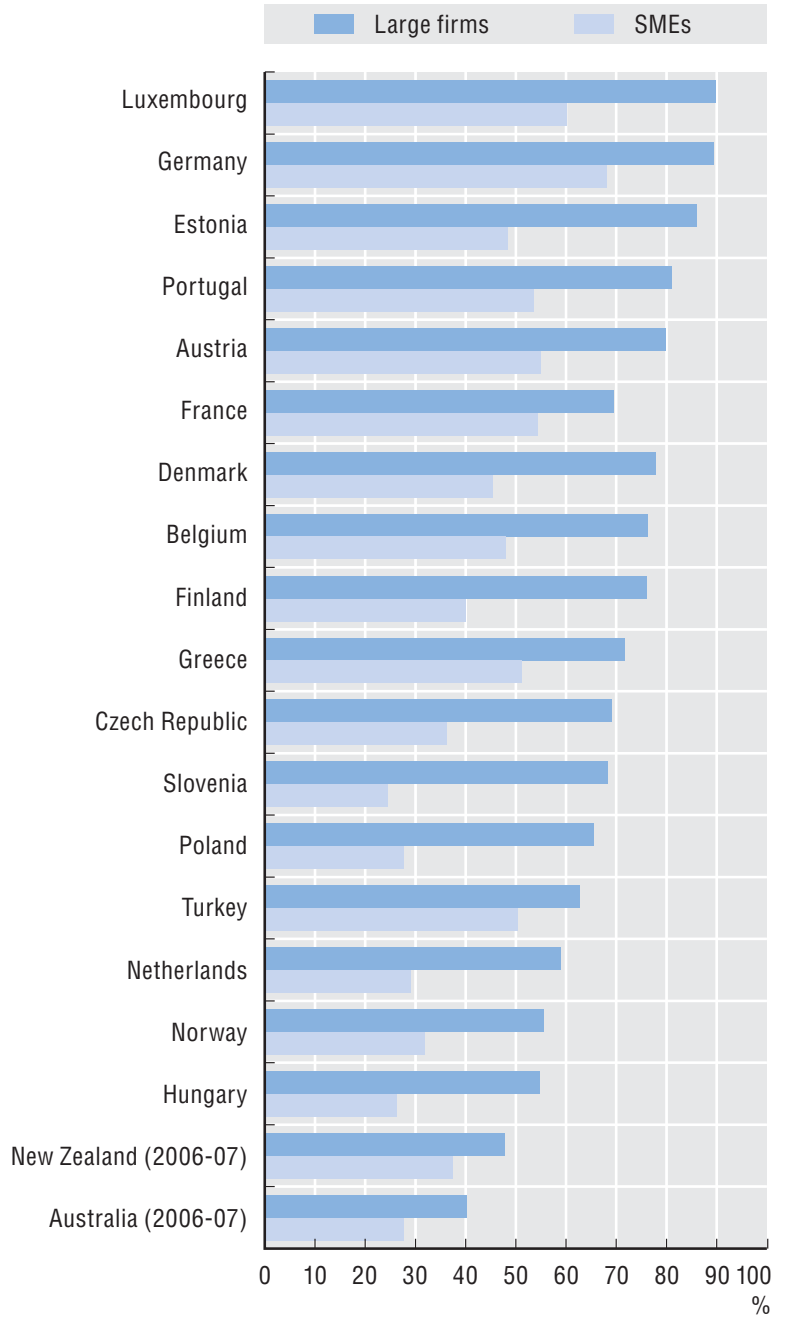

StatLink लाडस http://dx.doi.org/10.1787/745300803612
Non-technological innovators by sector, 2004-06 As a percentage of all firms

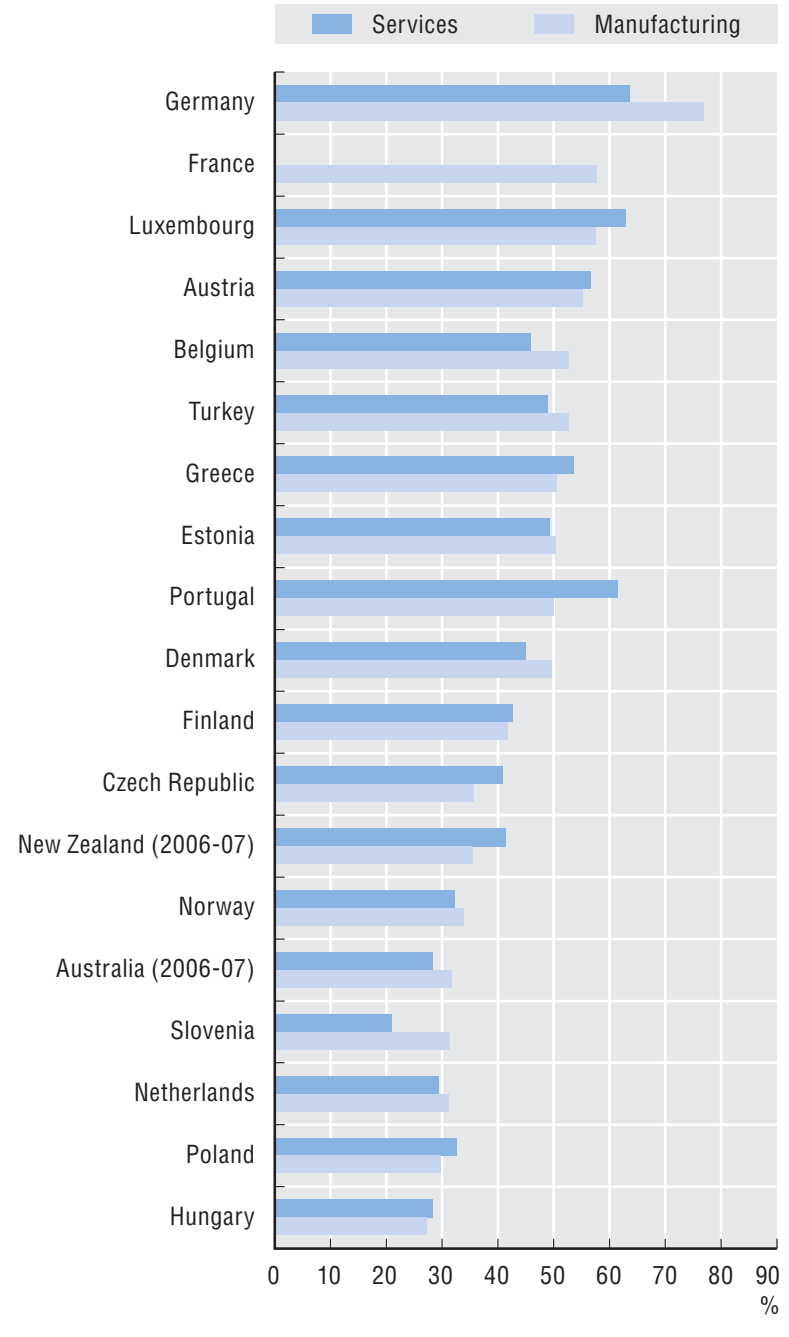

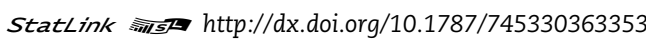


Trademarks are legal protections for distinctive signs of products, such as names or logos. They are often associated to new products as they enable to signal the novelty and do advertising. The number of new trademarks is then an indicator of product and marketing innovations. It makes notably possible to measure non-technological innovation and innovations in the services sector, which are not well captured by research and development and patents.

Cross border trademarks are a statistical concept which enables to compare trademark counts across countries. In 2007, the European Union and the United States had the highest number of cross-border trademarks, accounting for $34 \%$ and $30 \%$, respectively, of all crossborder trademarks worldwide.

Over 1997-2007, the number of cross-border trademarks from the European Union almost doubled. It also significantly increased for Japan and the United States, although to a lesser extent (by $25 \%$ and $23 \%$, respectively). Like other innovation indicators, trademarks are sensitive to the economic situation. The number of trademarks increased significantly from 1997-2000, dropped sharply in the aftermath of the dot-com bubble in 2001 and grew again from 2003 to 2007.

A trademark can cover goods, services or a combination of the two. Over the last decade the share of service trademarks in the European Union and the United States increased by 4 and 5 percentage points, respectively, indicating the growing importance of service innovations, e.g. in finance, insurance or consulting. The countries with the highest shares of pure-service trademarks in 2007 were Iceland, Singapore and Luxembourg (more than 30\%); those with the lowest shares were Finland, Turkey and Israel.

\section{Trademarks}

A trademark is a sign which enables to distinguish the goods or services of one undertaking from those of other undertakings. It is possible to register trademarks at a trademark office. The procedure is similar to patents, except that the application must designate one or several classes of products, and the trademark is then only protected in those fields.

A major issue concerning trademark counts is that they are subject to a home bias. Firms tend to file trademarks in their home country first, so that figures for the host country (such as US applicants filing at the United States Patent and Trademark Office (USPTO) and for other countries are not comparable.
The indicator used here is the number of applications at USPTO except for the United States and countries with a high propensity to file trademarks in the United States: Australia, Canada, Israel, New Zealand and Mexico. For those countries, counts are based on their relative share of filings in the Japan Patent Office (JPO) and the European Office for Harmonization in the Internal Market (OHIM). This method consists in taking as a reference the number of trademarks commercialised abroad, hence the name "cross-border trademarks".

The domestic bias also affects countries' comparability in terms of their relative shares of goods and services trademarks. As services are less exported than goods, there is a greater share of services in domestic than in foreign applications. Here the shares of goods and services are based on USPTO data for all countries except those biased towards USPTO, for which OHIM data are used. This enables to increase the comparability of countries, although lowering the share of services, as these are less likely to be commercialised abroad.

\section{Sources}

USPTO Trademark BIB ACE Database (Cassis), June 2008. OHIM and JPO annual reports 1997-2008.

World Intellectual Property Organization (WIPO) Trademark Statistics, December 2008

OHIM Trademark database, CTM download.

\section{Going further}

Millot, V. (2009), "Trademarks as an Indicator of Product and Marketing Innovations", OECD Science, Technology and Industry Working Papers 2009/6, OECD Paris, www.oecd.org/sti/working-papers.

\section{Figure notes}

Cross-border trademark counts correspond to the number of applications filed at USPTO except for Australia, Canada, Israel, Mexico, New Zealand and the United States. For those countries counts were based on OHIM and JPO distributions.

The shares of goods and services correspond to the applications at USPTO for all countries except the abovecited, for which applications at OHIM are used. 


\section{COMPETING IN THE WORLD ECONOMY}

\subsection{Product and marketing innovation using trademarks}

\section{Cross-border trademarks by economy, 2007}

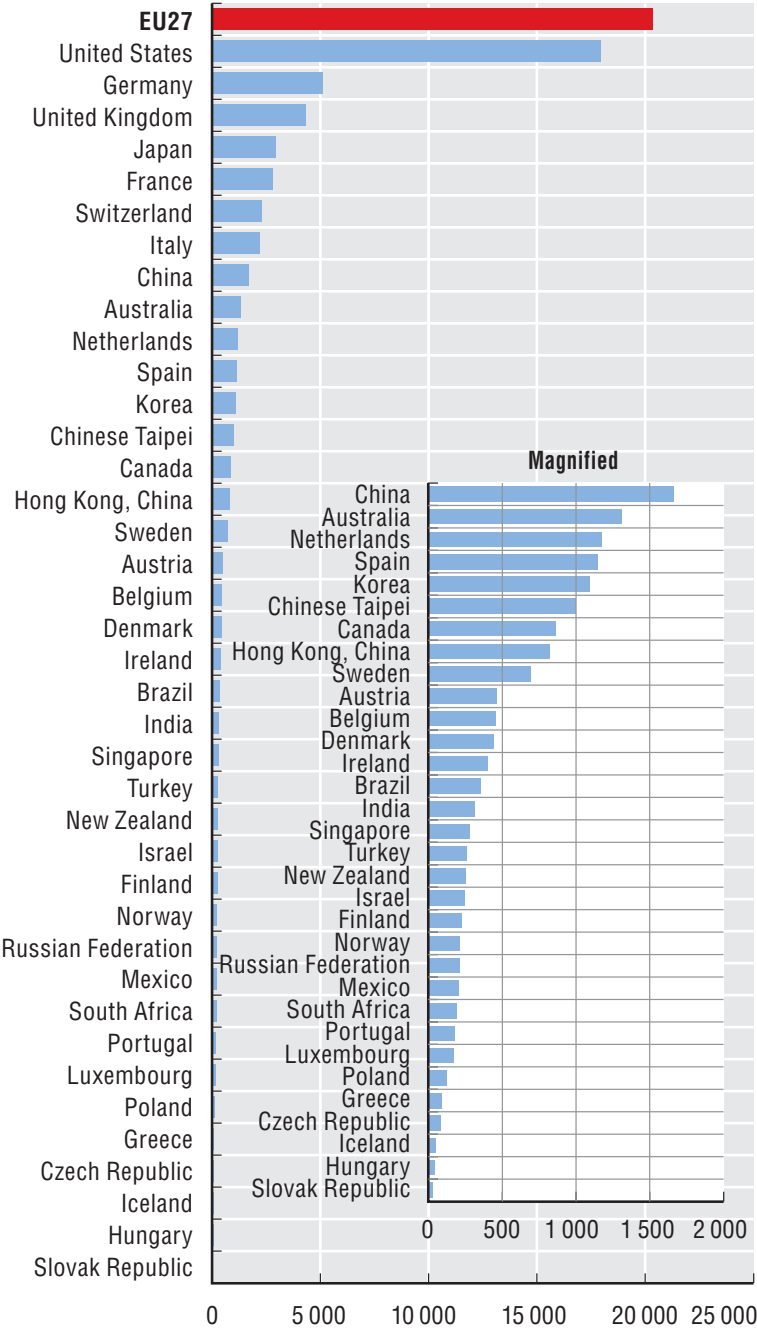

StatLink काजि http://dx.doi.org/10.1787/745353001167

Trends in cross-border trademarks, 1997-2007

Main OECD regions

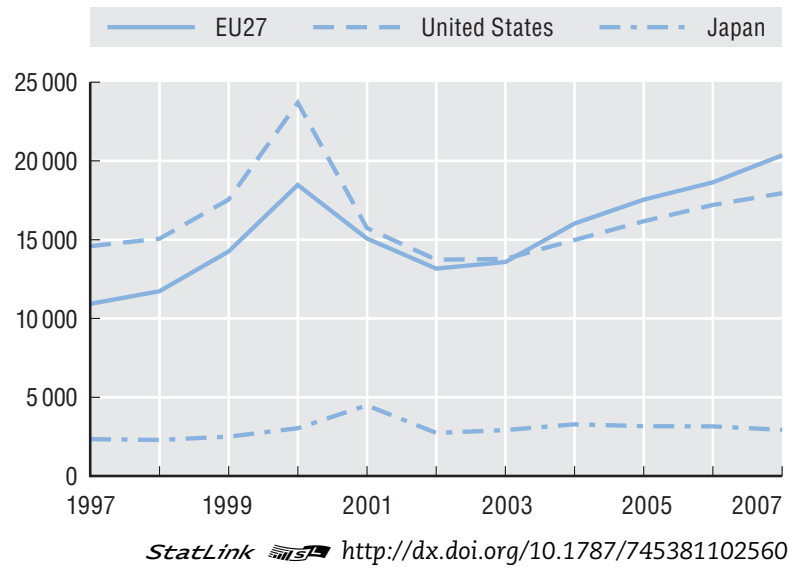

Goods and services in trademark filings, 2007

As a percentage of total filings

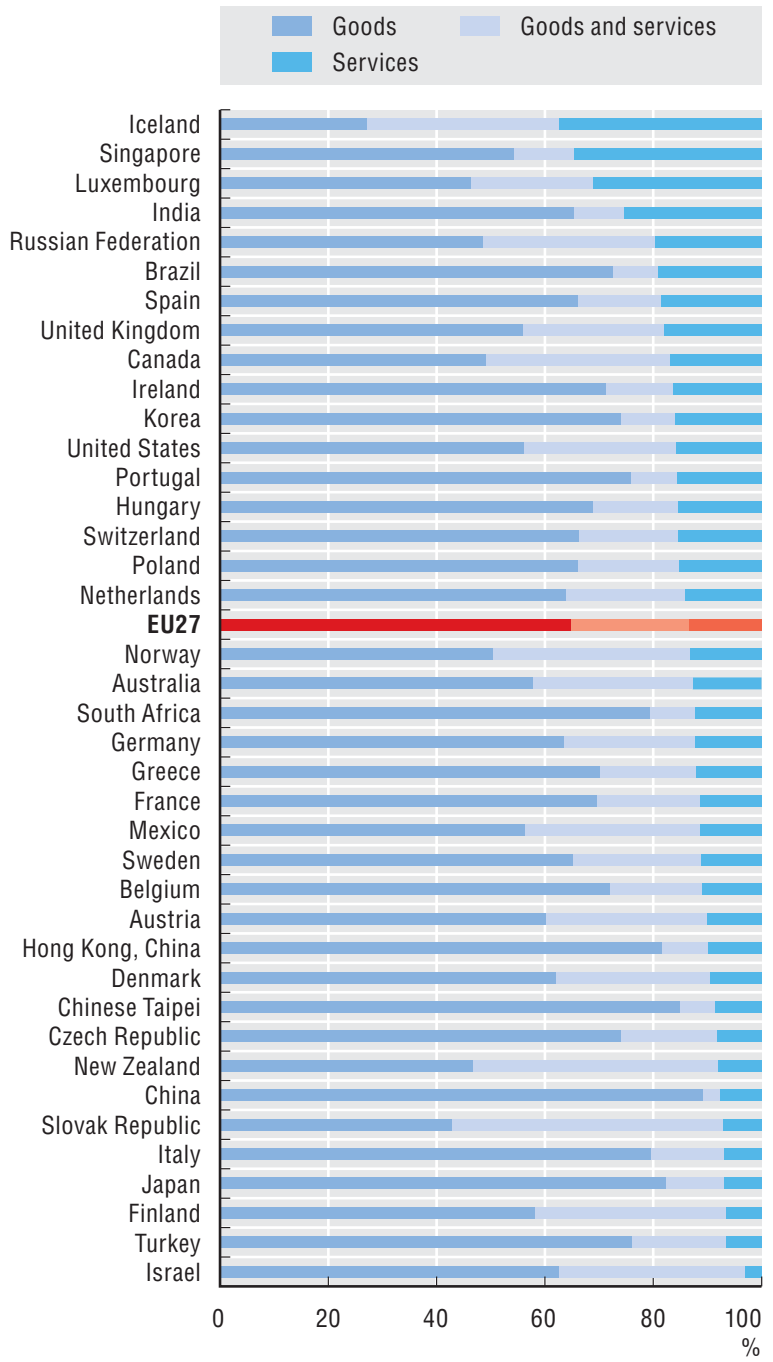

StatLink काज्ञा http://dx.doi.org/10.1787/745385425345

Share of service trademark filings, 1997-2007

As a percentage of total trademarks filings

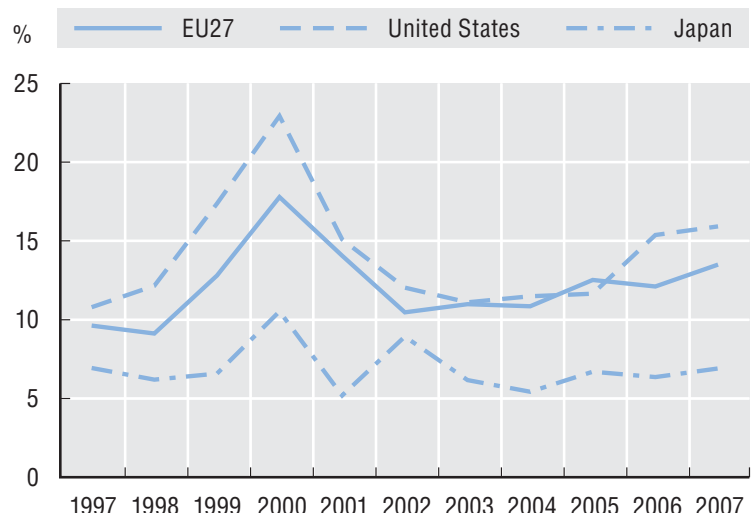

StatLink Aाग http://dx.doi.org/10.1787/745401246822 
The Internet is a tool which enables businesses to reach large numbers of new customers every day. Small and medium-sized enterprises can now advertise and reach customers on a scale that just a few years ago was possible for only a handful of large corporations. Broadband access to the Internet is therefore an important way to compete in the global economy.

Business use of the Internet has become fairly standard practice in most OECD countries. Increasingly, businesses use broadband platforms to connect to the Internet. The share of businesses that use broadband in all businesses with ten or more employees ranges from $46 \%$ in Mexico to $99 \%$ in Iceland. In Iceland, Korea, Canada, France, Spain, Finland, Belgium and New Zealand, over $90 \%$ of businesses have a broadband connection. The OECD average is $83 \%$.

In a majority of OECD countries, over half of businesses have their own website. The share of businesses with their own website in all businesses with ten or more employees ranges from $46 \%$ in Portugal to $89 \%$ in Japan, with an OECD average of $69 \%$. At $85 \%$ or higher, Japan, Denmark, Sweden and the Netherlands have the highest proportion of businesses with their own website.

Official data on access to and use of information and communication technologies (ICTs) by businesses are relatively scarce outside the OECD area, as the surveys to collect these data can be expensive to undertake and this is generally not a priority in developing countries. Supported by the work of the Partnership on Measuring ICT for Development (see "Going further" at right), the list of economies undertaking such surveys is set to grow in the coming years.

Most non-OECD economies for which data on Internet access by business are available report broadband penetration rates lower than those in OECD countries, although the figures presented here are certainly not representative of all developing countries.

\section{Comparing ICT use by businesses}

To improve data comparability, OECD countries agreed in 2001 on a model survey on ICT use by businesses. In order to maintain comparability and relevance of information, the model survey was revised in 2005.

The questionnaire is composed of self-contained modules which can be used either in their totality or as separate modules in specific national surveys. The model survey is intended to provide guidance for measuring ICT use (including e-commerce), and participating countries are encouraged to use it as a core part of their survey development work.
While the model survey has contributed to the use of common methodologies, concepts and data items across OECD countries, there is still some variation. The OECD has attempted to standardise data where possible; the main area of standardisation is the use of a common size cut-off. Most countries provide data based on a size cut-off of 10 or more employees. Because larger businesses are generally more likely to use ICT, penetration rates for countries that include businesses with fewer than 10 employees and those that do not would not otherwise be comparable. Several countries are unable to apply the common cut-off (Japan, Mexico, New Zealand and Switzerland). Their ICT use rates are therefore less comparable than those of other countries.

\section{Sources}

OECD, ICT Database, 2009.

Eurostat, Community Survey on ICT Usage in Enterprises, 2008.

UNCTAD, E-business database May 2009.

\section{Going further}

OECD (2009), "Guide to Measuring the Information Society 2009",

www.oecd.org/sti/measuring-infoeconomy/guide.

Partnership on Measuring ICT for Development, www.itu.int/ITU-D/ict/partnership/.

\section{Figure notes}

For Australia, website includes a presence on another entity's website.

For Japan, businesses with 100 or more employees. For Mexico, businesses with 50 or more employees. For New Zealand, businesses with 6 or more employees and with a turnover greater than NZD 30000 . For Switzerland, businesses with 5 or more employees.

Broadband: download speeds equal to or faster than $256 \mathrm{kbit} / \mathrm{s}$. Size cut-off: Brazil (9+), China (size unknown), Colombia $(0+)$, Thailand $(1+)$. For Hong Kong, China, establishments instead of enterprises. For Egypt, the sample was not extrapolated to the target population. 


\section{COMPETING IN THE WORLD ECONOMY}

\subsection{Internet access and use by businesses}

Business use of broadband and websites, 2008

Percentage of businesses with ten or more employees

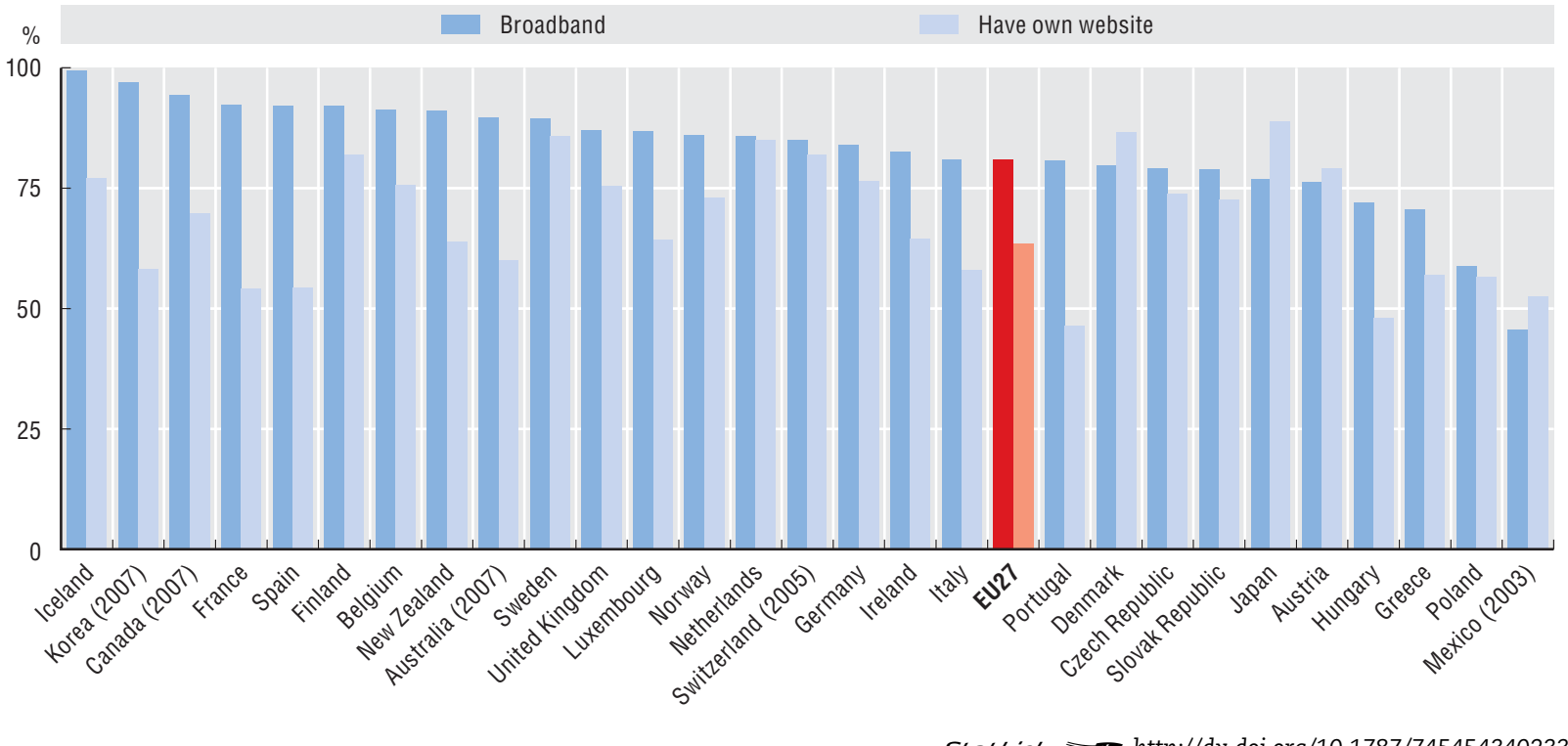

Business use of broadband and websites in non-OECD economies, 2008

Percentage of businesses with ten or more employees

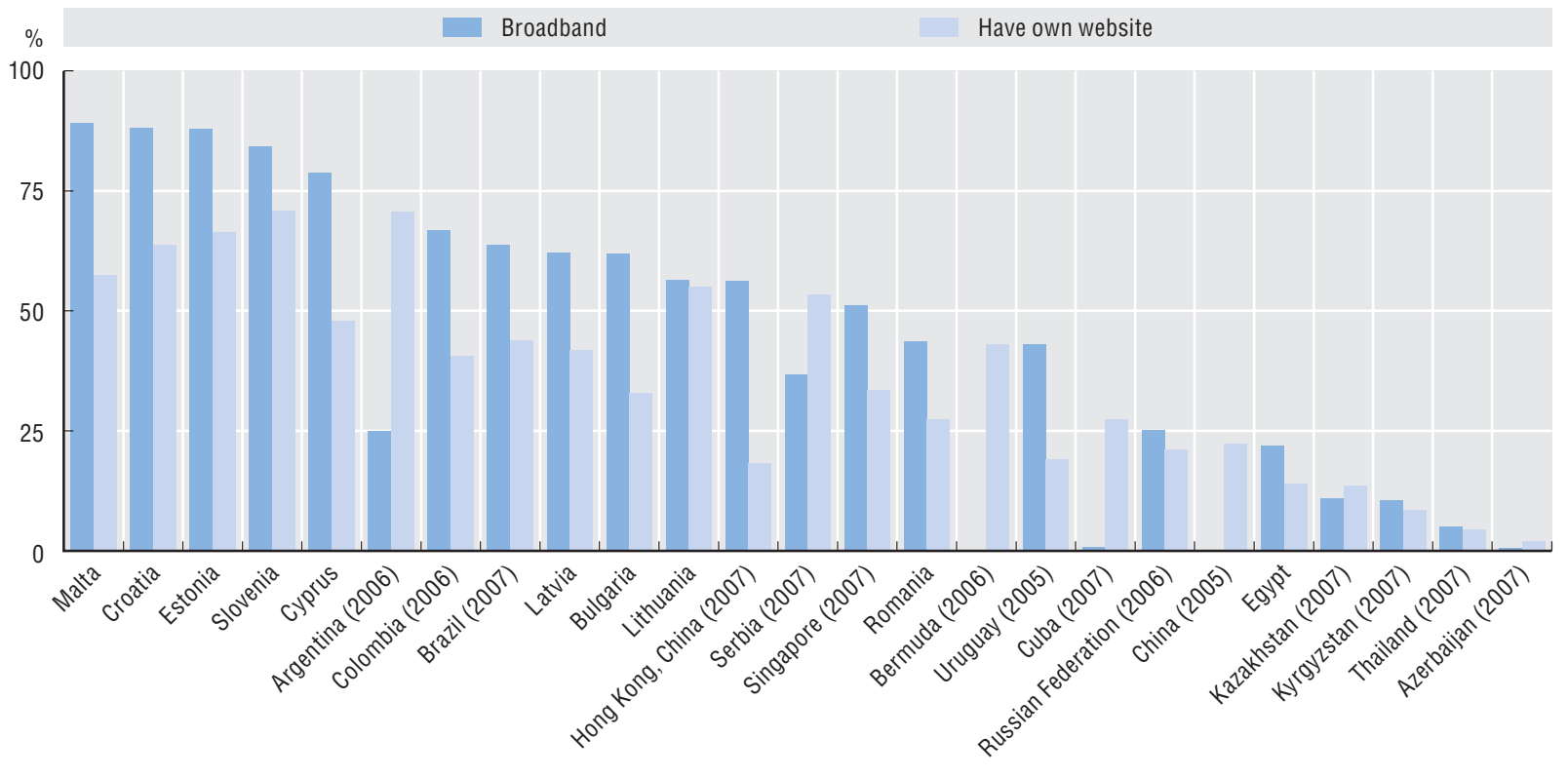

StatLink काISL $h t t p: / / d x . d o i . o r g / 10.1787 / 745457261215$ 


\section{COMPETING IN THE WORLD ECONOMY}

3.12. Fntrepreneurship

Entrepreneurship is increasingly recognised as an important driver of economic growth, productivity, innovation and employment. As firms enter and exit the market, theory suggests that the new arrivals will be more efficient than those they displace. Existing firms that are not driven out are forced to innovate and become more productive in order to compete. This is why policy attaches importance to the number of high-growth firms and the number of young, highgrowth firms (gazelles).

High administrative burdens for start-ups seem to discourage enterprise births, although the relation is not a strong one. This is consistent with findings that this is only one significant factor. Business research and development $(R \& D)$ investment in smaller firms appears, perhaps surprisingly, more strongly related to birth rates. However, more analysis is needed to show a causal relation and its direction.

For high-growth enterprises specifically there is a positive relation with investments in venture capital. However, in the Czech Republic and Hungary, venture capital does not appear to be related to high growth. This suggests that entrepreneurial regimes differ among countries. The link with entrepreneurial capabilities (measured in terms of attainment of tertiary education) is less clear, although the supply of skills is considered an important determinant of high growth.

The relation between determinants of entrepreneurial activity and performance may be clouded for several reasons: empirical indicators only measure some of the theoretical determinants; it takes time for the effects to materialise; determinants may only have an indirect effect on entrepreneurial performance; the effects may depend on enterprises reaching a certain threshold and/or differ between industries; other mechanisms may play a more important role (e.g. the strong economic expansion in Eastern European countries).

\section{Measuring entrepreneurship}

The joint OECD-Eurostat Entrepreneurship Indicator Programme (EIP) has developed empirical indicators to measure countries' entrepreneurial performance. An employer enterprise birth is defined as the birth of an enterprise with at least one employee. Employer enterprise birth rates are expressed as a percentage of the population of active enterprises with at least one employee. High-growth enterprises as measured by employment (or by turnover) are all enterprises with average annualised growth in employees (or in turnover) above $20 \%$ a year, over a threeyear period, and with ten or more employees at the beginning of the observation period. Shares of high-growth enterprises are expressed as a percentage of the population of enterprises with ten or more employees.

\section{Source}

OECD (2008), Measuring Entrepreneurship: A Digest of Indicators, OECD, Paris.

\section{Going further}

OECD (2006), Structural and Demographic Business Statistics 1996-2003, 2006 Edition, OECD, Paris.

Eurostat and OECD (2007), Eurostat-OECD Manual on Business Demography Statistics, OECD, Paris.

\section{Figure notes}

Data on employer enterprise births: 2004 for the United States. SME share of business R\&D: 2004 for Austria and Canada; 2003 for Denmark, Italy and the Netherlands. Venture capital: 2006 for New Zealand. 
Birth rate and the regulatory framework, 2005

Employer enterprise birth rate, 2005, \%

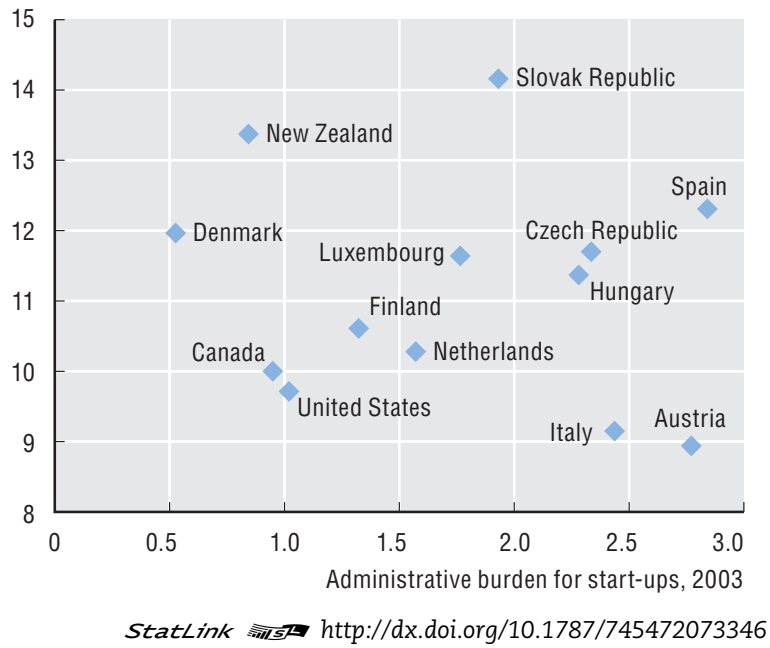

High-growth enterprises and education, 2005

Share of high-growth enterprises, 2005, \%

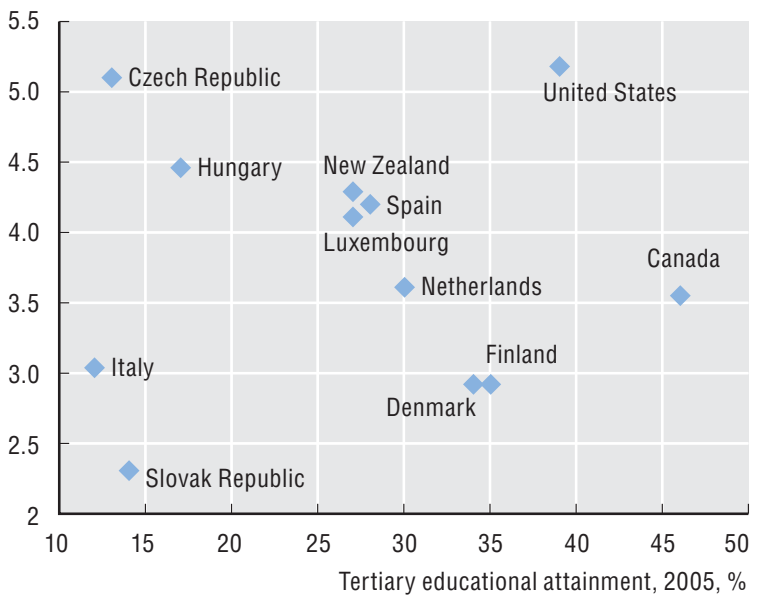

StatLink AाIs http://dx.doi.org/10.1787/745541258672
Birth rate and R\&D, 2005

Employer enterprise birth rate, 2005, \%

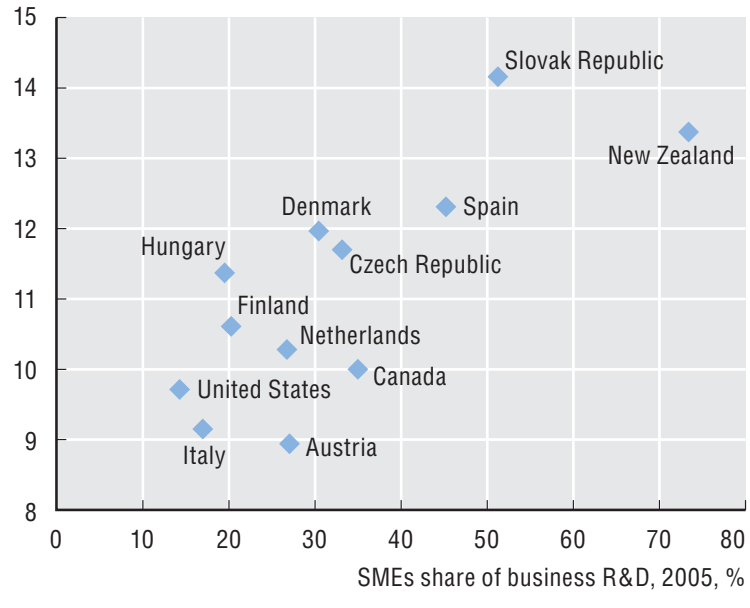

StatLink ताIs/ $h t t p: / / d x . d o i . o r g / 10.1787 / 745480262068$

\section{High-growth enterprises and venture capital, 2005}

Share of high-growth enterprises, 2005, \%

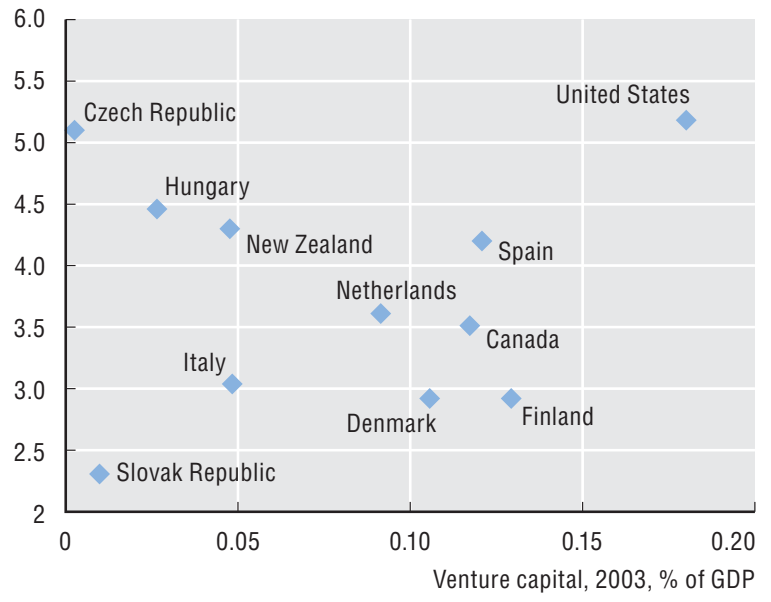

StatLink AाISL http://dx.doi.org/10.1787/745573422732 



\section{CONNECTING TO GLOBAL RESEARCH}

4.1. International co-operation in research................ 110

4.2. International research co-operation among regions . . . . . 112

4.3. International co-operation in science. ................. 114

4.4. Cross-border inventions . . . . . . . . . . . . . . . . . . . 116

4.5. Technology balance of payments ................... 118

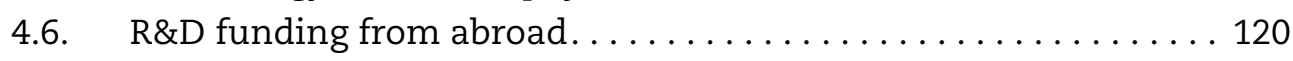

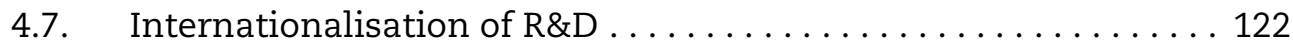

4.8. International collaboration on innovation.............. 124

4.9. International mobility of doctoral students............. 126

4.10. Foreign scholars in the United States ................. 128 


\section{CONNECTING TO GLOBAL RESEARCH}

\subsection{International co-operation in research}

International co-operation in research allows firms to stay abreast of developments and tap into a large base of ideas and technology. The innovation capability of a country depends to a significant extent on the degree of co-operation between its firms and their foreign partners.

International co-operation has increased in recent times. The average share of patent applications filed under the Patent Co-operation Treaty (PCT) that involved international co-invention increased from $6.6 \%$ in $1996-98$ to $7.3 \%$ in $2004-06$.

The degree of international co-operation differs significantly between small and large countries. On average, small and less developed economies engage more actively in international collaboration. This reflects their need to go beyond their small internal markets and/or have access to better research infrastructure. Co-invention is particularly strong in Chinese Taipei, Belgium and Switzerland, where over $40 \%$ of the patents filed in the mid-2000s resulted from collaboration with at least one inventor from abroad.

Among large countries, the degree of co-operation varies more. France, Germany, the United Kingdom and the United States report international co-operation of between $11 \%$ and $24 \%$ in 2004-06. European countries report a significant increase in international collaboration: in Sweden (18.6\%) and the United Kingdom (24.4\%), for instance, the share of co-invented patents increased by more than 5 percentage points from 1996-98. Japan and Korea have the smallest shares of international co-invention, and less than in the mid-1990s. Brazil, China, Japan and Korea report a contraction of more than $30 \%$ in international coinvention.

European countries mainly collaborate with other EU countries, except Ireland and the United Kingdom which co-operate most with the United States. In Canada, China, India, Israel, Korea, Mexico and Chinese Taipei the share of patents co-invented with the United States is at least twice as high as the share co-invented with European Union countries.

\section{Patents measuring co-inventions}

Co-invention of patents is a measure of the internationalisation of research. It provides an indicator of formal R\&D co-operation and knowledge exchange among inventors in different countries. International co-invention is measured as the number of patents invented by a country with at least one inventor located abroad as a share of total patents invented domestically.

As inventors in different countries differ in their specialisation and knowledge assets, they often need to seek competences or resources beyond their national borders. International collaboration by researchers can take place either within a multinational corporation (providing research facilities in several countries) or through a research joint venture among several firms or institutions (e.g. universities or public research organisations). For multinational corporations, international collaboration frequently reflects companies' strategies to integrate geographically dispersed knowledge (e.g. within the multinational network) and/or to develop complementarities with foreign inventors (firms or institutions) in the production of technology.

\section{Source}

OECD, Patent Database, June 2009, www.oecd.org/sti/ipr-statistics.

\section{Going further}

OECD (2009), OECD Patent Statistics Manual, OECD, Paris.

\section{Figure notes}

Co-inventions are measured as the share of patent applications filed under the PCT with at least one coinventor located abroad in total patents invented domestically.

Patent counts are based on the priority date and the inventor's country of residence. The EU is treated as one country; intra-EU co-operation is excluded. Average co-operation is provided for OECD total and total patents.

Figures only cover countries with more than 250 PCT filings over the periods. 


\section{CONNECTING TO GLOBAL RESEARCH}

4.1. International co-operation in research

PCT patent applications with co-inventors located abroad, 2004-06

Percentage

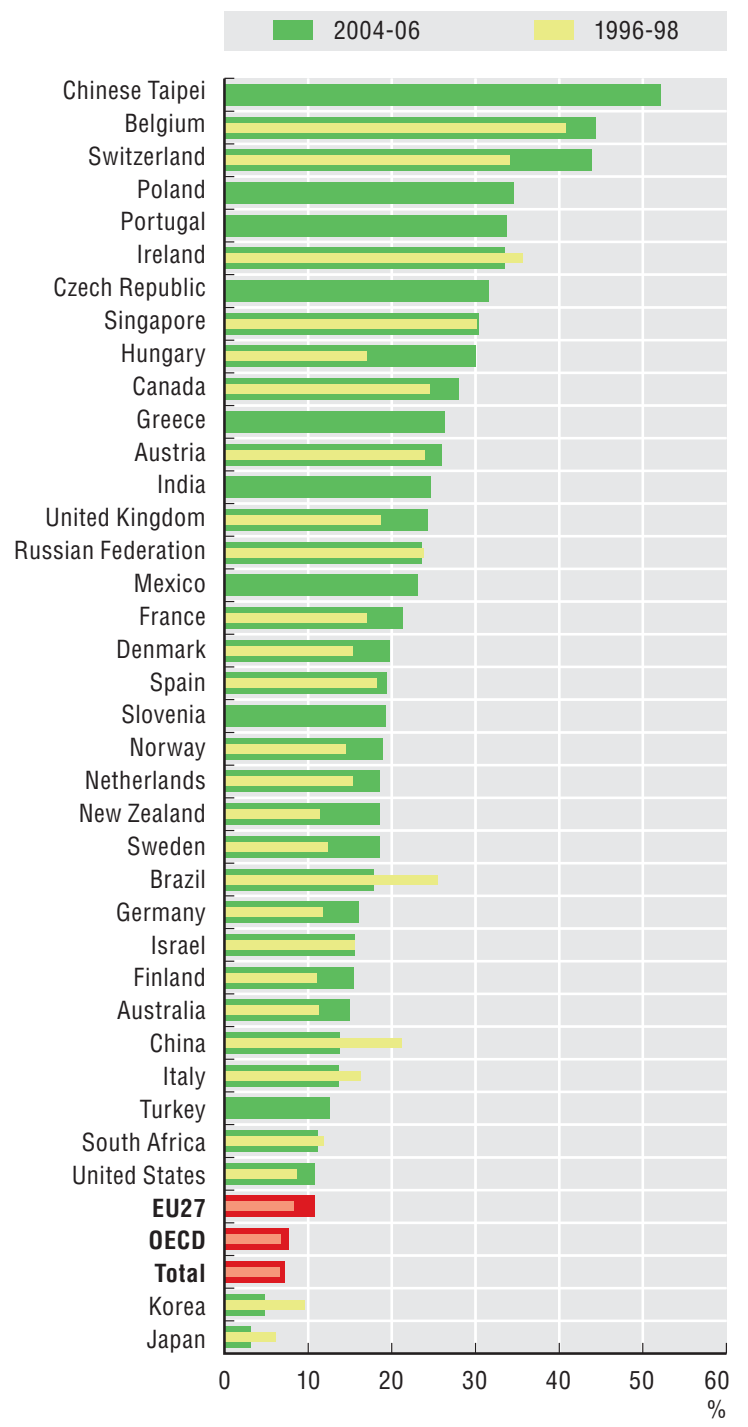

StatLink काIs http://dx.doi.org/10.1787/745612746632
PCT patent applications with co-inventors located abroad, by partner, 2004-06

Partner in the three major regions
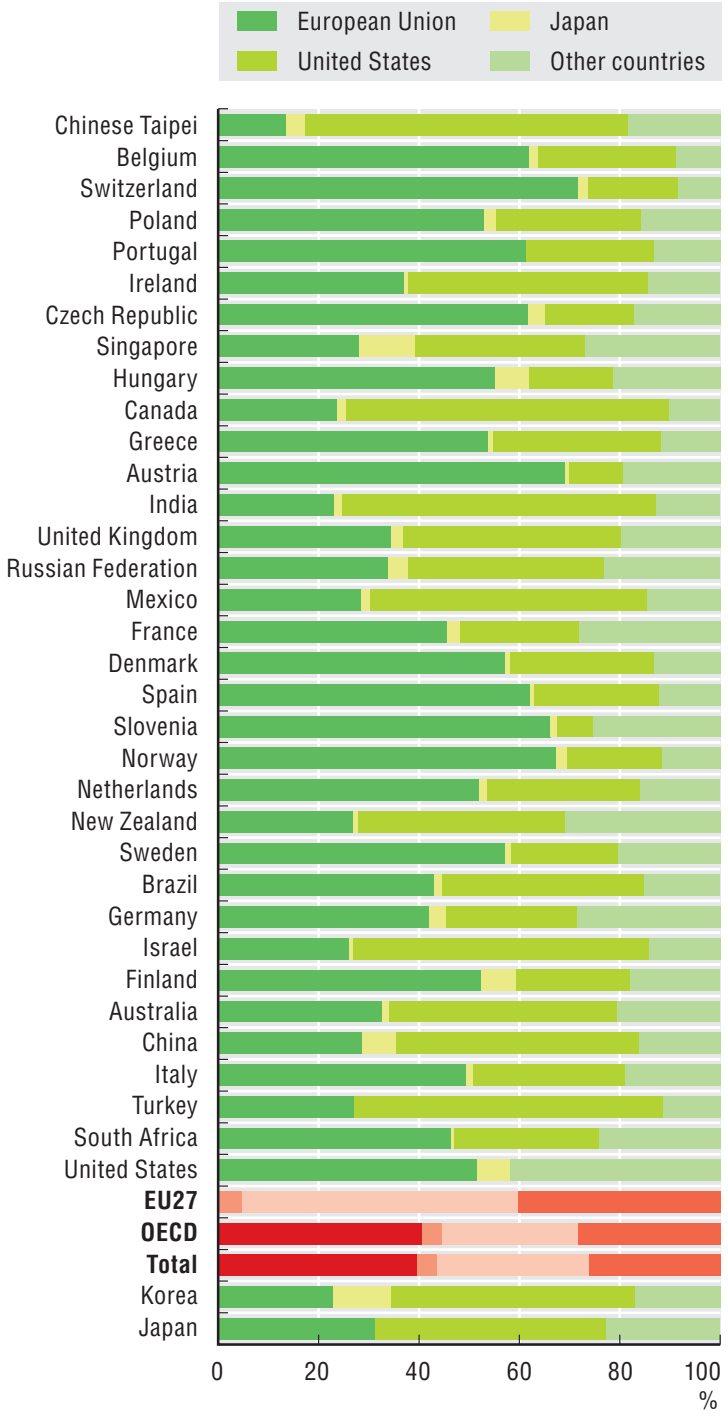

StatLink क्ञाज http://dx.doi.org/10.1787/745658281221 


\section{CONNECTING TO GLOBAL RESEARCH}

International research co-operation is unevenly distributed within countries, with a few regions accounting for most of the patents with foreign inventors. This suggests that a country's innovative capability depends on the ability of a very few of its regions to connect to global research networks.

Analysis of regional patenting helps to identify innovative regions that serve as important nodes of innovation networks. In 2004-06, the regional concentration of inventive activities was highest in large countries such as Australia (with an index of 92) and Canada (94), whereas Ireland (31) and Switzerland (28) showed the least concentration. In almost all countries, international co-invention of patents was slightly more concentrated in some regions than total patenting activity.

In the mid-2000s, among the top 20 collaborative regions in terms of the number of patents with at least one co-inventor located abroad, 11 were in the United States. However, none of the US regions remains in the top 20 when co-operation is measured in relative terms. The regions with the highest shares of patents with foreign co-inventors were mostly located in Europe. The high scores of the French regions (Haut-Rhin and Bas-Rhin) and the Swiss region of Basel-Landschaft can be ascribed to their geographical proximity: inventors from Haut-Rhin co-operate with German and Swiss inventors, mostly in companies located in Switzerland. The Belgian regions of Brussels and Vlaams Brabant tend to act as an innovation hub, with co-inventions between the main European countries and the United States. Outside Europe, the Indian state of Karnakata shows the largest share of international co-operation in its patenting activity (42\%), mostly with US co-inventors.

\section{Patents by regions}

Breaking down patent data by region allows for a broad range of analyses to address issues relating to the regional dimension of inventive activities. The addresses of the inventors and applicants - as provided in the patent document - have been linked to regions at a very detailed level for most OECD countries, plus China and India.

The OECD has classified regions within each member country, based on two territorial levels. The higher level (territorial level 2 - TL2) consists of 335 large regions, while the lower level (territorial level 3 - TL3) is composed of 1681 small regions.
All regions are defined within national borders and, in most cases, correspond to administrative regions. This classification, which for European countries is largely consistent with the Eurostat's Nomenclature of Territorial Units for Statistics (NUTS), facilitates comparisons between regions at the same territorial level. Indeed the two levels, which are officially established and relatively stable in all member countries, are used as a framework for implementing regional policies in most countries.

The geographic concentration index presented here is defined for the variable $y$ as:

$$
\left[\sum_{i=1}^{N}\left|y_{i}-a_{i}\right| / 2\right] \times 100
$$

where $y_{i}$ is the share of region $i$ in the national total $y, a_{i}$ is the area of region $i$ as a percentage of the country area, and $N$ stands for the number of regions. The index ranges from 0 (no concentration) to 100 (maximum concentration) in all countries. Its value is affected by the size of regions, and differences in geographic concentration among countries may be partially due to differences in the average size of regions in each country.

\section{Source}

OECD, REGPAT Database, June 2009, www.oecd.org/sti/ipr-statistics.

\section{Going further}

Maraut, S., et al. (2008), "The OECD REGPAT Database: A Presentation", OECD Science, Technology and Industry Working Papers 2008/2, OECD, Paris, www.oecd.org/sti/working-papers.

OECD (2009), OECD Patent Statistics Manual, OECD, Paris.

\section{Figure notes}

Counts are based on patent applications filed under the PCT, by priority date and inventor's region of residence, using simple counts.

The shares of international co-inventions by regions are measured as the share of PCT patent applications with at least one co-inventor located abroad in total patents invented by a given region.

The list of top 20 regions cover regions with more than 250 PCT filings over 2004-06. 


\section{CONNECTING TO GLOBAL RESEARCH}

Regional concentration of PCT patent applications with co-inventors located abroad, 2004-06

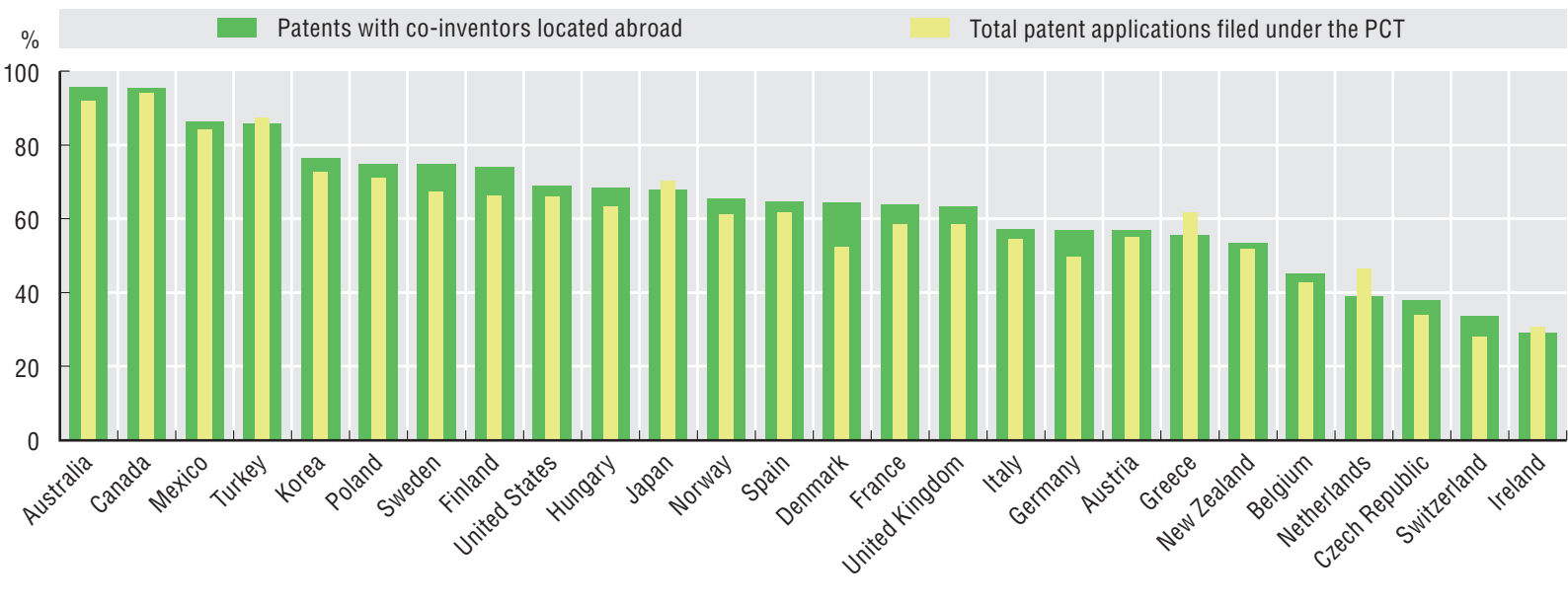

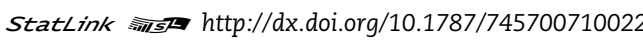

Top 20 regions by number of PCT patents with co-inventors located abroad, 2004-06

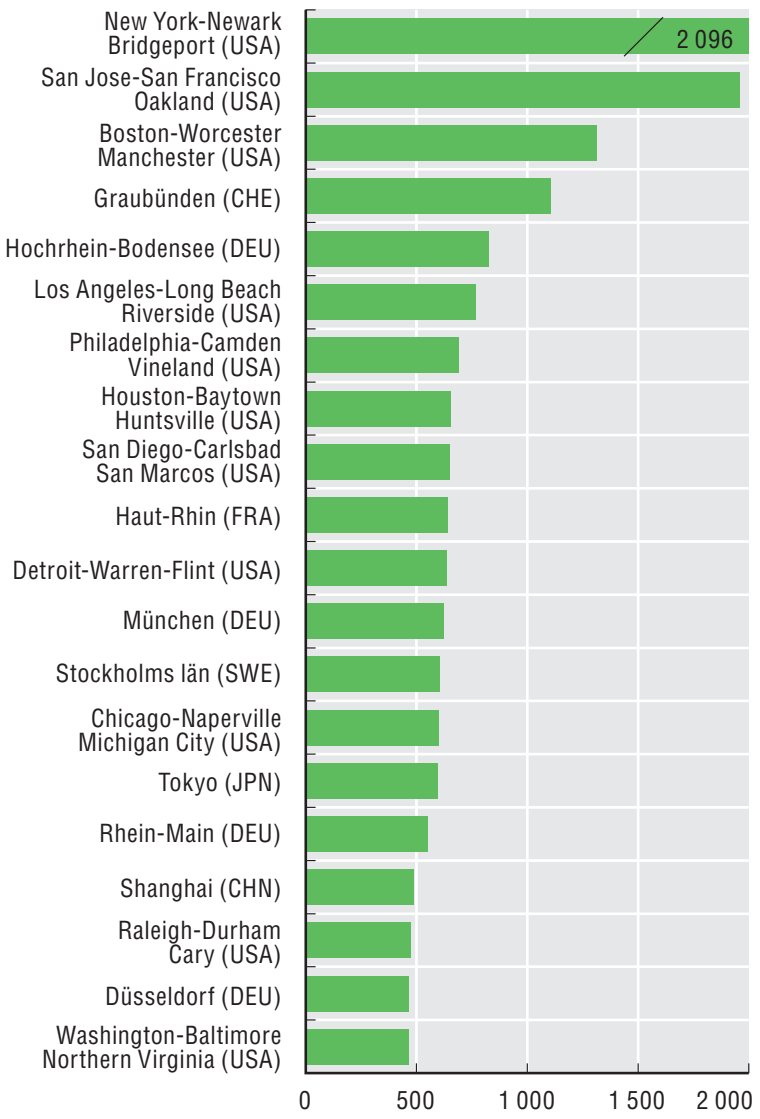

StatLink काIsL http://dx.doi.org/10.1787/745710883872
Top 20 regions by share of PCT patents with co-inventors located abroad, 2004-06

Percentage

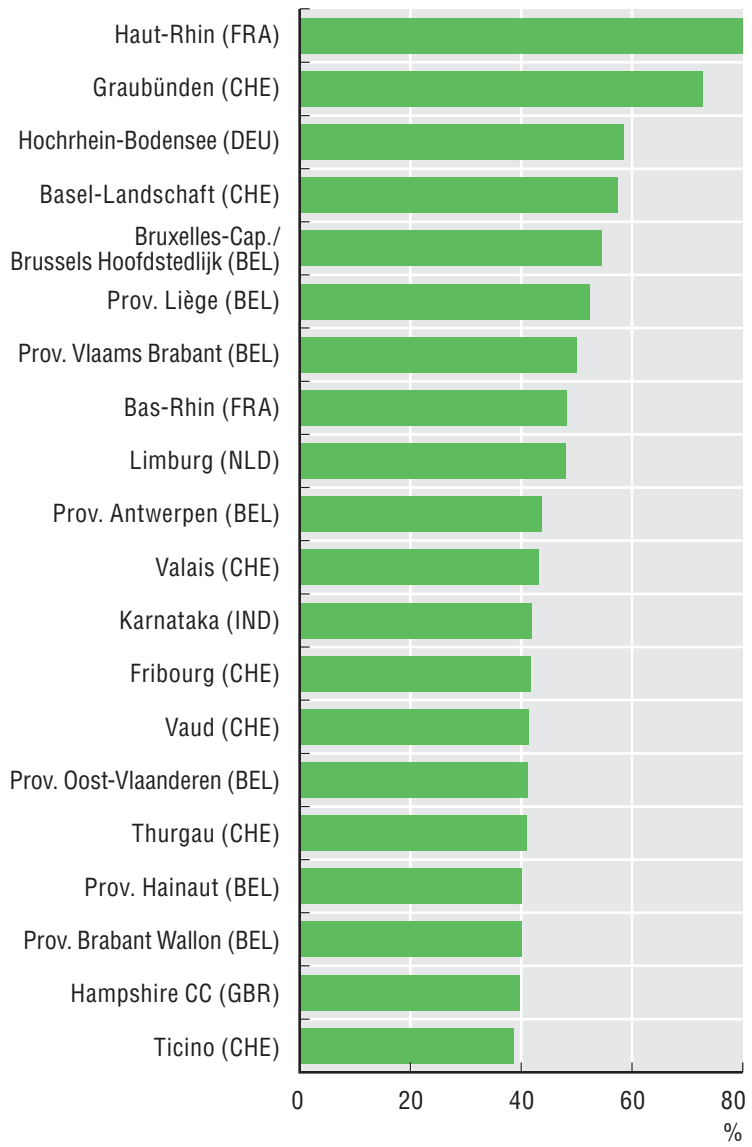

StatLink aाIS http://dx.doi.org/10.1787/745716774063 


\section{CONNECTING TO GLOBAL RESEARCH}

Co-authorship of research publications provides a direct measure of collaboration in science. Research publications may have a single author or two or more co-authors. Co-authorship may involve researchers in the same institution, in the same country, or in two or more countries. These indicators help to understand how knowledge is created among researchers and how collaboration in science is changing.

Collaboration among researchers in a single institution was the major form of collaborative research until the end of the 1990s. However, the percentage of single-institution co-authorship has been decreasing over the last two decades.

Co-authorship, both domestic and international, has grown in importance over the past decade. Domestic co-authorship, i.e. collaboration by researchers of different institutions in the same country, has been increasing rapidly. It surpassed the share of singleinstitution co-authorship in 1998 and has since been the most common form of scientific collaboration.

International co-authorship has been growing as fast as domestic co-authorship. In $2007,21.9 \%$ of scientific articles involved international co-authorship, a figure three times higher than in 1985. Increases in domestic and international co-authorship point to the crucial role of interaction among researchers as a way to diversify their sources of knowledge.

As a general trend, scientific knowledge production is shifting from individual to group, from single to multiple institutions, and from national to international. Researchers are increasingly networked across national and organisation borders.

The degree of international collaboration varies. Large countries tend to engage in less international collaboration. Large European countries (France, Germany and the United Kingdom) conduct more collaborative work than the United States and Asian countries.

\section{Measures of co-authorship}

Four types of authorship of scientific articles are analysed: single authorship, single-institution co-authorship, domestic co-authorship and international co-authorship. The analysis is based on the Science Citation Index on CD-ROM (1981-2007) provided by Thomson Scientific and analysed by the National Institute of Science and Technology Policy in Japan.
Single authorship measures scientific papers with a single author. Single-institution coauthorship measures scientific papers with two or more authors of the same institution. Domestic co-authorship measures scientific articles with two or more authors from different institutions in the same country. International coauthorship measures scientific articles with two or more authors from different countries. The boundary between single-institution co-authorship and domestic co-authorship is not always clear, as for example, when co-authors belong to different departments of same university. Here, the classification is based upon the number of addresses listed in each article.

Indicators of co-authorship draw attention to language barriers and geographical factors. However, these obstacles have diminished as English has become the language most commonly used internationally among researchers. Furthermore physical distance between researchers is likely to have some correlation with the ratio of co-authorship, although the effect of information and communication technology on knowledge flows has undoubtedly facilitated distance collaboration.

\section{Sources}

National Institute of Science and Technology Policy in Japan (2008), "Science and Technology Indicators", data updated in 2008 for the 5th edition, July.

OECD calculations, based on Scopus Custom Data, Elsevier, July 2009.

\section{Going further}

Igami, M. and A. Saka (2007), "Capturing the Evolving Nature of Science, the Development of New Scientific Indicators and the Mapping of Science", OECD Science,Technology and Industry Working Papers 2007/1, OECD, Paris, www.oecd.org/sti/working-papers.

\section{Figure notes}

Data are based on research articles in natural and medical sciences and engineering. 


\section{CONNECTING TO GLOBAL RESEARCH}

4.3. International co-operation in science

Trends in the co-operation in science, 1985-2007

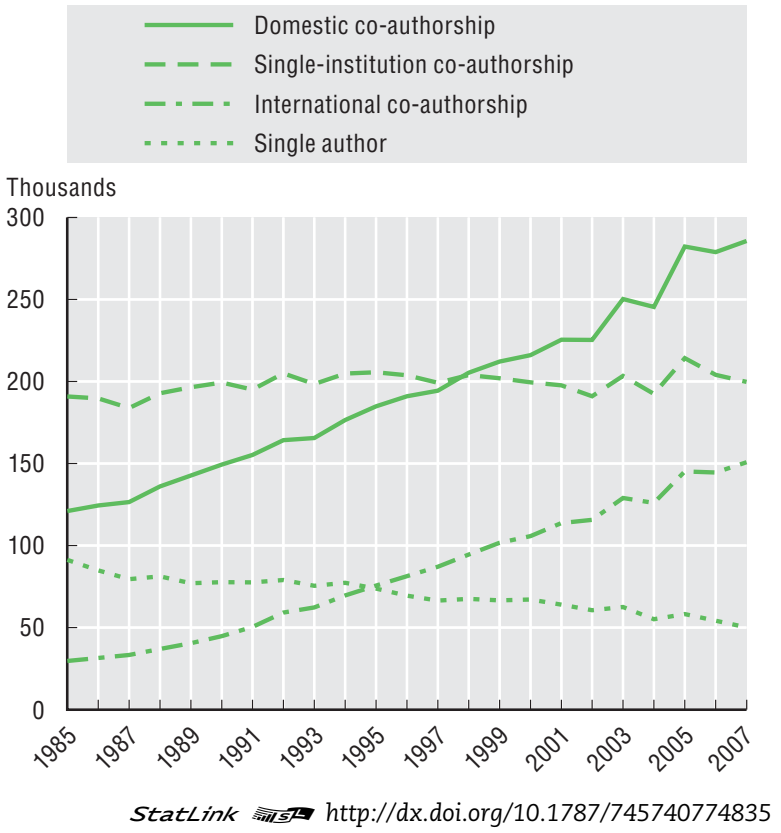

Share of co-authored scientific articles, 1982-87, 1992-97, 2002-07

As a percentage of total
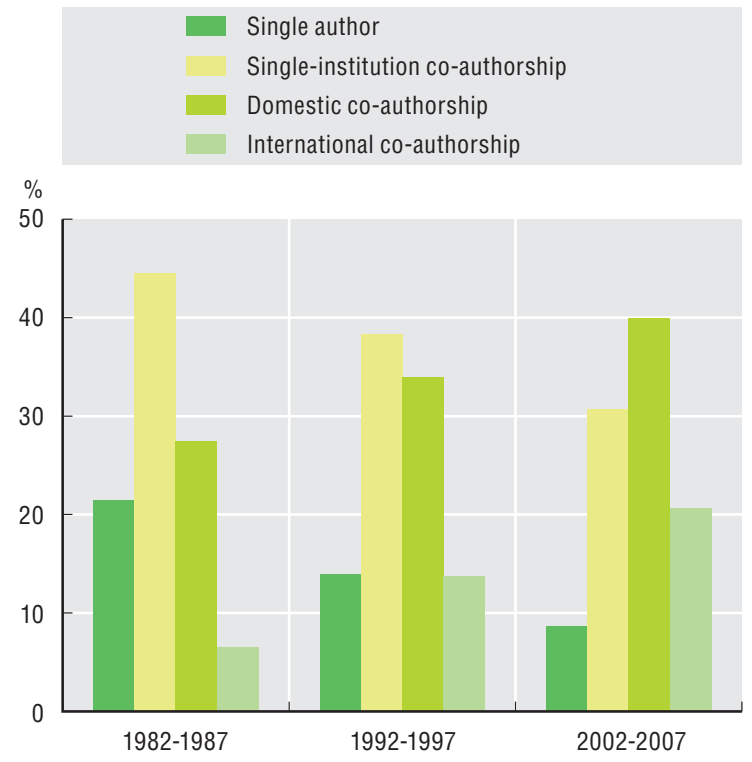

StatLink तiाs http://dx.doi.org/10.1787/745744166773

\section{Share of internationally co-authored scientific articles, 2007}

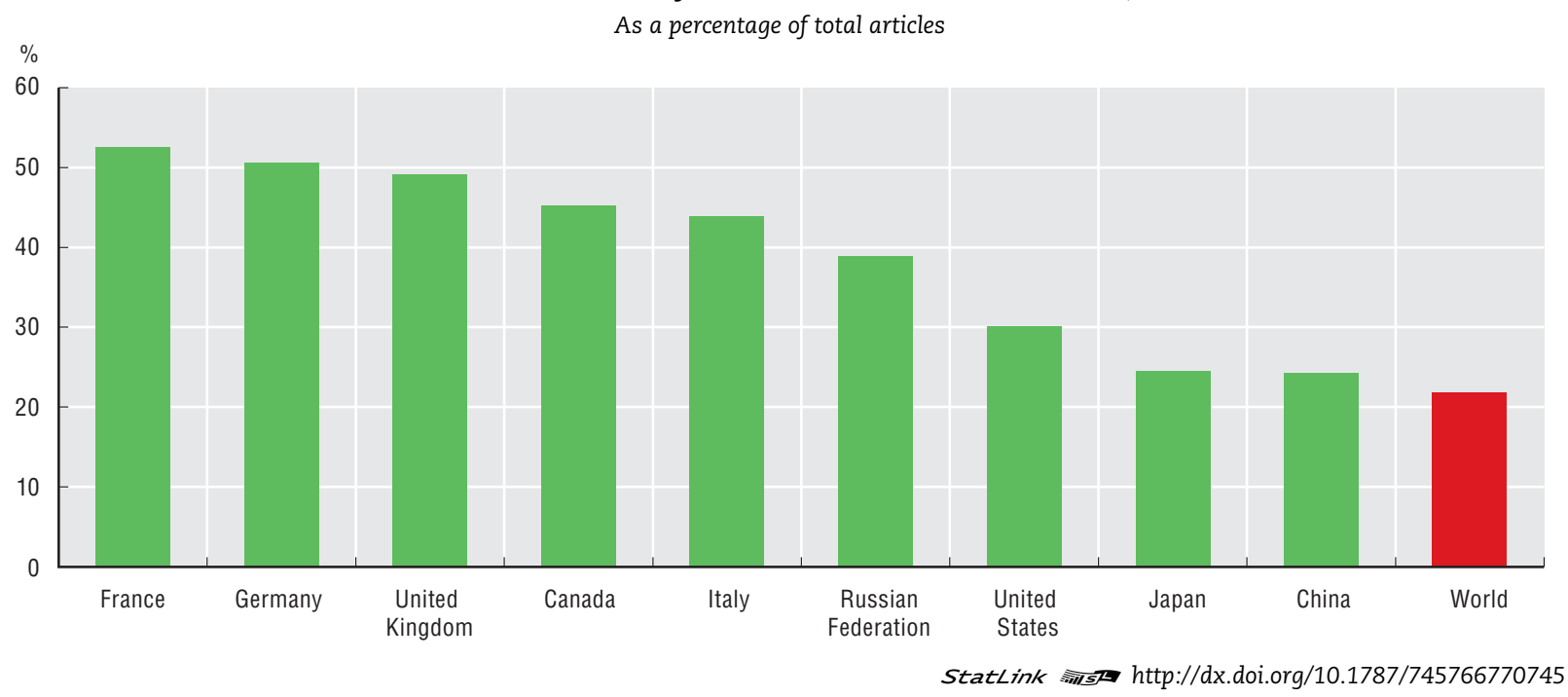




\section{CONNECTING TO GLOBAL RESEARCH}

\subsection{Gross-border inventions}

In the search for new technological competences, better adaptation to local markets, and lower research and development costs, companies are moving research activities abroad. This internationalisation of research activities is an important driver of innovative firms and country competitiveness.

Patents provide two complementary indicators of the internationalisation of research. The first is the share of patents filed by one country for an invention made in another country (ownership of inventions made abroad). The second is the share of inventions made in one country and patented by a foreign country (foreign ownership of domestic inventions).

For 2004-06, both indicators show a significant degree of internationalisation of research activities. On average, over $15 \%$ of the patents filed by an OECD country under the Patent Co-operation Treaty (PCT) concerned inventions made abroad. Similarly, the share of inventions owned by another country accounted for just under 15\% of all OECD filings.

The internationalisation of research activities varies substantially across countries. In 2004-06, Luxembourg $(87 \%)$ and Switzerland (63\%) mainly had patents for inventions made in other countries, mainly by EU residents. In small European countries, such as Austria, Belgium, Hungary, Poland and Portugal, over $40 \%$ of inventions were filed by foreign patent applicants, mostly European companies. This suggests that geographical and cultural proximity is an important factor in the localisation of research activities abroad.

During the same period, Japan and Korea had the least internationalisation of research, in terms both of domestic ownership of foreign inventions and of foreign ownership of domestic inventions. In these countries, most cross-border ownership involves a US partner.

\section{Patents measuring globalisation in S\&T}

Globalisation of technological activities can be quantified with the use of patents. Patents have a distinctive feature that makes them very attractive as an indicator of global science and technology (S\&T) activities: patent documents report the names of the inventor(s) and the applicant(s) - the owner of the patent at the time of application - along with their addresses and countries of residence.

Cross-border ownership occurs when the country of residence of the owner(s) and inventor(s) differ. In most cases, cross-border ownership of inventions is the result of activities of multinationals: the applicant is an international conglomerate and the inventors are employees of a foreign subsidiary. Patent documents therefore make it possible to trace the internationalisation of technological activities and the circulation of knowledge among countries.

The share of domestic ownership of inventions made abroad shows the extent to which domestic firms control inventions made by residents of other countries. The growth of this indicator basically reflects two motivations of S\&T activities by companies: the need to adapt products and processes to host markets ("asset-exploiting" strategies) and to acquire knowledge ("assetseeking" strategies).

Foreign ownership of domestic inventions is another measure of the globalisation of technological activities and reflects the extent to which foreign firms control domestic inventions. Foreign ownership also includes inventions in which the inventor country shares ownership (co-owned inventions), but this represents only a small part of total cross-border inventions.

\section{Source}

OECD, Patent Database, June 2009, www.oecd.org/sti/ipr-statistics.

\section{Going further}

Guellec, D. and B. van Pottelsberghe de la Potterie (2001), "The Internationalisation of Technology Analysed with Patent Data", Research Policy, Vol. 30, Issue 8, pp. 1253-1266.

OECD (2009), OECD Patent Statistics Manual, OECD, Paris.

\section{Figure notes}

The EU is treated as one country and excludes intra-EU co-operation; average co-operation is provided for OECD total and total patents.

Figures cover economies with more than 250 PCT filings over 2004-06.

Domestic ownership of inventions is defined as the share of patent applications filed under the PCT invented abroad in total patents owned by country residents, by priority date.

Foreign ownership of inventions is defined as the share of patent applications filed under the PCT owned by foreign residents in total patents invented domestically, by priority date. 
Domestic ownership of inventions made abroad, 2004-06

Partner in the three major regions

\begin{tabular}{ll}
\hline European Union & Japan \\
\hline United States & Other countries
\end{tabular}

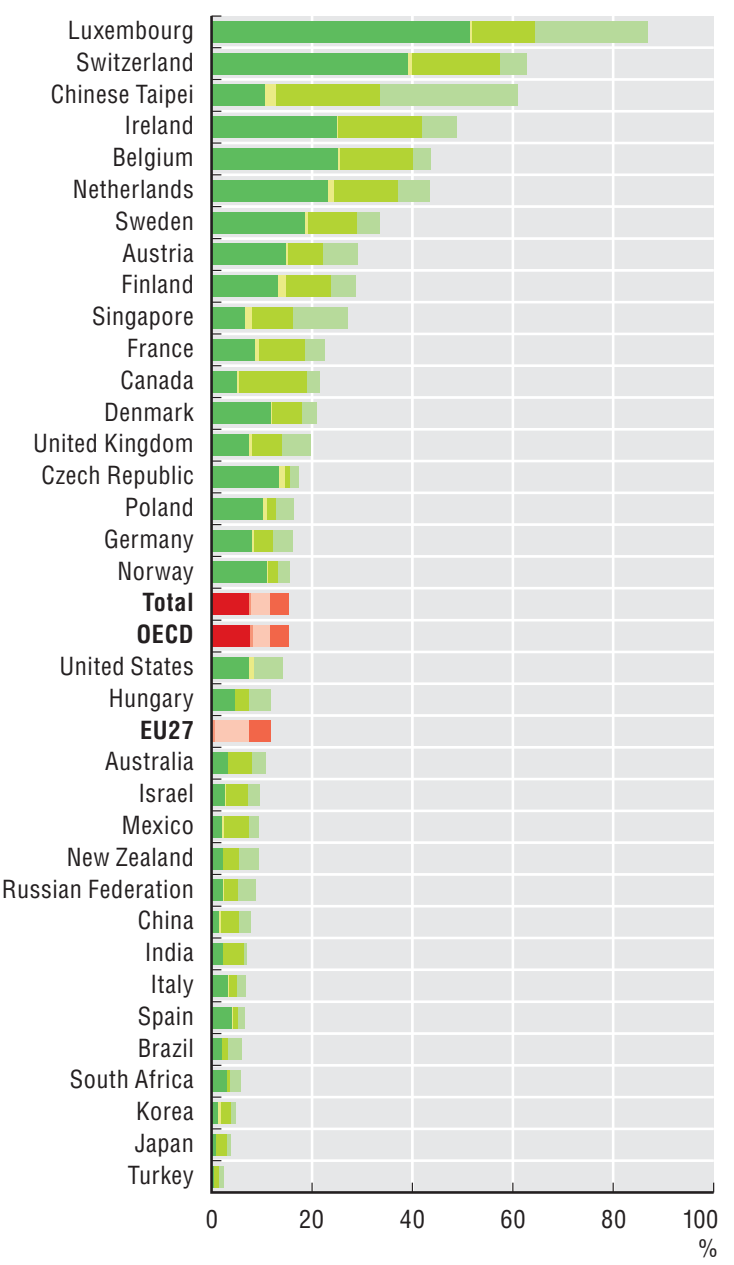

StatLink silsL $h t t p: / / d x . d o i . o r g / 10.1787 / 745826168641$
Foreign ownership of domestic inventions, 2004-06

Partner in the three major regions

\begin{tabular}{ll}
\hline European Union & Japan \\
\hline United States & Other countries
\end{tabular}

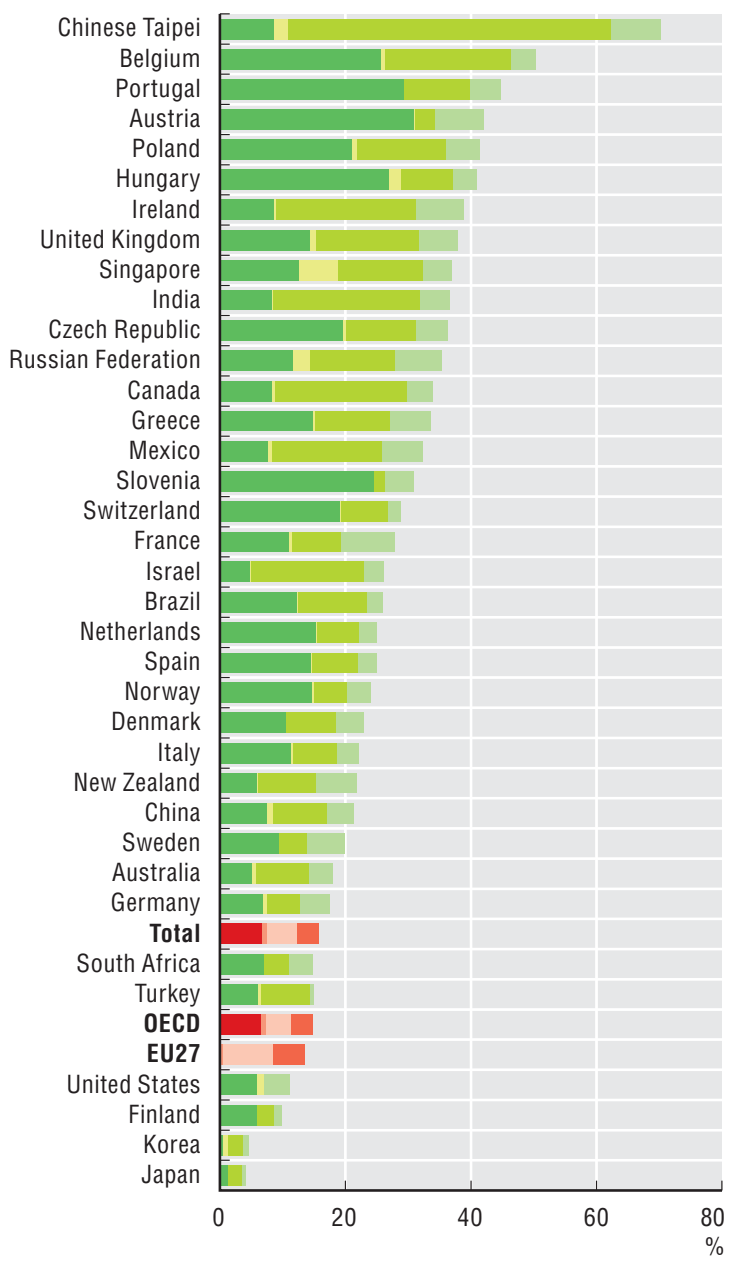

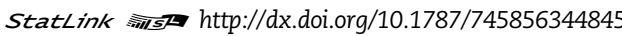




\section{CONNECTING TO GLOBAL RESEARCH}

\subsection{Technology balance of payments}

Technology balance of payments measures international technology transfers: licence fees, patents, purchases and royalties paid, know-how, research and technical assistance. Unlike research and development (R\&D) expenditure, these are payments for production-ready technologies.

In most OECD countries, technological receipts and payments increased sharply during the 1990s and up to mid-2000. Overall, the OECD area maintained its position as net technology exporter vis-à-vis the rest of the world.

Between 1996 and 2006, the European Union transformed its technology balance of payments deficit into a surplus, although this includes intra-EU flows. The US surplus increased slightly. The most spectacular change occurred in Japan where transactions involving new technology contracts have shown a very large surplus (receipts-payments) since 1980.

In 2007, the main technology exporters as a percentage of gross domestic product (GDP) were Ireland, Sweden, Switzerland, Luxembourg, Austria, the Netherlands, Denmark and Hungary.

The magnitude of Ireland's surplus in technology receipts is mainly due to the strong presence of foreign affiliates (particularly US and UK firms). The figures may also be affected by intra-firm transactions and transfer pricing.

Technological development can be achieved either through a national R\&D effort or the acquisition of foreign technology. Particularly in Greece, Hungary, Ireland, Poland and the Slovak Republic, expenditure on foreign technology (technological payments) is greater than expenditure for domestic business enterprise $R \& D$.

\section{Technology balance of payments}

Technology receipts and payments constitute the main form of disembodied technology diffusion. Trade in technology comprises four main categories:

- transfer of techniques (through patents and licences, disclosure of know-how);

- transfer (sale, licensing, franchising) of designs, trademarks and patterns;

- services with a technical content, including technical and engineering studies, as well as technical assistance;

- industrial R\&D.
Although the balance reflects a country's ability to sell its technology abroad and its use of foreign technologies, a deficit does not necessarily indicate low competitiveness. In some cases, it results from increased imports of foreign technology; in others, it is due to declining receipts.

Likewise, if the balance is in surplus, this may be due to a high degree of technological autonomy, a low level of technology imports or a lack of capacity to assimilate foreign technologies. Most transactions also correspond to operations between parent companies and affiliates. Additional qualitative and quantitative information is therefore important in order to analyse correctly a country's deficit or surplus position in a given year.

There is also the difficulty of dissociating the technological from the non-technological content of trade in services, which falls under the heading of pure industrial property. Thus, trade in services may be underestimated when a significant portion does not give rise to financial payments or when payments are not in the form of technology payments.

\section{Source}

OECD, Technology Balance of Payments (TBP) Database, May 2009.

\section{Going further}

OECD (2005), Measuring Globalisation: OECD Handbook on Economic Globalisation Indicators, OECD, Paris.

\section{Figure notes}

Technology flows refer to the average of technological payments and receipts.

Changes in technology flows include intra-area flows for EU15 and OECD total. Denmark, Greece, Iceland and Turkey are excluded. Data partially estimated. 
Trends in technology flows by main areas, 1997-2007

As a percentage of GDP

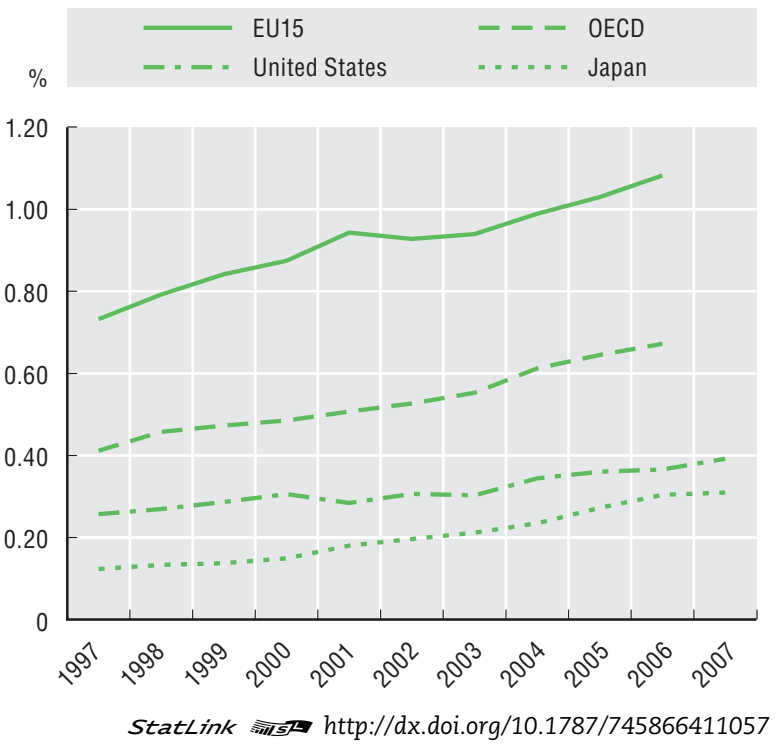

\section{Technology receipts, 2007}

As a percentage of GDP

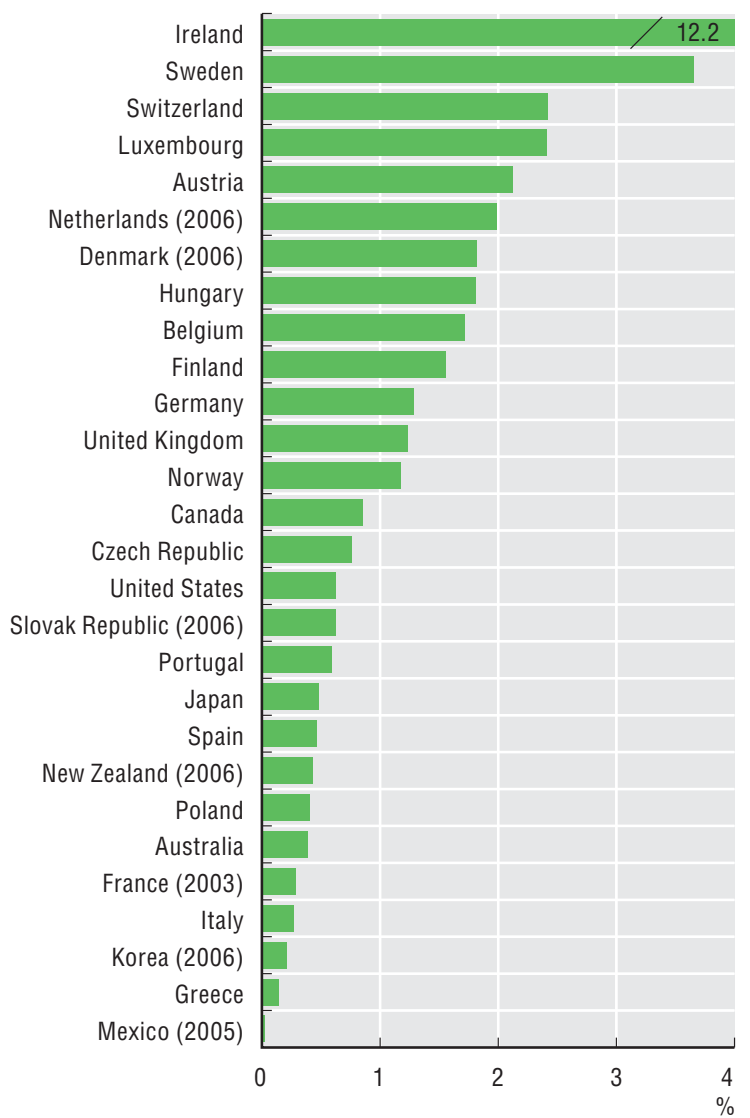

StatLink लाड< http://dx.doi.org/10.1787/746010177814
Change in the technology balance of payments by main areas, 1996 and 2006

As a percentage of GDP

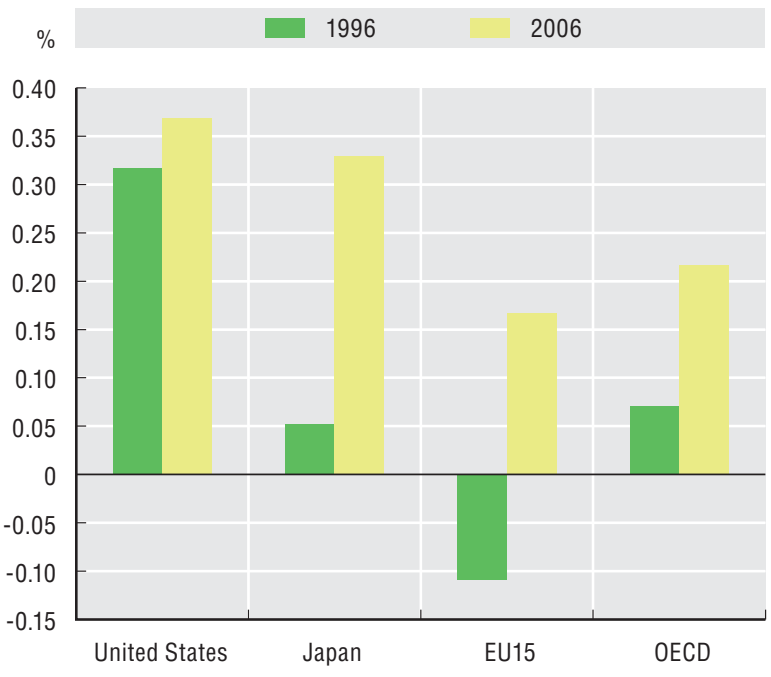

StatLink गाISस http://dx.doi.org/10.1787/746007243082

Technology balance of payments, 2007

As a percentage of GDP

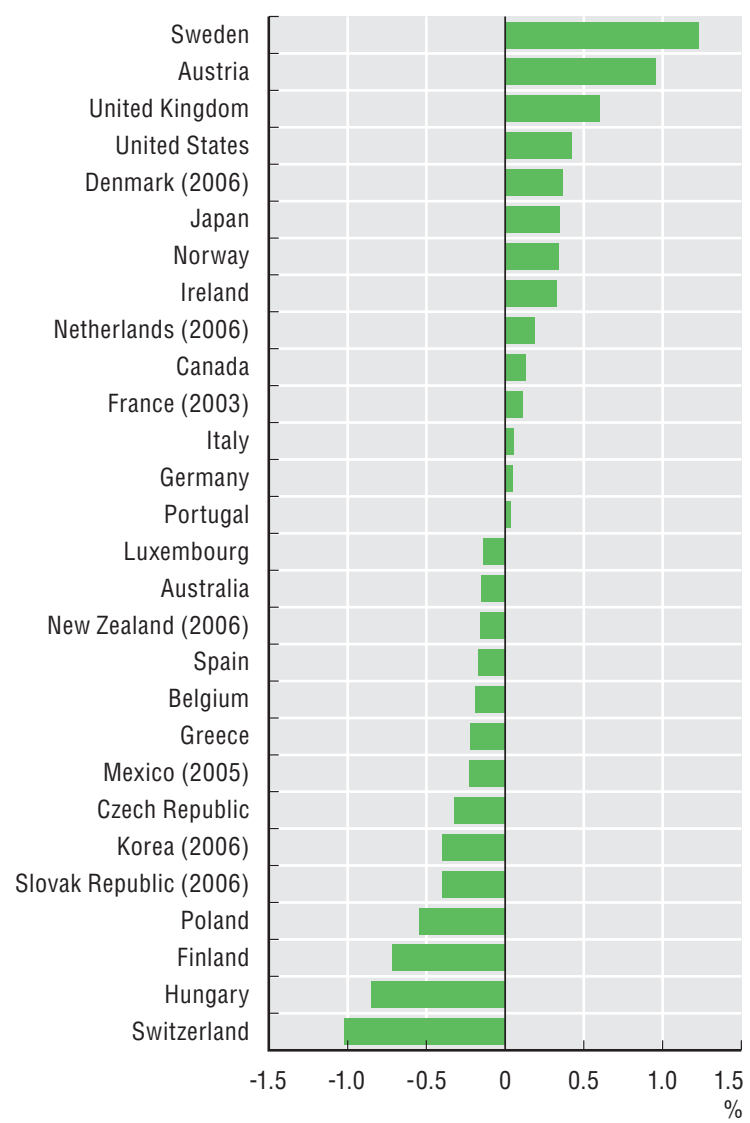

StatLink त्ञाs http://dx.doi.org/10.1787/746026520112 


\section{CONNECTING TO GLOBAL RESEARCH}

The sources of funding of business enterprise research and development (R\&D) may be national or foreign and originate from private business, public institutions (government and higher education) or international organisations. R\&D funding from abroad includes, for instance, R\&D performed by foreign affiliates when funded by the foreign parent company.

On average, R\&D funding from abroad plays quite an important role in the funding of business R\&D. In the EU27, it represented around 10\% of total business enterprise $R \& D$ in 2006. The weight of foreign multinationals in the economy and the domestic production of technology seem to matter in this respect. For Austria, Canada, Hungary, the Netherlands, the Slovak Republic and the United Kingdom, funds from abroad represented $15 \%$ or more of total business enterprise R\&D funding. In Chile, Israel, Korea, Japan and Turkey, they represented less than $1 \%$.

In most countries, the financing of business enterprise R\&D from abroad comes mainly from other business enterprises. In a group of 17 countries for which data are available, only Greece, Portugal and Turkey reported more than $30 \%$ of funding from international organisations (namely the European Union), a share which has been steadily declining. Spain was the only country reporting more than $10 \%$ of finance originating from other governments and foreign higher education institutions.

For countries for which data are available, around two-thirds of funding from business sources abroad is intra-company funding. It represented more than $85 \%$ in Denmark, Finland and the Slovak Republic, and more than two-thirds in Austria, Belgium, the Czech Republic, Norway, and Sweden. However, in Slovenia, foreign R\&D funding from non-affiliated enterprises accounted for more than $70 \%$ of all funds from abroad.

\section{Measuring flows of R\&D funds}

R\&D involves significant transfers of resources between units, organisations and sectors. In order to better measure and evaluate innovation policies and globalisation, it is important to trace the flow of R\&D funds. According to the Frascati Manual, these transfers may be measured in two ways.

One is performer-based reporting of the sums which one unit, organisation or sector has received or will receive from another unit, organisation or sector for the performance of intramural R\&D during a specific period.

The second is source-based reporting of extramural expenditures which are the sums a unit, organisation or sector reports having paid or committed itself to pay to another unit, organisation or sector for the performance of R\&D during a specific period. The first of these approaches is strongly recommended.

For such a flow of funds to be correctly identified, two criteria must be fulfilled:

- There must be a direct transfer of resources.

- The transfer must be both intended and used for the performance of R\&D.

For further details on the identification of these criteria, see the Frascati Manual.

\section{Sources}

OECD, Main Science and Technology Indicators Database, June 2009.

OECD, R\&D Database, June 2009.

\section{Going further}

OECD (2002), Frascati Manual: Proposed Standard Practice for Surveys on Research and Experimental Development, OECD, Paris, www.oecd.org/sti/frascatimanual. 


\section{CONNECTING TO GLOBAL RESEARCH}

4.6. R\&D funding from abroad

R\&D funds from abroad, 2007

As a percentage of business enterprise $R \& D$

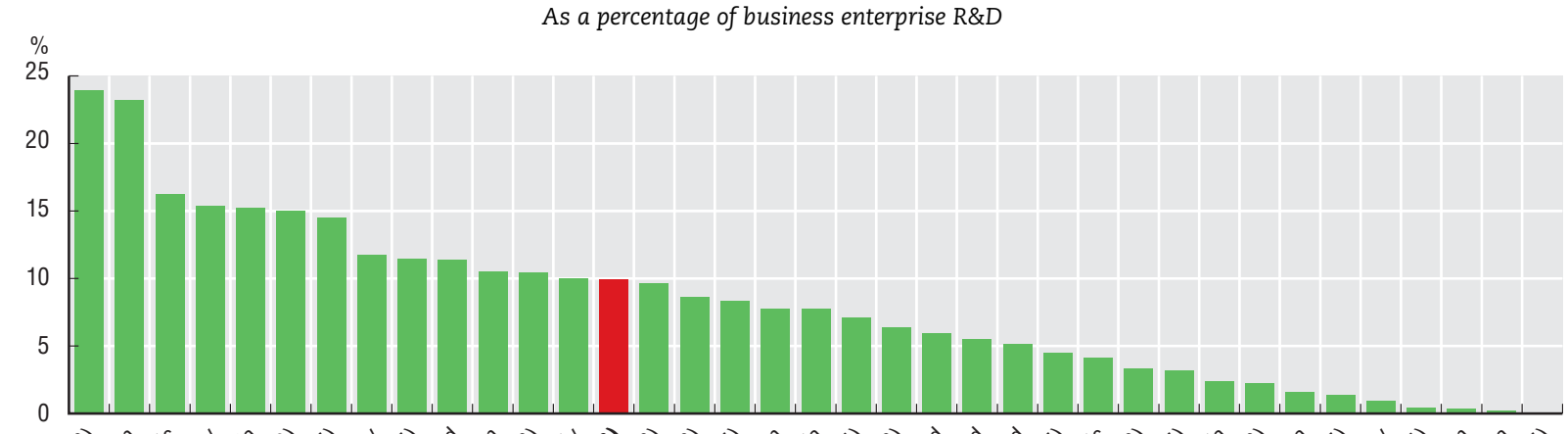

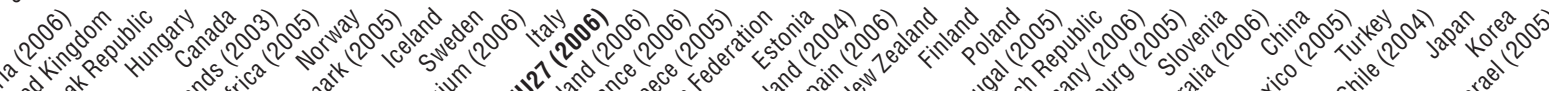

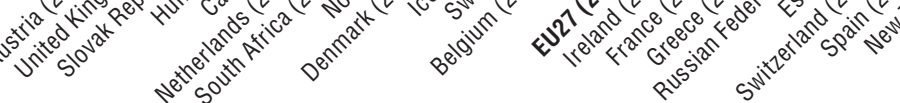

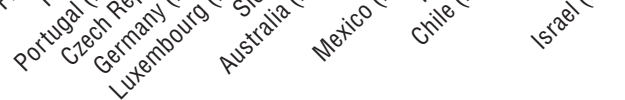

StatLink Aiाsस http://dx.doi.org/10.1787/746047260245

\section{Business enterprise R\&D funded from abroad, 2007}

By source of funds

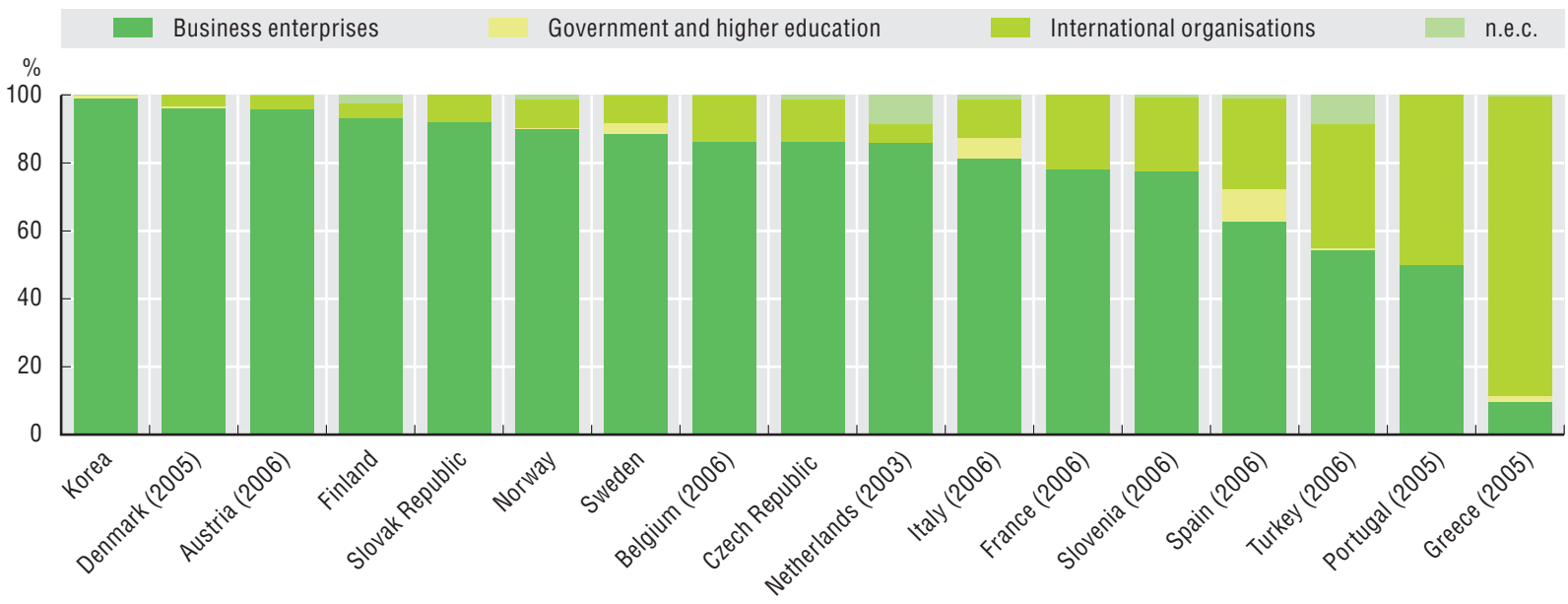

StatLink काग्रा http://dx.doi.org/10.1787/746176378108

R\&D funding from foreign enterprises, 2007

As a percentage of funds from abroad

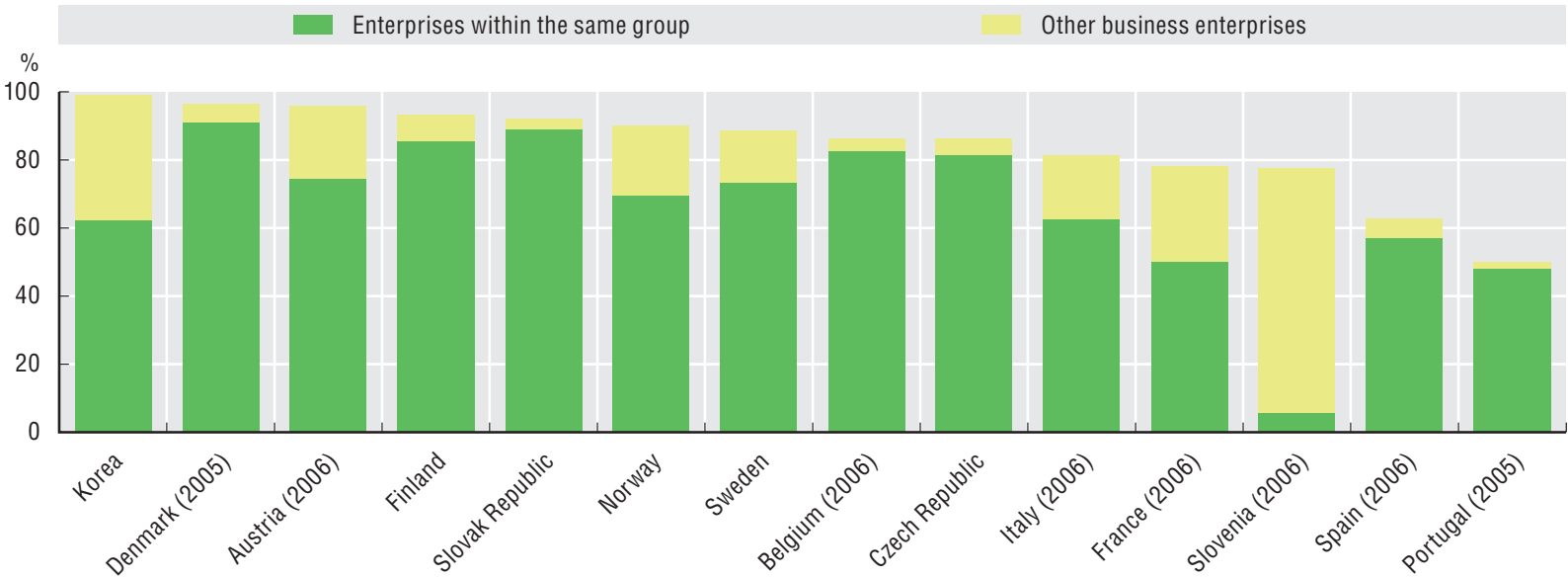

StatLink काIS $h t t p: / / d x . d o i . o r g / 10.1787 / 746182766483$ 


\section{CONNECTING TO GLOBAL RESEARCH}

Research is increasingly internationalised. In the search for new technological competences, better adaptation to local markets, and lower research and development (R\&D) costs, companies are moving their research activities abroad. This internationalisation of research activities is an important driver of innovative firms' and countries' competitiveness.

The share of foreign affiliates in industrial R\&D varies widely, ranging from $5 \%$ in Japan to over $60 \%$ in the Slovak Republic and Ireland. At over $40 \%$, the share of $R \& D$ conducted by foreign affiliates is also high in the Czech Republic, Belgium, Portugal and Sweden. In most countries, foreign affiliates have a higher share of total R\&D than of total turnover, which suggests that research is now more internationalised than production.

The share of foreign affiliates in $R \& D$ also reflects the size of their R\&D effort relative to that of domestic firms. In 2006, foreign affiliates carried out more R\&D than national firms in many countries. The intensity of R\&D (as a share of turnover) by foreign affiliates was notably higher than that of domestic companies in Sweden, Belgium and Portugal. In Japan, where domestic companies' average R\&D intensity was equal to $0.8 \%$ of turnover, it was superior to $2.7 \%$ for affiliates under foreign control. This is attributable in great part to the fact that Japanese foreign affiliates are concentrated in the motor vehicle industry (the alliance between Renault and Nissan). This sector has considerably increased its R\&D spending, in contrast to firms under domestic control, which operate in all sectors of activity.

\section{Defining foreign affiliates}

The term "foreign affiliate" is restricted to affiliates under foreign control. Accordingly, the geographical origin of a foreign affiliate is the country of residence of the ultimate controller. An investor (company or individual) is considered to be the investor of ultimate control if it is at the head of a chain of companies and controls directly or indirectly all the enterprises in the chain without itself being controlled by any other company or individual.

The notion of control implies the ability to appoint a majority of administrators empowered to direct an enterprise, to guide its activities and determine its strategy. In most cases, this ability can be exercised by a single investor holding more than $50 \%$ of the shares with voting rights.

Not all activities related to R\&D are recorded in company transactions. There are intra-company transfers (e.g. intra-company mobility of researchers) with no monetary counterparts which lead to R\&D efforts that do not appear in the statistics as $R \& D$ spending by foreign affiliates.

\section{Source}

OECD, AFA Database, May 2009.

\section{Going further}

OECD (2005), Measuring Globalisation: OECD Handbook on Economic Globalisation Indicators, OECD, Paris.

OECD (2008), The Internationalisation of Business R\&D: Evidence, Impacts and Implications, OECD, Paris.

\section{Figure notes}

Data for 2005 for Belgium, Germany, Ireland, Portugal, Spain and Sweden. Data for Germany, Hungary, Ireland, Portugal, the Slovak Republic and Spain, manufacturing sector only.

$R \& D$ intensity is defined as $R \& D$ expenditure as a percentage of turnover. 
R\&D and turnover of affiliates under foreign control, 2006

As a percentage of total

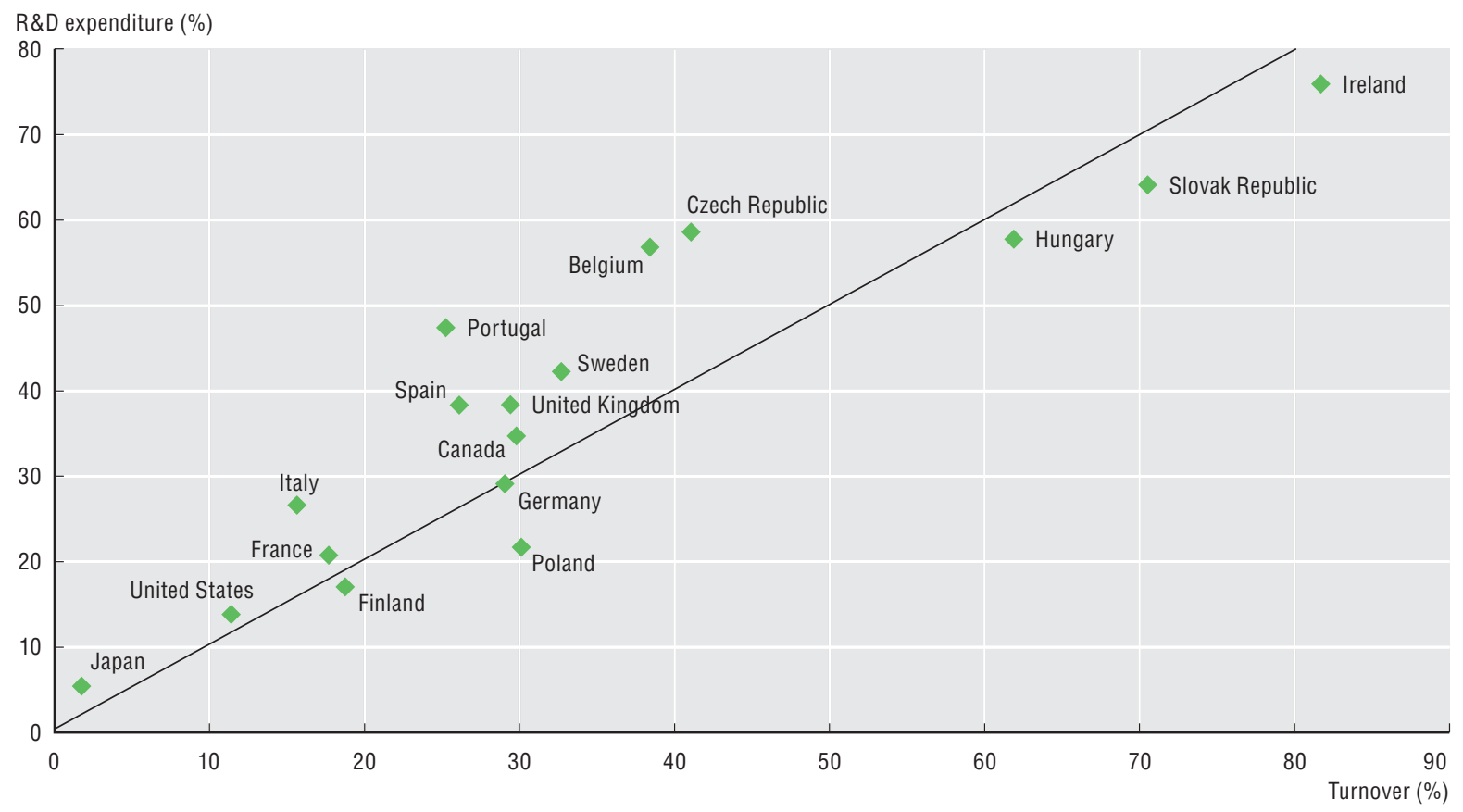

StatLink AाIsL http://dx.doi.org/10.1787/746183421062

R\&D intensity of foreign affiliates and of firms controlled by compiling countries, 2006

Affiliates under foreign control (\%)

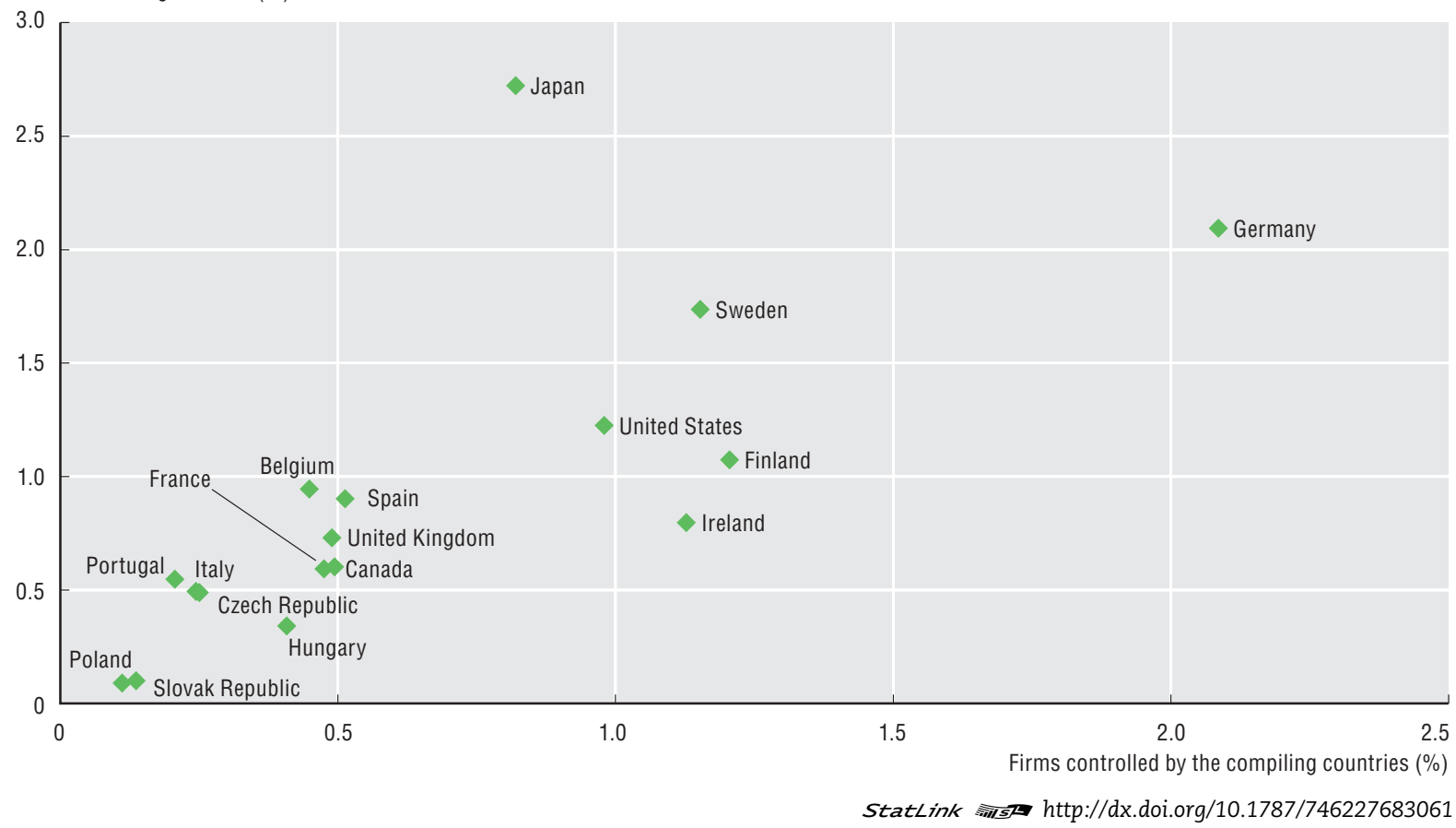




\section{CONNECTING TO GLOBAL RESEARCH}

\subsection{International collaboration on innovation}

Collaboration with foreign partners can play an important role in the innovation process by allowing firms to gain access to a broader pool of resources and knowledge at a lower cost and to share risks with partners.

The share of firms collaborating on innovation with partners across Europe ranges from less than 2\% in Spain and Turkey to over 13\% in Finland, Luxembourg and Slovenia. Collaboration with partners outside Europe is much less frequent and concerns between $1 \%$ and $5 \%$ of firms in most European countries. Overall, innovating firms from the Nordic countries and some small European economies (Belgium, Luxembourg, and Slovenia) tend to collaborate more frequently with partners abroad.

Cross-country differences in international collaboration may be due to two factors: the overall innovation rate of a country, and the propensity of its firms to collaborate with foreign partners. The latter factor seems to explain most of the observed difference in European countries. For example, Spain and Slovenia have similar innovation rates but very different international collaboration rates $(1.3 \%$ and $13.4 \%$, respectively) owing to large differences in the propensity of innovative firms to engage in foreign collaboration.

\section{International collaboration on innovation}

Collaboration on innovation with foreign partners is an important source of knowledge inflows. It can take a variety of forms with different levels of interaction ranging from simple one-way information flows to highly interactive and formal arrangements. These types of linkages allow firms to access a broader pool of inputs (e.g. information, technologies, human or financial resources) than what is available in their local environment. Collaboration with foreign customers or suppliers can also help firms develop new products, processes or other innovations.

\section{Sources}

Eurostat, Community Innovation Survey 2006 (NewCronos), June 2009.

National data sources.

\section{Going further}

OECD and Eurostat (2005), Oslo Manual: Guidelines for Collecting and Interpreting Innovation Data, 3rd edition, OECD, Paris, www.oecd.org/sti/oslomanual.

\section{Figure notes}

Innovation rates and intensity of foreign collaboration are expressed as percentage deviation from the EU averages (the EU average innovation rate is $35.2 \%$ and the EU average intensity of foreign collaboration is $14.8 \%)$. 


\section{CONNECTING TO GLOBAL RESEARCH}

Firms with foreign collaboration on innovation, 2004-06

As a percentage of all firms

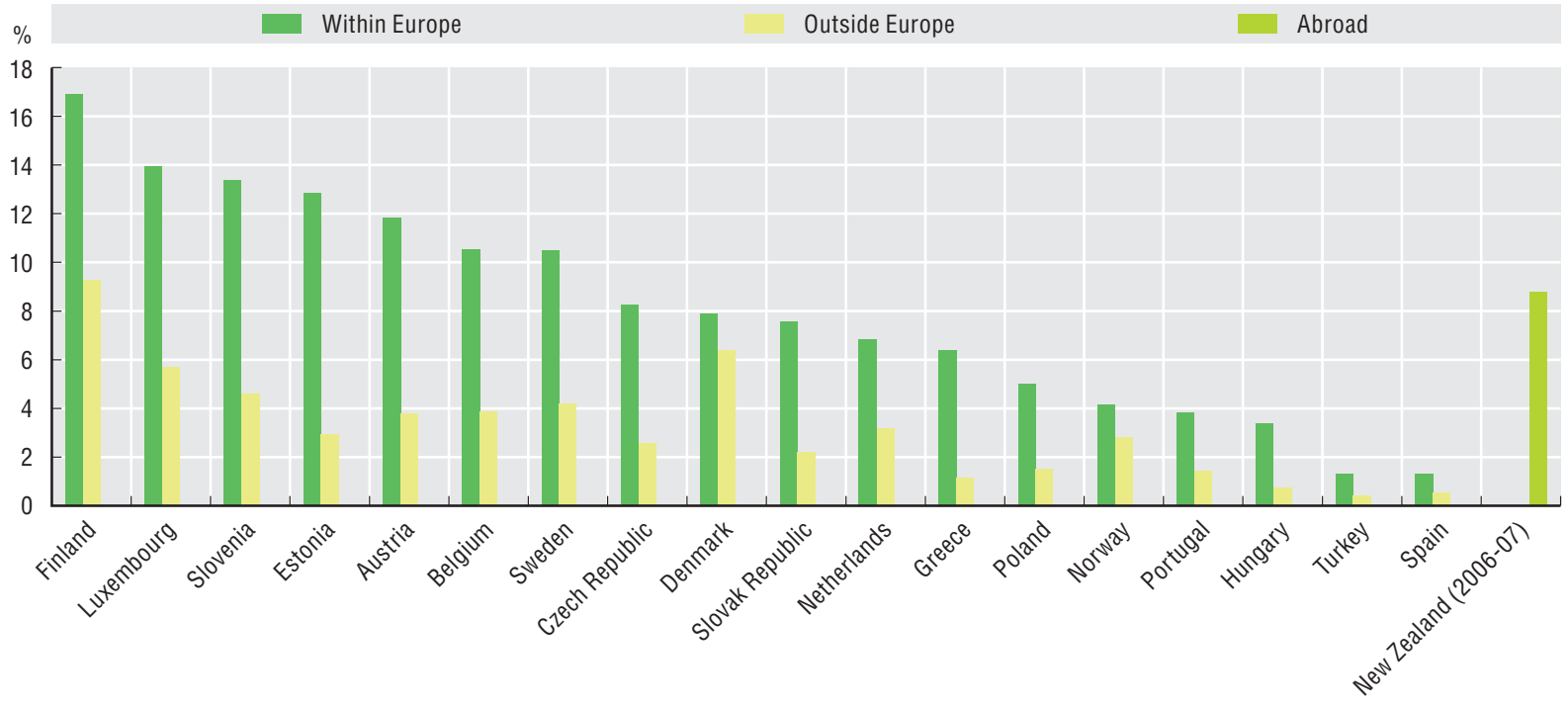

StatLink AाIs/ $h t t p: / / d x . d o i . o r g / 10.1787 / 746278011864$

\section{Foreign collaboration on innovation within Europe, 2004-06}

Deviation from the European average in percentage points

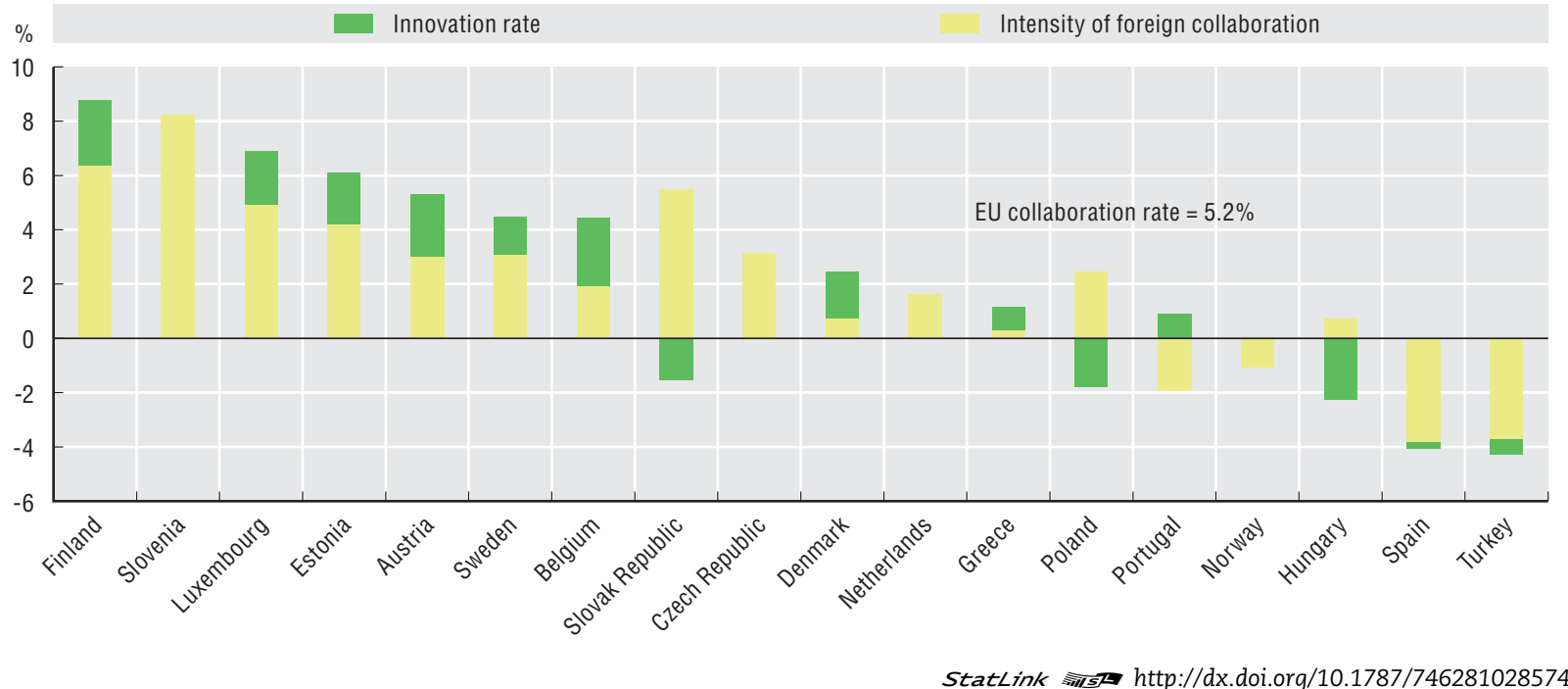




\section{CONNECTING TO GLOBAL RESEARCH}

International mobility of doctoral students is an indicator of the internationalisation of both the higher education sector and the research system. It also highlights the attractiveness of advanced research programmes and in some cases the existence of career opportunities for junior researchers in the host country. During their studies and afterwards, doctoral students contribute to the advancement of research in the host country. When returning home, they bring back new competences and connections with international research networks.

The share of foreign doctoral students in total enrolment differs widely across countries. Non-citizens represent more than $40 \%$ of the doctoral population in Switzerland, New Zealand and the United Kingdom, but less than $5 \%$ in Italy and Korea. Shares of foreign and international doctoral students are between 25\% and $40 \%$ in Canada, France, Belgium, Australia and the United States.

In absolute numbers, the United States hosted the largest foreign doctoral population, with more than 92000 students in 2006 from abroad, followed by the United Kingdom (38 000) and France (28 000).

Language plays a role in the choice of destination, notably for English-speaking countries or for Spain (students from Central and South America). However, other factors also matter: geographical proximity, cultural and historical links, the existence of exchange programmes (e.g. Erasmus) or scholarships, as well as immigration policies. Asian students (particularly from China, India, Korea and Chinese Taipei) represent the bulk of foreign doctoral students in the United States, whereas European universities enrol large shares of doctoral students from other European countries.

International mobility of doctoral students has increased over the past seven or eight years, most notably in Canada and New Zealand, as well as in Norway and in Spain. The share of foreign students enrolled in advanced research programmes rose in most countries between 1998 and 2006. Belgium, one of the main European host countries, is an exception.

Men still account for the majority of foreign doctoral students, but women are catching up, representing at least $45 \%$ of international students in half of the countries for which data are available.

\section{Foreign and international doctoral students}

The data are from the Indicators for Education Systems (INES) project conducted jointly by the OECD, the UNESCO Institute for Statistics (UIS) and Eurostat. Doctoral students are defined according to the International Classification of Education developed by UNESCO (ISCED 1997). ISCED level 6 corresponds to programmes that lead to an advanced research qualification, equivalent to a doctorate.

The term "international student" refers to students who have crossed borders expressly with the intention to study. The UNESCO Institute for Statistics, OECD and Eurostat define as international students those who are not residents of their country of study or those who received their prior education in another country. Overall, the country of prior education is considered a better criterion for EU countries in order to take account of intra-EU student mobility. The residence criterion is usually a good proxy in countries that require a student visa to enter the country. Since not all countries are yet able to report data on international students, data for "foreign students" are also presented here. However, it should be borne in mind that not all "foreign students" have come to the country with the intention to study.

\section{Source}

OECD, Education Database, 2009.

\section{Going further}

OECD (2004), Internationalisation and Trade in Higher Education: Challenges and Opportunities, OECD, Paris.

OECD (2008), Education at a Glance 2008: OECD Indicators, OECD, Paris, www.oecd.org/edu/eag2008.

\section{Figure notes}

Share of foreign doctoral students: Data refer to 1999 instead of 1998 for Belgium, Mexico, the Slovak Republic and Turkey; 2000 for Iceland and Portugal.

In the United States, data refer to 2001 in the case of foreign students and to 2006 in the case of international students.

Number of international doctoral students: International students are defined as non-resident students of reporting countries for all countries except Finland and Switzerland which define them as students with prior education outside the reporting country. 


\section{CONNECTING TO GLOBAL RESEARCH}

\subsection{International mobility of doctoral students}

Share of foreign doctoral students, 2006

As a percentage of total doctoral enrolment in host country

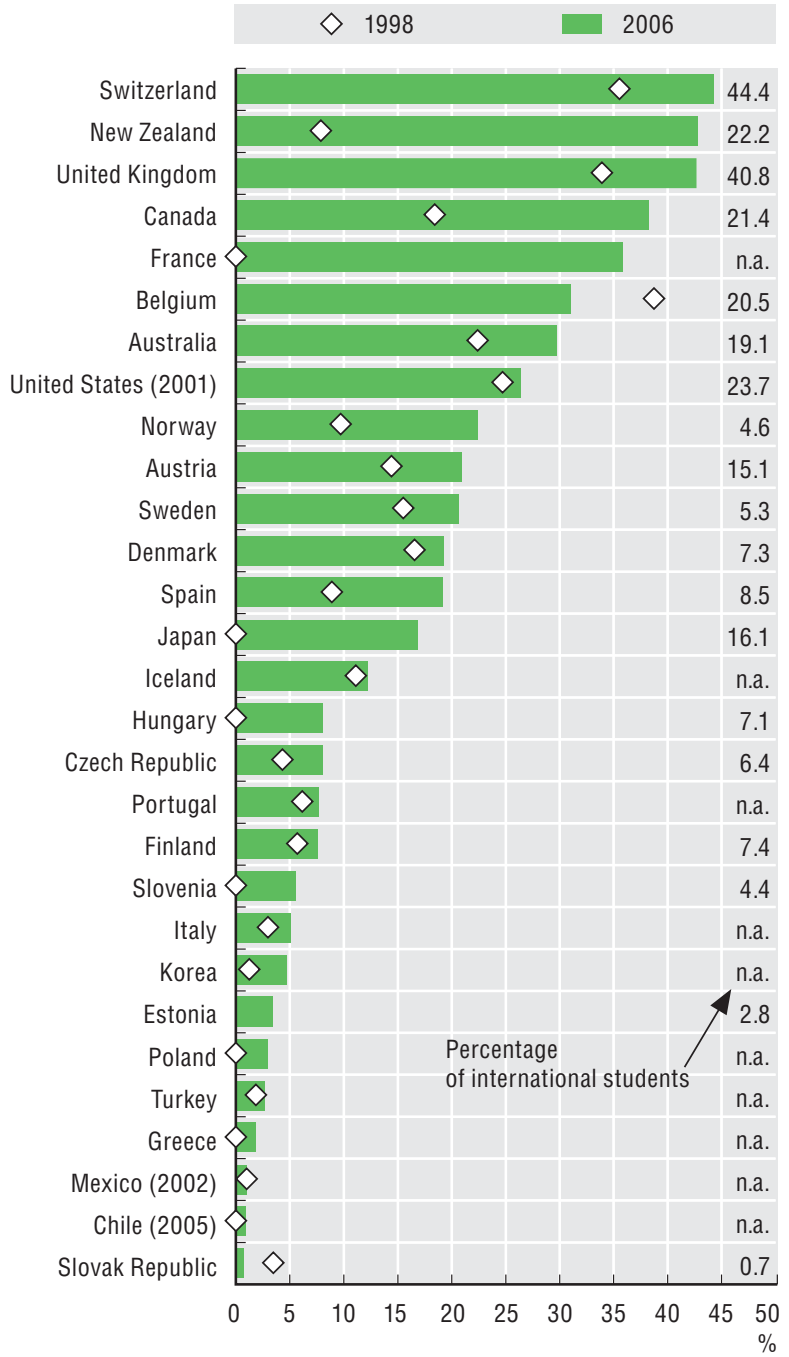

StatLink लाड़ी http://dx.doi.org/10.1787/746305288783

\section{Number of international doctoral students, 2006}

By host country

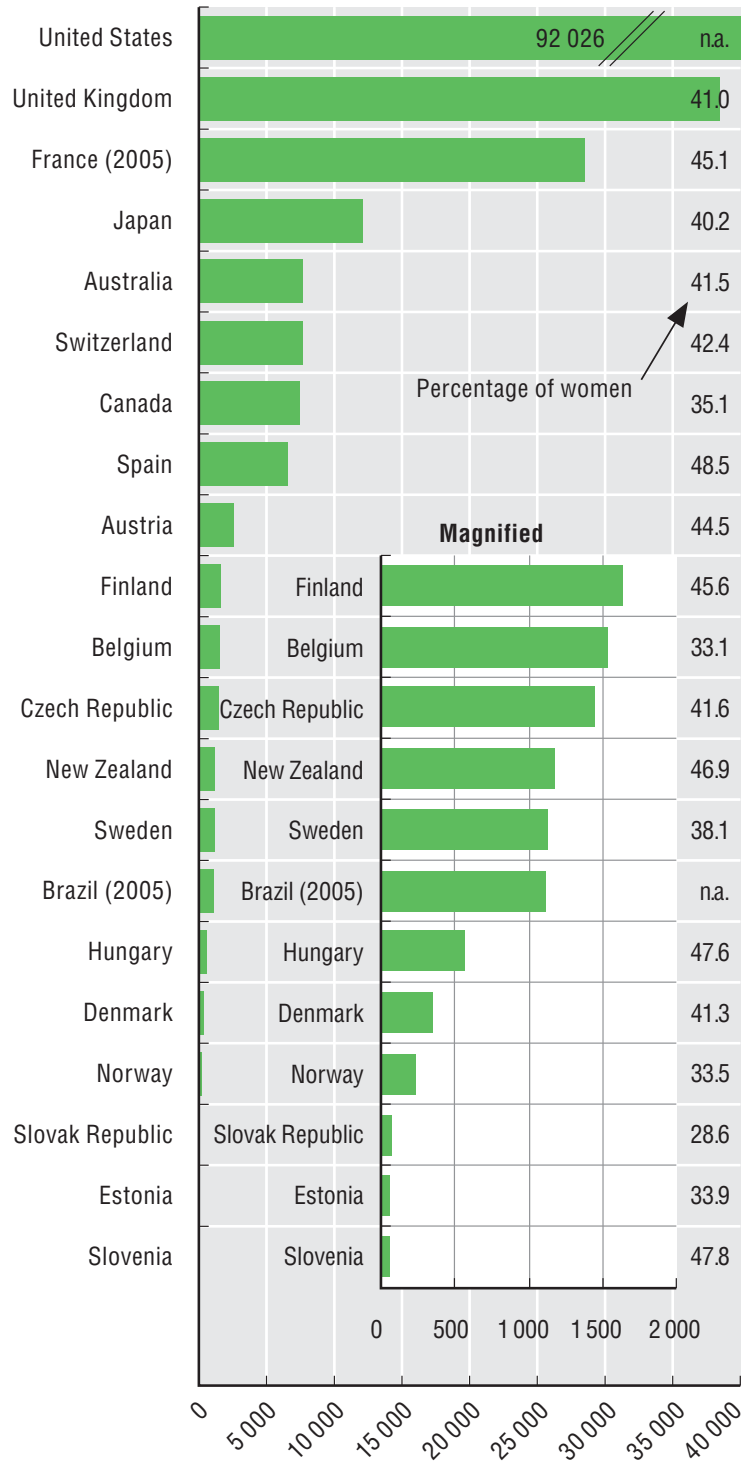

StatLink काIst http://dx.doi.org/10.1787/746324062876 


\section{CONNECTING TO GLOBAL RESEARCH}

The presence of foreign scholars in US higher education institutions is an indicator of the international attractiveness of the country's universities and of opportunities for researchers in the United States.

In 2007/08, US higher education institutions hosted 106000 foreign scholars. They conducted research or teaching activities. Most were however engaged in research and two-thirds in the life, biological, health or physical sciences and in engineering.

Just 20 countries account for $80 \%$ of foreign scholars in the United States. China is the leading country of origin and Asia the most important region. More than $22 \%$ were Chinese, around 9\% were Korean or Indian, and $5 \%$ Japanese. France, Germany, Italy, Spain and the United Kingdom each provided between $2 \%$ and $5 \%$ of foreign academic staff. Canada accounted for $4.5 \%$ of the total.

Mobility of scholars, compared to the size of the local academic population, varies across countries. For most OECD countries, from one to three scholars have positions in US universities per 100 working at home. Academic mobility is most significant from Korea (14 per 100), the Netherlands (8), the Russian Federation (6) and from Canada, Iceland, Ireland, Italy and Mexico (4 each).

The population of foreign scholars working in the United States has steadily increased over the past 14 years from the 60000 hosted in 1993/94. After a decline during the two academic years following the post-September 11 security-related change in visa policy, numbers have grown since 2004, and in 2007/08 they increased by $8 \%$ from the previous year.

Expansion of the population of foreign scholars has been driven by a massive and sustained arrival of Asian academics. Although many Asian academics worked in US universities in the mid-1990s, the number of scholars from Korea, India and China has kept growing at average annual rates of 8 to $9 \%$. Growth in academic mobility from Turkey (7\%), Chinese Taipei $(6 \%)$ and Italy $(6 \%)$ has also been rapid. The increase in mobility from most European countries has been moderate (around $2 \%$ a year on average).

Although most foreign scholars are still men, women are more numerous than in the past; in 2007/08 female academics accounted for $34 \%$ of all foreign scholars in the United States.

\section{Open Doors data}

The Institute of International Education (IIE) is a non-profit international organisation for educational and cultural exchange. The IIE conducts an annual statistical survey of the internationally mobile student population in the United States. Open Doors is a long-standing, comprehensive information resource on international students in the United States and on US students studying abroad. It highlights key facts and trends in international flows of scholars to the United States.

International scholars are defined as non-immigrant, non-student academics (teachers and/or researchers, and administrators). Scholars may also be affiliated with US institutions for activities such as conferences, colloquia, observation, consultations or other short-term professional development activities. The survey is limited to doctoral degree-granting institutions.

\section{Source}

OECD, based on data from the Institute of International Education (IIE), June 2008.

\section{Going further}

Institute of International Education (2008), Open Doors 2008: Report on International Educational Exchange, New York,

www.opendoors.iienetwork.org/page/OpenDoors2008.

\section{Figure notes}

The base year for the number of scholars per 100 university researchers in the economy of origin is 2007 for Argentina and the Russian Federation; 2006 for Chinese Taipei, France, Germany, Italy, Japan, Korea, Poland, Spain and Turkey; 2002 for Austria, Finland and Switzerland; 2003 for other economies. 


\section{CONNECTING TO GLOBAL RESEARCH}

4.10. Foreign scholars in the United States

\section{Top 20 places of origin of foreign scholars in the United States, 2007/08}

Headcounts

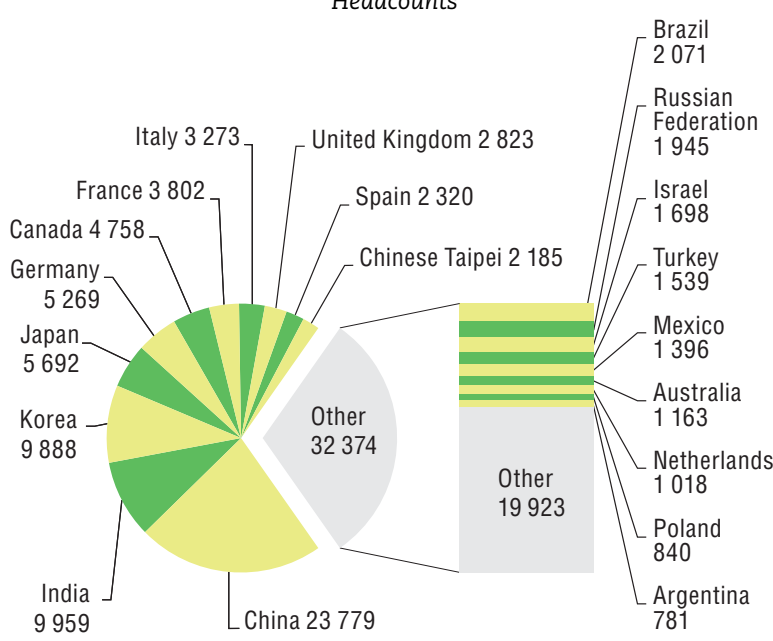

106123 foreign scholars working in the United States higher education sector in 2007-08

StatLink ला1s/4 http://dx.doi.org/10.1787/746356032852

\section{Growth of foreign scholars in the United States, by gender and activity, 1993/94-2007/08}

Headcounts and percentage of total foreign scholars

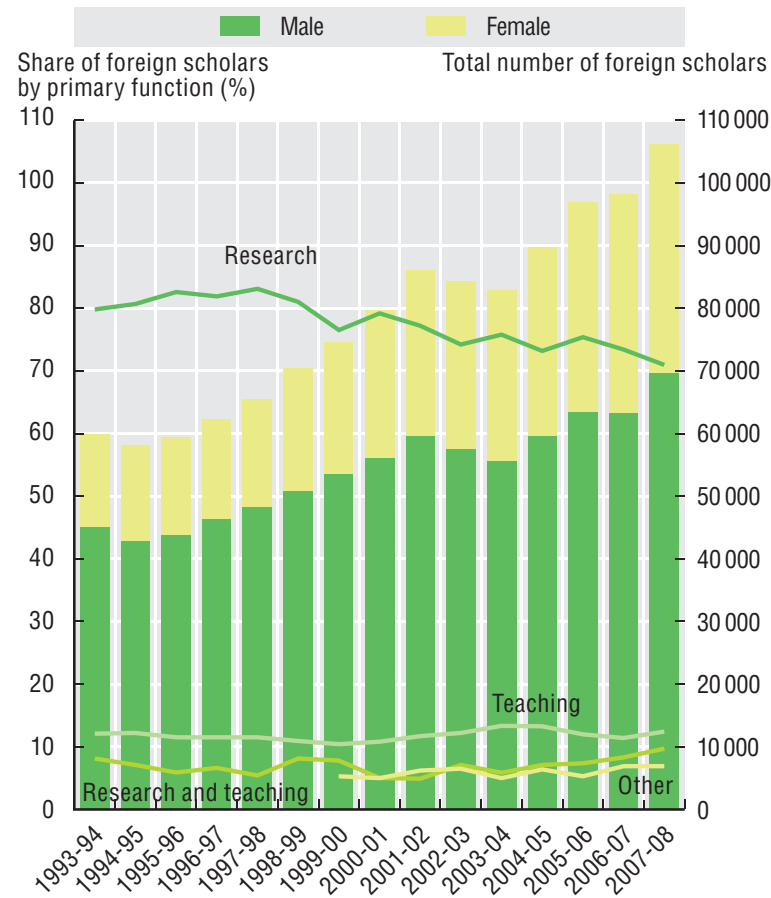

StatLink क्गाSस http://dx.doi.org/10.1787/746381855365

\section{Growth in foreign scholars in the United States, by economy of origin, 1996/97-2007/08}

Average annual growth rate

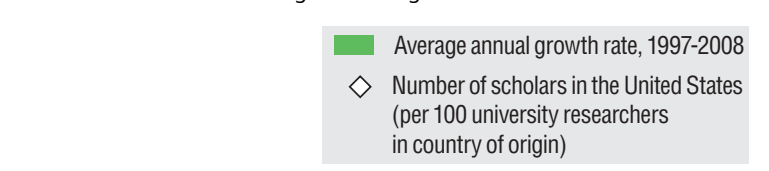

Ireland (1997-200

Slovak Republic (1997-2004)

Korea

Portugal (1997-2004)

Turkey

Chinese Taipei

Italy

Canada

Indonesia (1997-2004)

Mexico

Brazil

World

Israel

Greece (1997-2004)

Argentina

France

Spain

Belgium (1997-2004)

Total OECD (1997-2004)

Australia

New Zealand (1997-2004)

South Africa (1997-2004)

EU15 (1997-2004)

EU25 (1997-2004)

Sweden (1997-2005)

Germany

Czech Republic (1997-2004)

Luxembourg (1997-2004)

Japan

Poland

United Kingdom

Netherlands

Iceland (1997-2004)

Denmark (1997-2004)

Austria (1997-2004)

Switzerland (1997-2005)

Estonia (1997-2004)

Hungary (1997-2004)

Russian Federation

Finland (1997-2004)

Norway (1997-2004)

Slovenia (1997-2004)

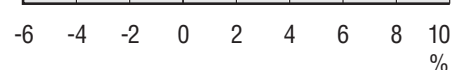

StatLink जाs http://dx.doi.org/10.1787/746383883227 
The number of new university graduates indicates a country's capacity to absorb, develop and diffuse knowledge and to supply the labour market with highly skilled workers.

In 2006, more than one young person in three graduated at the first-stage university level in the OECD area. This represents 7.1 million degrees awarded. Iceland, Australia and New Zealand had the highest graduation rates (over $50 \%$ of the relevant age cohort). Japan $(39 \%)$ ranks slightly above the OECD average (37\%). The United States (36\%) and the EU (35\%), the two main university systems with 2.9 million and 2.2 million degrees awarded, respectively, rank just below. In Europe almost twice as many degrees per age cohort were awarded in the Nordic countries, Poland and the Netherlands as in Belgium, Greece, Germany or Austria.

Emerging countries are also expanding their firststage university system. The Russian Federation had 1.1 million graduates in 2006 and the graduation rate (45\% of the relevant age cohort) was above the EU average. Brazil had 677000 graduates (13.5\%). In China the number of graduates (12\%), albeit still low compared to OECD average, has almost tripled since 2000.

Most university degree recipients graduate in the social sciences. Their share in total graduates exceeds $40 \%$ in Poland, Hungary or Australia, where many studied business and administration, or in Mexico, France and Switzerland, where many received law degrees. Scientific studies are more popular in Korea and the Nordic countries. Science and engineering degrees account for $37 \%$ and $29 \%$ of Korean and Finnish awards, respectively. In Denmark and Sweden, over $25 \%$ of degrees are in the health sciences.

OECD governments are concerned about the low level of female participation in scientific studies. On average $45 \%$ of women in the relevant age group received a university degree compared to less than $30 \%$ of men. However, they are less well represented in science and engineering (S\&E) studies. Their presence is overwhelming in humanities and the arts (67\%), health $(74 \%)$ and education $(75 \%)$ but minor in engineering $(23 \%)$ or computing $(23 \%)$. The female deficit is striking in Japan, where no more than $15 \%$ of S\&E degrees are awarded to women.

\section{Graduates and graduation rates}

The higher education system is the main source of human resources in science and technology (HRST). Immigration and job-to-job mobility complement the labour supply for highly skilled.

University graduates obtain tertiary degrees at levels 5A and 6 of the 1997 International Standard Classification of Education (ISCED 1997). The first stage (ISCED 5A) of university education is composed of long-stream programmes largely theoretically based or preparatory to research which provide qualifications to enter advanced research programmes at level ISCED 6 or professions with high skill requirements.

Science degrees include: life sciences; physical sciences; mathematics and statistics; and computing. Engineering degrees comprise: engineering and engineering trades; manufacturing and processing; and architecture and building.

Graduation rates represent the share of persons receiving a degree in the population at the typical age of graduation. Figures refer to net graduation rates, summing graduation rates by individual years of age. Up to 2004, rates were calculated on a gross basis as the share of graduates in the population at the typical age of graduation. For several countries for which net rates were not available, gross rates were used instead.

\section{Source}

OECD, Education Database, 2009.

UNESCO, Institute for Statistics, 2009.

China Statistical Yearbook, 2008.

\section{Going further}

OECD and Eurostat (1995), "Manual on the Measurement of Human Resources Devoted to S\&T - 'Canberra Manual'", OECD general distribution document, OCDE/ GD(95)77, www.oecd.org/dataoecd/34/0/2096025.pdf.

OECD (2008), Education at a Glance 2008: OECD Indicators, OECD, Paris, www.oecd.org/edu/eag2008.

\section{Figure notes}

A breakdown by gender is not available for France or the Russian Federation. The bar for women corresponds to graduation rates for both men and women.

For Brazil and the Russian Federation, ISCED 6 programmes are included. For South Africa, ISCED 5B and 6 programmes are included. 


\section{Graduation rates at first-stage university level by gender, 2006}

As a percentage of the relevant age cohort

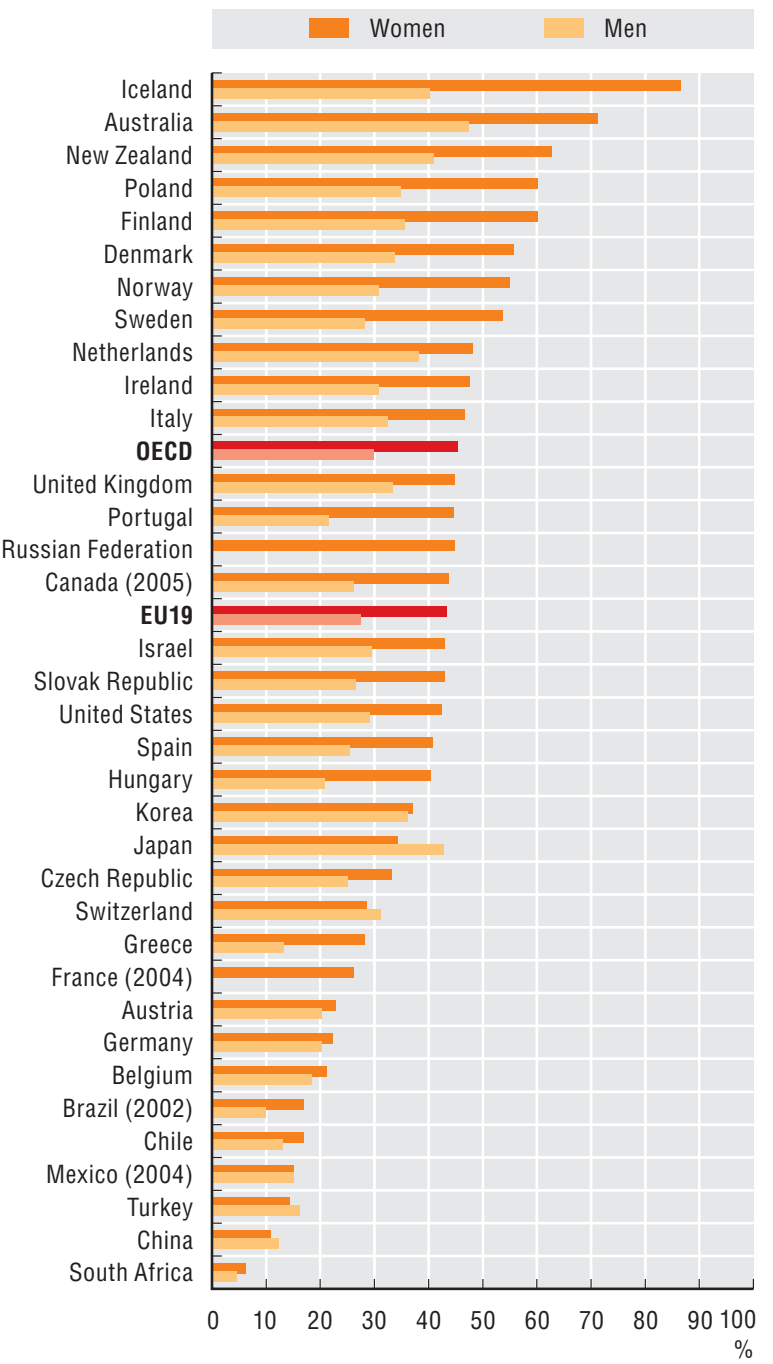

StatLink काIs/ http://dx.doi.org/10.1787/746387282741

\section{Science and engineering degrees at first-stage university level, 2006}

As a percentage of all new degrees at first-stage university level

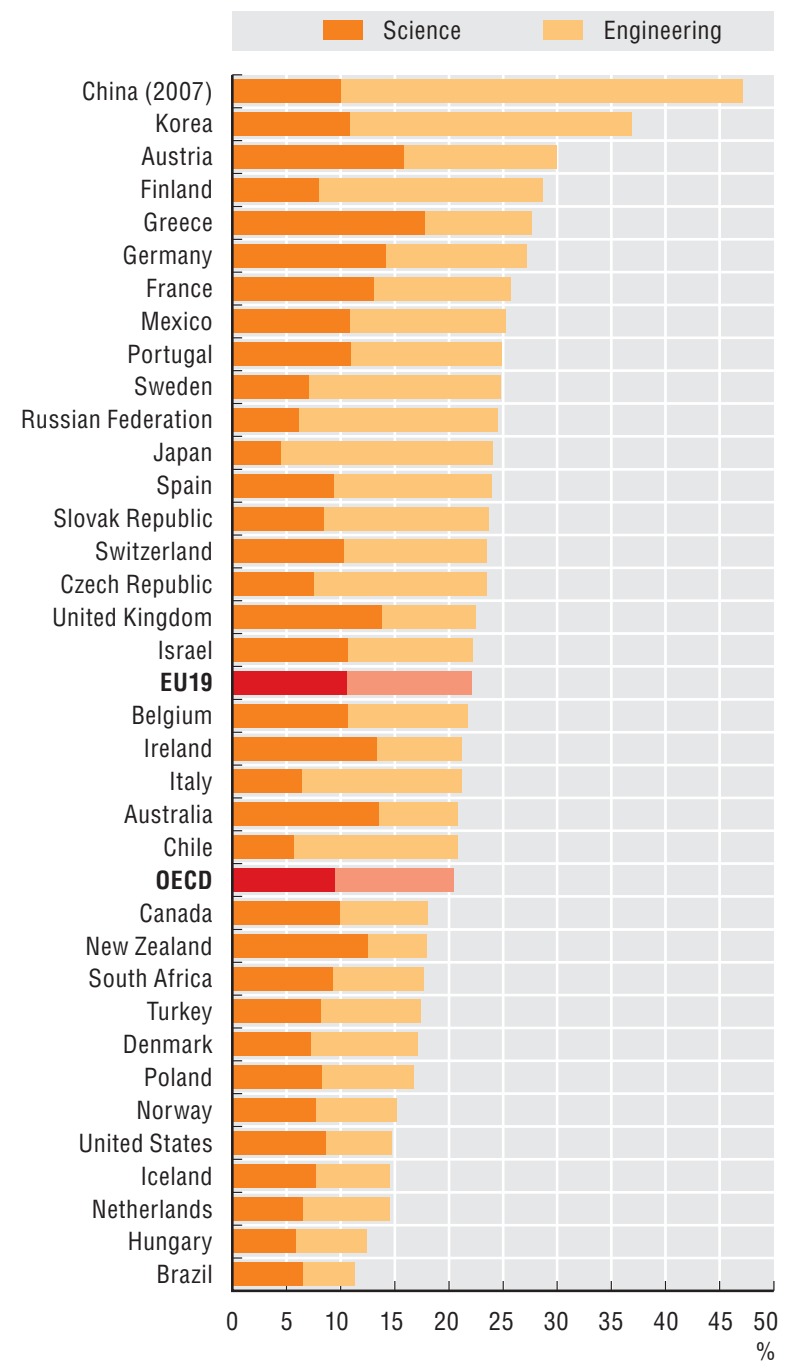

StatLink तारा http://dx.doi.org/10.1787/746402107676

New OECD first-stage university graduates by main country of graduation, 2006 As a percentage of total OECD new first-stage university graduates

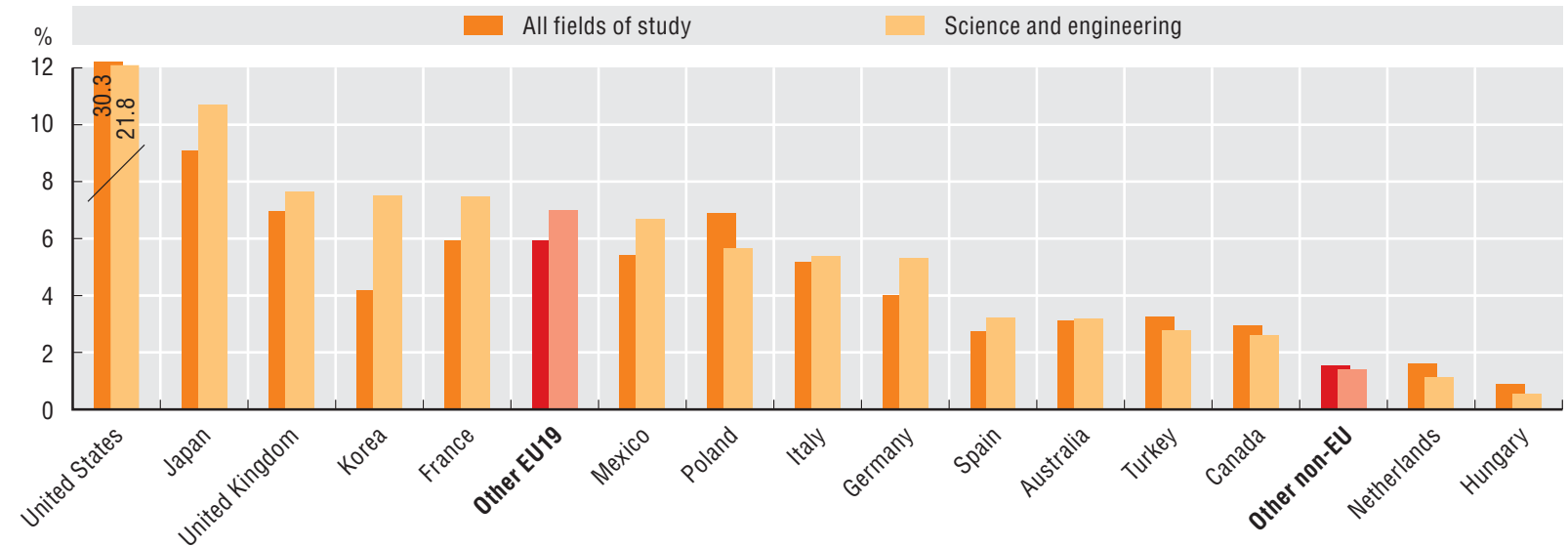


Doctoral graduates have attained the highest education level and are key players in research and innovation. They have been specifically trained to conduct research. They contribute to the diffusion of knowledge in society.

In 2006, OECD universities awarded 200000 doctorates to $1.3 \%$ of the population at the typical age of graduation. Over $3 \%$ of the population at the relevant age obtained a doctorate in Portugal and Switzerland and over $2 \%$ in Germany, Sweden, the United Kingdom and Finland. In many OECD countries doctoral degrees have multiplied faster than other university degrees. Since 2000 the number of OECD-area doctorates has increased by $5 \%$ a year and the number of first-stage university degrees has grown by $4.6 \%$.

Doctoral programmes have also progressed in emerging countries. In 2006, Brazil, the Russian Federation, India and China combined trained half as many doctoral graduates as OECD countries, taken together. Although graduation rates are lower outside the OECD area, Brazil and the Russian Federation deliver more doctorates per age cohort than the OECD average.

Some countries emphasise doctoral education. In Germany, Portugal, Switzerland and the United Kingdom, graduation rates at doctoral level are high relative to the OECD average while rates at first-stage university level are below the OECD average.

Most doctorates are in science and engineering (S\&E), followed by the social sciences. Despite the declining share of S\&E doctorates, $40 \%$ of OECD doctoral students graduate in scientific fields and more than 50\% in Greece, France, Ireland and Sweden. There are proportionally twice as many $S \& E$ graduates at doctoral level than at the first-stage university level. The S\&E orientation of doctoral programmes is even more pronounced in emerging countries.

More doctorates are awarded in science than in engineering; the opposite holds for the first-stage university level. France and Israel trained almost five scientists for one engineer, Spain and New Zealand four for one, and Germany and Switzerland nearly three for one. However, in Korea doctoral programmes produced twice as many engineers as scientists.

In 2006 EU universities awarded over 99000 doctorate degrees and half of the total OECD output. The United States and Germany awarded 56000 (28\%) and 25000 (13\%), respectively. The EU's role in doctoral education is even stronger in S\&E disciplines. France, Poland and the United Kingdom had a much higher share of graduates in scientific areas than in other disciplines.

Women are under-represented in advanced research programmes. They are often more present than men at earlier educational levels but fewer pursue doctoral studies. Female participation is weakest in Korea (27.4\%), Greece (35.5\%) and the Czech Republic (35.7\%). In S\&E programmes women accounted for just $32 \%$ of the OECD total.

\section{Advanced research programmes}

Doctoral graduates have attained the second stage of university education and obtain a degree at ISCED level 6 . They have successfully completed an advanced research programme and gained an advanced research qualification, e.g. Ph.D. They are qualified for faculty posts in institutions offering ISCED 5A programmes. In most countries the theoretical duration of a doctoral programme is three years full-time, although actual enrolment times are typically longer. The completion of an advanced research programme requires the submission of a thesis or dissertation of publishable quality which is the product of original research and represents a significant contribution to knowledge.

\section{Sources}

OECD, Education Database, 2009

UNESCO, Institute for Statistics, 2009

\section{Going further}

OECD (2008), Education at a Glance 2008: OECD Indicators, OECD, Paris, www.oecd.org/edu/eag2008.

\section{Figure notes}

Instead of 2000: Iceland, 2001; the Netherlands, 2002; and the United States, 2003. 


\section{INVESTING IN THE KNOWLEDGE ECONOMY}

5.2. New doctoral graduates

\section{Graduation rates at doctoral level, 2000 and 2006}

As a percentage of the relevant age cohort

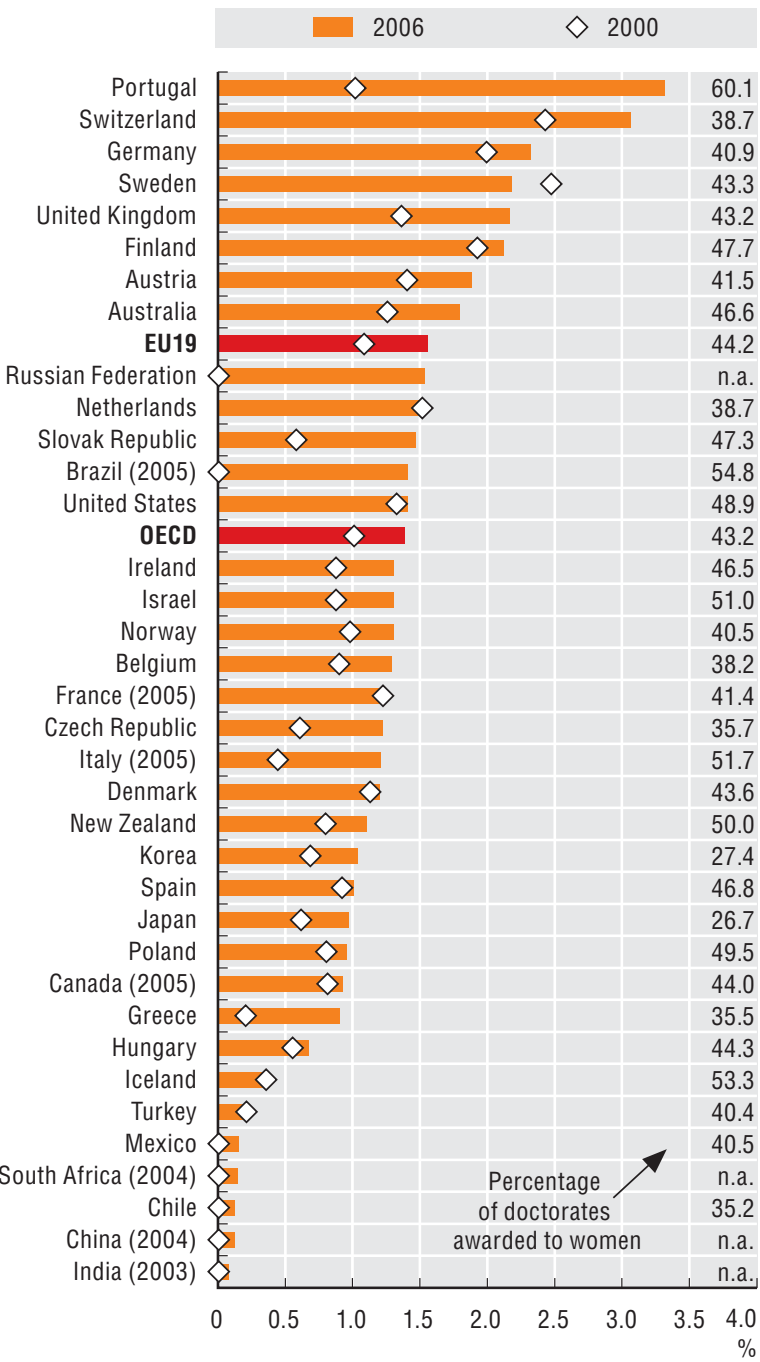

StatLink ला1st http://dx.doi.org/10.1787/746463344715
Science and engineering degrees at doctoral level, 2006

As a percentage of all new degrees at doctoral level

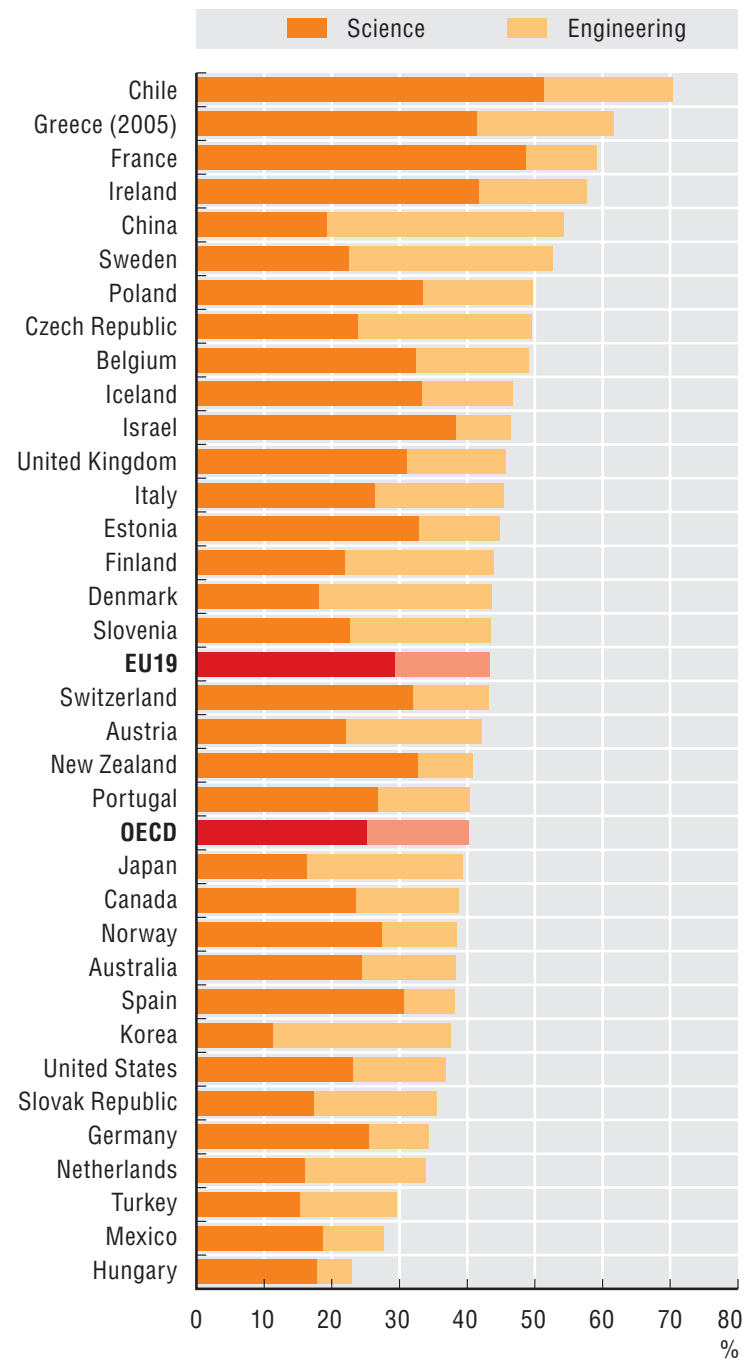

StatLink लाIsस http://dx.doi.org/10.1787/746464705616

New OECD graduates at doctoral level by main country of graduation, 2006

As a percentage of total OECD new graduates at doctoral level

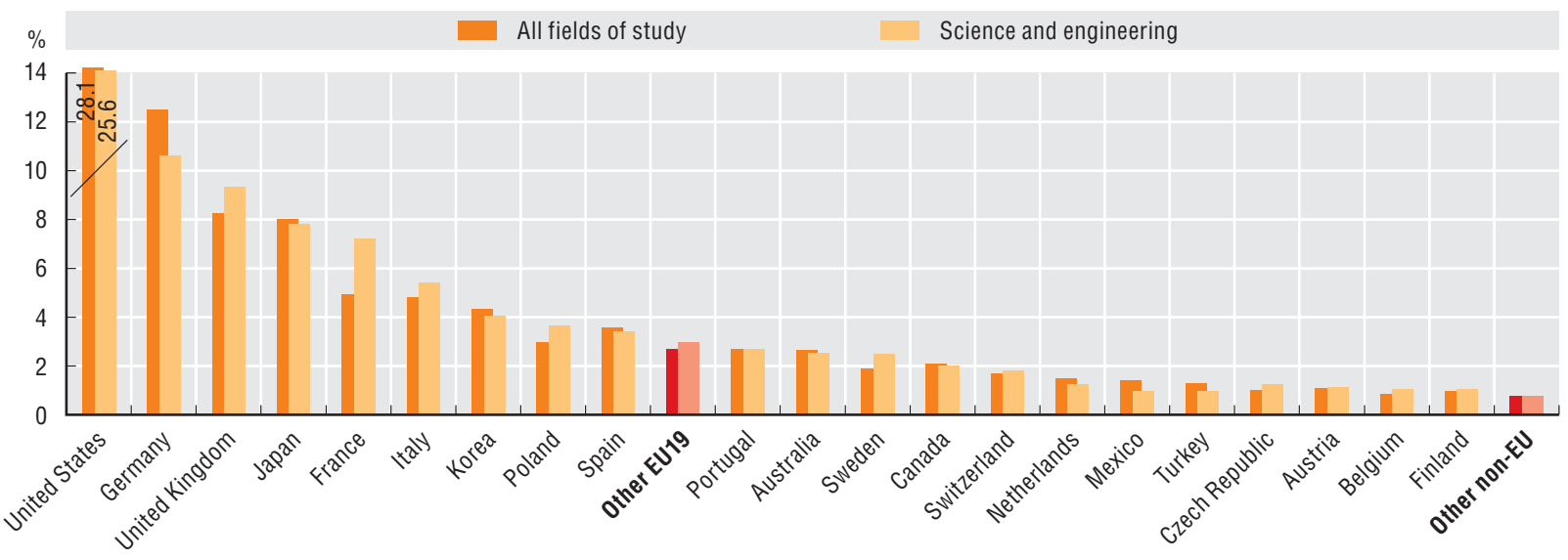

StatLink AाIsय http://dx.doi.org/10.1787/746560622054 
Human resources in science and technology (HRST) are major actors in innovation. In most OECD countries, they represented more than a quarter of total employment in 2008. The share was even larger in northern Europe $(39.6 \%$ in Sweden, $39.1 \%$ in Denmark, $38.0 \%$ in Norway, $34.2 \%$ in Finland) but also in Australia (35.8\%), Canada (35.5\%) and the United States (32.3\%). There is no single pattern in terms of the split between professionals and technicians: in some countries professionals are more numerous than technicians (Belgium, Ireland and Luxembourg); in others the opposite is true (Czech Republic, Italy and Norway).

A particular characteristic of HRST employment is the increasing share of women. Indeed, except in Turkey, where they only represent $34.2 \%$, women are traditionally more numerous than men among HRST employees in OECD countries. In Hungary, Poland and the Slovak Republic, $60 \%$ of HRST in 2008 were women.

A look at the industry structure of employment shows that HRST employees are more concentrated in services than in manufacturing. In 2007, the share of professionals and technicians in services varied between 19.6\% (in Japan) and $44.1 \%$ (in Luxembourg), whereas in manufacturing they were about $18 \%$ on average in OECD countries for which data were available.

Over the past decade, HRST occupations increased more rapidly than total employment in most OECD countries. In services, the average annual growth rate has always been positive, ranging from $1.1 \%$ (in the United States) to 6.3\% (in Spain). However, in manufacturing, the share of professionals and technicians decreased in Luxembourg $(-2.1 \%)$, the United States $(-1.3 \%)$, Japan $(-1.2 \%)$ and Sweden $(-0.5 \%)$. In Australia, both growth rates were stable over 1997-2007.

\section{Defining HRST workers}

Human resources in science and technology (HRST) are defined according to the Canberra Manual (OECD and Eurostat, 1995) as persons having graduated at the tertiary level of education or employed in a science and technology occupation for which a high qualification is normally required and the innovation potential is high.
HRST data reported here only concern occupations. This category of workers corresponds to professionals and technicians as defined in the International Standard Classification of Occupations (ISCO-88) major groups 2 and 3:

- Professionals (ISCO group 2) includes: physical, mathematical and engineering science professionals (physicists, chemists, mathematicians, statisticians, computing professionals, architects, engineers); life science and health professionals (biologists, agronomists, doctors, dentist, veterinarians, pharmacists, nursing); teaching professionals; and other professionals (business, legal, information, social science, creative, religious, public service administrative).

- Technicians and associate professionals (ISCO group 3) includes: physical and engineering science associate professionals; life science and health associate professionals; teaching associate professionals; other associate professionals (finance, sales, business services, trade brokers, administrative, government, police inspectors, social work, artistic entertainment and sport, religious).

The original data were collected according to the following industry classifications: European Union (NACE Rev. 1), Canada (NAICS 2002-Canada), Japan (JSIC 2002), United States (NAICS 2002-US), Australia (ANZSIC 1993). They have then been converted to ISIC Rev. 3 for the ANSKILL database. The industry groupings analysed here are: Manufacturing (ISIC 15 to 37); Services (ISIC 50 to 99).

\section{Source}

OECD ANSKILL Database, 2009 (forthcoming).

\section{Going further}

OECD and Eurostat (1995), "Manual on the Measurement of Human Resources Devoted to S\&T - 'Canberra Manual'", OECD general distribution document, OCDE/ GD(95)77, www.oecd.org/dataoecd/34/0/2096025.pdf.

\section{Figure notes}

Total HRST for Japan are likely to be underestimated. 


\section{INVESTING IN THE KNOWLEDGE ECONOMY}

5.3. Human resources in science and technology

HRST occupations, 2008

As a percentage of total employment

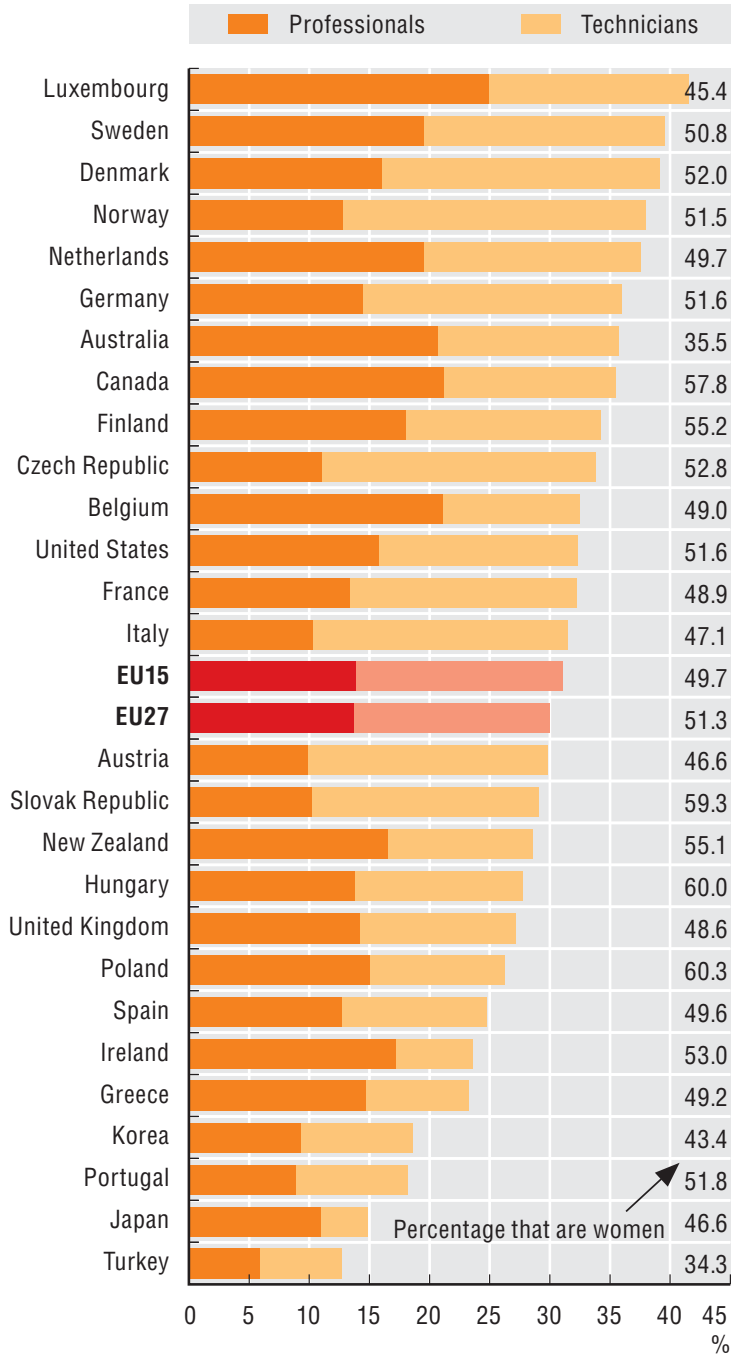

StatLink काजद http://dx.doi.org/10.1787/746567077843
Share of HRST employees by industry, 2007

As a percentage of total employees in the industry

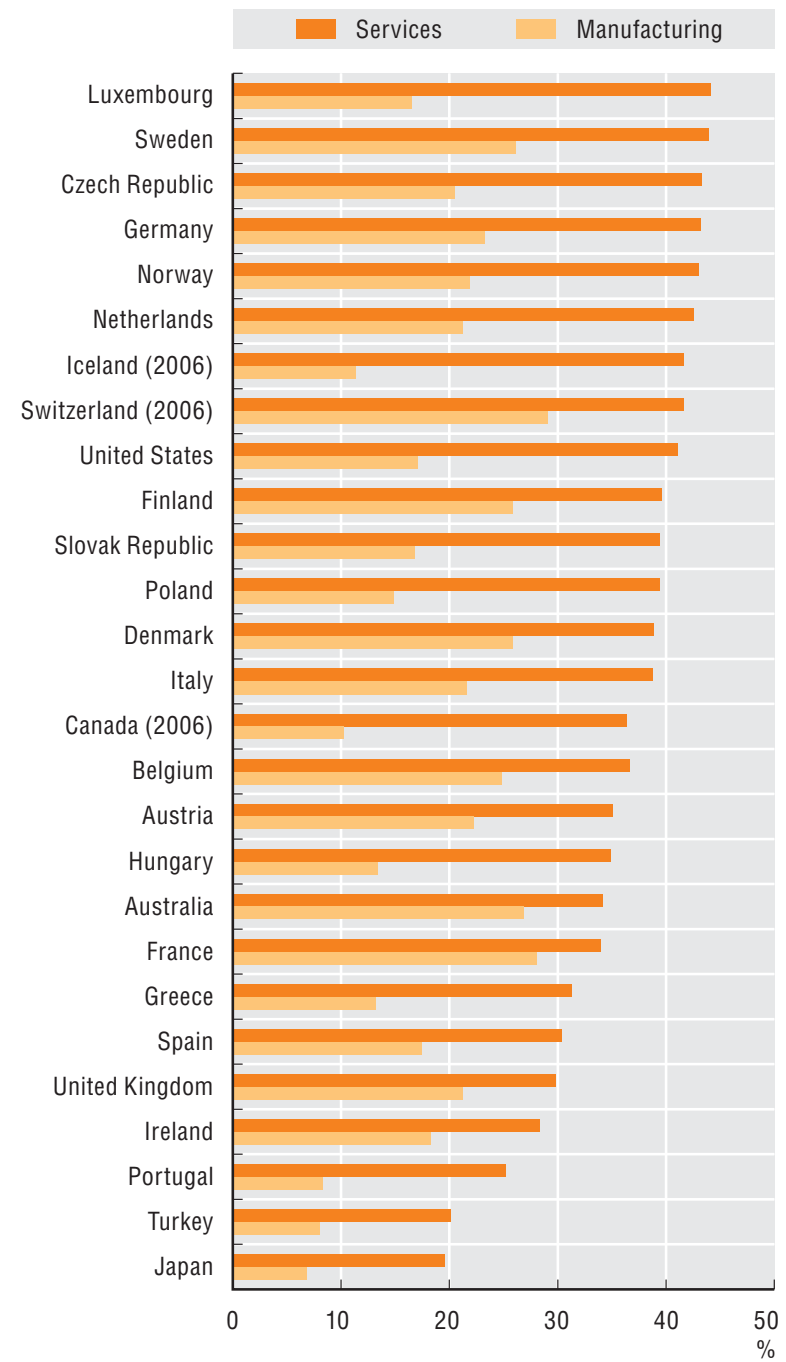

StatLink क्ताs< http://dx.doi.org/10.1787/746604472507

\section{Growth of HRST employees by industry, 1997-2007}

Average annual growth rate

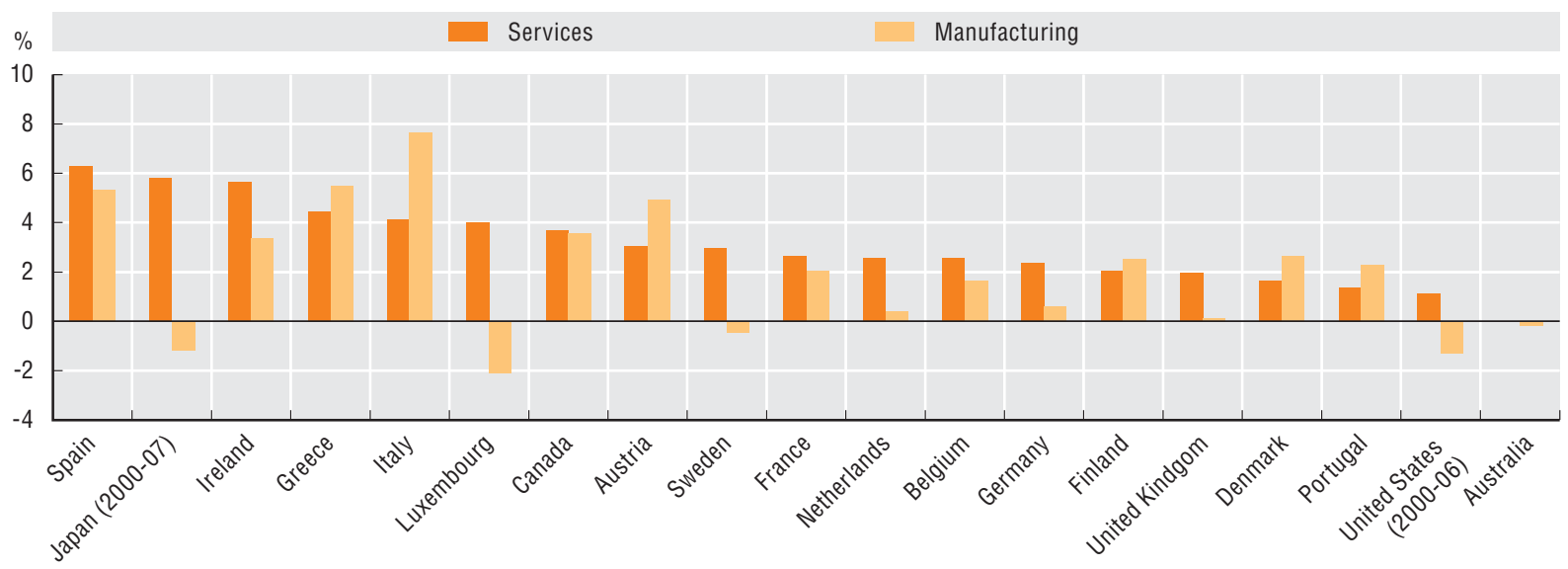


Employment of tertiary-level graduates is an indicator of the innovative potential of an economy and of the capacity of its labour market to allocate human capital to the production process.

Large investments in education have led to a rise in educational attainment which is reflected in the composition of employment. On average, $35 \%$ of persons employed in the OECD area had a tertiary-level degree in 2007. Canada (over 50\%), the United States, Japan, New Zealand and Finland (over 40\%) ranked far ahead of the European Union, where just over one worker in four holds a tertiary-level degree. In Finland, Belgium, Ireland, Norway and the United Kingdom, tertiarylevel graduates account for more than $35 \%$ of employment; in the Czech and Slovak Republics, Portugal and Italy they account for $20 \%$ or less.

Between 1998 and 2007, employment of tertiary-level graduates grew at an annual pace of about $3.6 \%$ in the OECD area. It increased in all countries and rose on average almost three times faster than total employment. The fastest growth was in Spain (8.2\%), Ireland $(7.6 \%)$ and Iceland (6.7\%); the slowest in Germany $(1.0 \%)$, Sweden $(2.1 \%)$ and Finland $(2.6 \%)$. In countries where tertiary-level graduates were already numerous (Canada, Japan, the United States), tertiary-level employment grew between $2.7 \%$ and $4 \%$ a year.

This growth is due in part to the increased presence of women in the labour market. Despite their greater propensity to graduate at tertiary level, fewer women work in certain countries. They represent on average $46 \%$ of tertiary-level employment, ranging from over $55 \%$ in Portugal, Sweden and Poland to less than 35\% in Turkey, Korea and Switzerland.

The population of tertiary-level workers is ageing. In 2007, almost four out of ten OECD workers with a tertiary-level degree was over 45 years of age. Over a span of nine years, the share of those aged 45-64 has increased in most countries. Compared to 1998, the number of countries in which this age group accounts for $40 \%$ of tertiary-level employment has increased from five to ten: Australia, Canada, the Czech Republic, Finland, Germany, the Netherlands, New Zealand, Sweden, Switzerland and the United States.

University graduates are generally less likely than non-graduates to remain unemployed. However, the unemployment rate among university graduates is high in Turkey (6.9\%) and Poland (6.2\%) and also higher in Greece (5.4\%) and France (5.3\%) than in other countries. Women with a university degree are less likely to be unemployed than women without one, yet their unemployment rate is higher than that of men with the same level of education. The largest gender gaps in university graduates' unemployment rates are found in Germany, Greece, Iceland and Turkey, where unemployment rates are almost twice as high for women as for men.

\section{Measuring employment of tertiary-level graduates}

The OECD Educational Attainment Database provides data on population at different levels of education distributed by sex, age and work status (employed, unemployed, inactive). It is compiled from member countries' labour force surveys and/or the European labour force survey. Adjustments are made to ensure comparability across countries, notably concerning national levels of education, which are recoded according to the International Standard Classification of Education (ISCED 1997).

Tertiary-level graduates are defined as holders of degrees at the ISCED levels 5B, 5A and 6. University graduates only include graduates at ISCED levels 5A and 6. ISCED level 5A programmes are long-stream programmes theoretically based or preparatory to research. The short streams (ISCED 5B) are more practically oriented. ISCED level 6 programmes are advanced research programmes.

\section{Source}

OECD, Educational Attainment Database, 2009.

\section{Going further}

OECD (2008), Education at a Glance 2008: OECD Indicators, OECD, Paris, www.oecd.org/edu/eag2008.

\section{Figure notes}

For Turkey, ISCED 5B programmes are not included. 


\section{Employment growth of tertiary-level graduates, 1998-2007}

Average annual growth rates

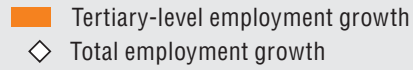

Tertiary-level employment growth

$\diamond$ Total employment growth

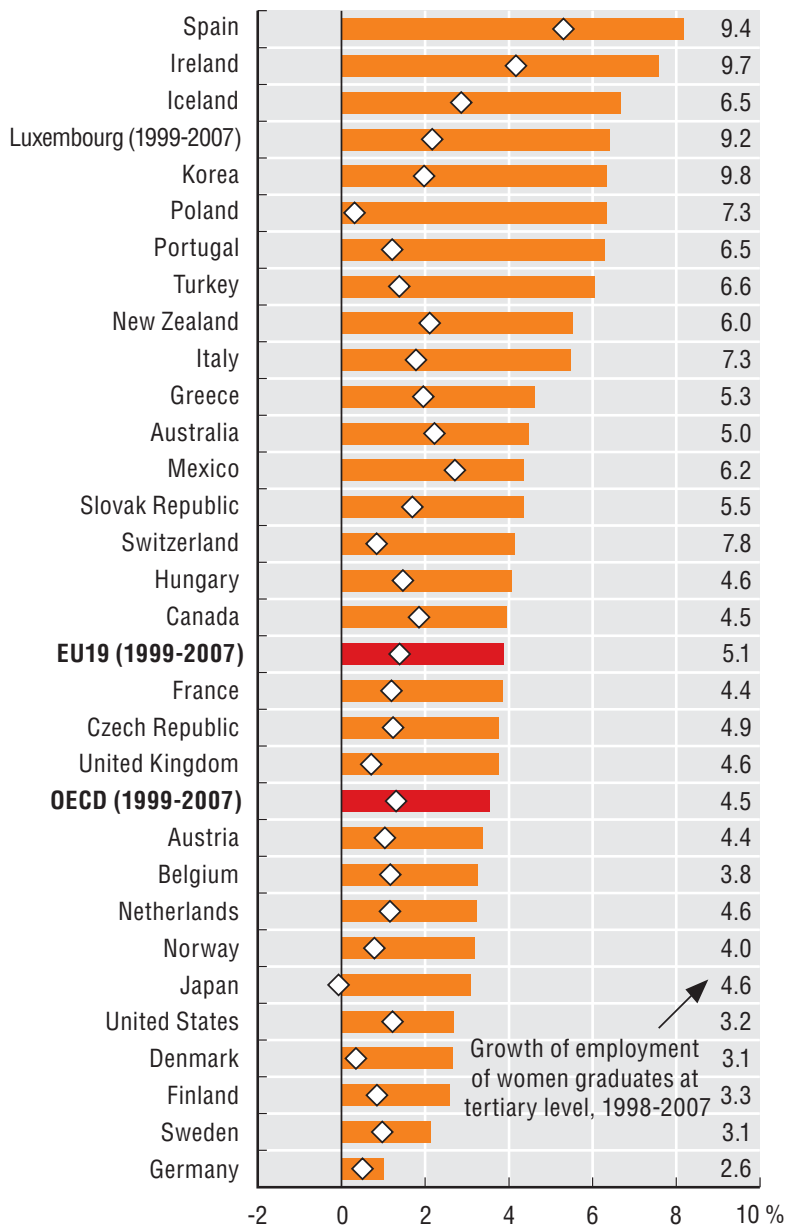

StatLink Ailst http://dx.doi.org/10.1787/746638012030
Tertiary-level graduates in total employment, 2007

As a percentage of total employment

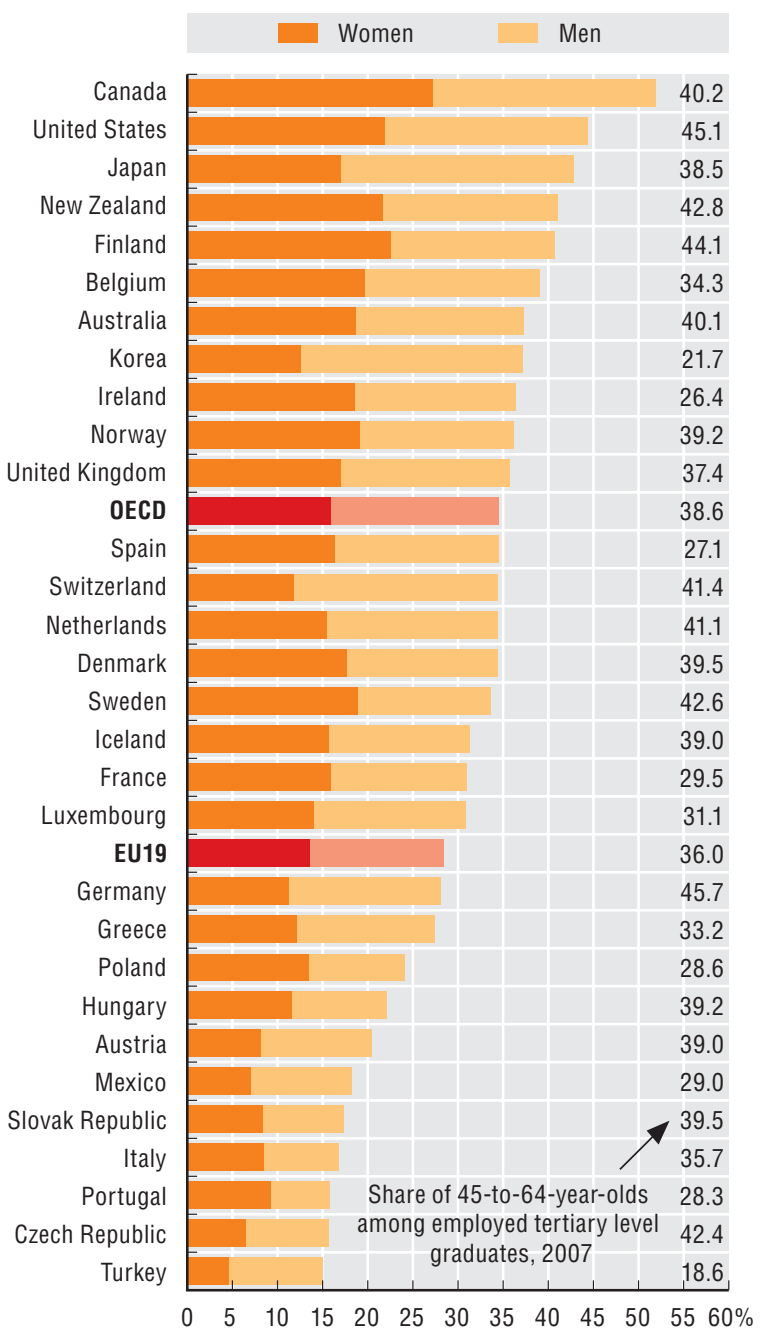

StatLink तiाsय http://dx.doi.org/10.1787/746671655733

Unemployment rates of university graduates, 2007

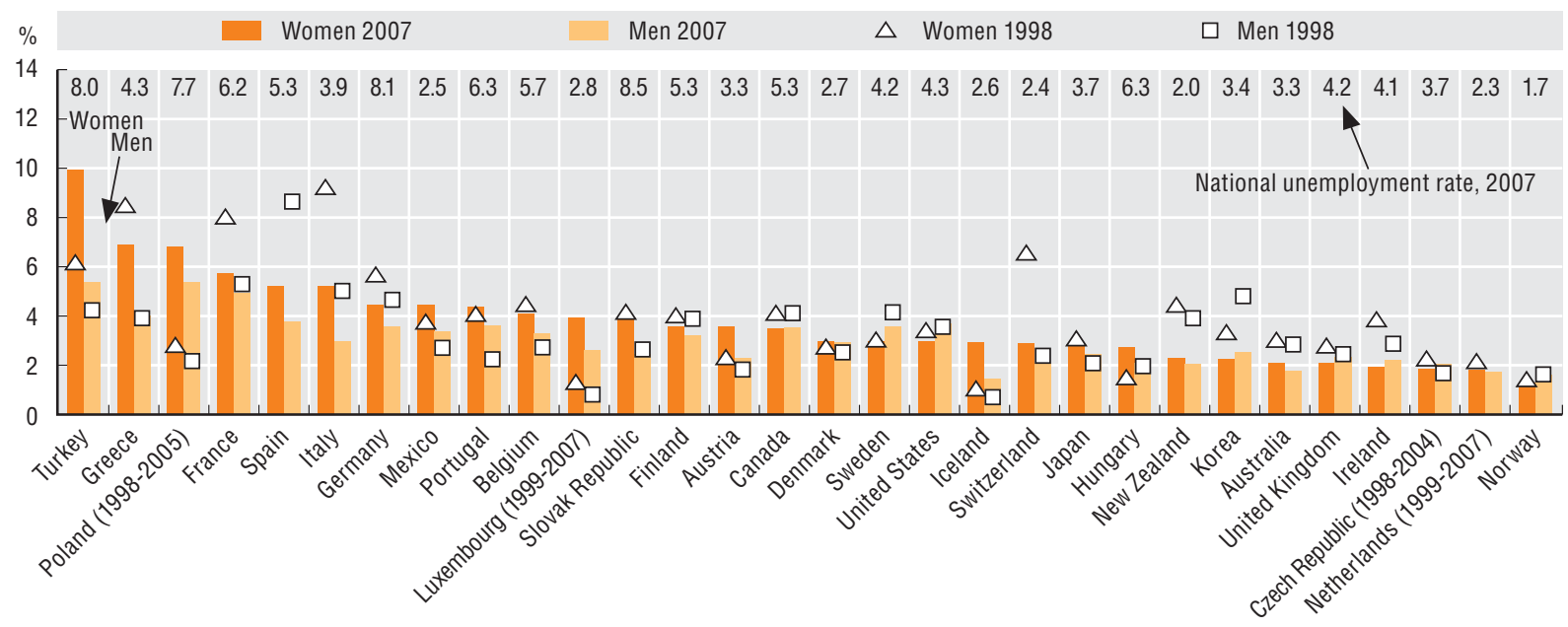

StatLink तilst http://dx.doi.org/10.1787/746675231067 
A country's capacity to engage human resources into innovation depends on the attractiveness of its research jobs. Doctorate holders have a research qualification and are a pillar of the research system. Their employment is an indicator of a country's capability to generate new knowledge and innovation.

Employment of the 1990-2006 doctoral graduates ranges from $93 \%$ to $98 \%$ and exceeds that of university graduates. Holders of doctoral degrees in the humanities, especially in Belgium, Denmark and Austria have less favourable prospects than those in other fields. The female employment rate is much lower than the male rate in Austria, Germany, the United States and Cyprus, where female inactivity exceeds unemployment.

The majority of doctorate holders are employed in the higher education and government sectors, particularly so in Portugal, Poland and Bulgaria. Over a third works in the business sector in Austria, Australia, the United States and Belgium. The bulk of the holders of a research qualification participate in research activities, but to a lesser extent in Austria and Belgium.

Many doctorate holders face temporary employment in the early stage of their careers. They can, in particular, be employed in postdoc positions for several years. After five years of activity, $60 \%$ of doctorate holders in the Slovak Republic and over $45 \%$ in Belgium, Germany and Spain are still under temporary contracts. Yet permanent engagements account for over $80 \%$ of all jobs in most countries.

\section{$\mathrm{CDH}$ guidelines}

The Careers of Doctorate Holders project (CDH) is a joint OECD-Eurostat-UNESCO Institute for Statistics project initiated in 2004 to develop a harmonised system of indicators on the careers and international mobility of doctorate holders.

Doctorate holders are defined as all residents below 70 years old, economically active or not, who have completed ISCED level 6 education anywhere in the world. Owing to country differences in population coverage, the data presented here only include doctoral graduates from 1990 onwards. Temporary employment is work under a fixed-term contract in contrast to permanent work (without an end date). Employees under temporary contract are often not eligible for the same conditions, in particular in terms of employment protection.

\section{Sources}

OECD, UNESCO Institute for Statistics and Eurostat data collection on careers of doctorate holders, 2007 and 2009.

OECD, Educational Attainment Database, 2009.

OECD, Main Science and Technology Indicators, May 2009.

OECD, Labour Force Survey (LFS) Database, 2009.

Eurostat, 2009.

\section{Going further}

Auriol, L. (2007), "Labour Market Characteristics and International Mobility of Doctorate Holders: Results for Seven Countries", OECD Science, Technology and Industry Working Papers 2007/2, OECD, Paris, www.oecd.org/sti/cdh.

Auriol, L., B. Felix and E. Fernandez-Polcuch (2007), "Mapping Careers and Mobility of Doctorate Holders: Draft Guidelines, Model Questionnaire and Indicators", OECD Science, Technology and Industry Working Papers 2007/6, OECD, Paris, www.oecd.org/sti/cdh.

\section{Figure notes}

For the Czech Republic, the employment rate of doctorate holders is overestimated. Czech doctorate holders who graduated before 1999 and were not employed in 2006 are excluded. The US data do not cover doctorate holders in humanities and some social sciences (education, law, communication).

Populations are in headcounts except researchers in Australia and the United States who are full-time equivalents. For Romania, the share of the higher education and government sectors in doctorate holders' employment is overestimated. Those working in small firms with fewer than 250 employees are not included. In Portugal, the share of higher and government employment is probably overestimated.

Doctorate holders on temporary contracts over career path: Data on median age of recent doctorate recipients at graduation refer to doctorate recipients within the past two years. 


\section{Employment rate of doctorate holders by field of doctorate award, 2006}

As a percentage of total doctorate holders

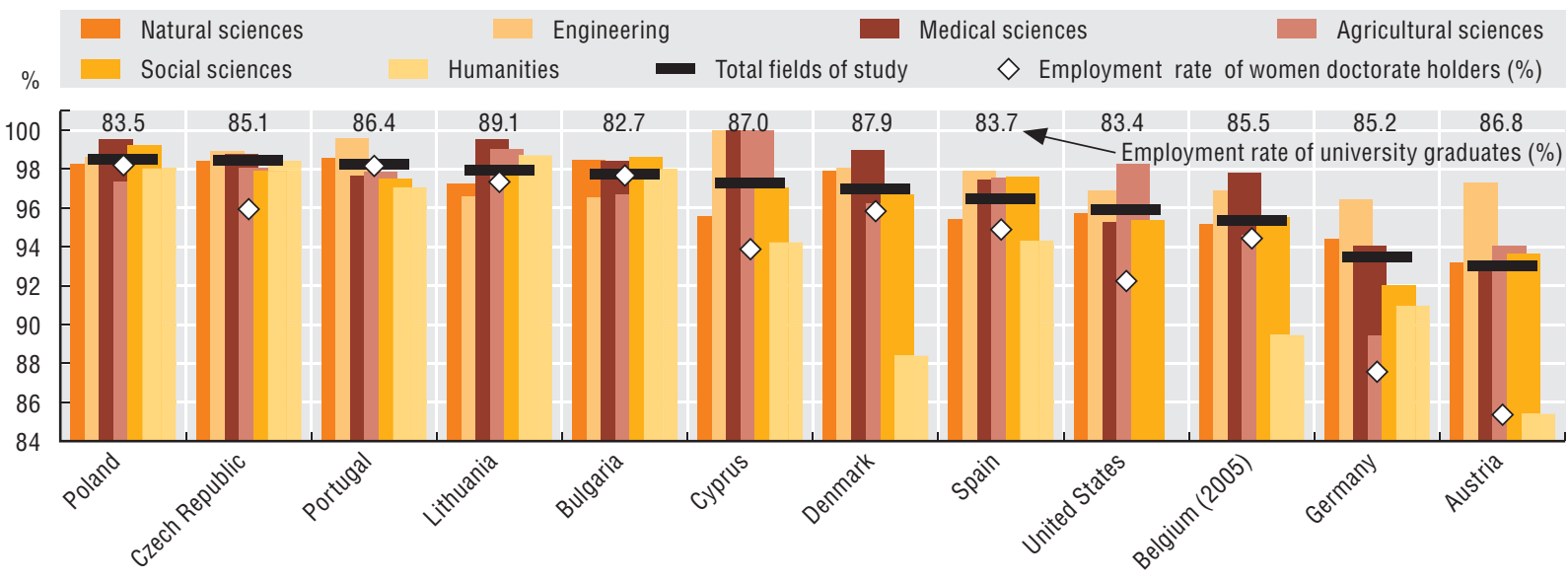

StatLink sils http://dx.doi.org/10.1787/746684788824

Employment of doctorate holders in the higher education and government sectors and participation in research activities, 2006

As a percentage of employed doctorate holders
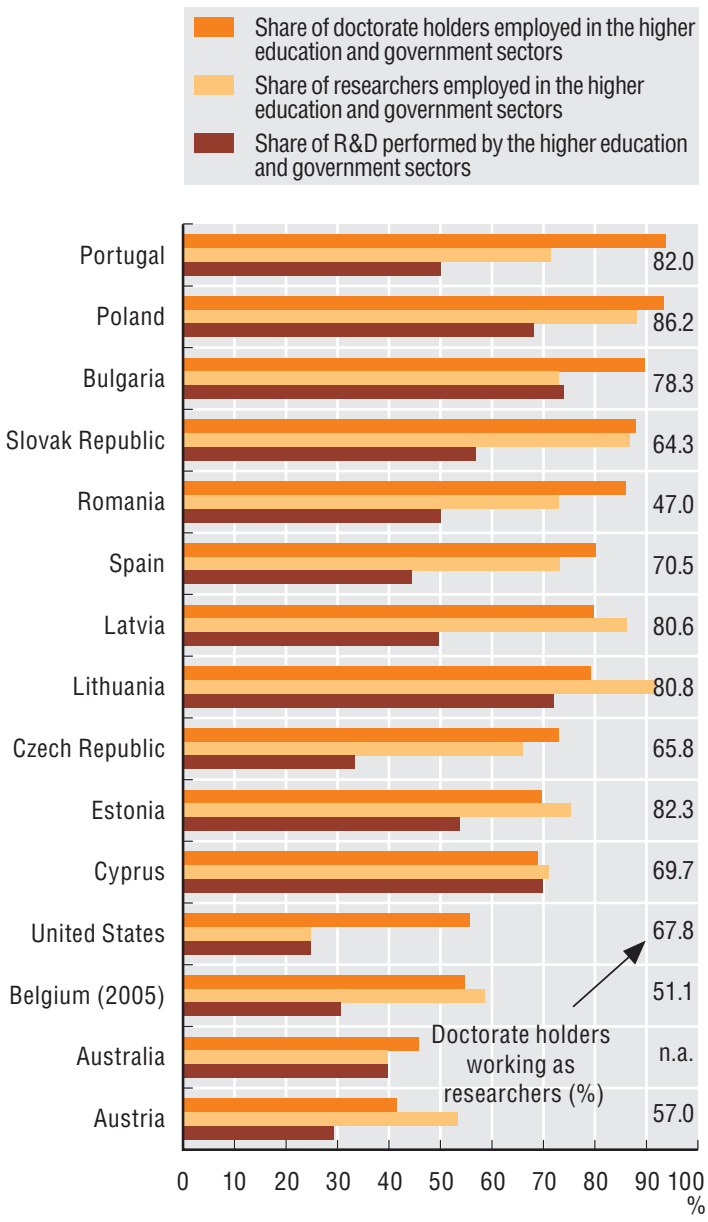

StatLink काजम http://dx.doi.org/10.1787/746685132680

\section{Doctorate holders on temporary contracts over career path, 2006}

As a percentage of employed doctorate holders

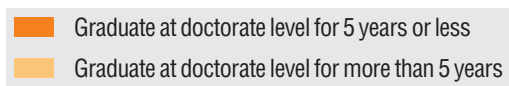

Slovak Republic

Czech Republic

Belgium (2005)

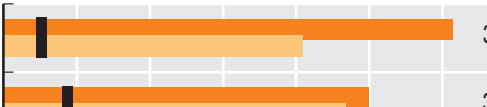

Spai

Germany

Portuga

Denmark

Austria

Estonia

Iceland

Cyprus

Bulgaria

Lithuania

Romania

Latvia

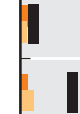

38

33

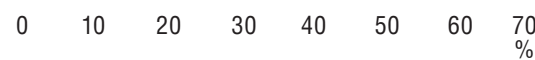

StatLink ताIs/ $h t t p: / / d x . d o i . o r g / 10.1787 / 746724506041$ 
The earnings premium from education is an important incentive for individuals to enrol in tertiary education. In all OECD countries, annual earnings increase with educational attainment levels. In Hungary, the average annual earnings of tertiary-level diploma holders was more than twice that of upper secondary and post-secondary non-tertiary education diploma holders in 2006. The next highest relative earnings were in the Czech Republic (183\%), Portugal $(177 \%)$ and the United States (176\%). Such earning differentials are traditionally smaller in Nordic countries (129\% in Norway, $126 \%$ in Sweden and $125 \%$ in Denmark) followed by New Zealand (115\%).

In many OECD countries, earnings differentials between individuals with tertiary education and those with upper secondary education are generally more pronounced than those between upper secondary and lower secondary or below. The exceptions are again the Nordic countries, but also Australia, Belgium, Canada, New Zealand and Spain.

Over the past decade, earnings differentials between workers with tertiary education and those with an upper-secondary and post-secondary non-tertiary educational attainment decreased the most in Italy $(-6.4 \%)$, Ireland $(-4.3 \%)$, Hungary $(-4 \%)$, Germany $(-3.4 \%)$ and Poland $(-2.9 \%)$. In other words, the earnings premium of highly skilled workers decreased compared to that of medium-skilled workers. The opposite trend is observed in New Zealand, Spain, Australia and Sweden where the earnings premium of highly skilled workers increased at an average annual rate of between $1 \%$ and $3 \%$.

In terms of gender, at identical levels of education, earnings differentials between males and females remain significant in all OECD countries. In Italy, Germany, the United States and Austria, women earn at least $40 \%$ less than men with tertiary level attainment. This gap is smaller in Belgium (22\%), Luxembourg (25\%), Spain (22\%) and Turkey (22\%). However, these figures should be interpreted with caution since most countries' earnings data include part-time work, which is an important characteristic of women's employment.

\section{Measuring earnings by educational attainment}

At the international level, educational attainment is measured according to the International Standard Classification of Education (ISCED 1997).

Earnings are before-tax income except for Belgium and Korea where they are after-tax income.

Earnings data for the Czech Republic, Hungary, Luxembourg, Poland and Portugal exclude part-time work. Earnings data for Hungary, Luxembourg, Poland and Portugal also exclude part-year or seasonal employment.

The length of the reference period is one week for Australia, New Zealand and the United Kingdom; one month for Belgium, France, Hungary, Ireland and Portugal; the calendar year for Austria, Canada, the Czech Republic, Denmark, Finland, Germany, Italy, Luxembourg, the Netherlands, Norway, Spain and Sweden; and other 12-month period for Korea, Switzerland and the United States.

\section{Source}

OECD, raw data for Education at a Glance 2008.

\section{Going further}

OECD (2008), Education at a Glance 2008: OECD Indicators, OECD, Paris, www.oecd.org/edu/eag2008.

OECD and Eurostat (1995), "Manual on the Measurement of Human Resources Devoted to S\&T - 'Canberra Manual'", OECD general distribution document, OCDE/ GD(95)77, www.oecd.org/dataoecd/34/0/2096025.pdf.

\section{Figure notes}

Population is 24-65 years old.

Changes in earning differentials are calculated as follows:

[(Final index value/Initial index value $)^{1 / n_{-1}}$ ] 100 ; where $n$ is equal to the difference between final and initial year. 
Relative earnings by level of education, 2006

Upper secondary and post-secondary non-tertiary education $=100$

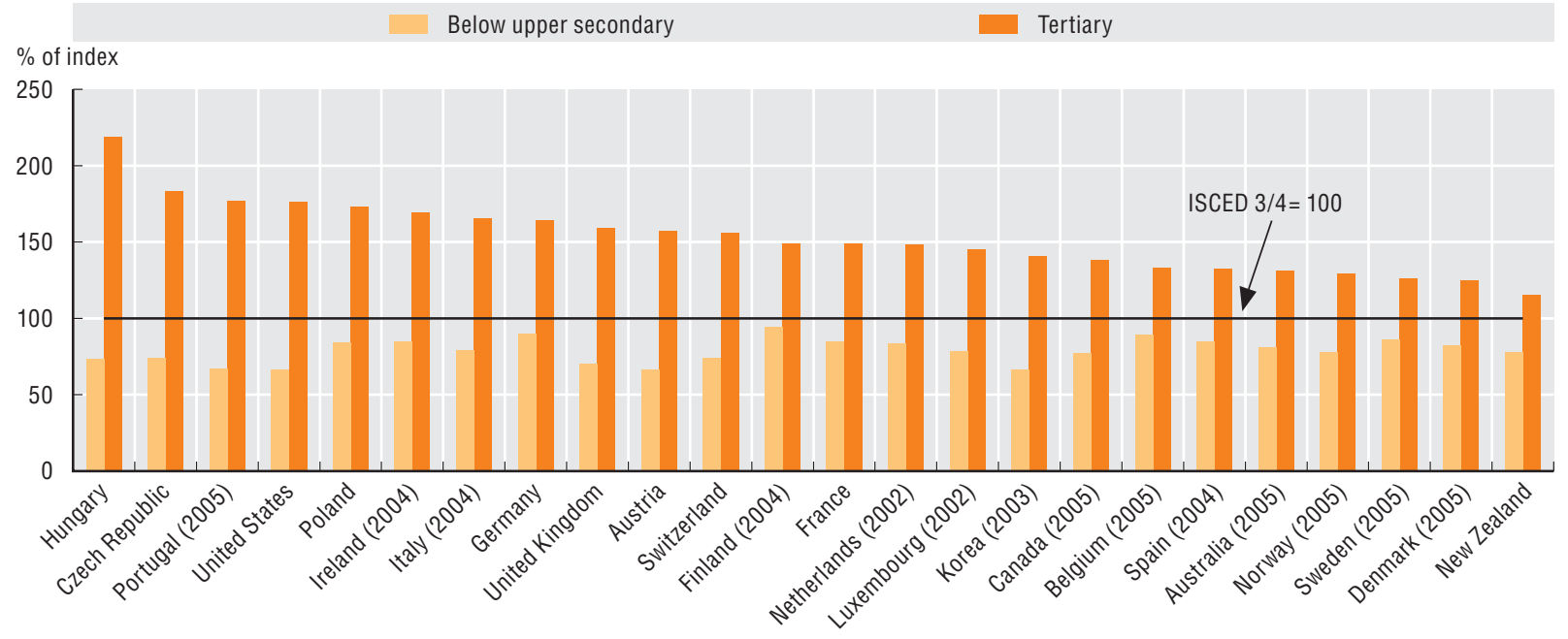

StatLink काIst http://dx.doi.org/10.1787/746738877323

\section{Change in earning differentials}

As compared to workers with ISCED 3/4 Average annual growth rate

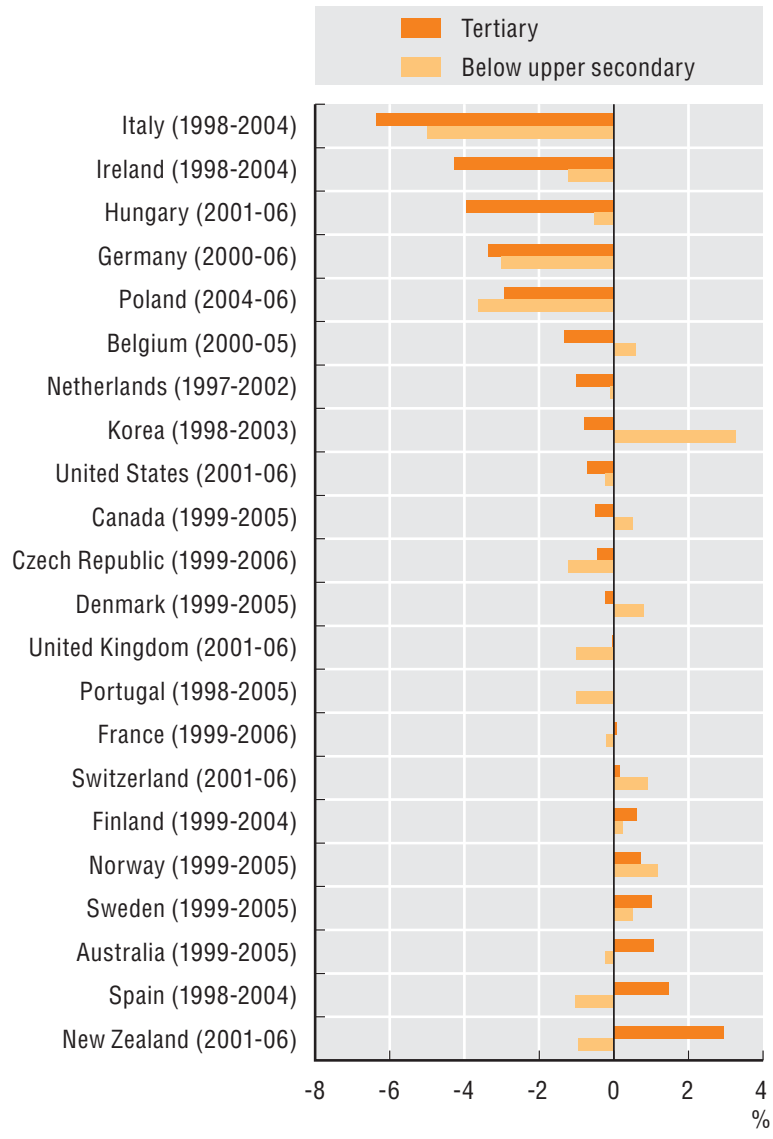

StatLink लाIs/ http://dx.doi.org/10.1787/746745505164

\section{Differences in earnings between females and males,} 2006

Average annual earnings of females as a percentage of males' earning

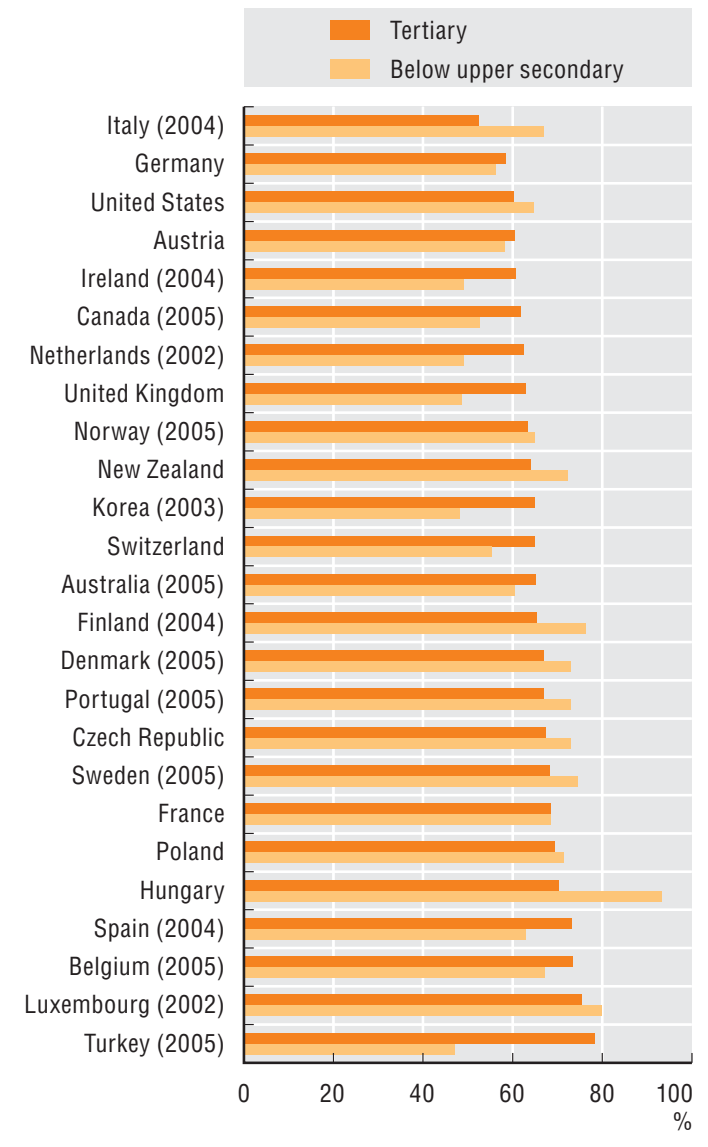

StatLink लाাs< http://dx.doi.org/10.1787/746822606135 
OECD PUBLISHING, 2, rue André-Pascal, 75775 PARIS CEDEX 16 PRINTED IN FRANCE

(92 2009031 P) ISBN 978-92-64-06371-6 - No. 569652009 


\section{OECD Science, Technology and Industry Scoreboard 2009}

The world is facing major global challenges. Economies are in the midst of the most severe economic downturn since the Great Depression. International competition from new players is eroding the lead of more established economies. Environmental pressure calls into question the sustainability of our development models over the next few decades.

This ninth edition of the OECD Science, Technology and Industry (STI) Scoreboard provides the statistical information necessary to define a response to these global challenges. How are countries tackling these challenges individually? What approaches are working? What are the effects of the crisis on innovation? How can innovation help solve environmental and social threats?

The OECD STI Scoreboard 2009 illustrates and analyses a wide set of indicators of science, technology, globalisation and industrial performance in OECD and major non-OECD countries (notably Brazil, the Russian Federation, India, Indonesia, China and South Africa). It includes the latest figures for research and development (R\&D), foreign direct investments, risk capital and technology-related trade.

Indicators are organised around five key issues:

- responding to the economic crisis;

- targeting new growth areas;

- competing in the world economy;

- connecting to global research; and

- investing in the knowledge economy.

By providing a complete set of indicators for policy analysis, the OECD STI Scoreboard has become a widely used reference which combines statistical rigour with easy access and readability. The key findings are presented in a user-friendly format alongside figures highlighting the relative performance of countries. In addition, brief technical notes provide further methodological details on the indicators, along with links to useful references and data sources.

The OECD STI Scoreboard 2009 is also available on line and provides easy access to individual sections and links to the databases used and "clickable" access to the Excel ${ }^{\circledR}$ spreadsheets containing the data used in the figures. Country profiles are also available: these allow users to compare countries' performance across multiple indicators.

For more information about the OECD STI Scoreboard, see www.oecd.org/sti/scoreboard.

The full text of this book is available on line via these links: www.sourceoecd.org/education/9789264063716 WWw.sourceoecd.org/environmentIT/9789264063716 www.sourceoecd.org/industrytade/9789264063716 www.sourceoecd.org/sciencelT/9789264063716

Those with access to all OECD books on line should use this link: www.sourceoecd.org/9789264063716

SourceOECD is the OECD online library of books, periodicals and statistical databases. For more information about this award-winning service and free trials ask your librarian, or write to us at SourceOECD@oecd.org. 